\title{
A Review and Experimental Revisit of Alternative Catalysts for Selective Oxidation of Methanol to Formaldehyde
}

\author{
Joachim Thrane $^{1}\left(\mathbb{D}\right.$, Uffe V. Mentzel $^{2}\left(\mathbb{D}\right.$, Max Thorhauge $^{2}$, Martin Høj $^{1}\left(\mathbb{D}\right.$ and Anker D. Jensen ${ }^{2, *(D)}$ \\ 1 Department of Chemical and Biochemical Engineering, Technical University of Denmark, \\ 2800 Kgs. Lyngby, Denmark; joathr@kt.dtu.dk (J.T.); mh@kt.dtu.dk (M.H.) \\ 2 Haldor Topsøe A/S, 2800 Kgs. Lyngby, Denmark; UFVM@topsoe.com (U.V.M.); mat@topsoe.com (M.T.) \\ * Correspondence: aj@kt.dtu.dk
}

check for

updates

Citation: Thrane, J.; Mentzel, U.V.; Thorhauge, M.; Høj, M.; Jensen, A.D. A Review and Experimental Revisit of Alternative Catalysts for Selective Oxidation of Methanol to Formaldehyde. Catalysts 2021, 11, 1329. https://doi.org/10.3390/ catal11111329

Academic Editor:

Enrique García-Bordejé

Received: 23 September 2021

Accepted: 26 October 2021

Published: 31 October 2021

Publisher's Note: MDPI stays neutral with regard to jurisdictional claims in published maps and institutional affiliations.

Copyright: (c) 2021 by the authors. Licensee MDPI, Basel, Switzerland. This article is an open access article distributed under the terms and conditions of the Creative Commons Attribution (CC BY) license (https:// creativecommons.org/licenses/by/ $4.0 /)$.

\begin{abstract}
The selective oxidation of methanol to formaldehyde is a growing million-dollar industry, and has been commercial for close to a century. The Formox process, which is the largest production process today, utilizes an iron molybdate catalyst, which is highly selective, but has a short lifetime of 6 months due to volatilization of the active molybdenum oxide. Improvements of the process's lifetime is, thus, desirable. This paper provides an overview of the efforts reported in the scientific literature to find alternative catalysts for the Formox process and critically assess these alternatives for their industrial potential. The catalysts can be grouped into three main categories: Mo containing, $\mathrm{V}$ containing, and those not containing Mo or V. Furthermore, selected interesting catalysts were synthesized, tested for their performance in the title reaction, and the results critically compared with previously published results. Lastly, an outlook on the progress for finding new catalytic materials is provided as well as suggestions for the future focus of Formox catalyst research.
\end{abstract}

Keywords: formaldehyde; Formox; selective oxidation; methanol; molybdenum

\section{Introduction}

Formaldehyde (FA), $\mathrm{H}_{2} \mathrm{CO}$, is the lightest of the aliphatic aldehydes and is present in low concentrations in nature since it is an important product in the metabolism of plants and animals. Furthermore, FA is formed from organic material by photochemical processes in the atmosphere, as well as by incomplete combustion [1].

FA is the most commercially important aldehyde as it is an irreplaceable $\mathrm{C}_{1}$ building block for higher-valued products due to its high reactivity [2].

The high reactivity means that pure anhydrous FA polymerizes to solid paraformaldehyde when the gas temperature is below $100^{\circ} \mathrm{C}$. The polymerization is accelerated by traces of polar compounds. FA is, therefore, commercially sold as an aqueous solution called formalin (typically $37 \mathrm{wt} \%$ ). In this solution, monomeric FA may react with water to form a hydrate, which reacts further with FA to form solid polyoxymethylenes; thus methanol $(\mathrm{MeOH})$ and other stabilizers are added to concentrated formalin solutions (37-57 wt \%) [1].

The main usage of FA and its polymers is the production of resins such as ureaformaldehyde, phenol-formaldehyde, and melamine-formaldehyde resins, which are used in wood products applied in the construction industry (e.g., plywood) [3], as well as adhesives [2] and plastics [4]. Lastly, FA plays an integral role in various other industries such as automotive, aviation, textile, and energy as well as being an indispensable antibacterial agent in various personal hygiene consumer products [4].

FA was first synthesized in 1859 by Butlerov [1], with commercial production from $\mathrm{MeOH}$ in Germany starting in 1889 [1,5]. Global production has grown to more than 50 million metric tons formalin per year with an expected production of more than 60 million metric tons per year in the late 2020s [6]. Its global market value is expected to grow with about $6 \%$ per year [7]. 
Processes

As mentioned above, FA has been produced commercially since 1889 [1,5]. Today there are three different processes used industrially, i.e., the silver process, the BASF process, and the Formox process. The first two utilize Ag catalysts, and the last utilizes a metal oxide catalyst. In addition to the industrial processes, other reaction pathways such as photocatalytic oxidation of $\mathrm{MeOH}$ [8], partial oxidation of $\mathrm{MeOH}$ in supercritical $\mathrm{CO}_{2}$ [9], liquid phase partial oxidation of $\mathrm{MeOH}$ [10], hydroboration of $\mathrm{CO}_{2}$ to $\mathrm{FA} \mathrm{[11],} \mathrm{selective}$ homogeneous one-step reduction of $\mathrm{CO}_{2}$ to FA [12], oxidation of methane to $\mathrm{MeOH}$ and FA [13], selective oxidation of methanol using $\mathrm{N}_{2} \mathrm{O}$ as oxidant [14], and partial oxidation of $S$ containing volatile organic compounds [15] have also received research interest.

The Ag catalyst processes usually operate at ambient pressure, with temperatures of $600-720^{\circ} \mathrm{C}$ and excess $\mathrm{MeOH}$. The conversion of $\mathrm{MeOH}$ to FA occurs through three main reactions (Reactions (1)-(3)) [1].

$$
\begin{gathered}
\mathrm{CH}_{3} \mathrm{OH}(\mathrm{g}) \rightleftarrows \mathrm{CH}_{2} \mathrm{O}(\mathrm{g})+\mathrm{H}_{2}(\mathrm{~g}) \\
\Delta \mathrm{H}_{298 \mathrm{~K}}^{\mathrm{o}}=84 \frac{\mathrm{kJ}}{\mathrm{mol}} \\
\mathrm{H}_{2}(\mathrm{~g})+\frac{1}{2} \mathrm{O}_{2}(\mathrm{~g}) \rightleftarrows \mathrm{H}_{2} \mathrm{O}(\mathrm{g}) \\
\Delta H_{298 \mathrm{~K}}^{\mathrm{o}}=-243 \frac{\mathrm{kJ}}{\mathrm{mol}} \\
\mathrm{CH}_{3} \mathrm{OH}(\mathrm{g})+\frac{1}{2} \mathrm{O}_{2}(\mathrm{~g}) \rightleftarrows \mathrm{CH}_{2} \mathrm{O}(\mathrm{g})+\mathrm{H}_{2} \mathrm{O}(\mathrm{g}) \\
\Delta H_{298 \mathrm{~K}}^{\mathrm{o}}=-159 \frac{\mathrm{kJ}}{\mathrm{mol}}
\end{gathered}
$$

Depending on the process, the operating temperature may be $650-720{ }^{\circ} \mathrm{C}$ with a conversion of $97-98 \%$ with no $\mathrm{MeOH}$ recovery (BASF process) or $600-650{ }^{\circ} \mathrm{C}$ and $77-87 \%$ single pass conversion with $\mathrm{MeOH}$ recovery through a distillation unit. The yields of the processes are $86.5-90.5 \%$ and $87-92 \%$, respectively $[1,16]$.

The metal oxide process (Formox) utilizes an iron molybdate catalyst (FeMo). In contrast to the $\mathrm{Ag}$ processes, where the formation of $\mathrm{MeOH}$ can happen by endothermic dehydrogenation (Reaction (1)), the formation of FA in the Formox process only occurs by oxidative dehydrogenation (Reaction (3)). The Formox process runs under ambient pressure, temperatures of $250-400{ }^{\circ} \mathrm{C}$, excess of air, and $\mathrm{MeOH}$ conversions above $99 \%$, with a yield between 88 and 92\% [1,16]. In a typical Formox plant (Figure 1), $\mathrm{MeOH}$ is added to air and recycled product gas in an evaporator before it is fed to the reactor. The product stream is then cooled, and FA is absorbed in $\mathrm{H}_{2} \mathrm{O}$ in an absorber yielding the FA product, typically $37 \mathrm{wt} \% \mathrm{FA}$ in $\mathrm{H}_{2} \mathrm{O}$ (formalin), but it can be up to $55 \mathrm{wt} \% \mathrm{FA}$ and less than $1 \mathrm{wt} . \% \mathrm{MeOH}$ in the bottom where a fraction of it is cooled and recycled back into the absorber. The product is fed through an anion-exchange column in order to reduce the amount of $\mathrm{HCOOH}$. The tail gas leaves the top of the tower, and part of it is recycled and mixed with the air feed before entering the evaporator. The feed composition is kept on the $\mathrm{MeOH}$ lean side of the explosive limit. Recycling tail gas decreases $\mathrm{O}_{2}$ content in the feed gas to around $10 \mathrm{~mol} \%$ and adds $\mathrm{H}_{2} \mathrm{O}$ from the absorber [16]. The $\mathrm{MeOH}$ concentration in the feed has increased from $6.5 \mathrm{~mol} \%$ in the $1960 \mathrm{~s}$ to around $10 \mathrm{~mol} \%$ after various process improvements [17]. The reactor is a multi-tube reactor, which is cooled by a fluid (typically oil) with a high boiling point, which produces steam in a heat exchanger to condense heat-transfer fluid. The reactor tubes are between 1 and $1.5 \mathrm{~m}$ long, and the outer shell diameter of the multi-tube reactor is $>2.5 \mathrm{~m} \mathrm{[16]}$.

The choice of process depends on various factors such as operating and capital cost, but it also depends on plant capacity, type of operation, and end product usage $[1,16]$. However, due to the increase in $\mathrm{MeOH}$ price from 125 euro/tonnes in January 2002, to 330 euro/tonnes in October 2017, with peak prices as high as 525 euro/tonnes [18], the market share has moved towards the Formox process due to its higher selectivity and yield. Thus, the global share of the produced FA from the Formox process is now around two thirds [19]. 


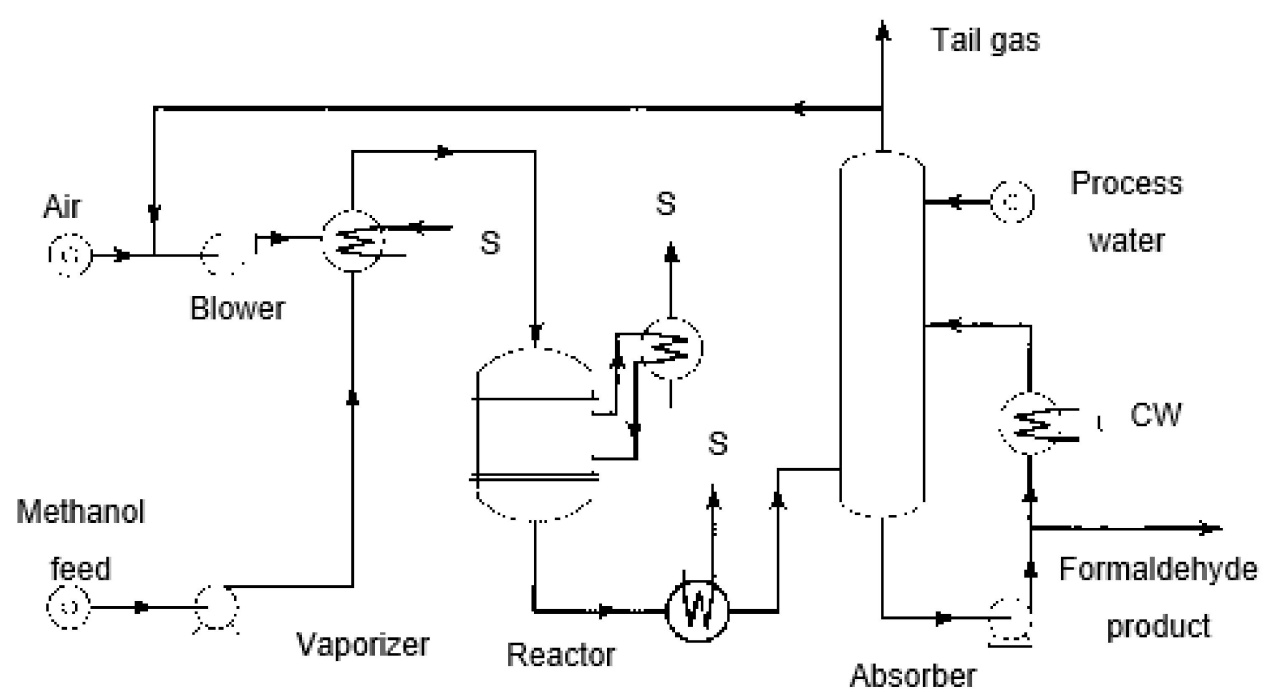

Figure 1. Process diagram of typical Formox process plant. $\mathrm{S}=$ steam; $\mathrm{CW}=$ cooling water. Copyright (C) (2013) by John Wiley \& Sons, Inc. [16].

\section{Literature Survey}

In 1921, the oxidation of $\mathrm{MeOH}$ to FA was first patented on a metal oxide (V oxide) and later in 1933 on Fe-Mo oxide, where the first commercial plant using FeMo was in operation by 1952. Since then, FeMo has become the most used catalyst in the Formox process. The main disadvantage for the Formox process stems from the deactivation of the FeMo catalyst, where Mo vaporizes in the front-end of the bed and deposits further down resulting in increasing pressure drop and an expensive change of catalyst every 6-18 months [20].

Before looking into possible methods for solving/remedying the problem, an understanding of the FeMo catalyst as well as knowledge about the reaction conditions and mechanism is needed, which is provided in the following section.

\subsection{Iron-Molybdenum Catalysts}

\subsubsection{Structure}

The industrial catalyst consists of iron (ferric) molybdate $\mathrm{Fe}_{2}\left(\mathrm{MoO}_{4}\right)_{3}$ with a surplus of $\mathrm{MoO}_{3}$. Thus, the main component of the catalyst is the bulk stoichiometric $\mathrm{Fe}_{2}\left(\mathrm{MoO}_{4}\right)_{3}$. A study by Abaulina et al. [21] on an industrial catalyst found the structure of the catalyst to be an Fe deficient $\mathrm{Fe}_{2}\left(\mathrm{MoO}_{4}\right)_{3}$ structure with $\mathrm{MoO}_{3}$ in the voids.

To understand the surface of the FeMo catalyst, a number of studies have been performed on catalysts with excess $\mathrm{Fe}_{2} \mathrm{O}_{3}$. Chapman et al. [22] studied a core-shell type $\mathrm{MoO}_{x} / \mathrm{Fe}_{2} \mathrm{O}_{3}\left(\mathrm{MoO}_{x}\right.$ shell and $\mathrm{Fe}_{2} \mathrm{O}_{3}$ core) catalyst doped and not doped with Al. The catalysts were investigated by X-ray photoelectron spectroscopy (XPS), which showed surface Mo enrichment for both samples. An amorphous surface layer of $\mathrm{MoO}_{3}$ was found by X-ray absorption near edge spectroscopy (XANES) on a $\mathrm{Fe}_{2}\left(\mathrm{MoO}_{4}\right)_{3}$ sublayer, which increased with Mo impregnation in the investigated range (1-6 monolayers (ML)). This was confirmed by using other techniques such as Raman, extended X-ray absorption fine structure spectroscopy (EXAFS), attenuated total reflectance infrared spectroscopy (ATR-IR) and X-ray diffraction (XRD) spectroscopy [22]. Brookes et al. [23-25] similarly found that octahedral Mo units, different from the tetrahedral $\mathrm{MoO}_{4}$ sub-units of bulk $\mathrm{Fe}_{2}\left(\mathrm{MoO}_{4}\right)_{3}$, were at the surface at all times. Moreover, characterization by Uhlrich et al. [26] of Mo deposited onto $\mathrm{Fe}_{2} \mathrm{O}_{3}$ thin films (app. $5 \mathrm{ML}$ of $\mathrm{Fe}_{2} \mathrm{O}_{3}$ ) on $\mathrm{Pt}(111)$ showed Mo concentration to be larger in the surface layers compared to the lower crystal layers (unless annealed at $>627^{\circ} \mathrm{C}$ ). At low temperatures, the iron oxide film was covered by $\mathrm{Mo}=\mathrm{O}$ terminated Mo oxide nano-particles. If the thin films were oxidized at temperatures above $627^{\circ} \mathrm{C}$, the Mo migrated into the surface layers of the iron oxide but retains iron oxide 
structure [26]. House et al. [27] also observed the segregation of Mo to the surface by scanning transmission electron microscopy (STEM) on a stoichiometric FeMo catalyst prepared by co-precipitation. A simplified schematic of the structure of the catalyst was proposed by Brookes et al. [28], summing up the findings in the literature, as a function of annealing temperature (Figure 2). The schematic was in agreement with the other findings regarding the structure of the catalysts with excess $\mathrm{Fe}_{2} \mathrm{O}_{3}$ mentioned above. However, the industrial catalyst has $\mathrm{MoO}_{3}$ in excess.

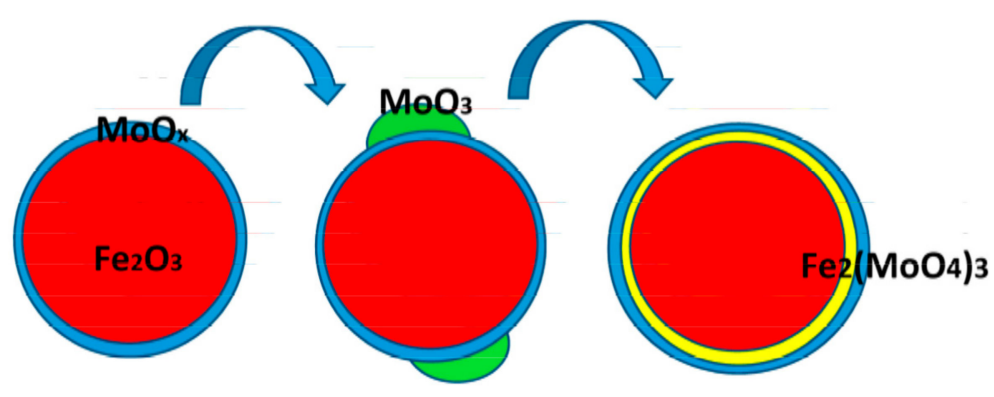

Figure 2. Evolution of the surface structure of $3 \mathrm{ML} \mathrm{MoO}_{3}$ deposited on $\mathrm{Fe}_{2} \mathrm{O}_{3}$ catalyst as function of the annealing temperature. Left: Structure at $120^{\circ} \mathrm{C}$. Middle: Structure at $400{ }^{\circ} \mathrm{C}$. Right: Structure at $500{ }^{\circ} \mathrm{C}$. (red) $\mathrm{Fe}_{2} \mathrm{O}_{3}$; (blue) amorphous layer of $\mathrm{MoO}_{x}$; (green) $\mathrm{MoO}_{3}$ nano-crystallites; (yellow) $\mathrm{Fe}_{2}\left(\mathrm{MoO}_{4}\right)_{3}$ [28]. Reproduced from [28] Copyright 2016, MDPI.

Routray et al. [29] investigated the synergistic effect between $\mathrm{MoO}_{3}$ and $\mathrm{Fe}_{2}\left(\mathrm{MoO}_{4}\right)_{3}$ on the catalytic oxidation of $\mathrm{MeOH}$ to FA and found, using low-energy ion scattering (LEIS), it to arise from excess $\mathrm{MoO}_{3}$ forming a surface $\mathrm{MoO}_{x}$ layer covering all the originally exposed Fe sites present in the surface layer of stoichiometric bulk $\mathrm{Fe}_{2}\left(\mathrm{MoO}_{4}\right)_{3}$. When the $\mathrm{Mo} / \mathrm{Fe}$ ratio increased further, an increase in the amount of observed crystalline $\mathrm{MoO}_{3}$ phase was observed in addition to the surface layer [29]. The structure starting from $\mathrm{Fe}_{2} \mathrm{O}_{3}$ in excess had a core of $\mathrm{Fe}_{2} \mathrm{O}_{3}$ with a layer of $\mathrm{Fe}_{2}\left(\mathrm{MoO}_{4}\right)_{3}$ around it, with an amorphous layer of $\mathrm{MoO}_{3}$ on top. When the $\mathrm{Mo} / \mathrm{Fe}$ ratio increased, the core of $\mathrm{Fe}_{2} \mathrm{O}_{3}$ decreased while the layer of $\mathrm{Fe}_{2}\left(\mathrm{MoO}_{4}\right)_{3}$ increased in thickness until $\mathrm{Mo} / \mathrm{Fe}=1.5$, where the core $\mathrm{Fe}_{2} \mathrm{O}_{3}$ disappeared and only $\mathrm{Fe}_{2}\left(\mathrm{MoO}_{4}\right)_{3}$ with the amorphous $\mathrm{MoO}_{3}$ on top remained. When the $\mathrm{Mo} / \mathrm{Fe}$ ratio further increased, the formation of crystalline $\mathrm{MoO}_{3}$ increased. These observations are supported by Bowker et al. [30].

\subsubsection{The Active Site}

Bowker et al. [31] determined the changes in the FA selectivity by the addition of Mo to $\mathrm{Fe}_{2} \mathrm{O}_{3}$ so that catalysts with a $\mathrm{Mo} / \mathrm{Fe}<1.5$ were synthesized. The selectivity changed from pure $\mathrm{CO}_{2}$ as product over $\mathrm{Fe}_{2} \mathrm{O}_{3}$ at low Mo loadings, to $\mathrm{CO}$ as the main product at intermediate Mo loadings, and to FA at high Mo loadings (Figure 3a). These observations, taken together with the evolution of Fe ensembles, Mo dual sites, and Mo single sites, resulted in the proposal of Mo dual sites being responsible for the formation of FA while Fe ensembles made $\mathrm{CO}_{2}$ and Mo single sites $\mathrm{CO}$ (Figure $3 \mathrm{~b}$ ).

The effects of surface Mo was further investigated by Bowker et al. [32] by addition of Mo oxide to $\mathrm{Fe}_{2} \mathrm{O}_{3}$ and performing diffuse reflectance infrared Fourier transform spectroscopy (DRIFTS) during temperature programmed oxidation/reduction (TPO/TPR) experiments. On the pure $\mathrm{Fe}_{2} \mathrm{O}_{3}, \mathrm{MeOH}$ adsorbed as methoxy groups and was oxidized to formate at around $200{ }^{\circ} \mathrm{C}$, which then desorbed as $\mathrm{CO}_{2}$. When a ML of molybdena had been formed on the hematite, the formate formation was blocked and formaldehyde became the main gas phase product from temperature programmed desorption (TPD) after $\mathrm{MeOH}$ adsorption [32]. This was supported by the earlier work by Bowker et al. [33] measuring the activity of the FeMo component oxides. The dual Mo sites for the FA formation was in agreement with previous studies [34-37]. Bowker et al. [38,39] also established the importance of the surface Mo being in the +6 oxidation state as they found $\mathrm{MoO}_{2}$ 
and surface reduced $\mathrm{MoO}_{3}$ to be most selective towards $\mathrm{CO}$, whereas $\mathrm{MoO}_{3}$ and surface oxidized bulk $\mathrm{MoO}_{2}\left(\mathrm{MoO}_{3}\right.$ surface layer) primarily yielded FA. It was furthermore stated by Trifiró et al. [40] that the Mo needed to have octahedral coordination to be active and selective, where both octahedral and tetrahedral coordination is possible for +6 oxidation state depending on the compound.

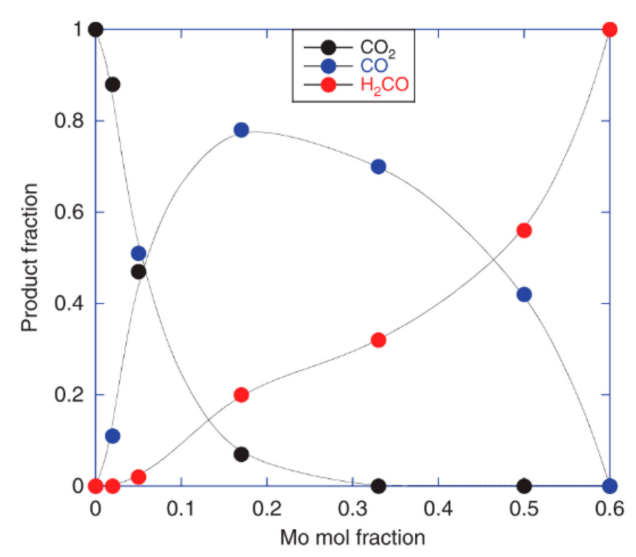

(a)

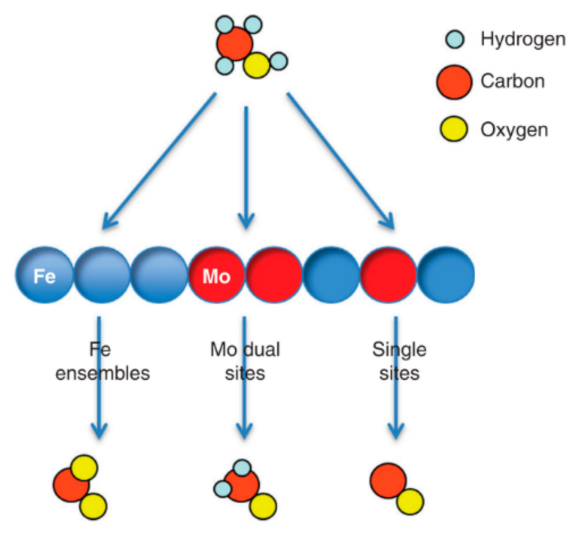

(b)

Figure 3. (a) Yields of $\mathrm{CO}, \mathrm{CO}_{2}$, and FA from $\mathrm{MeOH}$ oxidation observed in TPD vs. Mo fraction in the catalyst (Mo mole fraction of 0.6 corresponds to $\left.\mathrm{Fe}_{2}\left(\mathrm{MoO}_{4}\right)_{3}\right)$ [31]. (b) Model of the active sites on Fe-Mo oxide materials showing the variation in products from different site ensembles proposed by Bowker et al. [31]. Reproduced from [31] Copyright 2015, with permission from Taylor and Francis.

Dias et al. [41] investigated the role of suprastoichiometric Mo in the FeMo catalyst during $\mathrm{MeOH}$ oxidation to FA by the addition of surface $\mathrm{Mo}$ to $\mathrm{Fe}_{2}\left(\mathrm{MoO}_{4}\right)_{3}$ until a maximum of five $\mathrm{MLs}$ of $\mathrm{MoO}_{3}$. Crystalline $\mathrm{MoO}_{3}$ was not observed for any of the samples. All the samples showed a surface enrichment of Mo, and the addition of surface Mo was claimed to promote surface aggregation of Mo species, which was already observed for the stoichiometric molybdate before Mo addition. A higher yield of FA was achieved with loadings higher than $0.5 \mathrm{ML}$. Catalytic performance was concluded to be a cooperative effect between the high selectivity but low activity of $\mathrm{MoO}_{3}$ and the high activity of $\mathrm{Fe}_{2}\left(\mathrm{MoO}_{4}\right)_{3}[41]$.

Hummadi et al. [42] proposed Fe to be an activity promoter, where the important feature in the $\mathrm{Fe}(\mathrm{III})$ molybdate catalysts was the presence of -O-Mo-O-Fe-O-Mo-O-groups, which were found in $\mathrm{Fe}_{2}\left(\mathrm{MoO}_{4}\right)_{3}$, and $\mathrm{Fe}^{3+}$ finely dispersed in $\mathrm{MoO}_{3}$. This was in opposition to the work conducted by Bowker et al. [31], who found two Mo side by side to be the important feature. For higher Fe(III) concentrations, Hummadi et al. [42] found that patches of iron oxide or particles result in selectivity loss due to iron oxide catalyzing the total combustion of $\mathrm{MeOH}$ [42].

Taking these considerations together, the excess of Mo compared to Fe is important for ensuring that there is an amorphous overlayer of $\mathrm{MoO}_{x}$ on the surface. The overlayer ensures firstly that there are no Fe ensembles at the surface, which makes $\mathrm{CO}_{2}$, and secondly that the surfaces are covered by Mo-Mo sites, which are selective for oxidation to formaldehyde. Fe acts as an activity promoter. This is in agreement with work conducted by the authors of [43], who found FA selectivity to stay high even when most of the Mo was gone, as there was still a surface layer of $\mathrm{MoO}_{x}$.

\subsubsection{Influence of Catalyst Acidity/Basicity on Reaction Pathways}

Pernicone et al. [44] found a correlation between the surface acidity and the activity for $\mathrm{MoO}_{3}$ and $\mathrm{MoO}_{3}-\mathrm{Fe}_{2}\left(\mathrm{MoO}_{4}\right)_{3}$ (Figure 4). They proposed the surface acidity to be of the Brønsted type and suggested that an active catalyst needed to be Fe defective (have a small 
excess of Mo), as they observed a steep decline in catalyst activity with $\mathrm{Mo} / \mathrm{Fe}<1.7$, or that $\mathrm{Fe}_{2}\left(\mathrm{MoO}_{4}\right)_{3}$ had a promoting effect on $\mathrm{MoO}_{3}$ [44].

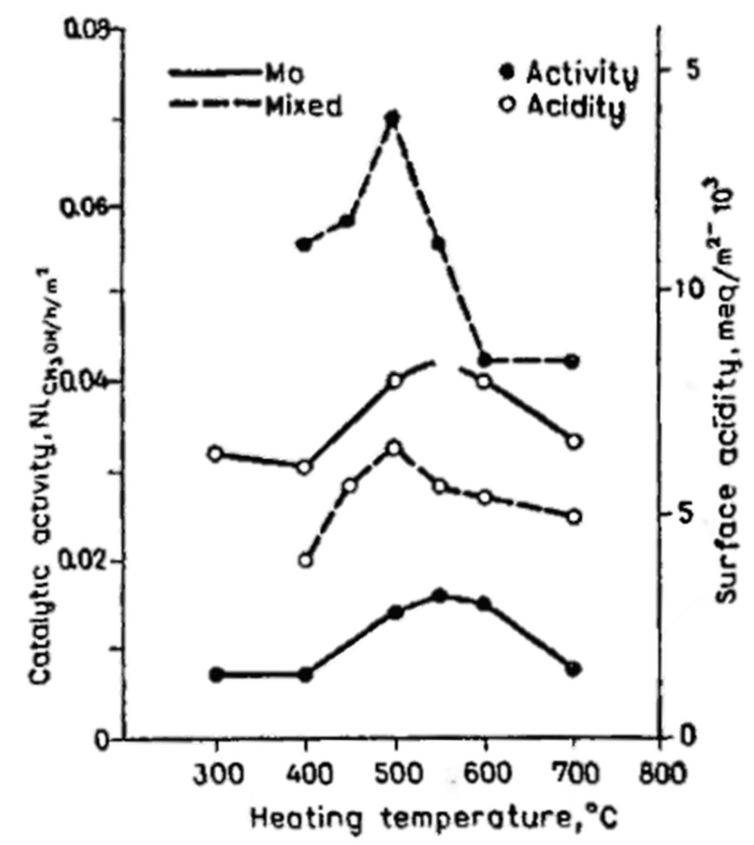

Figure 4. Catalytic activity in a differential reactor and surface acidity of pure $\mathrm{MoO}_{3}$ and mixed 2.5: 1 $\mathrm{MoO}_{3}-\mathrm{Fe}_{2}\left(\mathrm{MoO}_{4}\right)_{3}$ catalysts versus calcination temperature [44]. Reproduced from [44] copyright (1968) with permission from copyright holder.

The formation of FA comes from $\mathrm{MeOH}$ oxidation. However, FA is not the only possible product from $\mathrm{MeOH}$ and $\mathrm{O}_{2}$ over a catalyst. Tatibouët [45] proposed a scheme of the reaction pathways for $\mathrm{MeOH}$ oxidation/dehydration (Figure 5) [45].

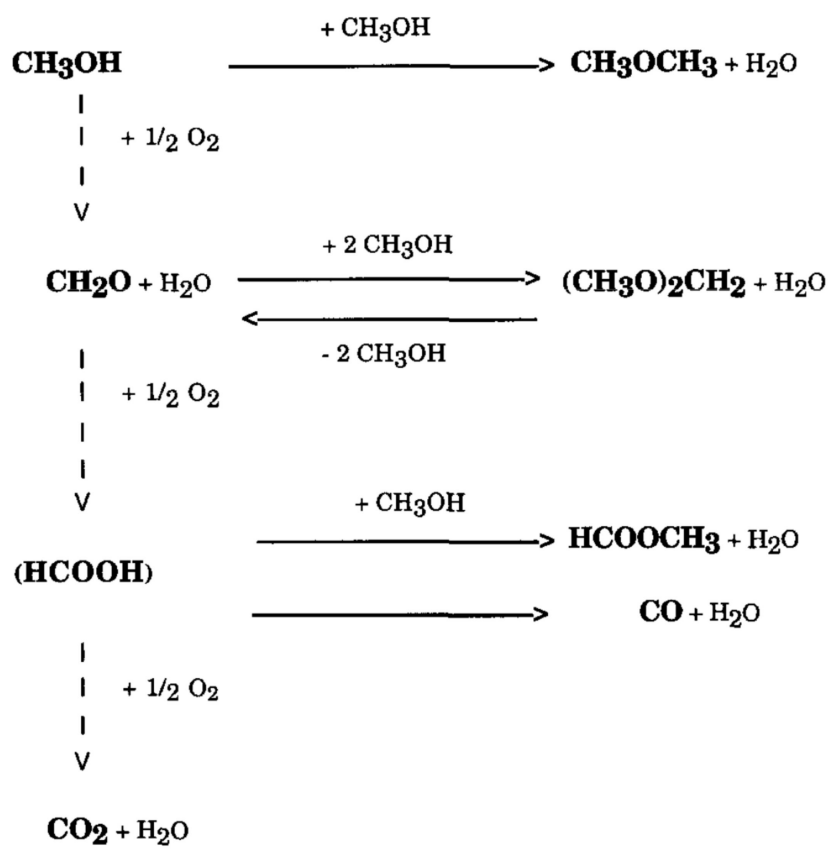

Oxidation reactions

Dehydration reactions

Figure 5. Scheme showing the reaction pathways for $\mathrm{MeOH}$ conversion via either oxidation or dehydration reactions. Reprinted from [45] Copyright (C) 1997 with permission from Elsevier. 
Part of the challenge is to stop oxidation after the first oxidative step and to prevent forming any of the dehydration products. Additionally, Tatibouët [45] mapped the products with respect to the catalyst's acid-base properties, which provided a simplified scheme as shown in Figure 6.

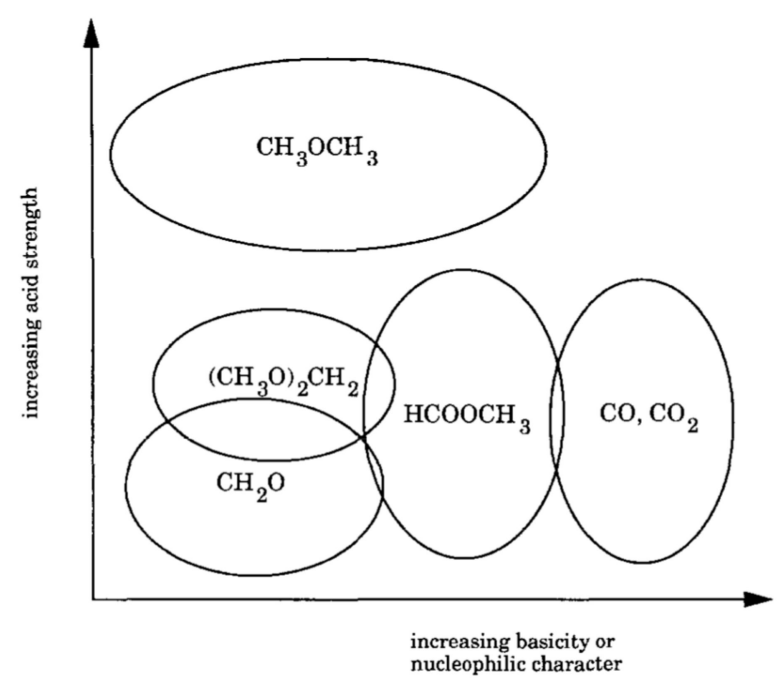

Figure 6. Rough sketch of the main reaction products as function of the acid-base character of the catalyst. Reprinted from [45] Copyright $@(1997)$ with permission from Elsevier.

Ivanov and Dimitrov [46] published an extension to the reaction scheme proposed by Tatibouët [45]. They found that independent oxidation reactions of DME took place on an industrial FeMo catalyst, producing $\mathrm{FA}, \mathrm{CO}$, and $\mathrm{CO}_{2}$ (which they stated were not an oxidation product from FA), and that $\mathrm{CO}$ could not be oxidized to $\mathrm{CO}_{2}$ in the relevant temperature range by the FeMo catalyst.

The influence of the catalyst's acid-base properties on $\mathrm{MeOH}$ oxidation in vapor-phase was investigated by $\mathrm{Ai}$ [47] over a series of composite oxide catalysts such as $\mathrm{MoO}_{3}-\mathrm{TiO}_{2}$, $\mathrm{MoO}_{3}-\mathrm{Fe}_{2} \mathrm{O}_{3}, \mathrm{MoO}_{3}-\mathrm{SnO}_{2}, \mathrm{MoO}_{3}-\mathrm{P}_{2} \mathrm{O}_{5}, \mathrm{MoO}_{3}-\mathrm{Bi}_{2} \mathrm{O}_{3}-\mathrm{P}_{2} \mathrm{O}_{5}, \mathrm{~V}_{2} \mathrm{O}_{5}-\mathrm{MoO}_{3}, \mathrm{WO}_{3}$-based and $\mathrm{U}_{3} \mathrm{O}_{8}$-based oxides, $\mathrm{SnO}_{2}-\mathrm{K}_{2} \mathrm{O}, \mathrm{Co}_{3} \mathrm{O}_{4}-\mathrm{K}_{2} \mathrm{O}$, and $\mathrm{Bi}_{2} \mathrm{O}_{3}-\mathrm{X}_{n} \mathrm{O}_{m}$ where $\mathrm{X}=\mathrm{P}, \mathrm{Mo}, \mathrm{W}, \mathrm{V}$, and $\mathrm{S}$. FA was obtained from acidic oxides such as $\mathrm{MoO}_{3}, \mathrm{WO}_{3}, \mathrm{~V}_{2} \mathrm{O}_{5}$, and $\mathrm{U}_{3} \mathrm{O}_{8}$. However, from more basic oxides such as $\mathrm{TiO}_{2}, \mathrm{Fe}_{2} \mathrm{O}_{3}, \mathrm{SnO}_{2}, \mathrm{Bi}_{2} \mathrm{O}_{3}, \mathrm{ZnO}$, and $\mathrm{Co}_{3} \mathrm{O}_{4}, \mathrm{FA}$ was not obtained, and selectivity was towards full oxidation to $\mathrm{CO}_{2}$. In general, selectivity decreased for FA and increased for $\mathrm{CO}_{2}$ with an increase in basicity. A more or less linear correlation between acidity and activity for FA formation was found for $\mathrm{V}_{2} \mathrm{O}_{5}$ and $\mathrm{MoO}_{3}$ containing catalysts with only small amounts of by-products, with the exception of $\mathrm{MoO}_{3} / \mathrm{SnO}_{2}$, which had high production of by-products [47].

Nikolenko et al. [48] recently investigated the adsorption of organic compounds (1-napthylamine; N,N-dimethylaniline; m-toluidine; pyridine-3-aldehyde; aniline; 2,8dimethylquinoline; pyridine; 2-picoline) on $\mathrm{Fe}_{2} \mathrm{O}_{3}, \mathrm{MoO}_{3}$, and $\mathrm{Fe}_{2}\left(\mathrm{MoO}_{4}\right)_{3}$ and found that they were adsorbed by surface hydrogen bonds. The adsorption propensity of organic bases was linearly correlated with the effective charge on nitrogen atoms giving the order $\mathrm{Fe}_{2} \mathrm{O}_{3}>\mathrm{MoO}_{3}>\mathrm{Fe}_{2}\left(\mathrm{MoO}_{4}\right)_{3}$. This resulted in the proposal stating that methanol and formaldehyde were adsorbed by oxygen atoms to Lewis acid sites or that the atoms in the $\mathrm{C}-\mathrm{H}$ bonds interacted with the Lewis basic centers for $\mathrm{MeOH}$ oxidation reactions. The good selectivity of the FeMo catalyst was concluded to arise from low adsorption of intermediate products in $\mathrm{MeOH}$ oxidation [48].

The dependence of active metal loading on an $\mathrm{Al}_{2} \mathrm{O}_{3}$ carrier on Brønsted and Lewis acidity was described by Wachs [49]. Brønsted acidity increased with metal loading on the surface (Figure 7a). For Lewis acidity, no apparent trend with metal loading was visible (Figure 7b) [49]. The acidity did not seem to be related to the coordination of the surface 
metal, as Re possessed 4-fold coordination at all coverages and had both 4-fold and 6-fold coordination at high coverages [49].

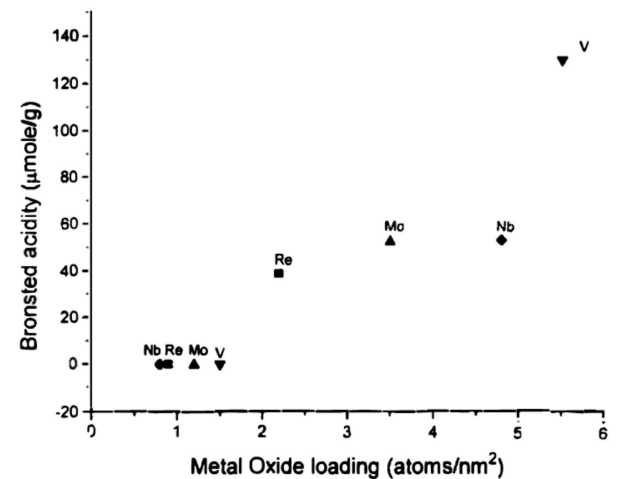

(a)

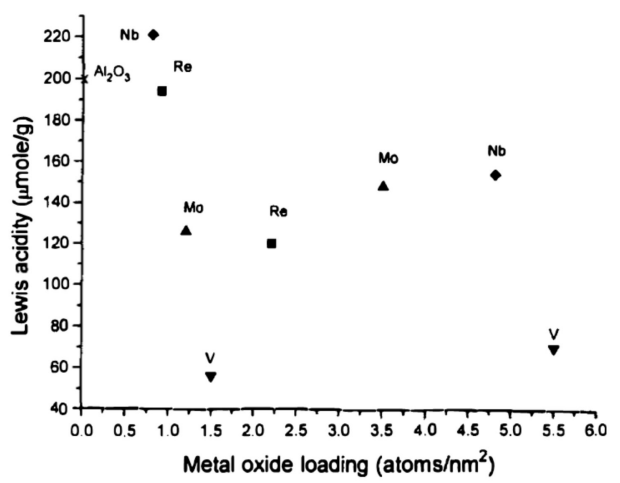

(b)

Figure 7. Dependence of (a) Brønsted and (b) Lewis acidity on metal loading on $\mathrm{Al}_{2} \mathrm{O}_{3}$ support. Reprinted from [49] Copyright (C) (1996) with permission from Elsevier.

The knowledge of the influence of acidity and basicity may be used as a tool to direct preparation if a catalyst is not sufficiently selective, since the by-products may be able to inform the direction in which the acid-base properties of the catalyst should be modified.

\subsubsection{Reaction Mechanism and Kinetics}

As discussed in the Introduction, the formation of FA over the FeMo catalyst occurs by an overall oxidative dehydrogenation reaction, Reaction (4).

$$
\begin{aligned}
\mathrm{CH}_{3} \mathrm{OH}(\mathrm{g})+\frac{1}{2} \mathrm{O}_{2}(\mathrm{~g}) & \leftrightarrows \mathrm{CH}_{2} \mathrm{O}(\mathrm{g})+\mathrm{H}_{2} \mathrm{O}(\mathrm{g}) \\
\Delta \mathrm{H}_{298 \mathrm{~K}}^{\mathrm{o}} & =-159 \frac{\mathrm{kJ}}{\mathrm{mol}}
\end{aligned}
$$

This section describes the reaction kinetics and reaction mechanism of the FA formation.

The effect of $\mathrm{H}_{2} \mathrm{O}$ on the formation of FA from $\mathrm{MeOH}$ was investigated by Pernicone et al. [50]. $\mathrm{H}_{2} \mathrm{O}$ strongly inhibited the reaction rate of $\mathrm{MeOH}$ formation (Figure 8). The effect was explained by the authors to arise from competitive adsorption between $\mathrm{H}_{2} \mathrm{O}$ and $\mathrm{MeOH}$ on the catalyst [50]. It should be noted that this study was conducted at a rather low temperature $\left(232{ }^{\circ} \mathrm{C}\right)$, and the inhibiting effect of water is expected to be lower at higher and industrially relevant temperature.

The reaction kinetics and mechanisms were further investigated by Pernicone et al. [51] in the temperature range of $180-280{ }^{\circ} \mathrm{C}$. The reaction was inhibited by $\mathrm{H}_{2} \mathrm{O}$ and by FA (although not as much), which was in agreement with their conclusion that reaction product desorption was the rate determining step at these temperatures. Under industrial conditions, the inhibition from formaldehyde desorption is, thus, very low in agreement with the selectivity towards FA being very high. Recent density functional theory (DFT) calculations showed that FA does not adsorb strongly [52]. Furthermore, the reaction rate was independent of reactant partial pressures (zero order kinetics) above $100 \mathrm{mmHg}$ for both methanol and oxygen, when the other reactant $\left(\mathrm{MeOH}\right.$ and $\mathrm{O}_{2}$, respectively) was kept constant at $180 \mathrm{mmHg}$. The results showed first order kinetics in both $\mathrm{MeOH}$ and $\mathrm{O}_{2}$ below $100 \mathrm{mmHg}$. The catalyst formed the same reaction products with and without $\mathrm{O}_{2}$ in the feed. This indicates that the reaction is of the Mars van Krevelen type where the catalyst supply lattice oxygen for the reaction and is subsequently re-oxidized by gaseous $\mathrm{O}_{2}$ [51]. Those findings were further supported by the same group with work in a pulse micro-reactor [53]. The effect of $\mathrm{H}_{2} \mathrm{O}$ vapor on the kinetics of $\mathrm{MeOH}$ oxidation was also investigated by Holstein and Machiels [54] in a continuous flow reactor with external 
recycling at temperatures between 200 and $300{ }^{\circ} \mathrm{C}$. Here, the kinetics were found to be well described by a power rate law expression as in Equation (5):

$$
r=k P_{\mathrm{MeOH}}^{x} P_{\mathrm{O}_{2}}^{y} P_{\mathrm{H}_{2} \mathrm{O}}^{z}
$$

where $x=0.94 \pm 0.06, y=0.10 \pm 0.05$, and $z=-0.45 \pm 0.07 . \mathrm{H}_{2} \mathrm{O}$ was suggested to inhibit the reaction by kinetic coupling, meaning that $\mathrm{H}_{2} \mathrm{O}$ adsorbs dissociatively as surface $\mathrm{OH}^{*}$ groups, which is in competition with the dissociative adsorption of $\mathrm{MeOH}$ to hydroxy and methoxy groups. Site blocking by non-dissociative $\mathrm{H}_{2} \mathrm{O}$ adsorption was dismissed at temperatures above $200{ }^{\circ} \mathrm{C}$, as the adsorption energy was too low to compete with $\mathrm{MeOH}$; however, it should be taken into consideration at lower temperatures. The reaction rate was found to be independent of FA partial pressure [54]. This was in contrast with Pernicone et al. [51] who found FA to inhibit the reaction rate, however, at lower temperatures. Drăgan and Kulic [55] also reported FA to significantly lower than $\mathrm{MeOH}$ oxidation rate; however, they added FA by bubbling an air stream through a $38 \%$ FA solution and did not comment on $\mathrm{H}_{2} \mathrm{O}$ inhibition nor on the removal of $\mathrm{H}_{2} \mathrm{O}$ from the feed when adding FA; hence, the measured inhibition was most likely from $\mathrm{H}_{2} \mathrm{O}$.

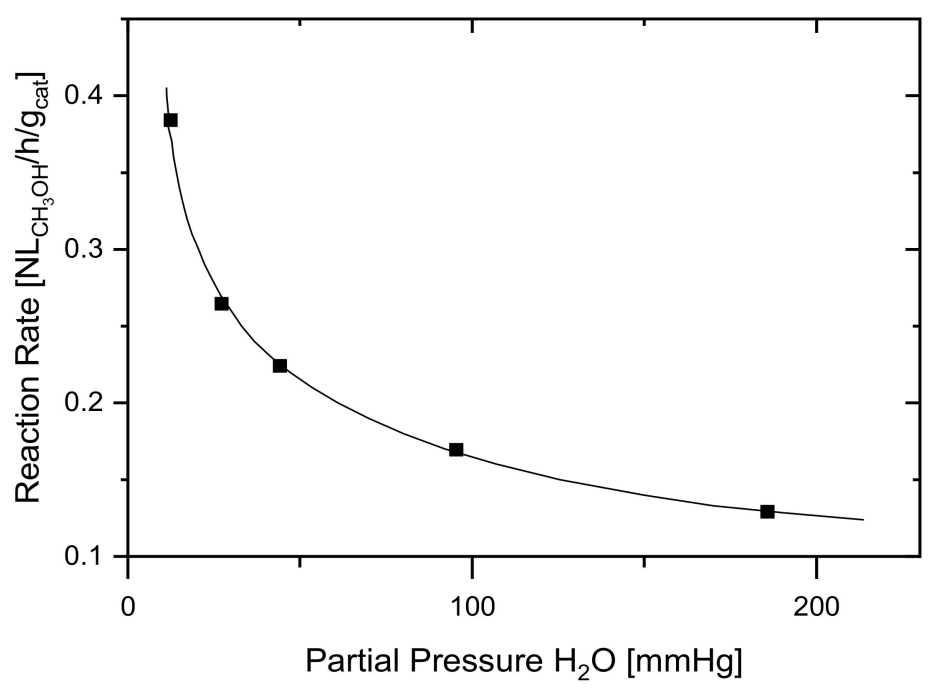

Figure 8. Influence of $\mathrm{H}_{2} \mathrm{O}$ partial pressure on the rate of $\mathrm{MeOH}$ oxidation. $\mathrm{T}=232{ }^{\circ} \mathrm{C}$; $P_{\text {tot }}=920 \mathrm{mmHg} ; P_{\mathrm{O}_{2}}=180 \mathrm{mmHg} ; P_{\mathrm{CH}_{3} \mathrm{OH}}=180 \mathrm{mmHg}$. Reproduced from [50] Copyright (C) (1968) with permission from Elsevier.

A non-exhaustive summary of rate expressions found in the literature is provided in Table 1. 
Table 1. Proposed rate expressions in literature for the oxidation of $\mathrm{MeOH}$ to FA.

\begin{tabular}{|c|c|c|c|}
\hline Authors & Year & Expression & Comments \\
\hline $\begin{array}{c}\text { Pernicone et al. [51] } \\
\text { (Bhattacharyya et al. [56]) a }\end{array}$ & $\begin{array}{c}1969 \\
(1967)\end{array}$ & $r=\frac{2 k_{1} k_{2} P_{\mathrm{O}_{2}}^{m} P_{\mathrm{MeOH}}^{n}}{k_{1} P_{\mathrm{MeOH}}^{n}+2 k_{2} P_{\mathrm{O}_{2}}^{m}}$ & $\begin{array}{l}m=n=0.5 \\
(m=n=1)\end{array}$ \\
\hline Bibin and Popov [57] & 1969 & $r=\frac{k_{1} C_{\mathrm{MeOH}}}{1+\alpha_{1} C_{\mathrm{MeOH}}+\alpha_{2} C_{\mathrm{H}_{2} \mathrm{O}}}$ & \\
\hline $\begin{array}{l}\text { Evemenenko and } \\
\text { Gorokhovatskii [58] }\end{array}$ & 1968 & $r=\frac{k C_{\mathrm{MeOH}}}{1+b_{1} C_{\mathrm{MeOH}}+b_{3} C_{\mathrm{H}_{2} \mathrm{O}}} \frac{C_{\mathrm{O}_{2}}}{1+b_{2} C_{\mathrm{O}_{2}}}$ & \\
\hline Santacesaria et al. [59] & 1981 & $r=\frac{k_{1} k_{2} P_{\mathrm{MeOH}} P_{\mathrm{O}_{2}}^{\frac{1}{2}}}{k_{1} P_{\mathrm{MeOH}}+k_{2} P_{\mathrm{O}_{2}}^{\frac{1}{2}}} \frac{1}{1+K_{\mathrm{H}_{2} \mathrm{O}} P_{\mathrm{H}_{2} \mathrm{O}}}$ & \\
\hline Holstein and Machiels [54] & 1996 & $r=k P_{\mathrm{MeOH}}^{x} P_{\mathrm{O}_{2}}^{y} P_{\mathrm{H}_{2} \mathrm{O}}^{z}$ & $\begin{array}{c}x=0.94 \pm 0.06 \\
y=0.10 \pm 0.05 \\
z=-0.45 \pm 0.07\end{array}$ \\
\hline Deshmukh et al. [60] & 2005 & $r=\frac{k_{\mathrm{MeOH} \rightarrow \mathrm{CH}_{2} \mathrm{O}} K_{\mathrm{MeOH}} P_{\mathrm{MeOH}} K_{\mathrm{O}_{2}} P_{\mathrm{O}_{2}}^{\frac{1}{2}}}{\left(1+K_{\mathrm{MeOH}} P_{\mathrm{MeOH}}+K_{\mathrm{H}_{2} \mathrm{O}} P_{\mathrm{H}_{2} \mathrm{O}}\right)\left(1+K_{\mathrm{O}_{2}} P_{\mathrm{O}_{2}}^{\frac{1}{2}}\right)}$ & \\
\hline Ulukardeslar et al. [61] & 2010 & $\frac{r \underset{\mathrm{MeOH} \rightarrow \mathrm{CH}_{2} \mathrm{O} \mathrm{K}_{\mathrm{O}_{2}}}{ } P_{\mathrm{O}_{2}} P_{\mathrm{MeOH}}}{\left(1+K_{\mathrm{O}_{2}} P_{\mathrm{O}_{2}}+K_{\mathrm{MeOH}} P_{\mathrm{MeOH}}+K_{\mathrm{H}_{2} \mathrm{O}} P_{\mathrm{H}_{2} \mathrm{O}}+K_{\mathrm{CH}_{2} \mathrm{O}} P_{\mathrm{CH}_{2} \mathrm{O}}\right)^{2}}$ & \\
\hline
\end{tabular}

a The work by Bhattacharyya et al. [56] was on $\mathrm{V}_{2} \mathrm{O}_{5}$.

Deshmukh et al. [60] performed kinetic investigations to derive a model for all the relevant reactions on a Perstorp industrial FeMo catalyst in a differential reactor. The oxidation of $\mathrm{MeOH}$ to FA was found to have a Langmuir-Hinshelwood (LH) type dependence on both $\mathrm{O}_{2}$ and $\mathrm{MeOH}$ concentrations (plateauing at $>5$ vol.\%). For the further oxidation of FA to $\mathrm{CO}$, the rate was first order in $\mathrm{CH}_{2} \mathrm{O}$ with identical $\mathrm{LH}$ behavior in $\mathrm{O}_{2}$ as for the $\mathrm{MeOH}$ oxidation, indicating that the same oxygen sites participate in further oxidation. DME formation was first order in $\mathrm{MeOH}$ feed concentration, and DMM formation was first order in both $\mathrm{MeOH}$ and FA concentrations. The formation of FA from DME showed first order LH contributions from both DME and $\mathrm{O}_{2} \cdot \mathrm{H}_{2} \mathrm{O}$ was found to have a large inhibiting effect on the $\mathrm{MeOH}$ oxidation, which reached a plateau at low $\mathrm{H}_{2} \mathrm{O}$ vapor concentrations. This was incorporated as LH competitive adsorption, giving the rate expressions (6)-(10) [60].

$$
\begin{aligned}
& r_{\mathrm{MeOH} \rightarrow \mathrm{CH}_{2} \mathrm{O}}=\frac{k_{\mathrm{MeOH} \rightarrow \mathrm{CH}_{2} \mathrm{O}} K_{\mathrm{MeOH}} P_{\mathrm{MeOH}} K_{\mathrm{O}_{2}} P_{\mathrm{O}_{2}}^{\frac{1}{2}}}{\left(1+K_{\mathrm{MeOH}} P_{\mathrm{MeOH}}+K_{\mathrm{H}_{2} \mathrm{O}} P_{\mathrm{H}_{2} \mathrm{O}}\right)\left(1+K_{\mathrm{O}_{2}} P_{\mathrm{O}_{2}}^{\frac{1}{2}}\right)} \\
& r_{\mathrm{CH}_{2} \mathrm{O} \rightarrow \mathrm{CO}}=\frac{k_{\mathrm{CH}_{2} \mathrm{O} \rightarrow \mathrm{CO}} P_{\mathrm{CH}_{2} \mathrm{O}} K_{\mathrm{O}_{2}} P_{\mathrm{O}_{2}}^{\frac{1}{2}}}{1+K_{\mathrm{O}_{2}} P_{\mathrm{O}_{2}}^{\frac{1}{2}}} \\
& r_{\mathrm{DME}}=k_{\mathrm{DME}} P_{\mathrm{MeOH}}-\frac{k_{\mathrm{DME}}}{K_{\mathrm{DME}}^{e q}} \frac{P_{\mathrm{DME}} P_{\mathrm{H}_{2} \mathrm{O}}}{P_{\mathrm{MeOH}}} \\
& r_{\mathrm{DME} \rightarrow \mathrm{CH}_{2} \mathrm{O}}=\frac{k_{\mathrm{DME} \rightarrow \mathrm{CH}_{2} \mathrm{O}} K_{\mathrm{DME}} P_{\mathrm{DME}} K_{\mathrm{O}_{2}} P_{\mathrm{O}_{2}}^{\frac{1}{2}}}{\left(1+K_{\mathrm{DME}} P_{\mathrm{DME}}\right)\left(1+K_{\mathrm{O}_{2}} P_{\mathrm{O}_{2}}^{\frac{1}{2}}\right)} \\
& r_{\mathrm{DMM}}=k_{\mathrm{DMM}} P_{\mathrm{CH}_{2} \mathrm{O}} P_{\mathrm{MeOH}}-\frac{k_{\mathrm{DMM}}}{K_{\mathrm{DMM}}^{\text {eq }}} \frac{P_{\mathrm{DMM}} P_{\mathrm{H}_{2} \mathrm{O}}}{P_{\mathrm{MeOH}}}
\end{aligned}
$$

This reconciled the differences in whether the rate was zero or first order as it depended on the regime because the LH type behavior will be approximately first order at low 
concentrations and approximately zero order at high concentrations. This is the same case for $\mathrm{O}_{2}, \mathrm{MeOH}$, and $\mathrm{H}_{2} \mathrm{O}$ inhibition, although the definition of high concentrations differ due to different adsorption equilibrium constants (at $250{ }^{\circ} \mathrm{C}: K_{\mathrm{MeOH}}=124 \mathrm{~atm}^{-1}$; $K_{\mathrm{O}_{2}}=15.4 \mathrm{~atm}^{-1} ; K_{\mathrm{H}_{2} \mathrm{O}}=245 \mathrm{~atm}^{-1}$ ). Tesser et al. [62] found that they could accurately simulate the axial temperature profile in their experiments in a fixed bed reactor with only rates for $\mathrm{MeOH}$ oxidation to $\mathrm{FA}$ (including $\mathrm{H}_{2} \mathrm{O}$ inhibition) and the oxidation of $\mathrm{FA}$ to $\mathrm{CO}$.

An investigation of the kinetic isotope effect on $\mathrm{MoO}_{3}, \mathrm{MoO}_{3} / \mathrm{Fe}_{2}\left(\mathrm{MoO}_{4}\right)_{3}, \mathrm{Fe}_{2}\left(\mathrm{MoO}_{4}\right)_{3}$, and $\mathrm{FeMoO}_{4}$ was performed by Machiels and Sleight $[63,64]$ with the use of $\mathrm{CH}_{3} \mathrm{OD}$ and $\mathrm{CD}_{3} \mathrm{OD}$. It was found unambiguously that the rate limiting step on the catalyst was the abstraction of $\mathrm{H}$ from the methyl group [63], which was supported by Yang and Lunsford [65].

An investigation of $\mathrm{MoO}_{3} / \mathrm{Fe}_{2}\left(\mathrm{MoO}_{4}\right)_{3}$ by use of $\mathrm{CH}_{3} \mathrm{OH}$-temperature programmed surface reaction (TPSR) performed by Routray et al. [29], looked into the roles of the catalyst components w.r.t. the Mars-van Krevelen (MvK) mechanism. In the experiment [66], a 2000 ppm $\mathrm{CH}_{3} \mathrm{OH}$ in $\mathrm{He}$ stream was fed over the catalyst sample for $30 \mathrm{~min}$ at $100{ }^{\circ} \mathrm{C}$, flushed with $\mathrm{He}$ at $110{ }^{\circ} \mathrm{C}$ for $60 \mathrm{~min}$. The temperature was then ramped to $490{ }^{\circ} \mathrm{C}$ with $10^{\circ} \mathrm{C} / \mathrm{min}$ with tracking of possible released surface species. The sample was then cooled to $100{ }^{\circ} \mathrm{C}$ concluding one cycle. The $\mathrm{Fe}_{2}\left(\mathrm{MoO}_{4}\right)_{3}$ catalyst stayed fully oxidized at the surface since the FA signal did not change between the cycles (Figure 9a). This meant that the catalyst supplied lattice oxygen to the surface for the reaction, since no $\mathrm{O}_{2}$ was fed between the cycles. Thus, $\mathrm{Fe}_{2}\left(\mathrm{MoO}_{4}\right)_{3}$ strongly facilitated a MvK mechanism by supplying oxygen from the bulk structure. On the other hand $\mathrm{MoO}_{3}$ alone did not facilitate the MvK mechanism as efficiently (Figure $9 \mathrm{~b}$ ), as the FA signal changed peak temperature $\left(\mathrm{T}_{\mathrm{p}}\right)$ and shape, which meant the lattice oxygen diffusion from the bulk to the surface was not high enough to fully keep the surface oxidized [29], which however may not be a problem with oxygen in the feed. This was supported by work in a temporal analysis of products (TAP) reactor study by Lafyatis et al. [67]. The lattice oxygen contribution was also supported by an investigation by electrical conductivity methods [68]. O'brien et al. [69] clearly observed MvK type oxygen transport in $\mathrm{MoO}_{3}$ by in situ measurements during anaerobic dehydrogenation, but this may not be as fast as for the FeMo catalyst. Bowker et al. [70] observed that a temperature of at least $250{ }^{\circ} \mathrm{C}$ was needed for oxygen lattice transport to the surface in anaerobic pulse $\mathrm{MeOH}$ reduction experiments and at $300{ }^{\circ} \mathrm{C}$ the surface was kept oxidized as Mo(VI) from lattice oxygen [39].

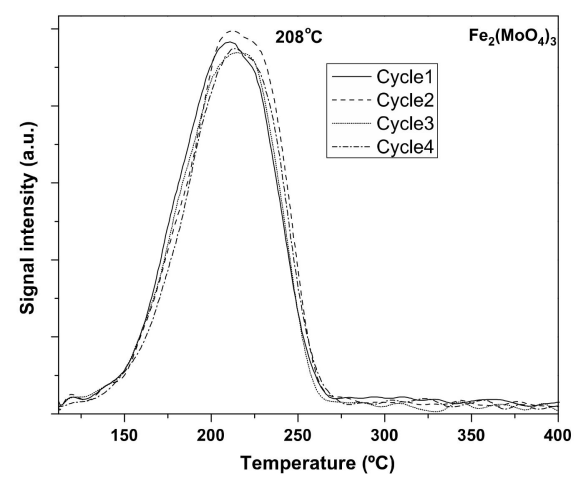

(a)

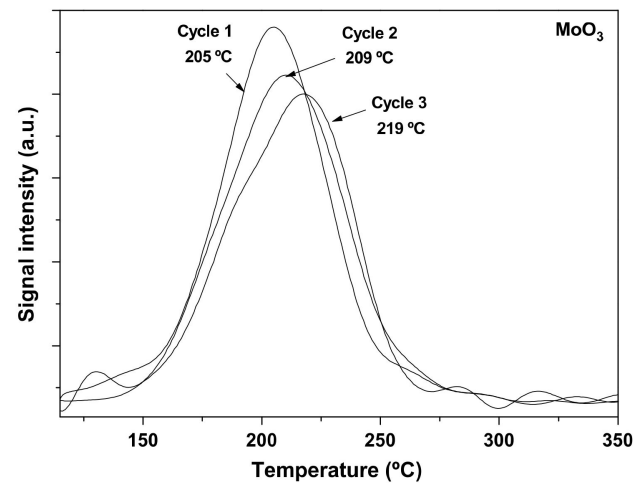

(b)

Figure 9. Cyclic $\mathrm{CH}_{2} \mathrm{O} / \mathrm{CH}_{3} \mathrm{OH}$-TPSR spectra with no oxidation between TPSR experiments for (a) bulk $\mathrm{Fe}_{2}\left(\mathrm{MoO}_{4}\right)_{3}$ catalyst $\mathrm{Mo} / \mathrm{Fe}=1.5$ and (b) bulk $\mathrm{MoO}_{3}$ catalyst. Reprinted from [29] Copyright (C) (2010) with permission from Elsevier.

In the study by Routray et al. [29], it was measured by IR that both surface $\mathrm{CH}_{3} \mathrm{OH}^{*}$ and $\mathrm{CH}_{3} \mathrm{O}^{*}$ could be converted directly to FA. This resulted in the suggestion of the following reaction mechanism (Reactions (11)-(18)) for the oxidation of MeOH to FA on a $\mathrm{MoO}_{3} / \mathrm{Fe}_{2}\left(\mathrm{MoO}_{4}\right)_{3}$ [29].

$$
\mathrm{CH}_{3} \mathrm{OH}+* \rightleftarrows \mathrm{CH}_{3} \mathrm{OH}^{*}
$$




$$
\begin{aligned}
& \mathrm{CH}_{3} \mathrm{OH}+\mathrm{O}^{*}+* \rightleftarrows \mathrm{CH}_{3} \mathrm{O}^{*}+\mathrm{OH}^{*} \\
& \mathrm{CH}_{3} \mathrm{OH}^{*}+\mathrm{O}^{*} \rightarrow \mathrm{CH}_{2} \mathrm{O}+\mathrm{H}_{2} \mathrm{O}+2 * \\
& \mathrm{CH}_{3} \mathrm{O}^{*}+\mathrm{O}^{*} \rightarrow \mathrm{CH}_{2} \mathrm{O}+\mathrm{HO}^{*}+* \\
& \mathrm{CH}_{3} \mathrm{O}^{*}+\mathrm{HO}^{*} \rightleftarrows \mathrm{CH}_{3} \mathrm{OH}+\mathrm{O}^{*}+* \\
& \mathrm{HO}^{*}+\mathrm{OH}^{*} \rightleftarrows \mathrm{H}_{2} \mathrm{O}+\mathrm{O}^{*}+* \\
& \mathrm{O}_{\text {bulk lattice }}^{*} \rightleftarrows \mathrm{O}^{*} \\
& \mathrm{O}_{2}+2 * \rightleftarrows 2 \mathrm{O}_{\text {bulk lattice }}^{*}
\end{aligned}
$$

Reactions (13) and (14) were suggested as rate limiting steps. Reactions (12) and (15) look very similar, with the difference in the notation indicating that $\mathrm{OH}$ may bind with the O-atom (Reaction (15)) or the H-atom (Reaction (12)), which does not seem realistic. The mechanism had both LH and Eley-Rideal kinetics. The authors suggested the catalytic active phase to be the $\mathrm{Fe}_{2}\left(\mathrm{MoO}_{4}\right)_{3}$ and that the $\mathrm{MoO}_{x}$ on the surface was the active sites in bulk FeMo catalysts, with the role of the excess $\mathrm{MoO}_{3}$ to keep the Fe sites covered when mobile $\mathrm{Mo}-\mathrm{CH}_{3} \mathrm{O}$ species leave the catalyst, which will be discussed further in Section 2.1.5 [29].

The mechanism has also been investigated by Rellán-Piñeiro and López [52] by using DFT calculations on $\alpha-\mathrm{MoO}_{3}(010)$ (Figure 10), as well as other Mo oxide surfaces. The reaction mechanism was similar to Reactions (11)-(18) proposed by Routray et al. [29], but with no direct reaction of molecularly adsorbed $\mathrm{MeOH}$ to form FA. FA adsorbs very weakly on the $\alpha-\mathrm{MoO}_{3}(010)$ surface. The decomposition pathway from FA was not investigated further than to $\mathrm{CHO}^{*}+\mathrm{OH}^{*}$ since the energy barrier over TS1F was stated by the authors to be too large compared to the desorption energy barrier, i.e., FA desorbs rather than oxidize further.

Rellán-Piñeiro and López [52] concluded from their work that the energy of oxygen vacancy formation was the major factor regarding activity and selectivity. They proposed that Fe contributed as an electron donor, rendering vacancy formation easier [52]. Choksi and Greeley [71] also investigated the $\mathrm{MoO}_{3}(010)$ facets by DFT and microkinetic modelling for $\mathrm{MeOH}$ oxidation, where they found a $\mathrm{CH}_{3} \mathrm{O}^{*}$ pathway, a $\mathrm{CH}_{2} \mathrm{OH}^{*}$ pathway, and a crossover pathway. They concluded that the $\mathrm{CH}_{3} \mathrm{O}^{*}$ pathway was the kinetically and thermodynamically preferred route in agreement with Rellán-Piñeiro and López [52]. As the $\mathrm{C}-\mathrm{H}$ cleavage of $\mathrm{CH}_{2} \mathrm{O}^{*}$ to $\mathrm{CHO}^{*}$ was very slow compared to FA desorption, the selectivity to FA was very high. $\mathrm{CH}_{2} \mathrm{O}$ formation was stated to have three kinetically important steps: C-H cleavage of $\mathrm{CH}_{3} \mathrm{O}^{*}$, recombination of $\mathrm{OH}^{*}$ to form $\mathrm{H}_{2} \mathrm{O}^{*}$, and oxidation of the reduced surface by gas phase $\mathrm{O}_{2}$, each of them being possible rate determining steps depending on the $\mathrm{O}_{2}$ pressure (proceeding from high to low pressure) [71].

Peyrovi et al. [72] concluded that the most important aspect of FA production was the presence of $\mathrm{Fe}_{2}\left(\mathrm{MoO}_{4}\right)_{3}$, and deactivation was due to the degradation of $\mathrm{Fe}_{2}\left(\mathrm{MoO}_{4}\right)_{3}$ to a smaller particle size, although this seems unlikely from the authors's views. They stated that there were no changes to the $\mathrm{MoO}_{3}$ phase after the reaction [72], which was in direct contrast to the other studies summarized above and seems unlikely. Peyrovi et al. [72] stated the reaction to be structure sensitive as they observed higher activity for a coprecipitated $\mathrm{FeMo} / \gamma-\mathrm{Al}_{2} \mathrm{O}_{3}$ catalyst with $\mathrm{Fe}_{2}\left(\mathrm{MoO}_{4}\right)_{3}$ particles of $29 \mathrm{~nm}$ compared to $16 \mathrm{~nm}$ achieved by impregnation. 


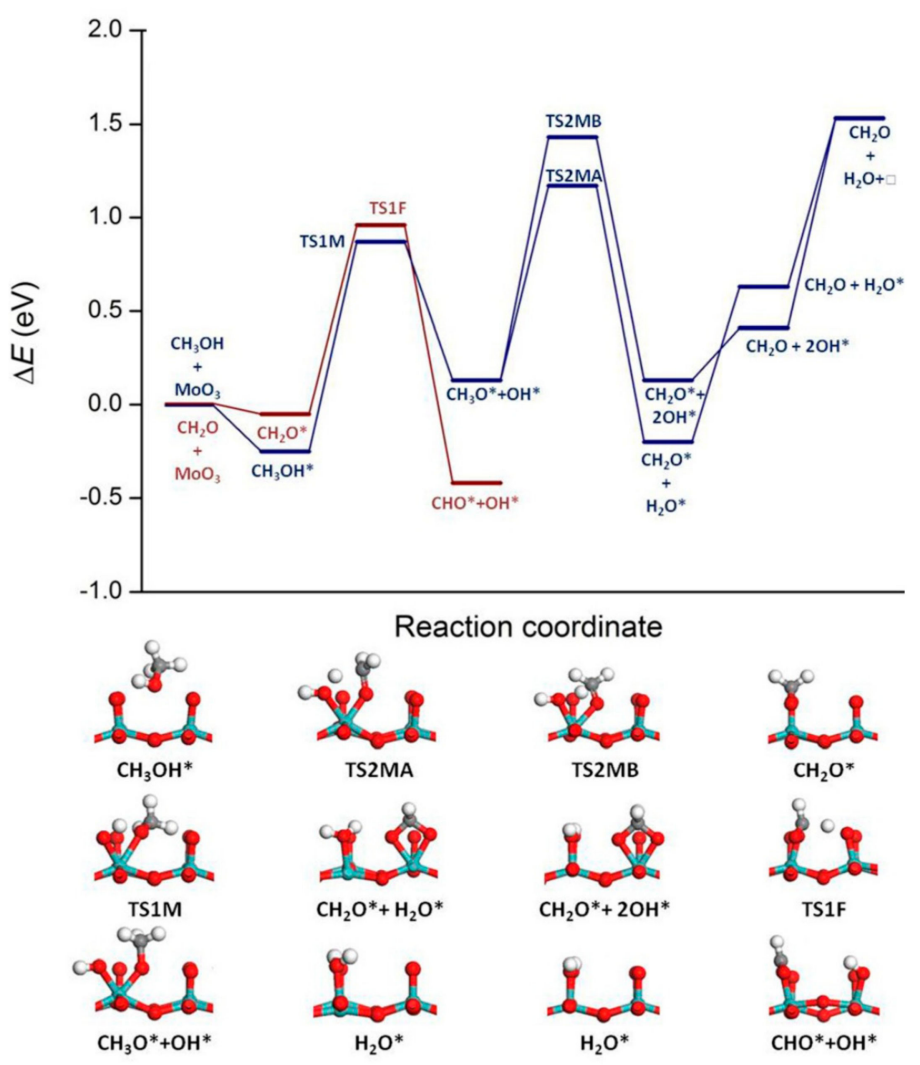

Figure 10. Reaction energy profile calculated by DFT for the oxidation of $\mathrm{MeOH}$ to FA via two different routes (blue lines) and FA decomposition (red line) on a $\alpha-\mathrm{MoO}_{3}(010)$ surface. Newly formed vacancies are marked by $\square$. Beneath the reaction energy profile, the structures for the different reaction coordinates are shown, where TS1F means that it was transition state 1 starting from FA, and TS1M was transition state 1 starting from methanol. For the structures, the colors are as follows: red: O; cyan: Mo; dark grey: C; white: H. (c) 2015 Wiley-VCH Verlag GmbH \& Co. KGaA, Weinheim [52].

\subsubsection{Reaction Engineering}

Later, Ivanov et al. [73] performed an operating parameter investigation in a "pseudoisothermal" reactor with up $60 \mathrm{~cm}$ of NEOCHIM SA industrial FeMo catalyst rings. More precisely, it seemed to be a reactor with an unknown degree of cooling, but it was not close to isothermal. An increase in the $\mathrm{MeOH}$ feed concentration drastically changed the catalyst's temperature profile with markedly higher hot-spot temperature and resulted in different product distributions as side reactions became more significant. Increasing space velocity produced the same kind of change in temperature profile and product distribution, although less drastically. $\mathrm{O}_{2}$ should have similar or higher concentrations with respect to $\mathrm{MeOH}$ and not have too large dehydration relative to DME and a displacement in the hot spot. Two to three percent of $\mathrm{H}_{2} \mathrm{O}$ in the feed increased process selectivity. Changes in the inlet temperature either resulted in low conversion if the temperature became too low or decreasing selectivity due to high inlet temperature. Using an adiabatic layer after the main reactor produced, in all cases, a loss of FA to $\mathrm{CO}$, but the oxidation of the remaining $\mathrm{MeOH}$ and the DME to FA, if controlled well, was a cheap method of optimizing formalin quality [73].

The kinetic models developed by Deshmukh et al. [60] were incorporated into a particle resolved CFD model for a fixed bed reactor by Partopur and Dixon [74] simulating beds with a length of $0.1 \mathrm{~m}$ for four different kinds of pellets generated numerically (Figure 11). The simulations included local and overall conversion, selectivity, pressure drop, voidage, velocity profiles, and heat transfer. The trilobes had the lowest pressure drop due to increased voidage, but the rings showed the highest overall conversion $(\sim 20 \%)$ and selectivity 
due to the best overall performance on the parameters. A mixture of rings with trilobes was simulated for a bed of $0.19 \mathrm{~m}$ and showed the possibility of a slight improvement in performance.

(a)

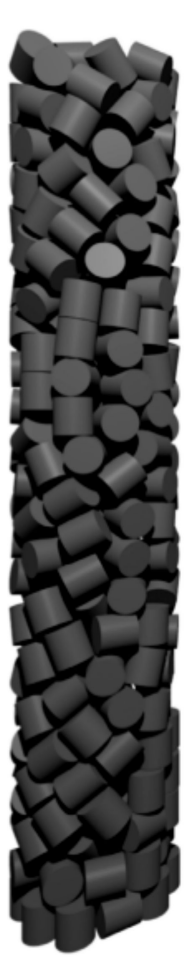

(b)

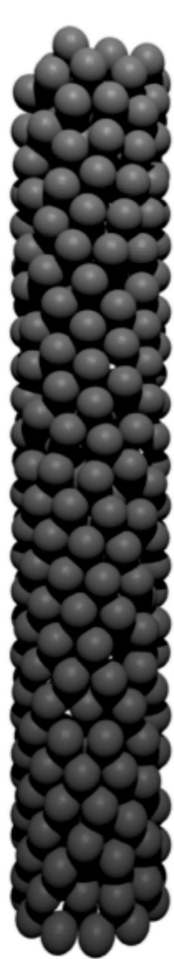

(c)

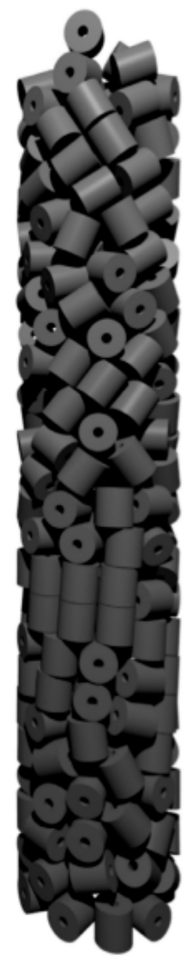

(d)

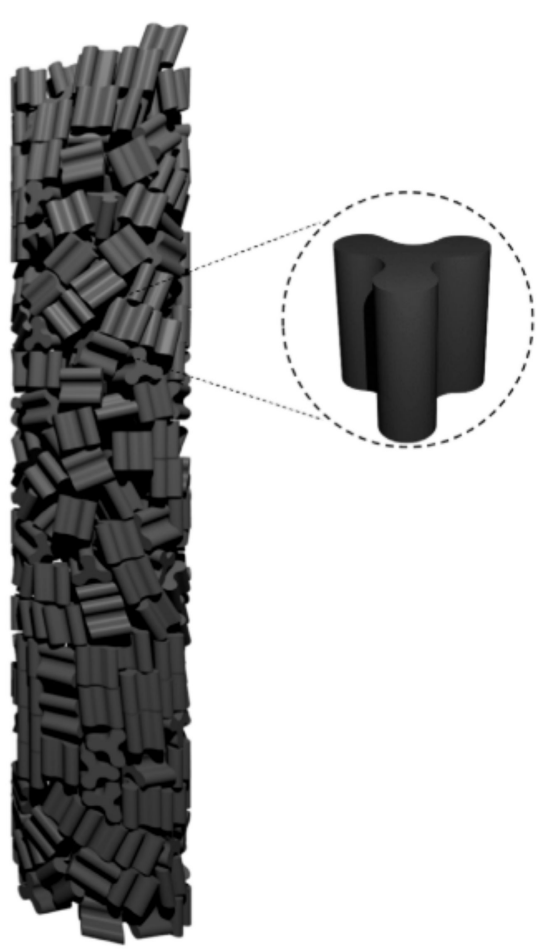

Figure 11. Four fixed bed models/packings investigated by CFD (tube wall invisible). Tube length: $0.1 \mathrm{~m}$; diameter: $0.021 \mathrm{~m}$; tube to particle diameter ratio: 4.7. (a) Cylinders, (b) spheres, (c) rings, and (d) trilobes. (C) 2019 American Institute of Chemical Engineers [74].

\subsubsection{Deactivation}

Earlier, it became apparent that Mo becomes volatile and that this was the main problem with the industrial catalyst. The volatility of the Mo was investigated specifically by Popov et al. [75] already in 1976 by collecting Mo volatile species formed at $350{ }^{\circ} \mathrm{C}$ in a trap inserted in a loop reactor system.

During investigations of industrial type FeMo catalysts with Mo/Fe ratios of 1.75 and 2.5 , the partial pressure of the volatile Mo species $\left(P_{\text {Mo }}\right)$ remained approximately constant when the activity of the catalyst remained constant. When the initial Mo/Fe ratio increased, the initial $P_{\text {Mo }}$ increased as well (Figure 12).

Under the reported conditions, pure $\mathrm{MoO}_{3}$ was found to have $P_{\mathrm{Mo}}$ of $6 \cdot 10^{-6} \mathrm{~atm}$. This was 40 times $P_{\mathrm{Mo}}$ of Mo/Fe ratio of 1.75. $P_{\mathrm{Mo}}$ decreased with increasing catalyst grain size and was directly proportional to $\mathrm{MeOH}$ concentration when the other parameters were kept constant. This suggested a first order reaction in $\mathrm{MeOH}$ in the formation of the volatile Mo-species. Volatility increased only initially with increasing contact time after which it became constant indicating that the gas phase was saturated by the volatile Mo-species. For a sample with $\mathrm{Mo} / \mathrm{Fe}$ of 1.75 , a grain size of $3 \times 3 \mathrm{~mm}$ (exact geometry not given) and a contact time $(\tau)$ of $11 \cdot 10^{-3} \mathrm{~s} P_{\mathrm{Mo}}$ in the reactor outlet could be estimated with Equation (19) [75]. 

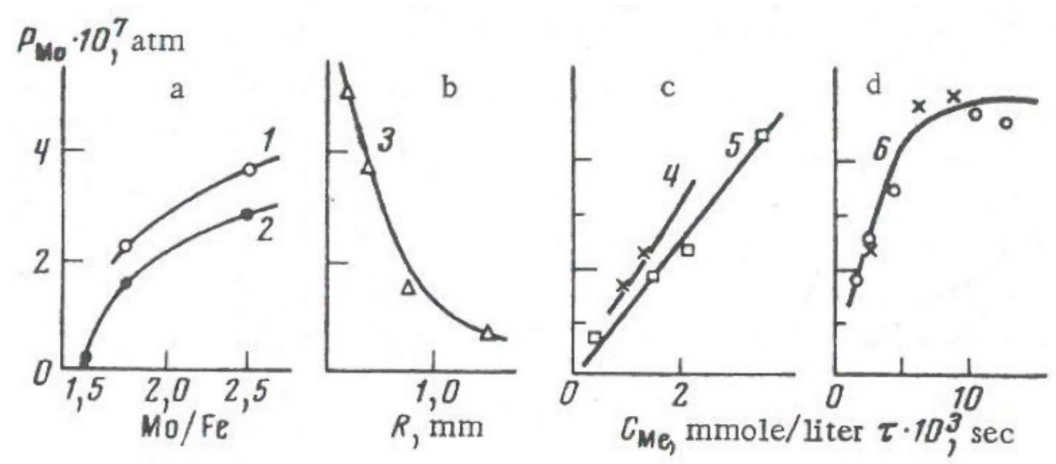

Figure 12. Dependence of the partial pressure for volatile Mo species in FeMo catalysts with respect to (a) Mo/Fe ratio, (b) diameter of catalyst grains, (c) $\mathrm{MeOH}$ concentration, and (d) contact time [75].

$$
P_{\mathrm{Mo}} \simeq 6.9 \cdot 10^{-4} P_{\mathrm{CH}_{3} \mathrm{OH}} \exp \left(-\frac{6500}{R T}\right)
$$

Lastly, when the formation of the volatile Mo species was assumed to be first order in $\mathrm{MeOH}$ and decomposition was assumed to be first order in volatile species, the rate constants were found to be $14 \mathrm{~s}^{-1}$ and $304 \mathrm{~s}^{-1}$ for the formation and decomposition of volatile Mo-MeOH species, respectively [75]. Moreover, Carbucicchio et al. [76] observed increased Mo volatilization with increasing $\mathrm{MeOH}$ pressure. In an industrial reactor after 150 days, Popov and Skomorokhova [77] observed a decreasing surface area along the catalyst bed due to $\mathrm{MoO}_{3}$ migration and deposition as needle-like crystals. The Mo volatilization was highest at the hot spot, where temperature and concentration of $\mathrm{MeOH}$ were both high. At the inlet, the volatilization was lower as the temperature was still low, and after the hot spot, the $\mathrm{MeOH}$ concentration decreased producing lower Mo volatilization [77]. This was in agreement with a previous study by Burriesci et al. [78]. Ma and Kmiotek [79] found that the decrease in specific activity for $\mathrm{MeOH}$ oxidation to FA could be correlated with the loss of reaction sites at the ferric molybdate surface due to Mo volatilization.

The exact mechanism of volatilization of the Mo is still debated. Smith and Rohrer [80] succeeded in studying the blue deposit formed in the reactor outlet from $\mathrm{MoO}_{3}$ treated with $\mathrm{MeOH}$ /air mixtures at $300{ }^{\circ} \mathrm{C}$ with scanning electron microscopy energy dispersive $\mathrm{X}$-ray analysis (SEM-EDX) and XRD and found the deposit to be $\mathrm{Mo}_{2} \mathrm{O}_{5}\left(\mathrm{OCH}_{3}\right)_{2}$. They suggested two routes of formation. The volatilization of Mo oxide-hydroxide which then reacted with $\mathrm{MeOH}$ to form $\mathrm{Mo}_{2} \mathrm{O}_{5}\left(\mathrm{OCH}_{3}\right)_{2}$ either in the gas phase or after deposition or desorption of a Mo oxy-methoxide which upon condensation formed $\mathrm{Mo}_{2} \mathrm{O}_{5}\left(\mathrm{OCH}_{3}\right)_{2}$. As no Mo evaporation was observed without $\mathrm{MeOH}$ in the feed, the second mechanism was considered the most plausible [80]. $\mathrm{Mo}_{2} \mathrm{O}_{5}\left(\mathrm{OCH}_{3}\right)_{2}$ could be formed by reaction of $\mathrm{MoO}_{3} \cdot 2 \mathrm{H}_{2} \mathrm{O}$ with $\mathrm{MeOH}$. Upon thermal decomposition $\mathrm{MeOH}, \mathrm{DME}, \mathrm{FA}$, and $\mathrm{H}_{2} \mathrm{O}$ were detected [81].

Catalyst deactivation was investigated in a Perstorp Formox plant using FeMo catalysts by Andersson et al. [20]. The plant was operating with a $\mathrm{MeOH}$ concentration of 10.2 vol.\% at the inlet. There were two consecutive catalyst layers. In the first layer, the $\mathrm{KH} 44 \mathrm{~L}$ catalyst $\left(4.5 \mathrm{~m}^{2} / \mathrm{g}, \mathrm{Mo} / \mathrm{Fe}=2.43\right)$ was mixed with inert rings while the second layer consisted of pure $\mathrm{KH} 26$ catalyst $\left(5.4 \mathrm{~m}^{2} / \mathrm{g}, \mathrm{Mo} / \mathrm{Fe}=2.29\right)$. The catalysts were investigated fresh, after half expected lifetime and after full lifetime. After operation, the KH44L catalyst in the mixed layer had an increase in surface area, which decreased when proceeding down the bed, while the $\mathrm{KH} 26$ catalyst in the second layer had a decrease in surface area in the top of the layer and no change further down. At the same time, an increase in pore volume was observed for the first layer at both half and full expected catalyst lifetime. This decreased down the bed. KH26 in the second layer showed a decrease in pore volume at half expected lifetime but an increase in pore volume for the first half of the second layer and a larger decrease in pore volume of the second part at full expected lifetime. 
By Atomic Absorption Spectroscopy (AAS), it was measured that the Mo/Fe ratio after termination was approximately 1.5 in the mixed oxide top layer after initially being 2.4, while the ratio had increased for the second (pure KH26) layer. It was measurable by XRD, Raman spectroscopy, and elemental analysis that Mo migrated from the inlet towards the outlet of the reactor. The migration of Mo was suggested mainly to result from the formation of volatile Mo methoxy species since the effect was moving from the top and downwards, from high to low $\mathrm{MeOH}$ concentration. If $\mathrm{H}_{2} \mathrm{O}$ was the main cause, the effect should have increased down the reactor. The Mo deposited as the $\mathrm{MeOH}$ concentration and temperature decreased, resulting in decreased surface area and pore volume and giving rise to an increased pressure drop, which ultimately, together with falling selectivity, resulted in shut down and change of the catalyst [20]. Andersson et al. [20] concluded a surplus of $\mathrm{MoO}_{3}$ was needed to maintain the active phase in the catalyst according to the redox reactions (Reactions (20)-(22)) [20].

$$
\begin{gathered}
\mathrm{CH}_{3} \mathrm{OH}+\mathrm{Fe}_{2}\left(\mathrm{MoO}_{4}\right)_{3} \rightarrow \mathrm{CH}_{2} \mathrm{O}+\mathrm{H}_{2} \mathrm{O}+2 \mathrm{FeMoO}_{4}+\mathrm{MoO}_{3} \\
2 \mathrm{FeMoO}_{4}+\mathrm{MoO}_{3}+\frac{1}{2} \mathrm{O}_{2} \rightarrow \mathrm{Fe}_{2}\left(\mathrm{MoO}_{4}\right)_{3} \\
3 \mathrm{FeMoO}_{4}+\frac{3}{4} \mathrm{O}_{2} \rightarrow \mathrm{Fe}_{2}\left(\mathrm{MoO}_{4}\right)_{3}+\mathrm{Fe}_{2} \mathrm{O}_{3}
\end{gathered}
$$

Reaction (20) was the main reaction, Reaction (21) was the reoxidation with $\mathrm{MoO}_{3}$ in excess, and Reaction (22) was the reoxidation with depletion of Mo, which resulted in the formation of an unselective $\mathrm{Fe}_{2} \mathrm{O}_{3}$ catalyst surface [20].

Catalyst deactivation phenomena found under FA production was studied on an industrial Neochim PLC-Dimitrovgrad FeMo catalyst by Ivanov and Dimitrov [82] over a period of 15 months with $6.2 \mathrm{vol} . \% \mathrm{MeOH}$ in the feed over two reactors, which had either good or bad heat transfer. This gave the reactors different temperature profiles, but the inlet and outlet temperatures were the same. In the reactor with bad heat transfer, a large region with temperatures between $300{ }^{\circ} \mathrm{C}$ and $335^{\circ} \mathrm{C}$ existed, whereas the temperature in the reactor with good heat transfer never exceeded $290^{\circ} \mathrm{C}$. In the hot reactor, the top catalyst layer had a distinct reddish-brown coloration when discharged. This was due to the formation of $\mathrm{Fe}_{2} \mathrm{O}_{3}$ under reoxidation of $\mathrm{FeMoO}_{4}$ according to Reaction (22) also found by Anderson et al. [20]. For the low temperature reactor, the catalyst composition at different positions in the bed was measured by ICP giving the profile shown in Figure 13.

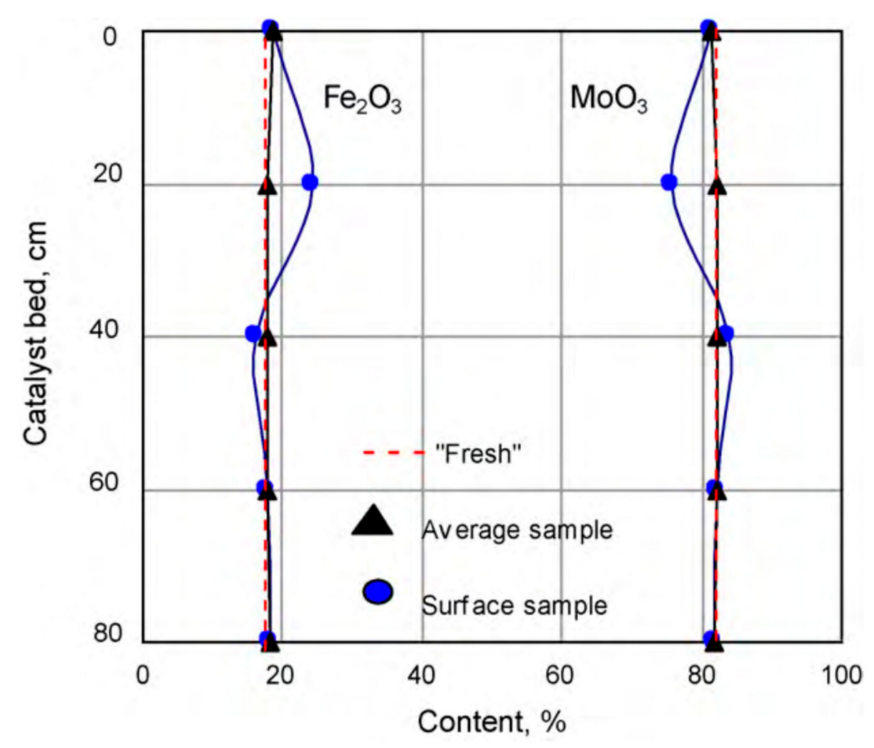

Figure 13. Catalyst composition measured by ICP along the catalyst bed in reactor with good heat transfer. Reprinted from [82] Copyright $@$ (2010) with permission from Elsevier. 
There was a shift of $\mathrm{MoO}_{3}$ content down in the reactor from the process intense zone (determined from the temperature profile), which produced a partly $\mathrm{MoO}_{3}$ depleted catalyst outer layer in the process intense zone (Reaction (23)) and deposition of $\mathrm{MoO}_{3}$ further down in the catalyst bed. It was claimed by Ivanov and Dimitrov [82] that the sublimation and, thus, the deactivation of the catalyst were driven by $\mathrm{H}_{2} \mathrm{O}$ according to Reactions (23) and (24) because no reddish-brown coloration from $\mathrm{FeMoO}_{4}$ oxidized to $\mathrm{Fe}_{2} \mathrm{O}_{3}$ was observed at low temperatures [82].

$$
\begin{gathered}
\mathrm{MoO}_{4}^{2-}+2 \mathrm{H}_{2} \mathrm{O} \rightarrow \mathrm{MoO}_{2}(\mathrm{OH})_{2}+2 \mathrm{OH}^{-} \\
\mathrm{MoO}_{2}(\mathrm{OH})_{2} \rightarrow \mathrm{MoO}_{3}+\mathrm{H}_{2} \mathrm{O}
\end{gathered}
$$

However, if excess $\mathrm{MoO}_{3}$ was still present, Mo can be volatilized without formation of $\mathrm{Fe}_{2} \mathrm{O}_{3}$, and the concentration of water is the highest in the outlet; thus, a larger degree of Mo volatilization in the last half the reactor should be significant for this to be probable.

The results by Andersson [20] and Ivanov and Dimitrov [82] were very similar, although the conclusions/suggestions for the deactivation mechanism differed. The major difference in the results was that the reactor with good heat transfer in the study by Ivanov and Dimitrov [82] did not deactivate from the top but a bit lower in the reactor (also observed by Popov and Skomorokhova [77]). However, this might arise from the temperature being too low in the inlet and the heating being too slow, so the temperature was not high enough for the deactivation to begin at the top as it did for the reactor with bad heat transfer. Thus, the difference in the deactivation profile may be explained from the temperature profile. Spatiotemporal imaging performed by $\mathrm{O}^{\prime}$ Brien et al. [83] on $\mathrm{MoO}_{3}$ with $\mathrm{MeOH}$ in $\mathrm{N}_{2}$ supported that the evaporation came from an Mo-methoxy species. However, a study by Soares et al. $[84,85]$ found $\mathrm{H}_{2} \mathrm{O}$ was strongly promoting the deactivation as adding 2 vol. $\% \mathrm{H}_{2} \mathrm{O}$ in the feed drastically increased the rate of deactivation, and they proposed this effect to come from inhibition of the reoxidation of the surface. However, as discussed above, $\mathrm{H}_{2} \mathrm{O}$ inhibits the oxidation of $\mathrm{MeOH}$ to FA. A more likely cause of the accelerated deactivation is, thus, the higher concentration of $\mathrm{MeOH}$, which promotes the volatilization of Mo. Furthermore, Soares et al. [86] proposed excess Mo to increase surface reoxidability [86].

The findings of Ivanov and Dimitrov [82] and Andersson [20] were also substantiated in the studies by Raun et al. $[43,87,88]$ utilizing Raman spectroscopy, XRD, XPS, SEM, and STEM on powder samples used at $384-416{ }^{\circ} \mathrm{C}$ for up to $600 \mathrm{~h}$ on stream. Excess $\mathrm{MoO}_{3}$ evaporated (within $10 \mathrm{~h}$ ), then $\mathrm{Fe}_{2}\left(\mathrm{MoO}_{4}\right)_{3}$ was reduced to the Mo depleted phases $\mathrm{FeMoO}_{4}$ (10-250 h on stream) and $\mathrm{Fe}_{2} \mathrm{O}_{3}$ (observed after $600 \mathrm{~h}$ on stream) due to the loss of Mo during operation. The catalyst could be reactivated by thermal treatment. The reactivation was believed to stem from re-establishing the Mo rich surface from crystalline $\mathrm{MoO}_{3}$ in the first phase and then later from the bulk $\mathrm{Fe}_{2}\left(\mathrm{MoO}_{4}\right)_{3}$ phase $[43,87,88]$. The deactivation was further investigated by Gaur et al. [89] by operando XAS/XRD and in situ Raman spectroscopy, finding similarly that $\alpha-\mathrm{MoO}_{3}$ evaporated. The evaporation rate $\left(\right.$ at $300{ }^{\circ} \mathrm{C}$ ) was found to increase with increasing $\mathrm{MeOH}$ concentration (increasing from 5 vol.\% to 9.5 vol. \% increased the rate by a factor of two), decreasing $\mathrm{O}_{2}$ concentration (increased by $67 \%$ for $\mathrm{O}_{2}$ concentration going from $10 \%$ to $5 \%$ ), and increasing temperature (three times higher at $350{ }^{\circ} \mathrm{C}$ compared to $300{ }^{\circ} \mathrm{C}$ ). The volatilization rate was also observed to be highly affected by the particle size [89]. Furthermore, in situ measurements during redox cycling on a FeMo catalyst showed phase reduction and segregation into $\mathrm{MoO}_{2}$ and $\mathrm{FeMoO}_{4}$, which needed to be oxidized at $500{ }^{\circ} \mathrm{C}$ in order to fully regenerate (not including the volatilized Mo) [90]. Other studies [70,91-95] show similar trends and results for deactivation and phase reduction. Raun et al. [96] developed a dynamic one-dimensional single particle model for Mo volatilization involving diffusion and reaction of $\mathrm{MeOH}$ to FA, formation and diffusion of a volatile Mo species, and the local change in Mo content in the pellet. Only the loss of free Mo was included-not the transformation to less oxidized FeMo. The model was compared to experimentally measured Mo loss in an industrial FeMo 
pellet. The pellets were subjected to different reaction conditions such as $1.6-4.5 \mathrm{vol} . \%$ $\mathrm{MeOH}, 2.5-10$ vol.\% $\mathrm{O}_{2}$, and $0-10.2$ vol. $\% \mathrm{H}_{2} \mathrm{O}$ in $\mathrm{N}_{2}$ at temperatures of 250,300 , and $350{ }^{\circ} \mathrm{C}$. Mo was shown by SEM-EDX to volatilize from the surface of the pellet, giving a sharp front of $\mathrm{Fe}_{2}\left(\mathrm{MoO}_{4}\right)_{3}$ depleted from excess $\mathrm{MoO}_{3}$, which moved inwards with increasing TOS. The sharp front indicated that Mo volatilization was equilibrium limited. The measured mass losses under the varying conditions were used to fit the kinetics of Mo depletion in the model, which was then verified against the placement movement of the depletion front showing good agreement. The model showed that increasing the pellet volume by $100 \%$ with the same dimensional ratios would decrease the volatilization by $20 \%$ over $400 \mathrm{~h}$ on stream [96]. The single particle model was then implemented into a dynamic model for Mo transport and pressure drop in a single tube fixed bed reactor (FBR) [97]. The FBR was modelled as a series of CSTRs and had fixed axial profiles of temperature and concentrations of $\mathrm{MeOH}$ and $\mathrm{H}_{2} \mathrm{O}$ as input from a pilot plant reactor. The model was fitted to experimental data for the hydraulic diameter of the cylindrical catalyst pellets and porosity of the deposited $\mathrm{MoO}_{3}$ from the pilot plant reactor. In agreement with Burriesci et al. [78] and Ivanov and Dimitrov [82], the simulations showed that not all the $\mathrm{MoO}_{3}$ was depleted from the inlet of the reactor even after 2 years because the temperature was too low. The study suggested that by having solid cylinders instead of rings for the first $21 \mathrm{~cm}$ of a $100 \mathrm{~cm}$ bed, the pressure drop over the bed could be decreased by $16 \%$ after 2 years, although the initial pressure drop would be $22 \%$ higher. Using pellets with no excess $\mathrm{MoO}_{3}$ for the first $21 \mathrm{~cm}$ was calculated to decrease pressure drop by $49 \%$ after 2 years; however, such pellets may have low mechanical stability. Thus, both strategies could decrease the pressure drop and, thus, increase process lifetime. The model should be further developed as the changes in activity and selectivity and, thus, temperature profile over time and from the catalyst modifications were not included in the model [97].

A patent for in situ regeneration of metal molybdate catalysts was taken by Wachs and Briand [98], where redispersion should happen in a stream of $\mathrm{MeOH}$ and inert gas. This may shortly regenerate/re-disperse Mo; however, the effect might be very short lived as the mechanism of regeneration was the same as the deactivation mechanism. It will likely be difficult to re-deposit Mo into the pores of the catalyst and obtain the distribution of Mo as in the fresh catalyst.

Overall, the findings indicate that the most important factors for the deactivation and Mo volatilization include increases with high temperature, high methanol concentration, and low oxygen concentration. From these findings, the most straight forward optimization when using a FeMo catalyst may be to modify operating conditions $[43,87-89]$ and optimizing pellet size and shape $[96,97]$.

\subsection{Alternative Catalysts}

An overview of the benefits and challenges of the currently applied industrial catalyst has been provided above. There are various methods to go about the problem of Mo volatilization, such as finding an alternative process or to change the existing process and/or catalyst. Only the latter would be applicable to the existing FA plants. Looking at the catalyst, there are two main routes. The first is to start with the existing FeMo catalyst and to try to find other preparation methods, conditions, or promoters to increase the stability of the catalyst without a significant loss of activity and selectivity. The other route is to look for a different catalyst that is more stable than the FeMo catalyst without sacrificing high selectivity. Such a catalyst does not need to be as active as the FeMo catalyst as long as it is sufficiently active, stable under reaction conditions, and possesses high selectivity, since a solution could be to have two layers of catalyst consisting of a stable, less active catalyst at the top and the FeMo catalyst beneath where the $\mathrm{MeOH}$ concentration is lower. The scope of the remaining part of this review is to provide an overview of the reported results, the problems to be aware of, and the progress made within finding an alternative catalyst for the Formox process. Furthermore, some results of the authors 
own screening studies will be included for comparison. Full details are shown in the Supplementary Materials.

\subsubsection{Overview of Catalysts Reported in the Literature}

The open literature was thoroughly searched for catalysts reported for selective oxidation of methanol to FA. Figures 14 and 15 summarize the identified catalyst compositions.

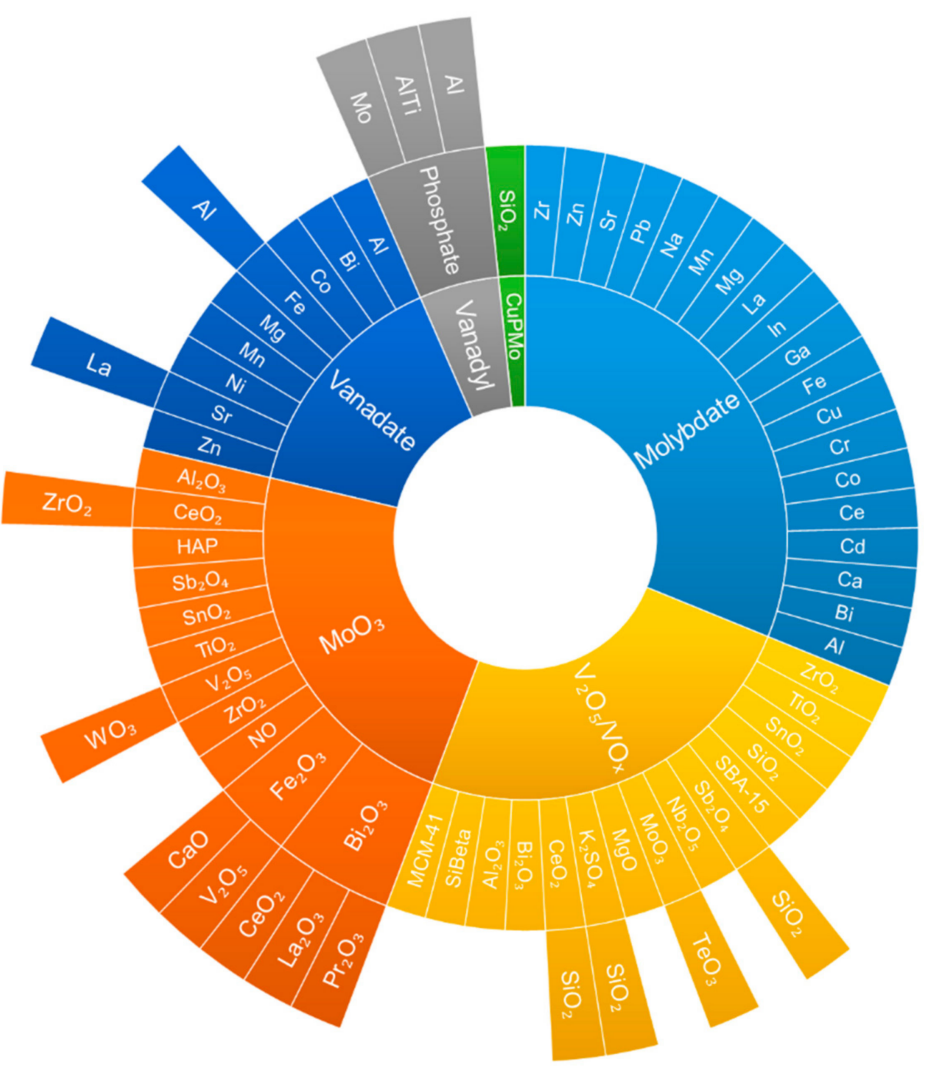

Figure 14. Solar plot for Mo and V containing catalysts showing main components (inner circle), secondary component or support material (middle circle), and tertiary component or support material (outer circle). Oxygen may be present without it being specified.

Most catalysts investigated contain either Mo or V in some form. Detailed descriptions of the reported results will be given in the following sections, roughly divided after the active catalyst component, with a section at the end presenting the results available on catalysts' stability and the volatility of active components.

\subsubsection{Mo Containing Catalysts}

Pernicone et al. [44] investigated various trivalent metal molybdates mixed with excess Mo oxide $\left(\mathrm{MoO}_{3}-\mathrm{Me}\left(\mathrm{MoO}_{4}\right)_{3}\right)$ as catalysts, $\mathrm{Me}=\mathrm{Al}, \mathrm{Cr}, \mathrm{Fe}$, In, and $\mathrm{La}$, in a pulse microreactor and a differential reactor at $232{ }^{\circ} \mathrm{C}, 1.25 \mathrm{bar}$, and $\mathrm{N}_{2} / \mathrm{O}_{2} / \mathrm{MeOH}=70 / 20 / 10 \mathrm{~mol} \%$. The catalysts were prepared with a Mo/Me ratio of six. The catalyst surface acidities were found to have no significant deviation to that of pure $\mathrm{MoO}_{3}$ in contrast to prior publications attributing formaldehyde selectivity to acidity. The catalyst activities were ranked as follows: $\mathrm{MoO}_{3}<9 \mathrm{MoO}_{3}+\mathrm{Al}_{2}\left(\mathrm{MoO}_{4}\right)_{3}<9 \mathrm{MoO}_{3}+\mathrm{In}_{2}\left(\mathrm{MoO}_{4}\right)_{3}<9 \mathrm{MoO}_{3}+$ $\mathrm{La}_{2}\left(\mathrm{MoO}_{4}\right)_{3}<9 \mathrm{MoO}_{3}+\mathrm{Cr}_{2}\left(\mathrm{MoO}_{4}\right)_{3}<9 \mathrm{MoO}_{3}+\mathrm{Fe}_{2}\left(\mathrm{MoO}_{4}\right)_{3}$. Pernicone et al. [44] found pure $\mathrm{Cr}_{2}\left(\mathrm{MoO}_{4}\right)_{3}$ and $\mathrm{Fe}_{2}\left(\mathrm{MoO}_{4}\right)_{3}$ (prepared by sublimation of $\mathrm{MoO}_{3}$ from the mixtures at $700{ }^{\circ} \mathrm{C}$ ) to be without activity and surface acidity. This was probably a result of the preparation method. This was in contrast with the findings mentioned in Section 2.1.5 by Andersson et al. [20] and may be due to the very low surface area resulting from high temperature treatment. The addition of $\mathrm{MoO}_{3}$ to $\mathrm{Cr}_{2}\left(\mathrm{MoO}_{4}\right)_{3}$ achieving $\mathrm{Mo} / \mathrm{Cr}=2$ pro- 
duced a catalyst three times as active as pure $\mathrm{MoO}_{3}$. Catalysts with $\mathrm{Me}_{2}\left(\mathrm{MoO}_{4}\right)_{3}$ mixed with $\mathrm{Me}_{2} \mathrm{O}_{3}$ having a $\mathrm{Mo} / \mathrm{Me}$ ratio of 1 were prepared for $\mathrm{Me}=\mathrm{Cr}$ and Al. They had no surface acidity nor any measurable activity. The $\mathrm{Cr}$ and Fe samples were proposed to be more active due to the nature of $\mathrm{Fe}^{3+}$ and $\mathrm{Cr}^{3+}$ ions. Due to differences in the rate observed in the differential reactor and pulse microreactor, the effect was proposed to come from an increased product desorption rate, as the catalyst surface was mostly product free in the pulse microreactor. This was questioned by Vichterlova et al. [44] who stated that an active catalyst must contain acidic sites to chemisorb $\mathrm{MeOH}$ and possess adequate reducibility, as acidic non-reducible catalysts had no activity [44]. In the discussion of [44] at the Fourth International Congress on Catalysis, Yu. I. Ermakov stated that in order for catalyst reduction to be the rate determining step, the rate of transition of the Me element from the highest to the lowest oxidation state determines the rate. The activity increased as the stability of the lower oxidation state increased, measurable by increased reducibility of the catalyst. He found the data by Kolovertnov [44] and Pernicone et al. [44] showed growing catalytic activity for $\mathrm{MeOH}$ oxidation with increasing electronegativity of the cation based on $\mathrm{pK}_{\mathrm{B}}$ for the hydroxyl compounds of the cations (Figure 16) showing the same curve.

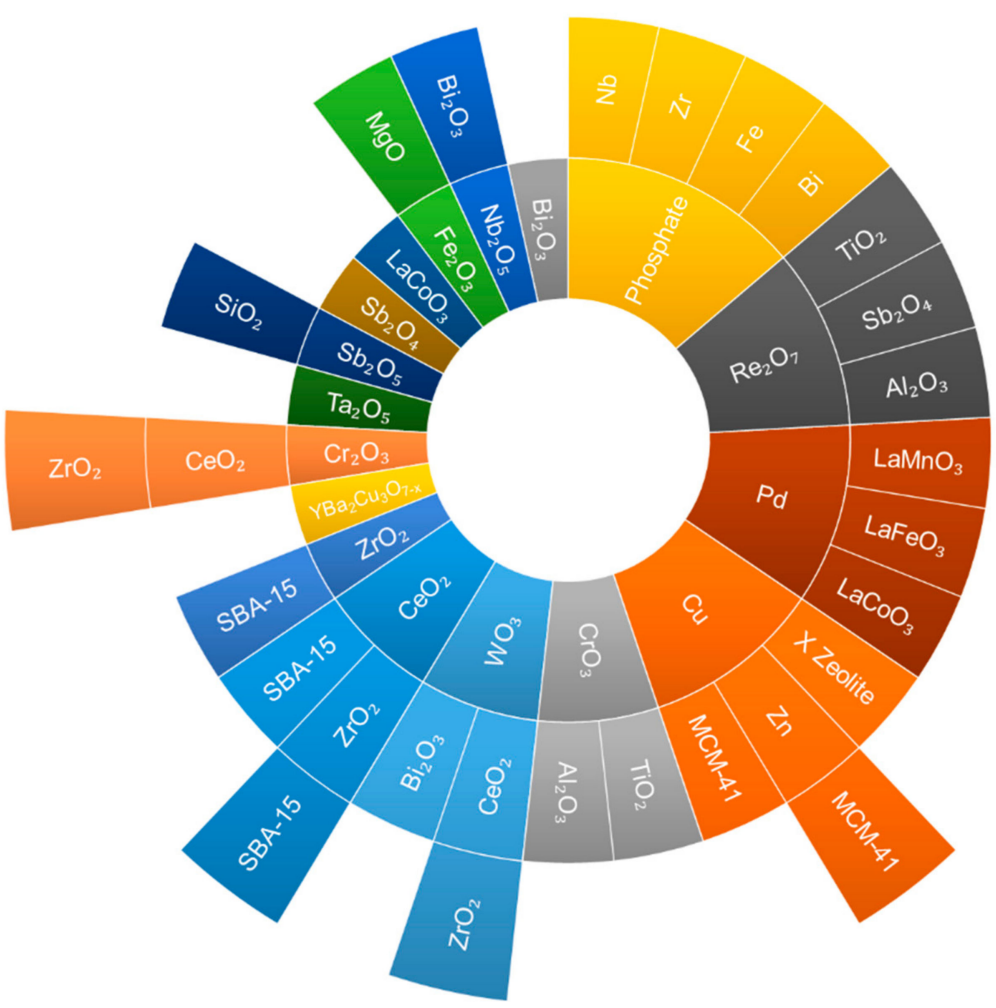

Figure 15. Solar plot for catalysts not containing V or Mo showing main components (inner circle), secondary component or support material (middle circle), and tertiary component or support material (outer circle). Oxygen may be present without it being specified. 


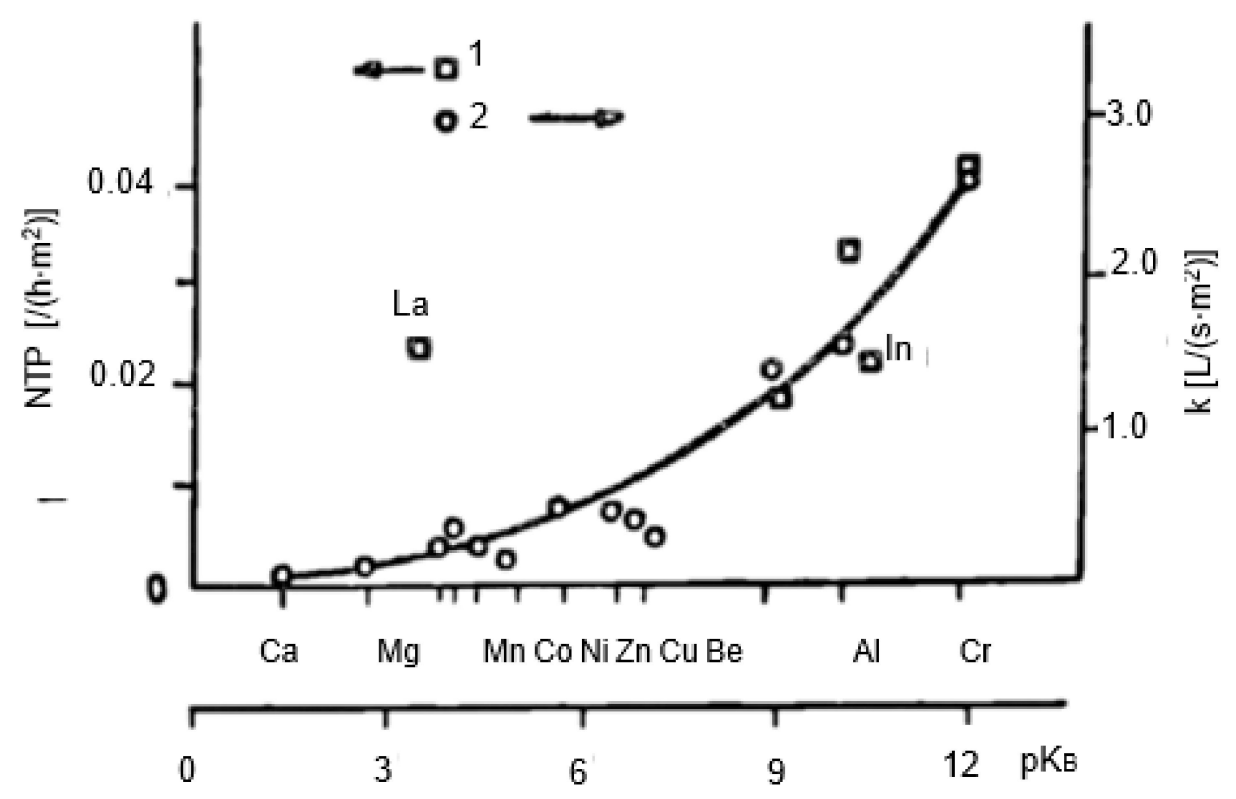

Figure 16. Activity vs. reducibility: (1) Pernicone's data ( $\square$ ) [NL/h/m²]; (2) Kolovertnov's data (o), $\mathrm{k}\left[\mathrm{mL} / \mathrm{s} / \mathrm{m}^{2}\right]$, [44]. Reproduced from [44] copyright (1968) with permission from copyright holder.

Lanthanum molybdate/hydroxide did not fit the curve due to anomalously high alkaline properties of the hydroxide. Other minor deviations were believed to stem from impurities in the prepared molybdates. Catalytic activity was shown to be a function of Mo-O bond ionicity, and it was stated to be largely independent of, e.g., cation valence, presence of d-electrons and Mo coordination with oxygen [44]. $\mathrm{Cu}$ and Ni molybdates were stated to be less active than Al molybdate [44]. A similar dependence of catalytic activity on electronegativity was observed by Kolovertnov for ortho-vanadates [44]. A similar relationship was reported by Burcham et al. $[99,100]$ between the electronegativity of the ligand cation (Mo-O-X) and turnover frequency. This was reported to be similar for both the supported molybdena and the bulk molybdates $\mathrm{Fe}_{2}\left(\mathrm{MoO}_{4}\right)_{3}, \mathrm{NiMoO}_{4}, \mathrm{MnMoO}_{4}$, $\mathrm{CoMoO}_{4}, \mathrm{ZnMoO}_{4}, \mathrm{Al}_{2}\left(\mathrm{MoO}_{4}\right)_{3}, \mathrm{Ce}\left(\mathrm{MoO}_{4}\right)_{2}, \mathrm{Bi}_{2} \mathrm{Mo}_{3} \mathrm{O}_{12}$, and $\mathrm{Zr}\left(\mathrm{MoO}_{4}\right)_{2}$.

In 1976, Popov et al. [101] tested the effect of excess $\mathrm{MoO}_{3}$ on molybdates of $\mathrm{Na}, \mathrm{Ca}$, $\mathrm{Sr}, \mathrm{Ni}, \mathrm{Ba}, \mathrm{Pb}, \mathrm{Cr}, \mathrm{Cd}, \mathrm{Bi}, \mathrm{Co}$, and $\mathrm{Fe}$ with respect to selectivity to $\mathrm{CH}_{2} \mathrm{O}$ and activity to $\mathrm{CH}_{2} \mathrm{O}$ and $\mathrm{CO}_{x}$ (Figure 17).

The selectivity and activity to FA from $\mathrm{MeOH}$ were greatly enhanced by the addition of $10 \mathrm{~mol} \%$ excess $\mathrm{MoO}_{3}$, while further addition only produced slight variations [101]. Although Figure 17 does not provide any accurate numbers for selectivity and activity, it does indicate the relative performances. The FeMo showed the best results in terms of both activity and selectivity, but several other molybdates may be of some interest.

The same group later studied Cd-Mo oxide catalysts $(\mathrm{Mo} / \mathrm{Cd}=1.0$ and $\mathrm{Mo} / \mathrm{Cd}=1.2)$ for the oxidation of $\mathrm{MeOH}$ (3.0-3.7 vol.\% MeOH in the feed) [102]. The stoichiometric molybdate was active in the dehydrogenation of $\mathrm{MeOH}$ to $\mathrm{CO}_{2}$ and $\mathrm{H}_{2}$, and at $350{ }^{\circ} \mathrm{C}$, conversions to $\mathrm{CH}_{2} \mathrm{O}, \mathrm{CO}_{2}, \mathrm{CO}$, and $\mathrm{H}_{2}$ were $7 \%, 55 \%, 2 \%$, and $59 \%$, respectively. The selectivity to FA changed with the addition of excess $\mathrm{MoO}_{3}$ to above $85 \%$ at $\sim 75 \%$ conversion. The oxidation of both $\mathrm{MeOH}$ and FA was reported to be first order. The $\mathrm{CO}_{2}$ formation over $\mathrm{CdMoO}_{4}$ was reported to come from oxidation of $\mathrm{CH}_{2} \mathrm{O}$, as the selectivity towards $\mathrm{CH}_{2} \mathrm{O}$ was $100 \%$ when the degree of conversion was close to zero [102]. They also performed semiempirical investigations (INDO method) of $\mathrm{MeOH}$ interaction with $\mathrm{Ga}_{2}\left(\mathrm{MoO}_{4}\right)_{3}$, which they stated had similar performance with respect to $\mathrm{MeOH}$ oxidation as $\mathrm{Fe}_{2}\left(\mathrm{MoO}_{4}\right)_{3}[103,104]$. 


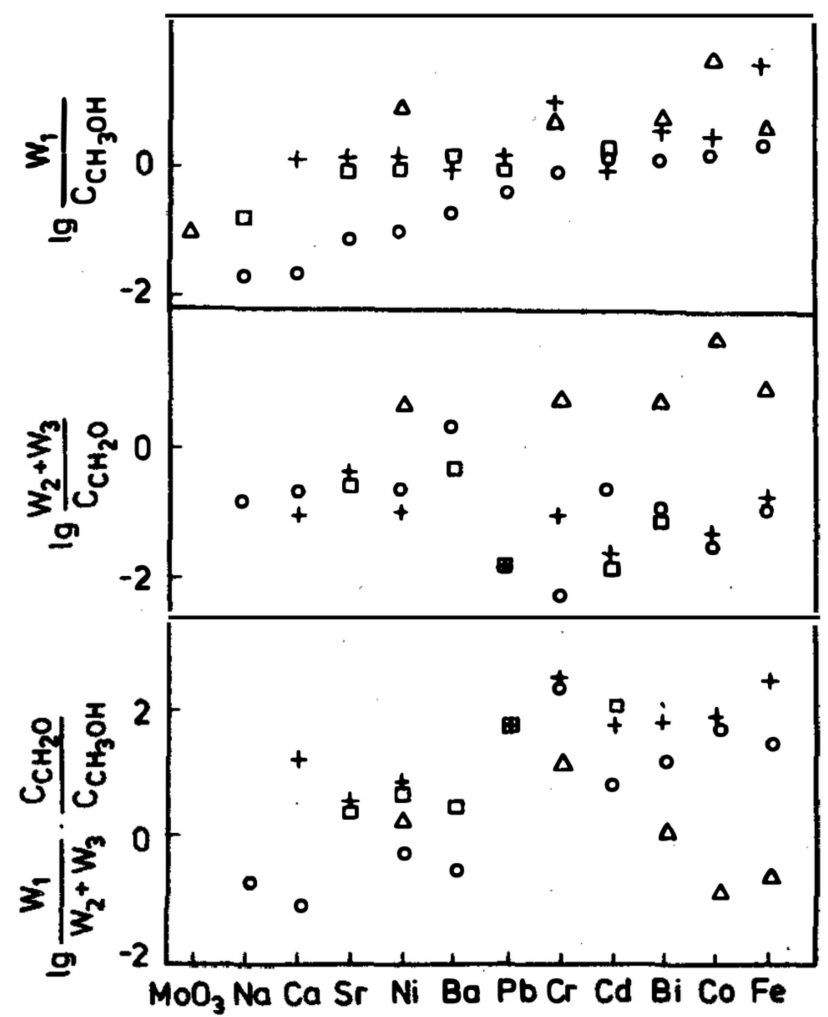

Figure 17. Presentation of the effect of excess $\mathrm{MoO}_{3}$ on the activity to $\mathrm{FA}\left(\ln \frac{W_{1}}{\mathrm{C}_{\mathrm{CH}_{3} \mathrm{OH}}}\right)$, activity to $\mathrm{CO}_{x}$ $\left(\ln \frac{W_{2}+W_{3}}{C_{\mathrm{CH}_{2} \mathrm{O}}}\right)$, and the selectivity to $\mathrm{CH}_{2} \mathrm{O}\left(\ln \frac{W_{1}}{W_{2}+W_{3}} \frac{C_{\mathrm{CH}_{2} \mathrm{O}}}{\mathrm{C}_{\mathrm{CH}_{3} \mathrm{OH}}}\right) . \Delta$ oxides; $\bigcirc$ normal molybdates; $\square$ molybdates with approximately $10 \mathrm{~mol} \%$ excess $\mathrm{MoO}_{3} ;+$ molybdates with approximately $20 \mathrm{~mol} \%$ excess $\mathrm{MoO}_{3}$. Reprinted by permission from [101] Springer, Reaction kinetics and catalysis, Copyright (C) (1969).

Popov et al. [105] investigated the effect on selectivity to FA of the excess of $\mathrm{MoO}_{3}$ on calcium molybdate at $350{ }^{\circ} \mathrm{C}$. At stoichiometric ratios of $\mathrm{Mo} / \mathrm{Ca}=1.0$, the selectivity to FA was $18.5 \%$. When the ratio was increased to 1.01 , the selectivity increased to $94 \%$ and the reaction rate doubled. Upon further increasing the ratio to 1.2 , selectivity stabilized at $96 \%$ to FA [105]. Malka and Tatibouët [106] reported selectivity to FA to be $48 \%$ on unsupported stoichiometric $\mathrm{CaMoO}_{4}$. They found that highly dispersed $\mathrm{CaMoO}_{x}$ (formed with excess of $\mathrm{Mo}$ ) on $\mathrm{SiO}_{2}$ was very active but with methyl formate as the main product [106]. Thrane et al. [107] prepared molybdates of alkali earth metals $\left(\mathrm{MgMoO}_{4}\right.$, $\mathrm{CaMoO}_{4}, \mathrm{SrMoO}_{4}$, and $\mathrm{BaMoO}_{4}$ ). In agreement with Popov et al. [101,105], excesses of Mo were found to be important for activity and selectivity towards FA, as the stoichiometric $\mathrm{CaMoO}_{4}$ and $\mathrm{MgMoO}_{4}$ had relatively low activities and considerably lower selectivity than the samples with excess Mo. The stoichiometric alkali earth metal molybdates showed very good catalytic stability, while excess Mo quickly evaporated [107].

The possibility of using hydroxyapatite $\left(\mathrm{HAP}\right.$ and $\left.\mathrm{Ca}_{5}(\mathrm{OH})\left(\mathrm{PO}_{4}\right)_{3}\right)$ as a support for Mo oxide was investigated by Said et al. [108] (2014-2016), where the catalyst was prepared by a sol-gel method. A selectivity and yield of $97 \%$ was achieved for the $5 \mathrm{wt} \%$ $\mathrm{MoO}_{3} / \mathrm{HAP}$ catalyst at $400{ }^{\circ} \mathrm{C}$, with an initial $\mathrm{MeOH}$ concentration of $1.6 \%$ (Figure 18) for the dehydrogenation of $\mathrm{MeOH}$ (although it was stated to be oxidation in the article, there was no $\mathrm{O}_{2}$ in the feed). 


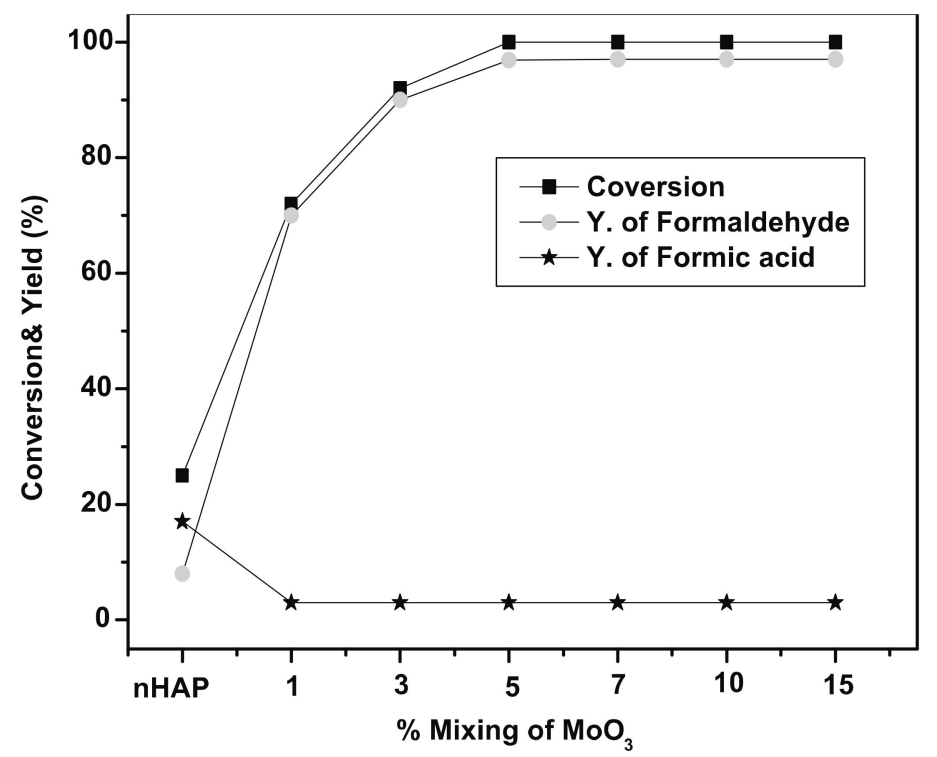

Figure 18. Conversion of $\mathrm{MeOH}$ and FA yield as function of $\mathrm{MoO}_{3}$ loading on HAP. Reprinted by permission from [108] Springer, Catalysis Letters, Copyright @ (2015).

The catalyst was reported stable for $90 \mathrm{~h}$ (the catalyst particle size was not reported). The active sites were concluded to be $\mathrm{Mo}^{6+}$, which produced Lewis and Brønsted acid sites of weak and intermediate strength [108]. The active phase of the catalyst was suggested to be calcium molybdate formed under calcination [108,109]. Thrane et al. [110] investigated $\mathrm{MoO}_{3}$ supported on hydroxyapatite and the Sr analogue in a feed of $150 \mathrm{NmL} / \mathrm{min}, 5 \mathrm{vol} . \%$ $\mathrm{MeOH}$, and 10 vol. $\% \mathrm{O}_{2}$ in $\mathrm{N}_{2} . \mathrm{MoO}_{3} / \mathrm{CaHAP}$ and $\mathrm{MoO}_{3} / \mathrm{SrHAP}$ were found to be more stable than an industrial reference FeMo catalyst when measured as powder catalysts for up to $600 \mathrm{~h}$ on stream at $350{ }^{\circ} \mathrm{C}$ (Figure 19). Additionally, the selectivity was found to be as high as $96 \%$ at $95 \%$ conversion, which is in agreement with Said et al. [108].

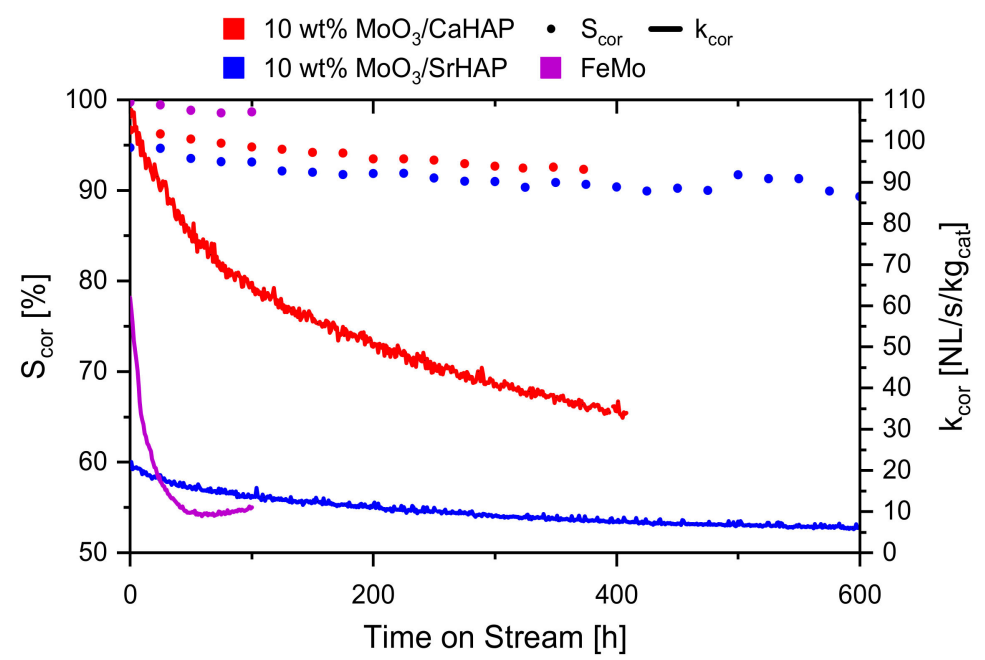

Figure 19. Reversible byproducts corrected selectivity towards FA and corrected activity at $350{ }^{\circ} \mathrm{C}$ measured on $25 \mathrm{mg}$ catalyst sample $(150-250 \mu \mathrm{m})$ in $150 \mathrm{mg}$ of SiC dilutant in a flow of $150 \mathrm{NmL} / \mathrm{min}$ consisting of 5 vol. $\% \mathrm{MeOH}$ and $10 \mathrm{vol} . \% \mathrm{O}_{2}$ in $\mathrm{N}_{2}$. Reprinted from [110] with permission from Wiley-VCH GmbH Copyright @ (2021).

The active phase was proposed to be amorphous $\mathrm{MoO}_{x}$ on the surface of the HAP support, which was observed with STEM, substantiated by XAS (XANES and EXAFS) and $X$-ray PDF, as previous studies found stoichiometric $\mathrm{CaMoO}_{4}$ by itself was not very active or selective. The phosphate was proposed to decrease selectivity towards $\mathrm{CO}$ and $\mathrm{CO}_{2}$ 
compared to stoichiometric $\mathrm{CaMoO}_{4}$ and $\mathrm{SrMoO}_{4}$ [110,111]. Thrane et al. [112] further investigated samples of $10 \mathrm{wt} \% \mathrm{MoO}_{3} / \mathrm{HAP}$ pressed as industrial sized Mo/HAP pellets with different pellet densities, measuring the catalytic performance in a single pellet reactor with $300 \mathrm{NmL} / \mathrm{min}, 5 \mathrm{vol} . \% \mathrm{MeOH}$, and $10 \mathrm{vol} . \% \mathrm{O}_{2}$ in $\mathrm{N}_{2}$. Both selectivity and activity increased with decreased pellet density (Figure 20). The difference between the selectivity of Mo/HAP pellets and FeMo pellets was larger than the difference observed between Mo/HAP powder and FeMo powder.

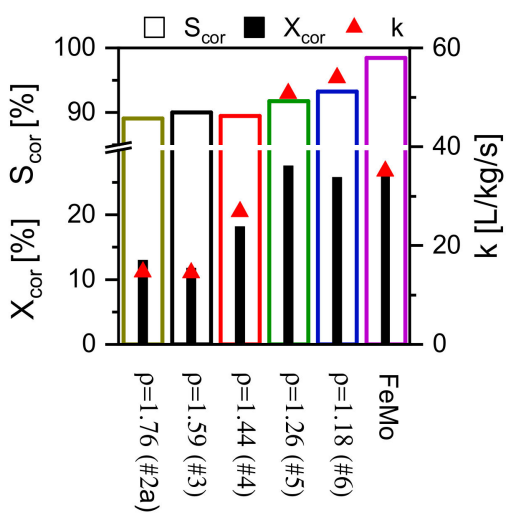

Figure 20. Observed first order rate constant and reversible byproduct corrected conversion and selectivities on single pellets of Mo/HAP with different densities and a FeMo pellet at $350{ }^{\circ} \mathrm{C}$ in $300 \mathrm{NmL} / \mathrm{min}, 5 \mathrm{vol} . \% \mathrm{MeOH}$, and $10 \mathrm{vol} . \% \mathrm{O}_{2}$ in $\mathrm{N}_{2}$. Reproduced from [112] with permission from the Royal Society of Chemistry.

In contrast to the powder results, the pellets of Mo/HAP and FeMo were found to have similar catalytic stability [112], highlighting the challenges in proceeding from powder screenings and upscaling to industrially relevant catalysts.

Stabilization of the FeMo catalyst by $\mathrm{CaO}$ has been investigated by Kostynyuk and Nikolenko [113]. The catalyst was tested at $300{ }^{\circ} \mathrm{C}$ with 5.9 vol. $\% \mathrm{MeOH}$ in the feed. The catalyst had $100 \%$ selectivity until $45 \%$ conversion after which it decreased dramatically (Figure 21) [113].

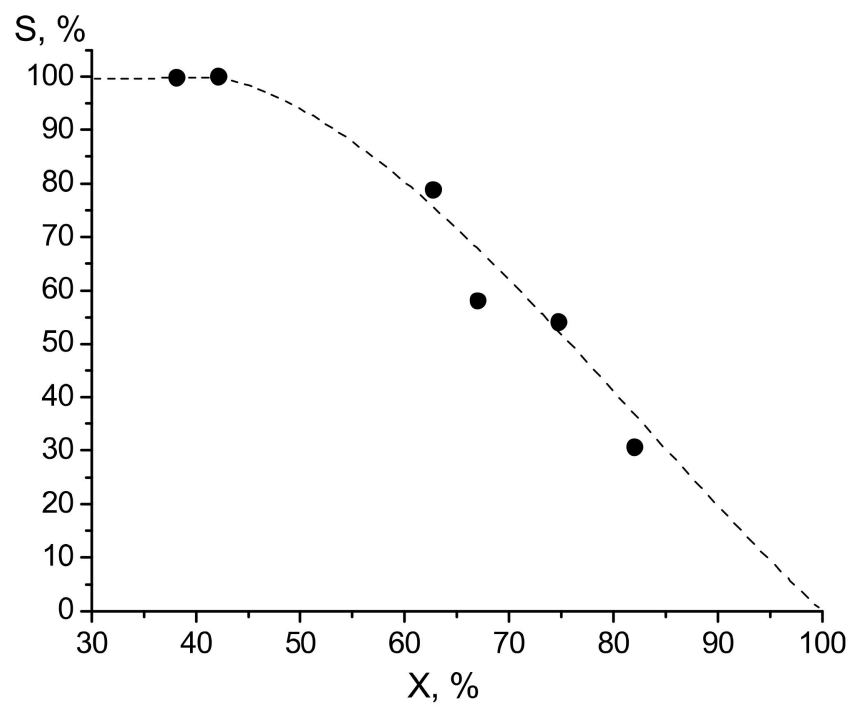

Figure 21. Selectivity of $\mathrm{Fe}_{2}\left(\mathrm{MoO}_{4}\right) / \mathrm{MoO}_{3} / \mathrm{CaO}=1 / 0.7 / 0.3$ towards $\mathrm{CH}_{2} \mathrm{O}$ from $\mathrm{CH}_{3} \mathrm{OH}$ at varying conversions at $300{ }^{\circ} \mathrm{C}$. Reprinted with permission from [113].

The very sudden decrease in selectivity was different from the expectations, which would be a more gradual decrease in selectivity. 
Na containing compounds was shown by Popov et al. [114] to have a significant impact on the activity of FeMo catalysts as $0.4 \mathrm{wt} \% \mathrm{Na}$ added as $\mathrm{Na}_{2} \mathrm{MoO}_{4}, \mathrm{NaCl}$, or $\mathrm{NaNO}_{3}$ decreased activity with a factor of 10 and 12 for $\mathrm{Mo} / \mathrm{Fe}=2.5$ and 1.5 catalysts, respectively. For samples supported on $\mathrm{SiO}_{2}$, a decrease in selectivity was also observed. The sample activity decreased exponentially with $\mathrm{Na}$ content in the sample. $\mathrm{NaCl}$ produced an even higher decrease in activity, and this was explained by the formation of molybdenum dioxychloride by Reaction (25), which was very volatile and evaporates at $400{ }^{\circ} \mathrm{C}$, thus, decreasing the Mo content [114].

$$
2 \mathrm{NaCl}+\mathrm{MoO}_{3} \rightarrow \mathrm{Na}_{2} \mathrm{MoO}_{4}+\mathrm{MoO}_{2} \mathrm{Cl}_{2}
$$

The catalytic properties of Cr-Mo oxide catalysts with Mo/Cr ratios of $0.4-6.5$ were investigated by Popov et al. $[115,116]$ who found maximum activity and selectivity at $\mathrm{Mo} / \mathrm{Cr}=1.6-1.9$, similarly to what they observed for FeMo catalysts. With 6.5 vol. $\%$ $\mathrm{MeOH}$ in the feed at $300{ }^{\circ} \mathrm{C}$, they achieved $96.9 \%$ and $96.2 \%$ selectivity at $85.4 \%$ and $87 \%$ conversion for the $\mathrm{Mo} / \mathrm{Cr}=1.6$ and 1.9 catalysts, respectively, and $>99.5 \%$ selectivity at $<21.2 \%$ conversion. This was similarly to the FeMo catalysts, which had $96.6 \%$ and $97.5 \%$ selectivity at $83 \%$ conversion and $99.7 \%$ and $99.8 \%$ selectivity at $20 \%$ conversion for $\mathrm{Mo} / \mathrm{Fe}=1.75$ and $2.5 \mathrm{Mo} / \mathrm{Cr}=1.9$ with particle size $0.25-0.5 \mathrm{~mm}$ losing $25 \%$ of its activity over $50 \mathrm{~h}$ at $300{ }^{\circ} \mathrm{C}$ with $2.2 \mathrm{mmol} / \mathrm{L} \mathrm{MeOH}$. The $\mathrm{Mo} / \mathrm{Fe}=1.75$ catalyst with similar particle size lost $80 \%$ of its activity. Chromium molybdate was, thus, more stable [115]; however, as $\mathrm{Cr}$ is highly poisonous, it is not fully viable to use chromium molybdates. The oxidation of $\mathrm{MeOH}$ with air and its kinetics on a $\mathrm{Cr}-\mathrm{Mo}$ oxide $(\mathrm{Cr} / \mathrm{Mo} \sim 3)$ catalyst supported on porous $\alpha-\mathrm{Al}_{2} \mathrm{O}_{3}$ were further investigated by the same group [117] at $300-350{ }^{\circ} \mathrm{C}$. The kinetics behaved similarly to the FeMo, with decreasing selectivity at higher temperatures. The activation energy for FA oxidation was determined to be lower than for $\mathrm{MeOH}$ oxidation, thus implying an optimum temperature where the catalyst was most selective. There was no significant inhibition from $\mathrm{H}_{2} \mathrm{O}$ nor FA. The extent of oxidation of $\mathrm{FA}$ to $\mathrm{CO} / \mathrm{CO}_{2}$ was reported to be $150 \%$ larger with no $\mathrm{MeOH}$ present in the gas [117]. The effect of $\mathrm{Na}$ on the activity was investigated by Ivanov et al. [118], who found that less than $0.2 \mathrm{wt} \%$ of $\mathrm{Na}$ from the precipitation did not have a large influence, but larger quantities from the precipitation or even small quantities by impregnation significantly reduced the activity. The formation of $\mathrm{Na}_{2} \mathrm{O} \cdot \mathrm{Cr}_{2} \mathrm{O}_{3} \cdot 3 \mathrm{MoO}_{3}$ was observed by XRD [118]. Similar trends for the addition of $\mathrm{Na}$ to $\mathrm{Fe}_{2}\left(\mathrm{MoO}_{4}\right)_{3}$ were reported in [119]. A study on alkali salts showed them to be active for the dehydrogenation of $\mathrm{MeOH}$ to anhydrous FA with a maximum of $75 \%$ selectivity for $\mathrm{NaCO}_{3}$ [120].

The preparation of Fe-Cr-Mo was studied by Del Arco et al. [121], who found the Mo content to be only dependent on Fe in the precipitation solutions; however, $\mathrm{Cr}$ content was very low in comparison and may, thus, have an influence that was not detected. A $\mathrm{Fe}-\mathrm{Cr}-\mathrm{Mo}$ oxide catalyst $(\mathrm{Mo} /(\mathrm{Fe}+\mathrm{Cr})=2.5 /(0.5+0.5))$ was investigated and compared with an industrial FeMo catalyst by Klissurski et al. [122]. They achieved a yield of above $80 \%$ at $275{ }^{\circ} \mathrm{C}$. The Fe-Cr-Mo catalyst $(0.3-0.6 \mathrm{~mm})$ was tested at $400-420{ }^{\circ} \mathrm{C}$ with a $\mathrm{MeOH}$ concentration of $4 \%$, where it had a constant activity for $100 \mathrm{~h}$ on stream in comparison to the industrial FeMo catalyst, which deactivated at about $20 \%$. The catalysts were shown to be partly reduced under reaction conditions [122]. A catalyst prepared similarly and pure $\mathrm{Fe}_{2}\left(\mathrm{MoO}_{4}\right)_{3}$ and $\mathrm{Cr}_{2}\left(\mathrm{MoO}_{4}\right)_{3}$ were investigated for stability in $\mathrm{MeOH}$ reduction by Pesheva et al. [123]. $\mathrm{Cr}_{2}\left(\mathrm{MoO}_{4}\right)_{3}$ was much more stable than $\mathrm{Fe}_{2}\left(\mathrm{MoO}_{4}\right)_{3}$ as XPS detected no changes after $2 \mathrm{~h}$ at $320{ }^{\circ} \mathrm{C}$ for $\mathrm{Cr}_{2}\left(\mathrm{MoO}_{4}\right)_{3}$. A $45 \%$ reduction of $\mathrm{Fe}^{3+}$ to $\mathrm{Fe}^{2+}$ was measured for $\mathrm{Fe}_{2}\left(\mathrm{MoO}_{4}\right)_{3}$, with only $30 \%$ reduction in the mixed FeCrMo sample. No reduction of $\mathrm{Cr}^{3+}$ nor $\mathrm{Mo}^{6+}$ was measured. Surface enrichment with $\mathrm{Cr}^{3+}$ was observed during reduction but was reversible upon oxidation. The $\mathrm{Mo} /(\mathrm{Fe}+\mathrm{Cr})$ ratio was permanently decreased by the reduction experiment, implying volatilization of $\mathrm{Mo} \mathrm{Cr}^{3+}$ was concluded to have a promoting effect on the reduction stability of $\mathrm{Fe}^{3+}$ in addition to its own higher stability [123]. A TAP reactor study of an Fe-Cr-Mo catalyst was performed by Lafyatis et al. [67]. The only products in significant quantity were $\mathrm{H}_{2} \mathrm{O}$ and FA [67]. 
Popov and Bibin [124] investigated $\mathrm{Bi}_{2} \mathrm{O}_{3}$ and $\mathrm{Bi}_{2}\left(\mathrm{MoO}_{4}\right)_{3}$ at $250-350{ }^{\circ} \mathrm{C}$. The $\mathrm{Bi}_{2} \mathrm{O}_{3}$ mostly made $\mathrm{CO}_{2}$ (selectivity towards $\mathrm{CH}_{2} \mathrm{O}$ was less than $3.2 \%$ ), but $\mathrm{Bi}_{2}\left(\mathrm{MoO}_{4}\right)_{3}$ had $85 \%$ selectivity to FA at $75 \%$ conversion at $300{ }^{\circ} \mathrm{C}$, which, however, was lower than the $90 \%$ and $95 \%$ selectivity on $\mathrm{Fe}_{2}\left(\mathrm{MoO}_{4}\right)_{3}$ and $\mathrm{MoO}_{3}$, respectively. The activation energies were found to be similar $(\sim 75 \mathrm{~kJ} / \mathrm{mol})$ for $\mathrm{Bi}_{2}\left(\mathrm{MoO}_{4}\right)_{3}, \mathrm{Fe}_{2}\left(\mathrm{MoO}_{4}\right)_{3}$, and $\mathrm{MoO}_{3}$ at $250-300{ }^{\circ} \mathrm{C}$, but $\mathrm{Bi}_{2}\left(\mathrm{MoO}_{4}\right)_{3}$ had an $E_{a}$ of $\sim 25 \mathrm{~kJ} / \mathrm{mol}$ at higher temperatures, implying different reaction mechanisms at low and high temperatures as the same behavior was observed for $\mathrm{B}_{2} \mathrm{O}_{3}$ at otherwise different rates, and it is lower than the $\mathrm{E}_{\mathrm{a}, \mathrm{app}}=\mathrm{E}_{\mathrm{a}} / 2$ observed from diffusion limitations [124]. Arora et al. [125] investigated various Bi containing metal-oxide catalysts for FA formation by using a feed of $6 \mathrm{vol} . \% \mathrm{MeOH}$ and $11 \mathrm{vol} \% \mathrm{O}_{2}$ at $280{ }^{\circ} \mathrm{C}$ at less than $10 \%$ conversion. The best catalyst reported was a $\mathrm{MoO}_{3} / \mathrm{Bi}_{2} \mathrm{O}_{3}$, calcined to yield $\beta-\mathrm{Bi}_{2} \mathrm{Mo}_{2} \mathrm{O}_{9}$, giving $97.2 \%$ selectivity towards $\mathrm{FA}$, with the main by-product being DME. For $\mathrm{MoO}_{3} / \mathrm{CeO}_{2} / \mathrm{Bi}_{2} \mathrm{O}_{3}, \mathrm{MoO}_{3} / \mathrm{Pr}_{2} \mathrm{O}_{3} / \mathrm{Bi}_{2} \mathrm{O}_{3}$, and $\mathrm{MoO}_{3} / \mathrm{La}_{2} \mathrm{O}_{3} / \mathrm{Bi}_{2} \mathrm{O}_{3}$, selectivities of $94.5 \%, 93 \%$, and $70 \%$ were achieved, respectively. For low loading $\mathrm{MoO}_{3}$ supported on $\mathrm{Bi}_{2} \mathrm{O}_{3}$ and calcined at $300{ }^{\circ} \mathrm{C}$, a selectivity of $95.2 \%$ was achieved, similarly to $\mathrm{MoO}_{x}$ on $\mathrm{Fe}_{2} \mathrm{O}_{3}$ core-shell catalysts [29].

Mann and Hahn [126,127] investigated a system of $20 \mathrm{wt} \% \mathrm{MnO}_{2}$ on $\mathrm{MoO}_{3}$. They found that with increasing temperature, the selectivity was approximately $100 \%$ until $365{ }^{\circ} \mathrm{C}$, where a conversion of $84 \%$ was achieved with an $\mathrm{O}_{2} / \mathrm{MeOH}$ ratio of 2.42. At $460{ }^{\circ} \mathrm{C}$, the conversion increased to $100 \%$, but the selectivity towards FA decreased to approximately 10\% [126,127]. Ivanov et al. [128-130] also investigated the manganese oxide system and found $\mathrm{MnMoO}_{4}$ with a small excess of Mo to be the most active and selective (>94\% selectivity at up to $95 \%$ conversion at $300-350{ }^{\circ} \mathrm{C}$ ) with a higher thermal stability than the FeMo catalyst [128-130]. Manganese(II) molybdates were found by researchers at Topsøe to have reasonable activity and selectivity, but the stability was not good enough [131].

More recently, an investigation of the molybdates $\mathrm{Al}_{2}\left(\mathrm{MoO}_{4}\right)_{3}, \mathrm{Ce}_{2}\left(\mathrm{MoO}_{4}\right)_{3}, \mathrm{Cr}_{2}\left(\mathrm{MoO}_{4}\right)_{3}$, $\mathrm{Fe}_{2}\left(\mathrm{MoO}_{4}\right)_{3}, \mathrm{MnMoO}_{4}$, and $\mathrm{Zr}\left(\mathrm{MoO}_{4}\right)_{2}$ was performed by Andersson et al. [6] and was compared to the Formox KH44L commercial catalyst at $300{ }^{\circ} \mathrm{C}$ with 10 vol. $\% \mathrm{MeOH}$ and $10 \mathrm{vol} . \% \mathrm{O}_{2}$ in the feed. None of the alternative molybdates performed as well as the Formox KH44L or pure $\mathrm{Fe}_{2}\left(\mathrm{MoO}_{4}\right)_{3}$. Especially at conversions above $50 \%$, the selectivity of, e.g., $\mathrm{Zr}\left(\mathrm{MoO}_{4}\right)_{2}$ and $\mathrm{Ce}_{2}\left(\mathrm{MoO}_{4}\right)_{2}$ was 76-87\% compared to 93-95\% for Formox KH44L and $\mathrm{Fe}_{2}\left(\mathrm{MoO}_{4}\right)_{3}$ (Figure 22). In general, they found the performance of the alternative catalysts worse than previously reported, in agreement with there being no examples of industrial implementations.

$\mathrm{MoO}_{3}-\mathrm{WO}_{3}$ mixtures were investigated by Mann et al. [132] who achieved $95 \%$ selectivity at $95.6 \%$ conversion at $480{ }^{\circ} \mathrm{C}, W / F=48.0 \mathrm{~g}_{\text {cat }} \cdot \mathrm{h} / \mathrm{mol}$, and $10 \mathrm{vol} . \% \mathrm{MeOH}$ in the feed. They fitted the kinetics to a two stage redox mechanism [132]. The $\mathrm{WO}_{3}$ was reported to be essentially inactive by Machiels et al. [133] as the activity reported per surface Mo was unchanged with changing Mo/W ratios.

Ivanov et al. $[119,134]$ investigated the effect of incorporation of up to $15.9 \mathrm{wt} \% \mathrm{WO}_{3}$ into $\mathrm{Fe}_{2}\left(\mathrm{MoO}_{4}\right)_{3}$, where the formation of a mixed $\mathrm{Fe}_{2}\left(\mathrm{MoO}_{4}\right)_{3}-\mathrm{Fe}_{2}\left(\mathrm{WO}_{3}\right)_{3}-\mathrm{MoO}_{3}$ oxide was observed by XRD and Mössbauer spectroscopy. An optimum in the activity and selectivity was found at $4.9 \mathrm{wt} \% \mathrm{WO}_{3}$ with $96.3 \%$ selectivity and $97 \%$ conversion at $350{ }^{\circ} \mathrm{C}$ with the major byproducts being CO and DME [134]. The Topsøe group found FeMo with $\mathrm{WO}_{3}$ instead of excess $\mathrm{MoO}_{3}$ showed loss of $\mathrm{MoO}_{3}$ from $\mathrm{Fe}_{2}\left(\mathrm{MoO}_{4}\right)_{3}$ and formation of $\mathrm{Fe}_{2}\left(\mathrm{WO}_{4}\right)_{3}$ [131]. 


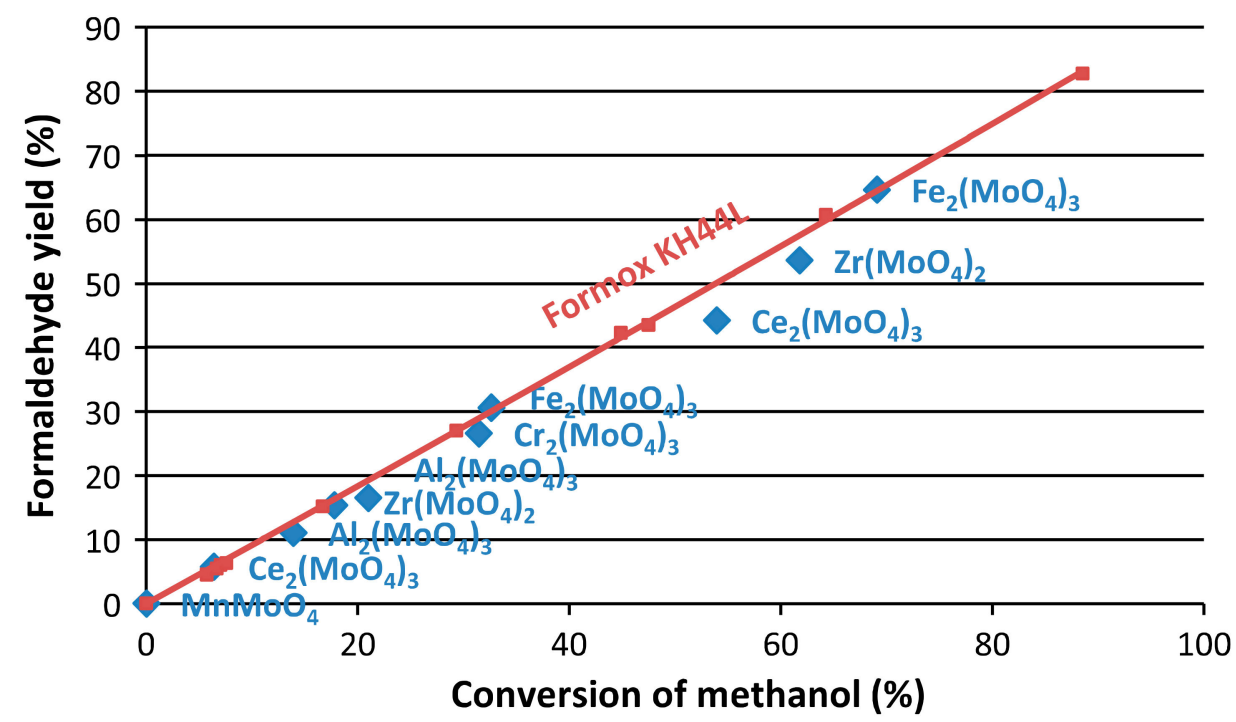

Figure 22. Comparison of catalyst performance of various molybdates to the Formox KH44L commercial catalyst showed as yield vs. conversion. $T=300{ }^{\circ} \mathrm{C}$. Feed: 6 vol. $\% \mathrm{MeOH}$ and 11 vol. $\% \mathrm{O}_{2}$ in inert gas. Flow: 227-277 mL/min. Catalyst loading: 25-1000 mg catalyst (surface area of catalyst 0.1-3 $\mathrm{m}^{2}$ ). Particle size: $0.215-0.425 \mathrm{~mm}$. Reprinted with permission from [6] Springer, Topics in catalysis, Copyright (C) (2016).

A Mo based mixed oxide catalyst with composition $\mathrm{Mo}_{0.65} \mathrm{~V}_{0.25} \mathrm{~W}_{0.10}$ was investigated for FA production by Ramachandra et al. [135]. Thermal treatment at $540{ }^{\circ} \mathrm{C}$ for $2 \mathrm{~h}$ in pure $\mathrm{N}_{2}$ increased the activity and selectivity substantially; however, it was still not higher than $65 \%$ selectivity for FA at nearly $90 \%$ conversion of $\mathrm{MeOH}$ (Figure 23) [135].

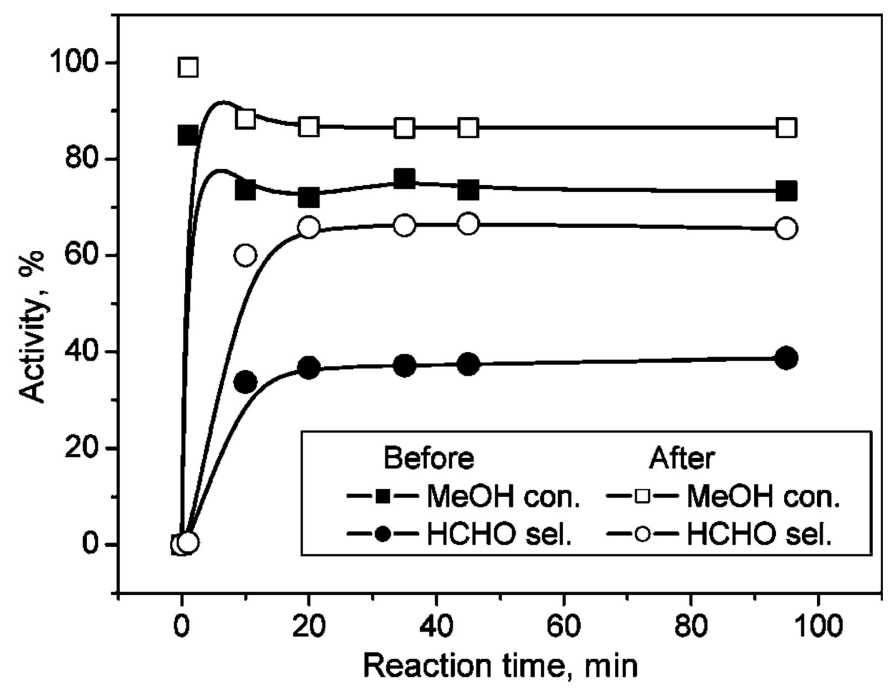

Figure 23. Activity of a $\mathrm{Mo}_{0.65} \mathrm{~V}_{0.25} \mathrm{~W}_{0.10}$ mixed oxide catalyst as function of reaction time at $350{ }^{\circ} \mathrm{C}$ before and after heat treatment at $540{ }^{\circ} \mathrm{C}$ for $2 \mathrm{~h}$ in $\mathrm{N}_{2}$. Feed: $\mathrm{O}_{2} / \mathrm{CH}_{3} \mathrm{OH}=1.47$. Reprinted with permission from [135] Springer, Catalysis Letters, Copyright (C) (1969).

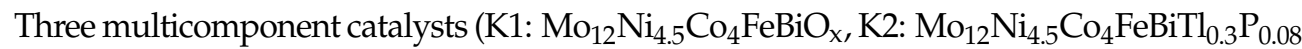
$\mathrm{O}_{\mathrm{x}}$, and $\mathrm{K} 3: \mathrm{Mo}_{12} \mathrm{Ni}_{4.5} \mathrm{Co}_{4} \mathrm{FeBiTl}_{0.3} \mathrm{P}_{0.08} \mathrm{O}_{\mathrm{x}} / \mathrm{SiO}_{2}$ ) with a particle size of $0.3-0.6 \mathrm{~mm}, 250 \mathrm{mg}$ cat, and $240 \mathrm{~mL} / \mathrm{min}$ were investigated by Klissurski et al. [136] at $270-420{ }^{\circ} \mathrm{C}$ inlet temperature and $3.5 \mathrm{vol} . \% \mathrm{MeOH}$ in air. The catalysts were prepared by simultaneous evaporation of an aqueous solution of ammonium paramolybdate and corresponding metal nitrates, with subsequent addition of phosphoric acid and Tl nitrate for K2. For all the catalysts, high selectivities were 
achieved ( $>97 \%$ for 360,370 , and $390^{\circ} \mathrm{C}$ ). During extended measurements, the deactivation was $30 \%$ within $80 \mathrm{~h}$ for $\mathrm{K} 1$, while for $\mathrm{K} 2$ and $\mathrm{K} 3$ it was around $5-10 \%$ in 60 days, at conversions of $50-60 \%$ [136].

Klissurski et al. [137] further investigated $\mathrm{MoO}_{3}$ supported on montmorillo Al-type pillared clays from $320-440{ }^{\circ} \mathrm{C}$ for selective oxidation of $\mathrm{MeOH}$ to FA. The catalysts did not show great selectivity towards FA.

Mann and Dosi [138] investigated catalysts of mixed $\mathrm{V}_{2} \mathrm{O}_{5}-\mathrm{MoO}_{3}$. They found an optimum of $20 \% \mathrm{~V}_{2} \mathrm{O}_{5}$ to provide $100 \%$ selectivity at more than $99 \%$ conversion at $466{ }^{\circ} \mathrm{C}$ with a feed space velocity of $31.7 \mathrm{~g}_{\text {cat }} / \mathrm{h} / \mathrm{mol}$ and $8 \mathrm{vol} . \% \mathrm{MeOH}$ in air in the feed. Increasing V content further increased the conversion but decreased selectivity, where until $20 \% \mathrm{~V}_{2} \mathrm{O}_{5}$ only an increase in selectivity was observed [138].

Molybdena was supported on $\gamma-\mathrm{Al}_{2} \mathrm{O}_{3}\left(6.9-58.5 \mathrm{wt} \% \mathrm{MoO}_{3}\right), \mathrm{TiO}_{2}$ (anatase and rutile) $\left(1-25 \mathrm{wt} \% \mathrm{MoO}_{3}\right), \mathrm{ZrO}_{2}\left(1-25 \mathrm{wt} \% \mathrm{MoO}_{3}\right)$, and $\mathrm{CeO}_{2}\left(5-25 \mathrm{wt} \% \mathrm{MoO}_{3}\right)$, and their activity for $\mathrm{MeOH}$ oxidation to FA was investigated by Matsuoka et al. [139] with $3.4 \mathrm{vol} . \% \mathrm{MeOH}$ in the feed at $225^{\circ} \mathrm{C}$. The TOF of the oxides were in the order of $\mathrm{ZrO}_{2}>\mathrm{TiO}_{2}>\mathrm{CeO}_{2}>\mathrm{Al}_{2} \mathrm{O}_{3}$, with the order of the selectivities towards FA for the most selective samples being $\mathrm{ZrO}_{2}>$ $\mathrm{CeO}_{2}>\mathrm{TiO}_{2}>\mathrm{Al}_{2} \mathrm{O}_{3}$ with selectivities of $89 \%, 88 \%, 83 \%$, and $66 \%$, respectively, and the major byproducts being DME, MF, and DMM with small amounts of $\mathrm{CO}_{2}$ and $\mathrm{CO}$ [139]. In our studies (see Supplementary Materials, Section 2.2.3, Figure S6, and Table S6) on $\mathrm{MoO}_{3}$ supported on $\alpha-\mathrm{Al}_{2} \mathrm{O}_{3}$, the selectivity of $6.2 \mathrm{wt} \% \mathrm{MoO}_{3} / \alpha-\mathrm{Al}_{2} \mathrm{O}_{3}$ towards $\mathrm{FA}$ was very high (>93\%) with DME being the main byproduct. With only $1 \mathrm{wt} \% \mathrm{MoO}_{3}$, the $\mathrm{CO}_{2}$ and $\mathrm{CO}$ selectivities were higher, which may be due to small imperfections in monolayer coverage.

Burcham et al. [140] investigated the ligand effect of $\mathrm{Fe}, \mathrm{Al}_{2} \mathrm{O}_{3}$, and $\mathrm{TiO}_{2}$ on $\mathrm{MoO}_{3}$ with $2000 \mathrm{ppm} \mathrm{MeOH}$ in the feed at differential conversions. The highest oxidation selectivity was obtained for $\mathrm{MoO}_{3} / \mathrm{TiO}_{2}$ with $89.9 \%$ towards $\mathrm{FA}$ and $\mathrm{CO}_{x}$ combined (reporting these combined makes it difficult to evaluate the usefulness of the catalyst), with $9 \%$ to MF and $1.4 \%$ to DME. $\mathrm{Fe}_{2}\left(\mathrm{MoO}_{4}\right)_{3}$ and $\mathrm{MoO}_{3} / \mathrm{Al}_{2} \mathrm{O}_{3}$ only achieved $83 \%$ and $68 \%$ combined $\mathrm{FA}$ and $\mathrm{CO}_{x}$ selectivity, respectively, but with DME selectivity of $17 \%$ and $32 \%$ making it the only side product [140]. The FA selectivity of the $\mathrm{Fe}_{2}\left(\mathrm{MoO}_{4}\right)_{3}$ catalyst was unexpectedly low in this study; however, it might have been better with higher conversion (due to conversion of reversible by-products such as DME to FA at high conversion) and/or feed concentration of $\mathrm{MeOH}$.

A series of $\mathrm{MoO}_{3} / \mathrm{SiO}_{2}$ prepared by different researchers with different silicas and preparation methods was studied by in situ Raman spectroscopy and X-ray photo electron spectroscopy by Bañares et al. [141]. The surface Mo species were assigned to be isolated, highly distorted octahedral mono-oxo Mo structure. The Mo coverage was found to be the only relevant factor with respect to the catalytic properties for $\mathrm{MeOH}$ oxidation. All loadings above $0.1 \mathrm{Mo} / \mathrm{nm}^{2}$ were found to be unstable due to transformation and aggregation into $\beta-\mathrm{MoO}_{3}$. The decrease in activity was found to be proportional with the decrease in the number of exposed Mo sites due to agglomeration.

In an investigation by Inokawa et al. [142] was conducted on group 6B elements supported on $\mathrm{CeO}_{2}-\mathrm{ZrO}_{2}$, among those which include $\mathrm{MoO}_{3}$, which produced the best selectivity of the investigated samples. A FA selectivity of $60 \%$ was found at $50 \%$ conversion at $375{ }^{\circ} \mathrm{C}$. This was the best result in the investigated temperature interval of 275-450 ${ }^{\circ} \mathrm{C}$ [142]. Overall, a rather low selectivity was observed.

Niwa et al. [143] measured the ESR signal for $\mathrm{Mo}$ in a $\mathrm{SnO}_{2}-\mathrm{MoO}_{3}$ catalyst under $\mathrm{MeOH}$ oxidation. Pure $\mathrm{SnO}_{2}$ made $\mathrm{CO}_{2}$, but together with $\mathrm{MoO}_{3}$ the catalyst showed selective activity from $180^{\circ} \mathrm{C}$. The $\mathrm{SnO}_{2}-\mathrm{MoO}_{3}$ system was stated to have higher activity than compared to $\mathrm{MoO}_{3}-\mathrm{TiO}_{2}(1 / 1), \mathrm{Fe}_{2} \mathrm{O}_{3}-\mathrm{MoO}_{3}(1 / 1)$, and $\mathrm{Co}_{3} \mathrm{O}_{5}-\mathrm{MoO}_{3}(1 / 1)$. They concluded from following the $\mathrm{Mo}^{5+}$ signal that the activity came from a $\mathrm{Mo}^{5+} \rightleftharpoons \mathrm{Mo}^{4+}$ redox cycle, as no hysteresis behavior was observed upon changing the $\mathrm{MeOH}$ partial pressure, resulting in the belief that $\mathrm{Mo}^{5+}$ was reduced to $\mathrm{Mo}^{4+}$, but $\mathrm{Mo}^{6+}$ was not reduced [143] Only little change in the activity and selectivity was found as the Mo/Sn ratio was changed from $9 / 1$ to $3 / 7$ [144]. In a later study, they stated that the $\mathrm{Mo}^{6+}$ reduction rate was much 
smaller than that of $\mathrm{Mo}^{5+}$; thus, $\mathrm{Mo}^{5+}$ was a much more reactive oxidation site [145]. At $20 \%$ conversion, the selectivity towards other products than FA (mainly DME and MF) was stated to be negligible with $80 \% \mathrm{ML}$ coverage of $\mathrm{MoO}_{x}$ on the $\mathrm{SnO}_{2}$ (a full ML coverage was reported not achievable, even with addition of more four times the theoretical amount of Mo for full surface coverage). Adsorption of $\mathrm{MeOH}$ on Brønsted acid sites on $\mathrm{MoO}_{3}$ instead of on $\mathrm{SnO}_{2}$ was found important for the selectivity in their studies [146-148]. Narishige and Niwa [149] exchanged $\mathrm{SnO}_{2}$ with $\mathrm{ZrO}_{2}$ and performed MeOH TPD experiments and found again that FA was formed on the surface of $\mathrm{MoO}_{3}$ and desorbed during the temperature ramp, while $\mathrm{ZrO}_{2}$ adsorbed $\mathrm{MeOH}$ strongly as dioxymethylene and carbonates as an intermediate to full oxidation [149]. The partial oxidation of $\mathrm{MeOH}$ on a coprecipitated mixed Sn-Mo oxide catalyst was investigated by Valente et al. [150], with the best selectivity towards FA being 43\%; however, in most samples, the highest selectivity was towards methyl formate [150] in contrast to the reports by Niwa et al. [143-148]. However, the difference may be a result of comparing a mixed Sn-Mo oxide [150] with $\mathrm{MoO}_{3}$ supported on $\mathrm{SnO}_{2}$ [143-148].

The oxidation of $\mathrm{MeOH}$ to FA over a Sb-Mo oxide catalyst $\left(\mathrm{Sb}_{2} \mathrm{O}_{4} / \mathrm{MoO}_{3}\right)$ prepared by impregnation was investigated by Mann and Diaz-Real [151] at $350{ }^{\circ} \mathrm{C}$ to $425{ }^{\circ} \mathrm{C}$ and 6 vol. \% MeOH in air. A maximum in conversion and selectivity of $82 \%$ and $100 \%$, respectively, was achieved at $400{ }^{\circ} \mathrm{C}$ and with a $\mathrm{Sb}_{2} \mathrm{O}_{4} / \mathrm{MoO}_{3}$ ratio of two. The conversion was observed to increase with temperature, with no apparent decrease in selectivity [151]. Later, an investigation of the catalytic abilities of a mechanical mixture of $\alpha-\mathrm{Sb}_{2} \mathrm{O}_{4}$ and $\mathrm{MoO}_{3}$ was conducted by Castillo et al. [152]. Even with only a mechanical mixture, a promoting effect of $\mathrm{Sb}_{2} \mathrm{O}_{4}$ on $\mathrm{MoO}_{3}$ was observed. The selectivity of the mixture was $>99 \%$ at $350-450{ }^{\circ} \mathrm{C}$, with $94 \%$ conversion at $450{ }^{\circ} \mathrm{C}$. The selectivity was stated to be equal to or surpassing those of commercial FeMo catalysts. The promotional effect was suggested to be a result of remote spillover of oxygen from $\alpha-\mathrm{Sb}_{2} \mathrm{O}_{4}$ increasing the rate of reoxidation of $\mathrm{MoO}_{3}$ [152]. Similar results have been proposed by Xiong et al. [153-155] for the oxidation of isobutene to methacrolein and ethanol to acetaldehyde at 420 and $450{ }^{\circ} \mathrm{C}$ by $\mathrm{Fe}_{2}\left(\mathrm{MoO}_{4}\right)_{3}$ and $\alpha-\mathrm{Sb}_{2} \mathrm{O}_{4}$ and $\mathrm{Fe}_{2}\left(\mathrm{MoO}_{4}\right)_{3}$ mixed in n-pentane, agitated for 10 min by ultra-sonication, and then evaporated and dried. $\mathrm{A}-\mathrm{Sb}_{2} \mathrm{O}_{4}$ stabilized ethanol oxidation so that the conversion decreased less for the mixture than for pure FeMo. Furthermore, XRD showed less reduction of $\mathrm{Fe}_{2}\left(\mathrm{MoO}_{4}\right)_{3}$ to $\mathrm{FeMoO}_{4}$ and $\mathrm{MoO}_{2}$ in the presence of $\alpha$ $\mathrm{Sb}_{2} \mathrm{O}_{4}$ [155]. This is in opposition with our own investigations of a mixed Mo-Sb oxide from co-precipitation (see Supplementary Materials, Section 2.2.3, Figure S6, and Table S6), which lost $58 \%$ of its activity within $8 \mathrm{~h}$ at $400{ }^{\circ} \mathrm{C}$ compared to $36 \%$ for $6.2 \mathrm{wt} \% \mathrm{MoO}_{3} / \alpha-$ $\mathrm{Al}_{2} \mathrm{O}_{3}$. In our study (see Supplementary Materials, Section 2.2.3, Figure S6, and Table S6), a mixed Mo-Sb oxide was co-precipitated. Selectivity was found to be $>98 \%$, but a maximum conversion of $12.5 \%$ was achieved as the activity was low.

The oxidation of $\mathrm{MeOH}$ to FA over heteropolyacids (probably Keggin structure, $\mathrm{H}_{\mathrm{x}-8}\left[\mathrm{XM}_{12} \mathrm{O}_{40}\right]^{\mathrm{x}-8}, \mathrm{X}=\mathrm{P}, \mathrm{Si}, \mathrm{As}, \mathrm{Ge}$, etc.; $\mathrm{M}=\mathrm{Mo}, \mathrm{W}, \mathrm{V}$, and $\mathrm{Co}$ ) and their salts has also been investigated [156]. The selectivity in the presence of the salts was higher than on the heteropolyacids because of their lower acidity. At $260{ }^{\circ} \mathrm{C}$, with a contact time of $0.6 \mathrm{~s}$, the selectivity towards FA from $\mathrm{MeOH}$ was $82 \%$ on $\mathrm{CuPMo} / \mathrm{SiO}_{2}$ with a conversion of $70 \%$. The byproducts were DME and CO [156].

The catalytic properties of Mo phosphate, $\left(\mathrm{MoO}_{2}\right)_{2} \mathrm{P}_{2} \mathrm{O}_{7}$ promoted with $\mathrm{V}$, was investigated by Whiting et al. [157] in the temperature range of $200-480{ }^{\circ} \mathrm{C}$ in a feed containing 5 vol. $\%$ MeOH. For pure Mo phosphate, the selectivity was $100 \%, 91.4 \%$, and $89.5 \%$ at conversions of $5.3 \%, 50.8 \%$, and $95.8 \%$ obtained at 200,400 , and $480{ }^{\circ} \mathrm{C}$, respectively. The conversion increased when doping with $\mathrm{V}$ at all temperatures, and this was also the case for the selectivity at $400{ }^{\circ} \mathrm{C}$, while it decreased slightly at $200{ }^{\circ} \mathrm{C}$ and a bit more at $480{ }^{\circ} \mathrm{C}$. The promotion was concluded to stem from the formation of vanadium or vanadyl phosphate phases, which increased the reducibility of the catalyst [157].

At Haldor Topsøe, various alternative catalysts have been investigated [131]. $\mathrm{Li}_{2.8} \mathrm{Fe}_{2} \mathrm{Mo}_{3.2}$ showed promising activity, selectivity, and stability in a sieve fraction of $150-300 \mu \mathrm{m}$ at $450{ }^{\circ} \mathrm{C}$ 
and 5 vol. $\% \mathrm{MeOH}$ and 5 vol. $\% \mathrm{O}_{2}$ in the feed. The investigation, however, was stopped since full conversion was difficult to obtain over the activated catalyst, and the activity and selectivity were found to be insufficient when the catalyst was tested as whole pellets. Furthermore, the pellets were found to be fragile and suffered from $\mathrm{MoO}_{3}$ evaporation [131]. The Topsøe group found that $\mathrm{FeCr}\left(\mathrm{MoO}_{4}\right)_{3}$ was more stable towards $\mathrm{MoO}_{3}$ loss than $\mathrm{Fe}_{2}\left(\mathrm{MoO}_{4}\right)_{3}$. When investigating pure $\mathrm{Cr}_{2}\left(\mathrm{MoO}_{4}\right)_{3}$, the stability of the system was good; however, selectivity was only approximately $90 \%$. For $\mathrm{Al}_{2}\left(\mathrm{MoO}_{4}\right)_{3}$, the selectivity was not satisfying, and the catalyst deactivated quickly and became even less selective. This also showed that there are other important factors than the molybdate ion and crystal structure, as $\mathrm{Cr}_{2}\left(\mathrm{MoO}_{4}\right)_{3}, \mathrm{Al}_{2}\left(\mathrm{MoO}_{4}\right)_{3}$, and $\mathrm{Fe}_{2}\left(\mathrm{MoO}_{4}\right)_{3}$ are isostructural [158]. Upon incorporation of $\mathrm{Al}$ into hematite with subsequent addition of 1 to $3 \mathrm{ML}$ of Mo to the surface, an increase in surface area was not only achieved but also increased $\mathrm{CO}$ and $\mathrm{CO}_{2}$ formation [159]. Bi molybdates were investigated and were discarded due to too low selectivity for FA over $\mathrm{Bi}_{2} \mathrm{MoO}_{6}(87-89 \%)$ and too low activity for FA over $\mathrm{Bi}_{2}\left(\mathrm{MoO}_{4}\right)_{3}$, which, however, showed high selectivity $(97 \%)$. $\mathrm{CoMoO}_{4}$ and $\mathrm{CuMoO}_{4}$ had too low activity, while $\mathrm{NiMoO}_{4}$ had too low selectivity. FeMo in a mechanical mixture with $\mathrm{Sb}_{2} \mathrm{O}_{4}$ and no excess $\mathrm{MoO}_{3}$ showed "surprisingly" fast deactivation. Lastly, $\alpha-\mathrm{FeMoO}_{4}$, $\beta-\mathrm{FeMoO}_{4}, \mathrm{Cs}_{3} \mathrm{Pmo}_{12} \mathrm{O}_{40}$, and $\mathrm{Fe}\left[\mathrm{Pmo}_{12} \mathrm{O}_{40}\right]$ have been tested. A-FeMoO 4 (low temperature structure [160]) had very low activity but good selectivity ( $>95 \%)$. B-FeMoO 4 (high temperature structure, formed at $>400{ }^{\circ} \mathrm{C}$ [160]) had low selectivity $(<81 \%)$ and low activity. Both of the $\left[\mathrm{Pmo}_{12} \mathrm{O}_{40}\right]^{2-}$ salts had too low activity [131].

A study of nitric oxide (NO)-doped $\beta-\mathrm{MoO}_{3}$ was performed by Pham et al. [161] at 260-350 ${ }^{\circ} \mathrm{C}$ achieving $99 \%$ conversion of $\mathrm{MeOH}$ with a selectivity of $\sim 98 \%$ to FA at $320{ }^{\circ} \mathrm{C}$ at a catalyst to feed ratio of $28 \mathrm{gcat} / \mathrm{h} / \mathrm{mol}$. The $\mathrm{NO}$-doped $\beta-\mathrm{MoO}_{3}$ had a surface area trice that of their industrial reference. The $\mathrm{NO}$-doping was inferred but not proven to have increased oxygen mobility. A stability test at $300{ }^{\circ} \mathrm{C}$ for $30 \mathrm{~h}$ was conducted with $W / F=70 \mathrm{~g}_{\text {cat }} / \mathrm{h} / \mathrm{mol}$ (Figure 24 ), where the selectivity and conversion were both $98 \%$ for the test period [161]. Unfortunately, it is not possible to evaluate catalyst stability at such high conversion.

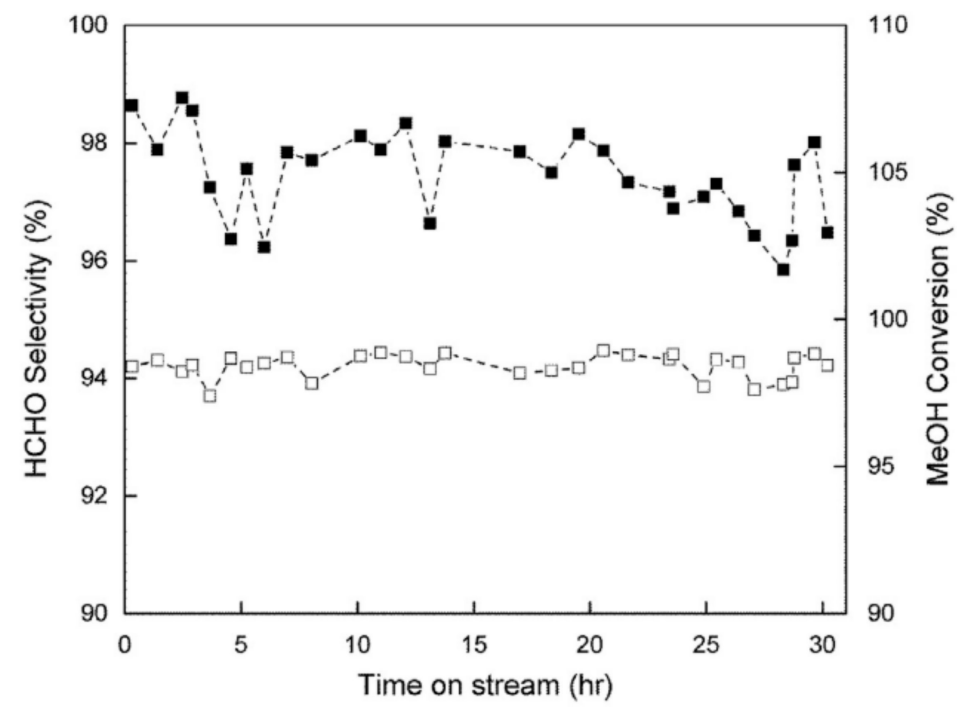

Figure 24. $\mathrm{MeOH}$ conversion ( $\square$ ) and FA selectivity over $\mathrm{NO}$-doped $\beta-\mathrm{MoO}_{3}$ at $300{ }^{\circ} \mathrm{C}$ $W / F=70 \mathrm{~g}_{\text {cat }} / \mathrm{h} / \mathrm{mol}$. Reprinted from [161] Copyright $(C$ (2016), with permission from Elsevier.

Most of the results reported in the literature for the Mo containing catalysts are summarized as selectivity as a function of conversion in Figure 25 (when possible). Interesting catalysts are found in the upper right corner of the figure, and relevant catalysts should show $>95 \%$ conversion at high conversion such as the FeMo catalyst. High selectivity was reported for many molybdates, e.g., chromium, bismuth, and manganese molybdate, but molybdenum based catalysts with a reducible second component (e.g., Ce and $\mathrm{Zr}$ ) and 
supported molybdenum oxide in general showed lower selectivity, with the antimony based catalysts as exception. One should be cautious when the conversion is reported to be " $100 \%$ ", as the selectivity is then influenced (negatively) by the residence time in the reactor near full conversion.

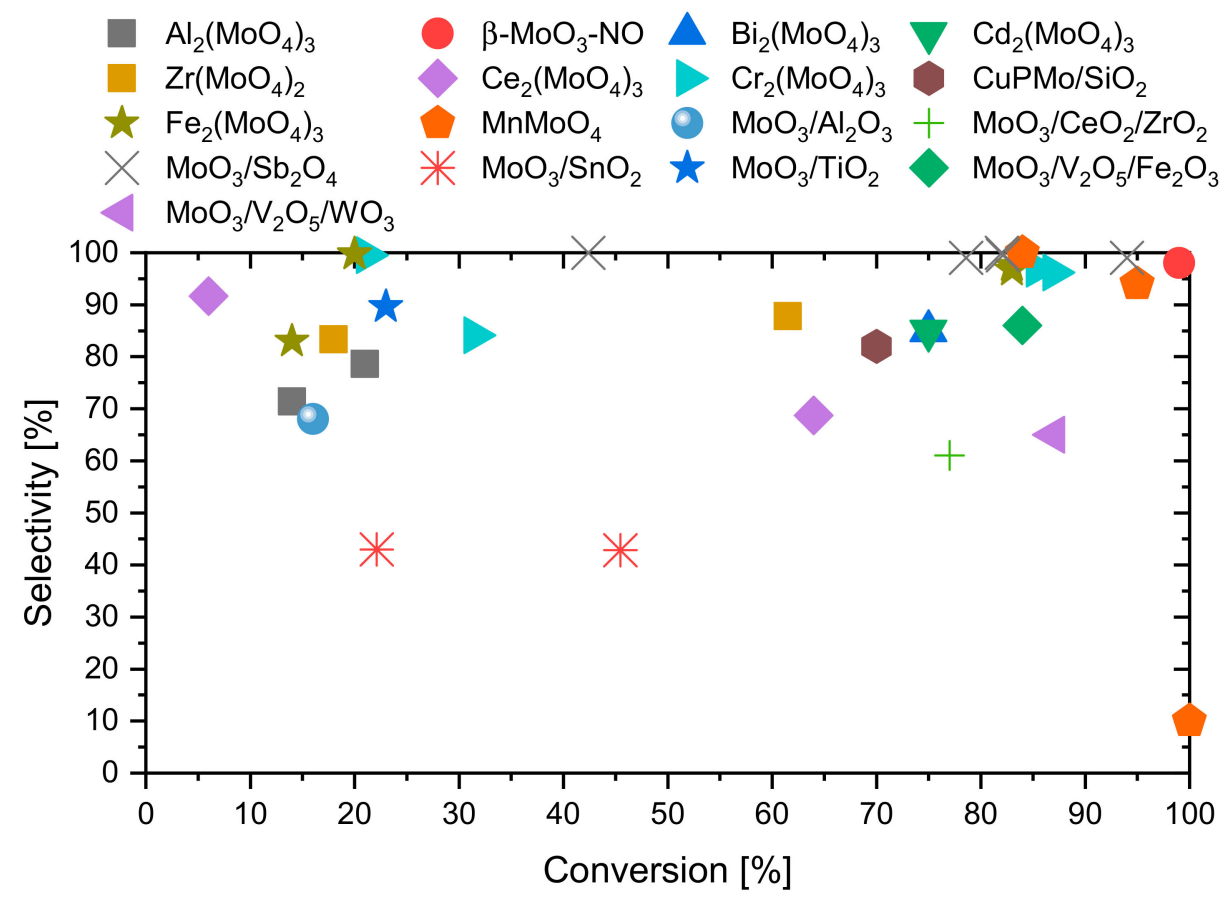

Figure 25. Summary of catalytic test results for Mo containing catalysts in the literature shown as selectivity vs. conversion [108,113,125,135,139,140,150-152,156,157].

\subsubsection{Containing Catalysts}

$\mathrm{V}$ oxides have been reported in the literature for a number of different selective oxidation reactions. Depending on the preparation method, it can have a number of different structural configurations. As a supported catalyst, it can yield isolated $\mathrm{VO}_{x}$ ions, dimeric or polymeric species, two-dimensional over-layers, three dimensional over-layers, mixed metal oxide surfaces, or a mixture of it all [162]. In addition, bulk vanadium oxide, mixed metal vanadates, and vanadyl phosphates are also tested as catalysts for selective oxidation reactions, including $\mathrm{MeOH}$ to FA.

Vanadium phosphates. In the late 1990s the catalytic activity of V-Ti aluminophosphate molecular sieve with MFI structure was investigated by Kapoor and Raj [163] in 20 vol. $\% \mathrm{MeOH}$ and 10 vol. $\% \mathrm{O}_{2}$ at $200{ }^{\circ} \mathrm{C}$. A maximum selectivity of $79.2 \%$ was achieved with $5.73 \%$ conversion with $\mathrm{CO}$ being the largest byproduct and without Ti in the catalyst. The performance became worse when Ti was introduced to the structure [163].

Vanadyl phosphate catalysts were tested for $\mathrm{MeOH}$ oxidation by Whiting et al. [157]. For $\mathrm{VOHPO}_{4} \cdot 0.5 \mathrm{H}_{2} \mathrm{O}$ and $\mathrm{VOPO}_{4} \cdot 2 \mathrm{H}_{2} \mathrm{O}$, the selectivities were $100 \%, 74.8 \%, 29 \%$, and $100 \%, 98.6 \%, 78.4 \%$ at 200,400 , and $480{ }^{\circ} \mathrm{C}$, respectively [157]. The use of $\mathrm{V}$ phosphates as catalysts for selective $\mathrm{MeOH}$ oxidation was investigated by Behera et al. $[164,165]$. They investigated the promotional effect of $\mathrm{Al}$ [164] and tungstate [165] in $\mathrm{V}$ phosphate, with a feed of $5 \mathrm{vol} . \% \mathrm{MeOH}$ and $10 \mathrm{vol} . \% \mathrm{O}_{2}$. It was found for $\mathrm{Al}$ promotion that $5 \% \mathrm{Al}$ performed better than the other $\mathrm{Al}$ doped samples. One hundred percent selectivity was observed at 200 and $250{ }^{\circ} \mathrm{C}$ with conversions less than $30 \%$. Selectivity decreased drastically with increasing temperature to $62 \%$ at $350{ }^{\circ} \mathrm{C}$ with $94 \%$ conversion [164]. For tungstate promotion, the catalyst containing $25 \mathrm{wt} \% \mathrm{WO}_{3}$ performed the best, with a selectivity of $98.9 \%$ at $200{ }^{\circ} \mathrm{C}$, which decreased to $95.8 \%$ at $300{ }^{\circ} \mathrm{C}$ where full conversion was achieved. The yield of FA was $89.9 \%$ or better at $250-350{ }^{\circ} \mathrm{C}$, which was the same as the industrial process but at lower temperatures. The promotional effect of $\mathrm{WO}_{3}$ was thought to stem 
from a combination of enhanced Brønsted acidity from $\mathrm{WO}_{3}$ and good redox properties of $\mathrm{V}$ phosphate [165]. The high selectivity of the $\mathrm{V}$ phosphates was confirmed in our study (see the Supplementary Materials, Section 2.2.2, Figure S8, and Table S8) by the synthesis methods by Behera et al. [164,165]. However, the activities were only moderate.

The Topsøe group [131] investigated a $\mathrm{V}$ oxide promoted with $\mathrm{W}, \mathrm{P}$, and $\mathrm{Cs}$ on $\mathrm{TiO}$, with a final composition of $3.9 \% \mathrm{~V}, 3.1 \% \mathrm{~W}, 0.79 \% \mathrm{P}$, and $<0.22 \% \mathrm{Cs}$. The sample was found to have almost $100 \%$ selectivity at conversions of nearly $90 \%$ at a temperature of $330{ }^{\circ} \mathrm{C}$. Above $330{ }^{\circ} \mathrm{C}$, the selectivity decreased as $\mathrm{CO}$ and $\mathrm{CO}_{2}$ formation increased. A study of $\mathrm{V}$ phosphate promoted by $\mathrm{K}$ and supported on $\mathrm{TiO} 2$ and $\mathrm{SiO}_{2}$ was also conducted. The particle sizes were $300-500 \mu \mathrm{m}$, gas feed of $5 \mathrm{vol} . \% \mathrm{MeOH}, 5 \mathrm{vol} . \% \mathrm{O}_{2}$, and $3 \mathrm{vol} . \% \mathrm{H}_{2} \mathrm{O}$ in $\mathrm{N}_{2}$. Selectivities were high (>90\%) at temperatures below $375{ }^{\circ} \mathrm{C}$ for all samples using $\mathrm{TiO}_{2}$, where the sample with $0.61 \mathrm{wt} \% \mathrm{~V}, 0.82 \mathrm{wt} \% \mathrm{~K}$, and $1.05 \mathrm{wt} \% \mathrm{P}$ had selectivities of $98 \%$ at 300 and $325{ }^{\circ} \mathrm{C}, 96 \%$ at $350{ }^{\circ} \mathrm{C}, 94 \%$ at $375{ }^{\circ} \mathrm{C}$, and $91 \%$ at $400{ }^{\circ} \mathrm{C}$. This was later investigated in a pilot plant where the temperature showed runaway behavior with a feed temperature of $250{ }^{\circ} \mathrm{C}, 8.4$ vol. $\% \mathrm{MeOH}, 10$ vol. $\% \mathrm{O}_{2}$, and 4 vol. $\% \mathrm{H}_{2} \mathrm{O}$ in $\mathrm{N}_{2}$. This was also found for a similar catalyst with lower $\mathrm{V}$ content $(0.6 \mathrm{wt} \% \mathrm{~V}, 0.9 \mathrm{wt} \% \mathrm{P}$, and $0.3 \mathrm{wt} \% \mathrm{~K})$ when the $\mathrm{MeOH}$ concentration in the feed became too high ( $7 \%$ ) with an inlet temperature of $280^{\circ} \mathrm{C}$. The same $\mathrm{V}, \mathrm{P}$, and $\mathrm{K}$ loadings were tested on $\gamma-\mathrm{Al}_{2} \mathrm{O}_{3}$ and also without $\mathrm{K}$ and with only $\mathrm{V}$. In all cases, the DME and $\mathrm{CO}_{x}$ selectivities were unacceptably high [131].

The results reported in the literature for vanadyl phosphate catalysts are summarized in Figure 26 as formaldehyde selectivity against conversion (when possible). The phosphates with high amounts of Al generally had lower selectivity (V-Ti-AlPO and V-AlPO), but lower amounts of $\mathrm{Al}$ (VPO-Al) was also detrimental for selectivity at higher conversions. $\mathrm{VOHPO}_{4} \cdot 0.5 \mathrm{H}_{2} \mathrm{O}$ had too low selectivity as it was below $80 \%$. $\mathrm{VOPO}_{4} \cdot 2 \mathrm{H}_{2} \mathrm{O}$ had good selectivity ( $>95 \%$ ) at low conversion, but it lost its selectivity near $100 \%$ conversion. MoPO-V had selectivity that was too low in general to be of real interest ( $90 \%)$. In general, the vanadyl phosphates showed good selectivity at low conversions. The most promising vanadyl phosphate was the $\mathrm{VPO}-\mathrm{WO}_{3}$, which had $>95 \%$ selectivity at $100 \%$ conversion.

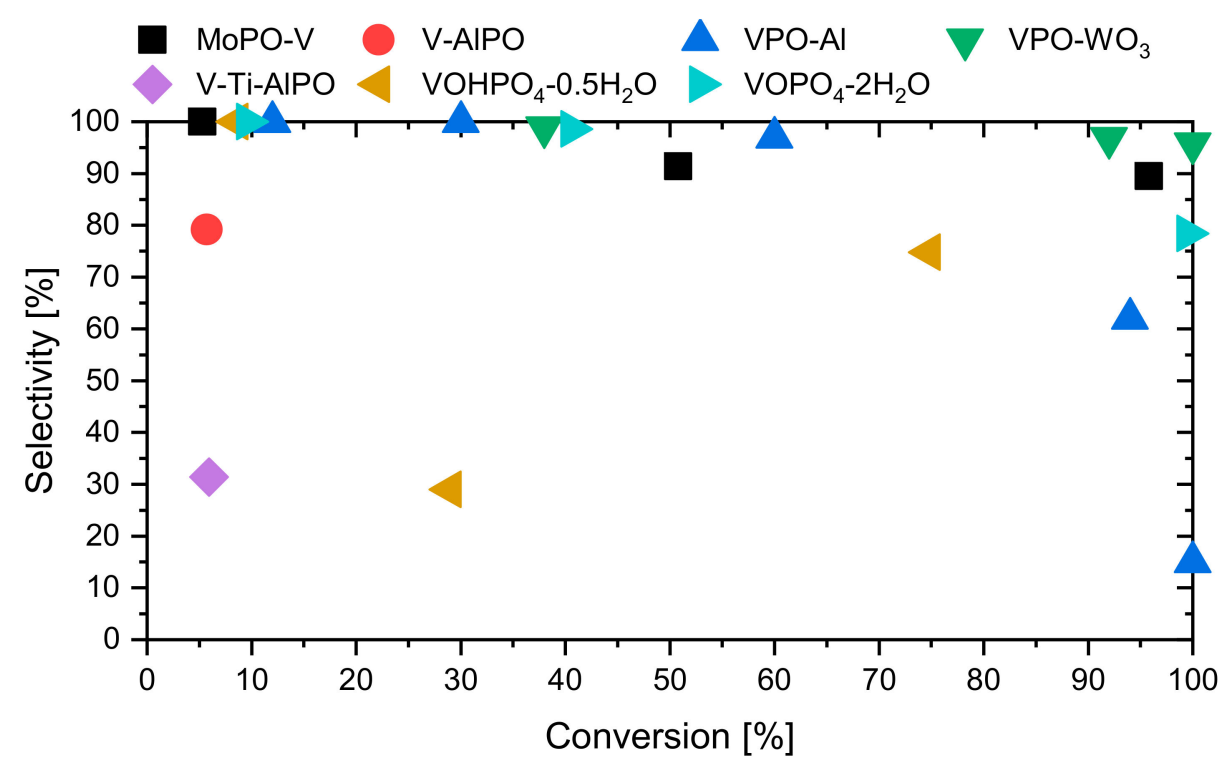

Figure 26. Summary of catalytic test results for vanadyl phosphate catalysts in the literature [157,163-165].

Vanadium mixed metal oxides and supported catalysts. In an investigation conducted by Klissurski and Pesheva [166], the temperature dependence of pure vanadia was investigated. The selectivity went from $100 \%$ at $250{ }^{\circ} \mathrm{C}$ to approximately $70 \%$ at $430{ }^{\circ} \mathrm{C}$ with 3.8 vol.\% MeOH in the feed $\left(\mathrm{O}_{2}\right.$ concentration not specified) [86].

Smith et al. [167] investigated vanadia supported on SBA-15 at temperatures of $300-400{ }^{\circ} \mathrm{C}$ with 4 vol. $\% \mathrm{MeOH}$ and 10 vol. $\% \mathrm{O}_{2}$ in the feed. The selectivity to FA was 
never higher than $75 \%$. It was reported that the surface roughness of SBA-15 represented by the surface fractal dimension $\left(D_{f}\right)$, calculated from the fractal-FHH equation (FrenkelHalsey-Hill equation for multilayer adsorption)[168] as a measure of the micro porosity, was important for the selectivity at $300{ }^{\circ} \mathrm{C}$, since the selectivity was $20 \%$ higher on rough surfaces than on smooth surfaces at the same conversion. The effect was observed to decrease at higher temperatures and conversions [167].

A study of a nanostructured $\mathrm{VO}_{x}$ /SBA-15 model catalyst was performed by Hess [169] with 3 vol. $\% \mathrm{MeOH}$ and $7 \mathrm{vol} . \% \mathrm{O}_{2}$ in the feed. At $350{ }^{\circ} \mathrm{C}$, a selectivity of $94 \%$ was achieved with $15.7 \%$ conversion. It was stated that FA and the byproducts of MF and DMM were formed over redox sites, while $\mathrm{DME}$ and $\mathrm{CO}_{x}$ were formed over acidic and basic sites, respectively [169]. This is in agreement with Figure 6.

An investigation of a V-MCM-41 catalyst (V incorporated in the crystal structure) with respect to the effect of pore diameter on the oxidation of $\mathrm{MeOH}$ to FA was performed by Yang et al. [170] with 3 vol.\% of both $\mathrm{MeOH}$ and $\mathrm{O}_{2}$ in the feed. The study was motivated by reports of highly porous materials with large surface areas having positive influences on selectivity and activity for other reactions as well as on apparent acidic strength. Selectivity increased from approximately $60 \%$ at a pore diameter of $1.9 \mathrm{~nm}$ to $99 \%$ at $20 \%$ conversion at $350{ }^{\circ} \mathrm{C}$ at the optimum pore diameter of approximately $2.5 \mathrm{~nm}$, which then decreased to below $85 \%$ selectivity at approximately $2.9 \mathrm{~nm}$ in pore diameter and $350{ }^{\circ} \mathrm{C}$ [170] (Figure 27).

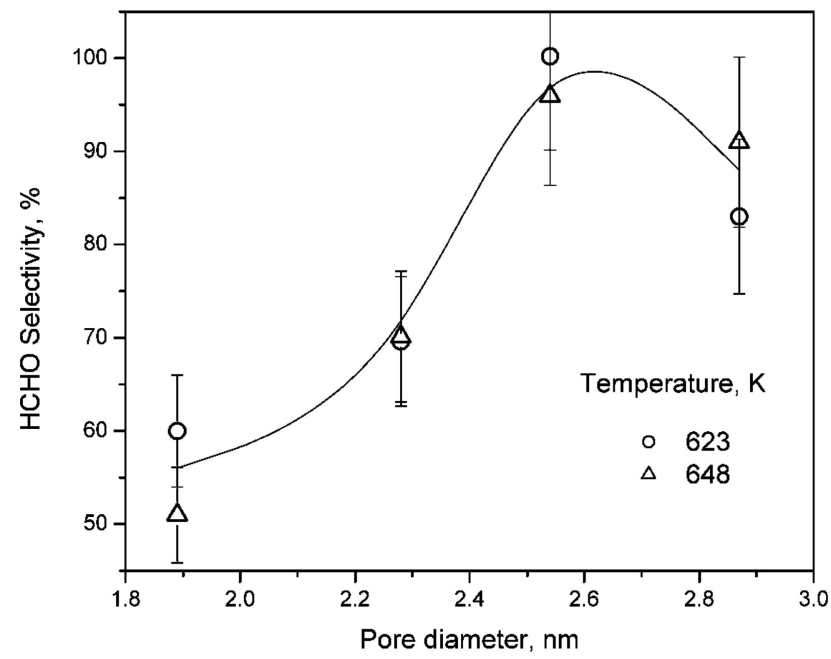

Figure 27. Selectivity of $\mathrm{MeOH}$ oxidation to FA as function of pore diameter in V-MCM-41 catalyst at $350{ }^{\circ} \mathrm{C}$ and $375{ }^{\circ} \mathrm{C}$ in a feed of 3 vol. $\% \mathrm{MeOH}$ and 3 vol. $\% \mathrm{O}_{2}$ in He. Reprinted from [170] Copyright (C) (2005), with permission from Elsevier.

Such high influence from such small changes in the pore radius seems unlikely and may well be from the changes in the other synthesis parameters needed to change the pore size [171].

Mechanistic studies of V oxide supported on MCM-48 was performed by Bronkema and Bell [172,173]. The oxidized $\mathrm{V}$ was in the form of isolated $\mathrm{VO}_{4}$ units (no evidence of $\mathrm{V}-\mathrm{O}-\mathrm{V}$ bonds was found). When adsorbing $\mathrm{MeOH}$ on the surface, $\mathrm{V}-\mathrm{OCH}_{3} / \mathrm{Si}-\mathrm{OH}$ or $\mathrm{V}-\mathrm{OH} / \mathrm{Si}-\mathrm{OCH}_{3}$ were formed in roughly equal amounts. FA was exclusively formed from the $\mathrm{V}-\mathrm{OCH}_{3}$ specie and was believed to happen by $\mathrm{H}$-abstraction. The $\mathrm{Si}-\mathrm{OCH}_{3}$ was found to contribute to the formation of $\mathrm{CO}$ and $\mathrm{CO}_{2}$, which was especially observed at higher temperatures [172,173].

Guido Busca [35] made a FT-IR study of adsorption of $\mathrm{MeOH}, \mathrm{FA}$, and $\mathrm{HCOOH}$ on $\mathrm{V}_{2} \mathrm{O}_{5}$ and $\mathrm{V}_{2} \mathrm{O}_{5} / \mathrm{SiO}_{2}$. MeOH adsorbed as methoxy groups and was oxidized to dioxymethylene, which desorbed at $177^{\circ} \mathrm{C}$ as dimethoxymethane. Dioxymethylene and polyoxymethylene species were observed to desorb near room temperature after adsorp- 
tion of FA, leaving a clean surface. The results show that dioxymethylene is a common product on adsorption. No formate groups were found from adsorbing $\mathrm{MeOH}$ nor FA [35]. Kortewille et al. [8] showed isolated $\mathrm{VO}_{4}$ species on $\mathrm{SiO}_{2}$ being able to convert methoxy species to FA by following C-H vibrational bands in DRIFTS under a TPD procedure [8].

A DFT study on $\mathrm{V}$ oxide supported on $\mathrm{SiO}_{2}$ by Döbler et al. [174] proposed the oxidation of $\mathrm{MeOH}$ to FA to occur through a two-step redox mechanism, dissociative adsorption of $\mathrm{MeOH}$ forming a methoxy group, and the rate-limiting $\mathrm{H}$ abstraction step from the methoxy group. They studied $\mathrm{O}=\mathrm{V}\left(\mathrm{OCH}_{3}\right)_{3},\left(\mathrm{O}=\mathrm{V}\left(\mathrm{OCH}_{3}\right)_{3}\right)_{2}$, and $\mathrm{O}=\mathrm{V}\left(\mathrm{OCH}_{3}\right)_{3}{ }^{\bullet+}$ as model molecules in addition to the $\mathrm{V}=\mathrm{Si}_{7} \mathrm{O}_{12} \mathrm{H}_{7}$ molecule, as the catalysts for the selective oxidation. A proposal of the support effect arising from the strength of adsorption was made as the energy barrier for the $\mathrm{H}$ abstraction was found to be very similar [174].

The influence of preparation $\mathrm{pH}$ and $\mathrm{V}$ surface species was evaluated by Trejda et al. [175] for $\mathrm{V}_{x} \mathrm{SiBeta}$ catalysts with $x=0.25-4.0 \mathrm{wt} \% \mathrm{~V}$ with $40 \mathrm{mg}$ of catalyst in a flow of $40 \mathrm{~mL} / \mathrm{min}$ consisting of $\mathrm{Ar} / \mathrm{O}_{2} / \mathrm{MeOH}=88 / 8 / 4 \mathrm{~mol} \%$ at $250{ }^{\circ} \mathrm{C}$. At low $\mathrm{V}$ loading and $\mathrm{pH}=2.5, \mathrm{~V}$ was incorporated into the Beta framework evidenced by $(\mathrm{SiO})_{2}(\mathrm{HO}) \mathrm{V}=\mathrm{O}$ vibrations in FT-IR increasing with increasing $\mathrm{V}$ content. For $\mathrm{pH}=6$, the incorporation only happened at higher loadings, and then only a fraction of the $\mathrm{V}$ was incorporated. The $\mathrm{MeOH}$ conversion was $5 \%$ and $2 \%$ before the incorporation of $\mathrm{V}$, respectively. This increased to $16 \%$ and $5 \%$ with $4.0 \mathrm{wt} \%$ $\mathrm{V}$, while DME selectivity decreased from 100 to $32 \%$ and $37 \%$, FA selectivity increased to $44 \%$ and $45 \%$ and total partial oxidation selectivity increased to $67 \%$ and $65 \%$, respectively [175] (not taking into account that DMM and MF are also reversible products from dehydration reactions). The pseudo-tetrahedral hydroxylated $(\mathrm{SiO})_{2}(\mathrm{HO}) \mathrm{V}=\mathrm{O}$ species were concluded to be responsible for the selectivity towards FA and the activity, acting as either redox or acidic and basic centers [175].

The redox dynamics of $V$ impregnated into 3D Ferrierite and 2D ITQ-6 siliceous supports with 1-10 $\mathrm{wt} \% \mathrm{~V}$ were investigated by Vieira et al. [176], who found that dispersion and stabilization of $\mathrm{V}$ oxides were improved by isolated silanol groups on the surface before impregnation. XRD, XAS, and DR-UV-Vis spectroscopy identified V to be highly dispersed at $1 \mathrm{wt} \%$ and $5 \mathrm{wt} \% \mathrm{~V}$ in Si-ITQ- 6 with monomeric and polymeric species or oxide clusters while $10 \mathrm{wt} \%$ in Si-ITQ-6 and Si-FER showed formation $\mathrm{V}_{2} \mathrm{O}_{5}$ clusters on the surface. EXAFS and XANES showed complete reduction of $\mathrm{V}^{5+}$ to $\mathrm{V}^{4+}$ and back by isothermal periods of non-oxidizing atmosphere followed by regeneration with $\mathrm{O}_{2}$. All $\mathrm{V}$ species were concluded to be active in the oxidation of $\mathrm{MeOH}$ albeit with different rates due to differences in the $\mathrm{V}^{5+} / \mathrm{V}^{4+}$ equilibrium under oxidant conditions as reoxidation was limited [176]. In a study by Zhang et al. [177] on co-electrospun $\mathrm{VtiO}_{x}$ hollow nanofibers, a yield of $90 \% \mathrm{MF}$ was reached at $150{ }^{\circ} \mathrm{C}$ and was attributed to a high surface content of $\mathrm{V}^{4+}[177]$.

A catalyst consisting of $10 \% \mathrm{~V}_{2} \mathrm{O}_{5}, 20 \% \mathrm{~K}_{2} \mathrm{SO}_{4}$, and $70 \% \mathrm{SiO}_{2}$ gel was chosen as an optimum composition for the vanadia-potassium sulfate system and subjected to $\mathrm{MeOH}$ oxidation at $330-410{ }^{\circ} \mathrm{C}$ (Figure 28a) by Agarwal et al. [178]. It showed 100\% selectivity below $340{ }^{\circ} \mathrm{C}$ and $55 \%$ conversion, which decreased to $\sim 85 \%$ at $410{ }^{\circ} \mathrm{C}$ and $95 \%$ conversion (Figure 28b). The improved selectivity from $\mathrm{K}_{2} \mathrm{SO}_{4}$ promotion was proposed to be a result of the weakening strength of the $\mathrm{V}=\mathrm{O}$ bond [178].

In the 1980s, investigations of MLs of $\mathrm{V}$ on support oxides picked up speed with the investigation by Roozeboom et al. [179] of a $\mathrm{ML} \mathrm{V}$ on $\gamma-\mathrm{Al}_{2} \mathrm{O}_{3}, \mathrm{CeO}_{2}, \mathrm{TiO}_{2}$, and $\mathrm{ZrO}_{2}$ as catalyst for $\mathrm{MeOH}$ oxidation at temperatures between 100 and $400{ }^{\circ} \mathrm{C}$ with 4 vol. $\% \mathrm{MeOH}$ in the feed. The order of selectivity was $\mathrm{V}_{2} \mathrm{O}_{5}>\mathrm{V}_{2} \mathrm{O}_{5} / \gamma-\mathrm{Al}_{2} \mathrm{O}_{3}>\mathrm{V}_{2} \mathrm{O}_{5} / \mathrm{TiO}_{2}>\mathrm{V}_{2} \mathrm{O}_{5} / \mathrm{CeO}_{2}$ $>\mathrm{V}_{2} \mathrm{O}_{5} / \mathrm{ZrO}_{2}$ at the temperatures, which gave $50 \%$ conversion with a fixed loading of $0.2 \mathrm{~g}$ catalyst and a feed flow of $40 \mathrm{NmL} / \mathrm{min}$. The order of the selectivities was the reverse of the reducibility of the catalysts, except for $\mathrm{V}_{2} \mathrm{O}_{5} / \mathrm{TiO}_{2}$ being more reducible than $\mathrm{V}_{2} \mathrm{O}_{5} / \mathrm{CeO}_{2}$. Basic oxides such as $\mathrm{ZrO}_{2}$ and $\mathrm{CeO}_{2}$ yielded $\mathrm{CO}_{2}$ already at $200-250{ }^{\circ} \mathrm{C}$ [179]. This is in accordance with Figure 6. 


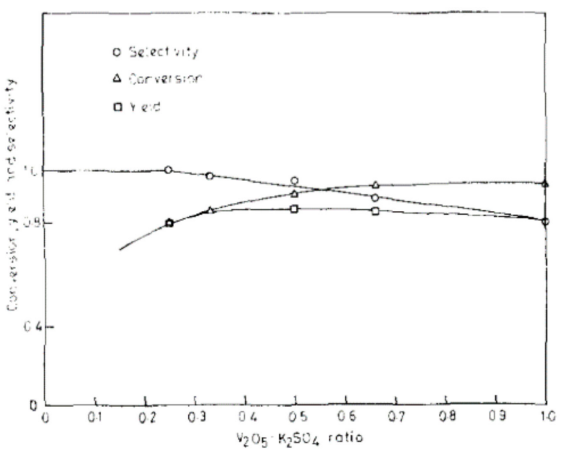

(a)

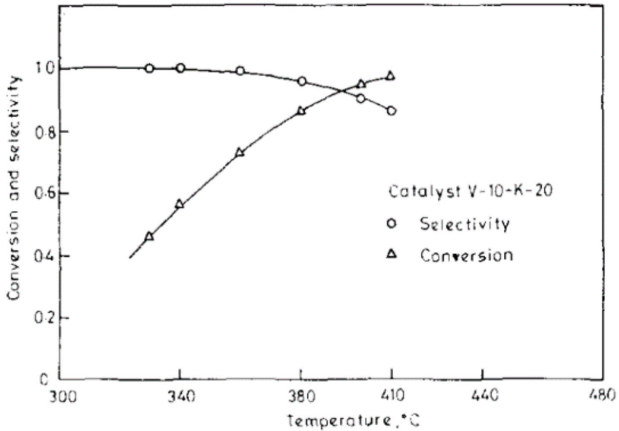

(b)

Figure 28. (a) Effect of catalyst composition on conversion, yield, and selectivity: $W / F=42.0 \mathrm{~g} \cdot \mathrm{h} / \mathrm{mol}$, $\mathrm{T}=410^{\circ} \mathrm{C}$, and $10 \mathrm{vol} . \% \mathrm{MeOH}$ in air. (b) Effect of temperature on conversion and selectivity for $W / F=41 \mathrm{~g} \cdot \mathrm{h} / \mathrm{mol}$ and $10 \mathrm{vol} . \% \mathrm{MeOH}$ in air. Reprinted from [178] Copyright (C) (1978), with permission from Elsevier.

The catalytic activity ranking of vanadia supported on oxides was investigated by Deo and Wachs [180] for $\mathrm{SiO}_{2}, \mathrm{ZrO}_{2}, \mathrm{TiO}_{2}, \mathrm{Nb}_{2} \mathrm{O}_{3}$, and $\mathrm{Al}_{2} \mathrm{O}_{3}$. At $230{ }^{\circ} \mathrm{C}$ and 6 vol.\% $\mathrm{MeOH}$ in the feed, the TOFs were ranked $\mathrm{SiO}_{2}<\mathrm{Al}_{2} \mathrm{O}_{3}<\mathrm{Nb}_{2} \mathrm{O}_{5}<\mathrm{TiO}_{2}<\mathrm{ZrO}_{2}$, while selectivity was ranked $\mathrm{Al}_{2} \mathrm{O}_{3}<\mathrm{SiO}_{2}<\mathrm{ZrO}_{2}<\mathrm{Nb}_{2} \mathrm{O}_{5}<\mathrm{TiO}_{2}$, where the by-products was mostly DME. Deo and Wachs [180] found the same tendency for reducibility as Roozeboom et al. [179], although the measured values differed significantly due to differences in conditions and setup. The pre-exponential factors were found to depend on the support [180]. Activity ranking was supported by Fievez et al. [181] and by later work in the Wachs group [100]. Kaichev at al. [182] investigated the catalytic properties for $\mathrm{V}$ oxide on $\mathrm{SiO}_{2}, \gamma-\mathrm{Al}_{2} \mathrm{O}_{3}$, $\mathrm{ZrO}_{2}$, and $\mathrm{TiO}_{2}$ at $100-250{ }^{\circ} \mathrm{C}$, where at low temperature and conversion, all samples had selectivities towards DMM $>80 \%$ and mostly MF at higher temperatures. Crystalline $\mathrm{V}_{2} \mathrm{O}_{5}$ species were formed on $\mathrm{SiO}_{2}$ and $\gamma-\mathrm{Al}_{2} \mathrm{O}_{3}$, which were less active than the monomeric $\mathrm{VO}_{x}$ species formed on $\mathrm{ZrO}_{2}$ and $\mathrm{TiO}_{2}$, which were less active than the polymeric $\left(\mathrm{VO}_{x}\right)_{n}$ species on $\mathrm{TiO}_{2}$ [182]. In another study, the $\mathrm{V}_{2} \mathrm{O}_{5}$ crystals were reported to be formed on $\mathrm{ZrO}_{2}$ regardless of $\mathrm{V}$ content, whereas $\mathrm{V}_{2} \mathrm{O}_{5}$ crystallites only formed above the amount for an ideal $\mathrm{ML}$ on $\mathrm{TiO}_{2}$ [183].

The origin of the support effect of metal oxides was investigated by Burcham and Wachs [184] regarding the TOF values on vanadia supported on $\mathrm{CeO}_{2}, \mathrm{ZrO}_{2}, \mathrm{TiO}_{2}$, and $\mathrm{Al}_{2} \mathrm{O}_{3}$. The surface steady-state concentration of methoxy exhibited the same tendency as the TOF values in a fixed bed reactor $\left(\mathrm{V}_{2} \mathrm{O}_{5} / \mathrm{CeO}_{2}>\mathrm{V}_{2} \mathrm{O}_{5} / \mathrm{ZrO}_{2}>\mathrm{V}_{2} \mathrm{O}_{5} / \mathrm{TiO}_{2}>\mathrm{V}_{2} \mathrm{O}_{5} / \mathrm{Al}_{2} \mathrm{O}_{3}\right)$, arising from changes in desorption and adsorption constants (Figure 29) [184].

This was further investigated by Burcham et al. [140]. However, in the presentation of the results, there was no distinction between $\mathrm{FA}$ and $\mathrm{CO}_{x}$, which renders the selectivities difficult to interpret. The ligand effect was concluded to come from the electronegativity of the support cation. The electropositive (basic) supports $\left(\mathrm{CeO}_{2}\right.$ and $\left.\mathrm{TiO}_{2}\right)$ always have higher TOFs than the electronegative (acidic) supports $\left(\mathrm{SiO}_{2}\right.$ and $\left.\mathrm{Al}_{2} \mathrm{O}_{3}\right)$ [140]. Kim and Wachs [185] prepared a series of supported $\mathrm{V}_{2} \mathrm{O}_{5}(1-27 \%)$ on $\mathrm{Al}_{2} \mathrm{O}_{3}$. They found that, above ML coverage, the activity decreased because crystalline $\mathrm{V}_{2} \mathrm{O}_{5}$ covered the active $\left[\mathrm{VO}_{4}\right]$ redox surface sites. They found no correlation between activity and surface acidity nor reducibility measured by $\mathrm{H}_{2}$-TPR. 


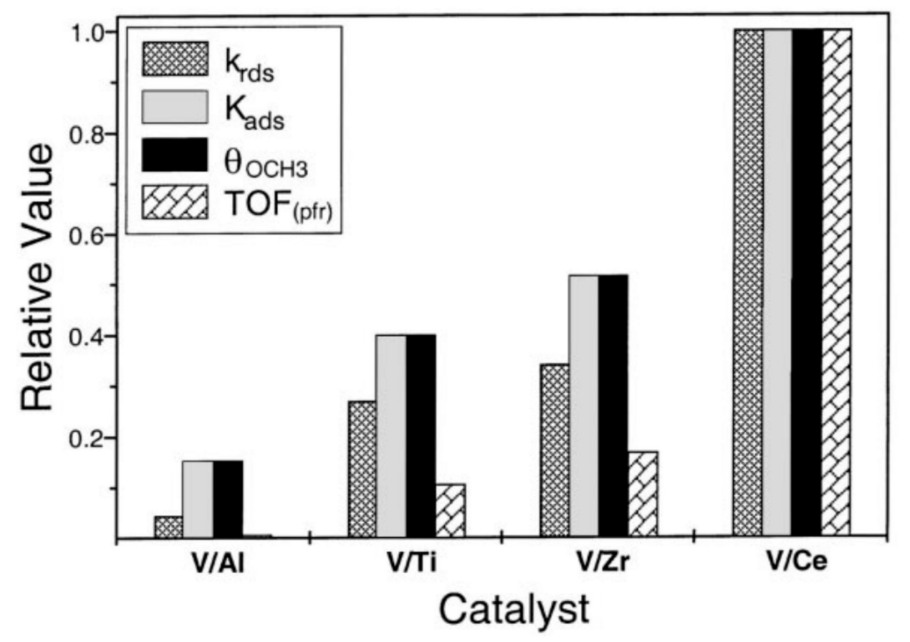

Figure 29. Relative changes in kinetic parameters, methoxy coverage, and TOF as function of support at $225^{\circ} \mathrm{C}$. Reprinted from [184] Copyright (C) (1999), with permission from Elsevier.

Khaliullin and Bell [186] investigated the oxidation of $\mathrm{MeOH}$ to FA by DFT calculations of $\mathrm{VO}_{4}$ isolated surface units on $\mathrm{SiO}_{2}, \mathrm{ZrO}_{2}$, and $\mathrm{TiO}_{2}$ by using the $\mathrm{B} 3 \mathrm{LYP} / 6-31 \mathrm{G}^{*}$ functional, finding good geometric agreement with experimental investigations. However, they found $E_{a}$ of $\mathrm{MeOH}$ oxidation to FA to be independent of the support and higher than the experimental values. It was proposed that the methoxy group broke the V-O-M bond upon adsorption and that the abstraction of $\mathrm{H}$ from the methoxy group adsorbed to $\mathrm{V}=\mathrm{O}$ could be by transfer of $\mathrm{H}$ to an adjacent $\mathrm{VO}_{4}$ unit or dimer unit $\left(\mathrm{V}_{2} \mathrm{O}_{7}\right)$ [186]. The dimer units have been reported on $\mathrm{TiO}_{2}$ and $\mathrm{ZrO}_{2}$ but not on $\mathrm{SiO}_{2}$ [182]. This would explain why the theoretical investigation could not reproduce the difference in rate observed by experiments [186]. This conclusion/proposal was questioned by Zhanpeisov [187] as he strongly disagreed with $\mathrm{Zr}$ and Ti having tetrahedral $\mathrm{VO}_{4}$ surface units but octahedral instead. He stated that breaking of the V-O-M bond was not necessary and that with proper use of the cluster models (tetrahedral vs. octahedral), the difference in TOF was readily described with the B3LYP /6-31G* functionals without the need of adjacent $\mathrm{VO}_{4}$ units or dimers [187].

The industrial $\mathrm{V}_{2} \mathrm{O}_{5}-\mathrm{TiO}_{2}$ catalyst for oxidation of o-xylene was tested for $\mathrm{MeOH}$ oxidation by Makedonski et al. [188] with $3.5 \mathrm{vol} . \% \mathrm{MeOH}$ in the feed and a conversion of $20 \%$. The catalysts were found to have high selectivity to FA at low temperatures of 200-330 ${ }^{\circ} \mathrm{C}$, but selectivity decreased with increasing temperature [188].

A mechanistic study of isolated vanadate sites supported on high surface area anatase utilizing temperature programmed experiments, IR, Raman, and XANES performed by Bronkema et al. [173] showed $\mathrm{V}$ to be in $\mathrm{VO}_{4}$ units after calcination. At $50{ }^{\circ} \mathrm{C}, \mathrm{MeOH}$

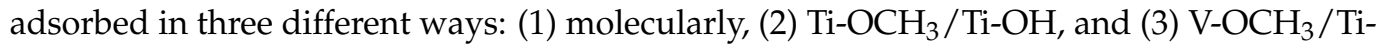
$\mathrm{OH}$. Upon heating, $\mathrm{TiO}_{2}$ produced small amounts of $\mathrm{FA}$; however, small additions of $\mathrm{V}$ greatly improved the rate of FA formation. It was believed to stem from reverse spillover of methoxy species from Ti to V. $E_{a, a p p}$ was found to be at $67 \mathrm{~kJ} / \mathrm{mol}$. Most of the difference in activity for $\mathrm{V}$ on $\mathrm{SiO}_{2}$ and $\mathrm{TiO}_{2}$ comes from the difference in $E_{a}(96 \mathrm{~kJ} / \mathrm{mol}$ when supported on $\mathrm{SiO}_{2}$ ) [173]. Similar adsorption species were found when $\mathrm{ZrO}_{2}$ was used as support with an $E_{a}$ of $75 \mathrm{~kJ} / \mathrm{mol}$ [189].

A theoretical investigation of isolated vanadate species on $\mathrm{TiO}_{2}$ was conducted by Goodrow and Bell [190] in order to understand why $\mathrm{VO}_{x} / \mathrm{TiO}_{2}$ was three orders of magnitude more active than $\mathrm{VO}_{x} / \mathrm{SiO}_{2}$. The difference did not arise from intrinsic electronic effects on the active site of the support but from the difference in O-vacancy formation next to the active site where the concentration is larger for $\mathrm{TiO}_{2}$ but $\mathrm{Ti}^{4+}$ also becomes $\mathrm{Ti}^{3+}$ and increases lattice Ti-Ti distance, where the lattice distance becomes smaller in $\mathrm{SiO}_{2}$. The calculations showed $E_{a}$ to proceed from 95.4 to $66.5 \mathrm{~kJ} / \mathrm{mol}$ when introducing an $\mathrm{O}$-vacancy in $\mathrm{TiO}_{2}$ next to a vanadate site. A correlation between TOF per $\mathrm{V}$ atom and the 
O-vacancy formation energy was also presented with experimental data from other work (Figure 30) [190].

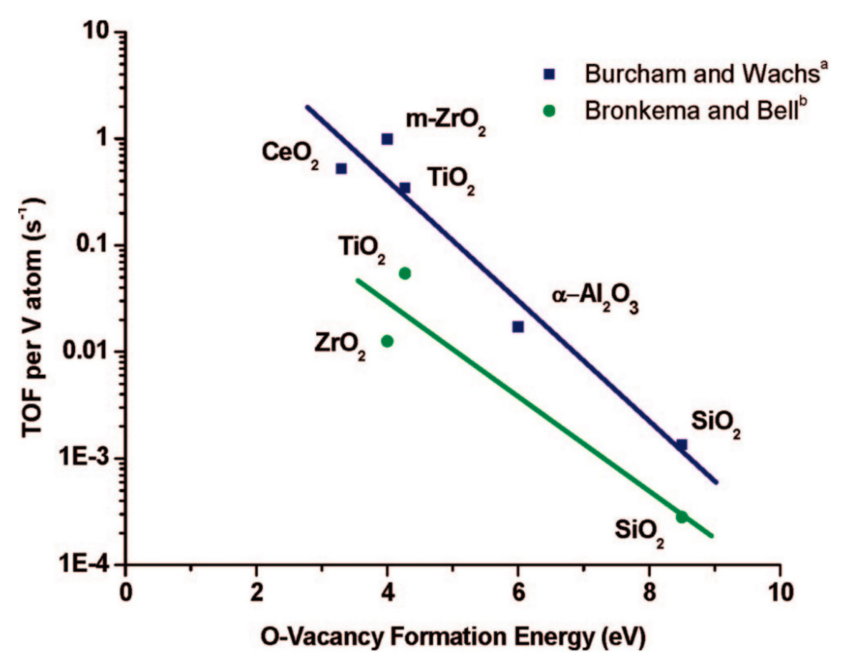

Figure 30. TOF per $\mathrm{V}$ atom for $\mathrm{MeOH}$ oxidation as function of the O-vacancy formation energy. a $[184] ;{ }^{b}[172,173,189]$. Reprinted from [190] Copyright (C (2008) American Chemical Society.

The reaction mechanism and kinetics of $\mathrm{MeOH}$ oxidation to FA of vanadia supported on $\mathrm{TiO}_{2}$ have been investigated by González-Navarrete et al. [191] by utilizing DFT calculations using the B3LYP functional. The most stable intermediate was methoxy on tetrahedral $\mathrm{VO}_{4}$, with the rate-limiting step being the abstraction of $\mathrm{H}$ from methoxy. $E_{a}$ was $100 \mathrm{~kJ} / \mathrm{mol}[191]$.

In a study by Busca et al. [192] on $\mathrm{V}_{2} \mathrm{O}_{5} / \mathrm{TiO}_{2}$, the selectivity towards FA decreased drastically with increased temperature with an observed increase in selectivity towards MF first and $\mathrm{CO}$ later and $\mathrm{CO}_{2}$ already at $200{ }^{\circ} \mathrm{C}$ with a ratio of 0.9 between $\mathrm{CH}_{3} \mathrm{OH}$ and $\mathrm{O}_{2}$ [192].

The difference between isolated V, Mo, and $\mathrm{Cr}$ clusters supported on rutile $\mathrm{TiO}_{2}(110)$ was investigated by Kim et al. [193] by utilizing DFT calculations. By analyzing three different dehydration paths, the schemes were exoergic for the $\mathrm{VO}_{3}$ cluster, while they were endoergic for $\mathrm{MoO}_{3} \cdot \mathrm{CrO}_{3}$ had one exoergic scheme and two endoergic schemes. The supported $\mathrm{VO}_{3}$ cluster was concluded to be the better catalyst in terms of activity by far from having a much lower $E_{a}$ than $\mathrm{MoO}_{3}$ and $\mathrm{CrO}_{3}$ [193].

The role of $\mathrm{CeO}_{2}$ in the oxidative dehydrogenation of $\mathrm{MeOH}$ on supported vanadia catalysts was investigated by Ganduglia-Pirovano et al. [194] by using $\mathrm{VO}_{x} / \mathrm{CeO}_{2}(111)$ model catalysts. TPD measurements showed product desorption at much lower temperatures than for pure $\mathrm{CeO}_{2}$ or vanadia supported on $\mathrm{SiO}_{2}$. Calculations using DFT also predicted increased reactivity of the vanadia $/ \mathrm{CeO}_{2}$ from the hydrogenation and oxygen vacancy energies. The support effect was concluded to stem from $\mathrm{CeO}_{2}$ stabilizing reduced states [194]. Oxidative dehydrogenation of $\mathrm{MeOH}$ on $\mathrm{CeO}_{2}$ supported vanadia oligomers was investigated by using simulations by Kropp et al. [195] after an initial investigation on monomeric vanadia species [196]. The trimeric $\mathrm{VO}_{x}$ specie $\mathrm{V}_{3} \mathrm{O}_{6}$ was the most thermodynamically stable species under slightly reducing conditions. The trimers were stated to bind $\mathrm{MeOH}$ less strongly than the monomers $\left(\mathrm{VO}_{2}\right.$ in $\mathrm{VO}_{4}$ geometry with the surface $\mathrm{O}^{\prime} \mathrm{s}$ in $\mathrm{CeO}_{2}$ ). This seemed to be only partly true from the trimers showing FA desorption at $227^{\circ} \mathrm{C}$, while the monomer showed desorption at $97^{\circ} \mathrm{C}$ and $257^{\circ} \mathrm{C}$. The intrinsic barriers for $\mathrm{MeOH}$ oxidation were stated to be similar for $\mathrm{V}_{3} \mathrm{O}_{6}$ and $\mathrm{CeO}_{2}$ (111), but they have pre-exponential factors differing by two orders of magnitude, making the $\mathrm{V}$ trimer more active [195].

A TPD study of $\mathrm{CeO}_{2}$ supported V oxide was conducted by Feng and Vohs [197]. The primary desorption species of adsorbed $\mathrm{MeOH}$ on $\mathrm{CeO}_{2}$ were $\mathrm{MeOH}$ and $\mathrm{CO}$. Small 
amounts of $\mathrm{FA}$ and $\mathrm{H}_{2} \mathrm{O}$ were observed. For vanadia on $\mathrm{CeO}_{2}$, the primary desorption product (when excluding $\mathrm{MeOH}$ ) was FA. However, significant amounts of $\mathrm{CO}$ and $\mathrm{CO}_{2}$ were also observed. Three different FA peaks were observed during the TPD, $252{ }^{\circ} \mathrm{C}$, $277^{\circ} \mathrm{C}$, and $337^{\circ} \mathrm{C}$. They were attributed to $\mathrm{V}^{5+}, \mathrm{V}^{4+}$, and $\mathrm{V}^{3+}$, respectively. Calorimetry measurements showed no difference in the heat of adsorption between the oxidation states, and the lower oxidation states were concluded to destabilize the transition state of the $\mathrm{H}$-abstraction reaction, thus producing a higher $E_{a}$ and lower reaction rate [197].

The structure and activity of $\mathrm{VO}_{x} / \mathrm{SiO}_{2}$ and $\mathrm{VO}_{x} / \mathrm{CeO}_{2} / \mathrm{SiO}_{2}$ catalysts were investigated by Vining et al. [198]. TOF was nearly two orders of magnitude larger for $\mathrm{VO}_{x} / \mathrm{CeO}_{2} / \mathrm{SiO}_{2}$ compared to $\mathrm{VO}_{x} / \mathrm{SiO}_{2}$ at $270{ }^{\circ} \mathrm{C}$. In both cases, the vanadia existed as pseudo-tetrahedral vanadate species bonded to either $\mathrm{SiO}_{2}$ or $\mathrm{CeO}_{2}$. The increase in activity was explained by a decrease in activation energy of the rate determining step of $\mathrm{H}$-abstraction from methoxy bound to a V-O-Ce site compared to V-O-Si site [198].

An investigation by Zhang et al. [199] examined utilizing $\mathrm{SiO}_{2}$ supported $\mathrm{Sb}-\mathrm{V}$ mixed oxide catalysts for $\mathrm{MeOH}$ conversion to FA. For a feed containing $1 \mathrm{vol} . \% \mathrm{MeOH}$, a one-pass yield of $91 \%$ was achieved on a $\mathrm{VSbO}_{x} / \mathrm{SiO}_{2}$ catalyst at $425^{\circ} \mathrm{C}$. The mixed oxide catalyst had increasing selectivity to FA (due to increasing conversion of reversible by-products and no significant increase in overoxidation) with increasing temperature, whereas the selectivity decreased with increasing temperature if there was no Sb (Figure 31).
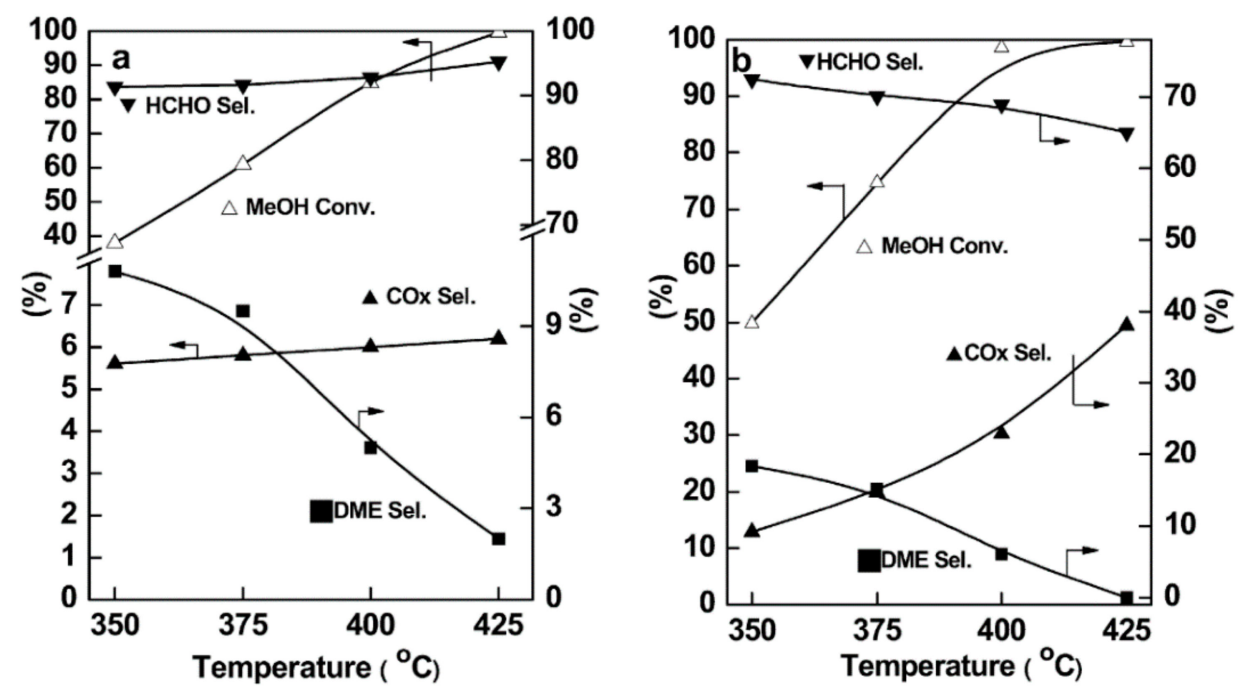

Figure 31. Catalytic conversion and selectivity of (a) $5.3 \mathrm{wt} \% \mathrm{~V}_{2} \mathrm{O}_{5-} 19.5 \mathrm{wt} \% \mathrm{Sb}_{2} \mathrm{O}_{5} / \mathrm{SiO}_{2}$ and (b) $5.4 \mathrm{wt} \% \mathrm{~V}_{2} \mathrm{O}_{5} / \mathrm{SiO}_{2}$ catalysts as function of temperature. Reprinted from [199] Copyright (C) (2008), with permission from Elsevier.

The active phase of the mixed oxide catalyst was found to be monomeric $\mathrm{VO}_{x}$ species stabilized in the mixed oxide phase. The oxidation state of $\mathrm{V}$ could be influenced by the $\mathrm{Sb} / \mathrm{V}$ ratio between the +5 and +4 state, where +5 was most active but +4 was most selective towards FA [199]. Guerrero-Pérez et al. [200] found that antimonates promoted the surface redox sites of $\mathrm{V}$ oxides. In our investigations of a $\mathrm{V}$ oxide supported on $\mathrm{Sb}$ oxide, a selectivity of $98.9 \%$ at $22.6 \%$ conversion at $400{ }^{\circ} \mathrm{C}$ was achieved (see Supplementary Materials, Section 2.2.2, Figure S8, and Table S8); thus, the selectivity was good, but the activity was too low compared to the industrial FeMo catalyst (selectivity of $98 \%$ at $97 \%$ conversion).

An investigation of the oxidative dehydrogenation of $\mathrm{MeOH}$ on a $\mathrm{V}-\mathrm{Mg}-\mathrm{O}$ catalysts was conducted by Isaguliants and Belomestnykh [201]. A $12 \mathrm{wt} \% \mathrm{~V}_{2} \mathrm{O}_{5}$ catalyst calcined at $550{ }^{\circ} \mathrm{C}$ had above $97 \%$ selectivity in the range of $250-450{ }^{\circ} \mathrm{C}$ with a conversion of $95 \%$ at $450{ }^{\circ} \mathrm{C}$ with $17 \mathrm{vol} . \% \mathrm{MeOH}$ in air in the feed. The catalyst contained pyrovanadate species, with $\mathrm{V}^{5+}$ and $\mathrm{V}^{4+}$ ions in octahedral and tetrahedral coordination. Over $60 \mathrm{~h}$, the average 
FA yield and selectivity were $91 \%$ and $97 \%$, respectively, with no visible change in activity (Figure 32) [201]. However, it is difficult to observe any deactivation when the conversion is very high in the stability test.

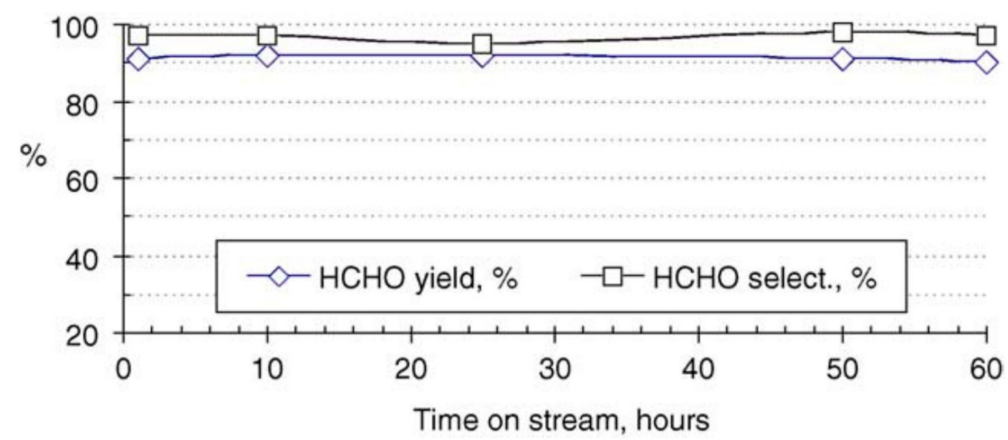

Figure 32. Oxidative dehydrogenation of $\mathrm{MeOH}$ over $\mathrm{V}-\mathrm{Mg}-\mathrm{O}$ catalyst at $420{ }^{\circ} \mathrm{C}, \mathrm{LHSV}$ of $1.5 \mathrm{~h}^{-1}$, and $\mathrm{CH}_{3} \mathrm{OH} / \mathrm{O}_{2}$ of $1 / 1$. Reprinted from [201] Copyright $@(2005)$, with permission from Elsevier.

Whether $\mathrm{MgO}$ may turn into $\mathrm{MgCO}_{3}$ over time would have to be tested since experience has showed this carbonate to be rather stable [202]. The Topsøe group [131] has investigated $\mathrm{V}_{2} \mathrm{O}_{5} / \mathrm{TiO}_{2}$ and $\mathrm{V}_{2} \mathrm{O}_{5} / \mathrm{MgO}$. Both catalysts were found to have high selectivity relative to $\mathrm{FA}$ until a certain temperature at which the non-selective oxidation to $\mathrm{CO}$ and $\mathrm{CO}_{2}$ dominated, and the total consumption of $\mathrm{MeOH}$ was reached [131].

Experiments on vanadia supported on phosphate modified $\gamma-\mathrm{Al}_{2} \mathrm{O}_{3}$ was conducted by Lakshmi et al. [203] at $175^{\circ} \mathrm{C}$ with 4 vol. \% MeOH in the feed. The highest conversion was $30.5 \%$, and the total selectivity towards FA and DME was approximately $98 \%$ for the investigated catalyst loadings, with increasing conversion and selectivity to FA (decreasing towards DME) with higher vanadia loadings; thus, FA selectivity was $83.5 \%$ with $20 \mathrm{wt} \%$ vanadia [203].

In the $1980 \mathrm{~s}$, a $\mathrm{V}_{2} \mathrm{O}_{5}-\mathrm{MoO}_{3}-\mathrm{TeO}_{2}$ catalyst was investigated by Bliznakov et al. [204] at $390-400{ }^{\circ} \mathrm{C}$ with $3.5 \mathrm{vol} . \% \mathrm{MeOH}$ in the feed gas. When the catalyst loading of $\mathrm{TeO}_{2}$ was $5-15 \mathrm{wt} \%$, the reported selectivity was $100 \%$ relative to FA but only $94 \%$ with no $\mathrm{TeO}_{2}$. The distribution of $\mathrm{V}^{5+}$ vs. $\mathrm{V}^{4+}$ was measured ex situ. In all samples, more than $80 \%$ of the samples were in the $5+$ state. Mo was present as $\mathrm{Mo}^{6+}$ in the samples, and Te was present as $\mathrm{Te}^{4+}$ at the surface [204]. Pesheva et al. [205] also investigated the mixed vanadia and molybdena supported on montmorillonite and compared to vanadia on montmorillonite. The Mo containing sample had higher selectivity but lower activity in the temperature range of $300-475^{\circ} \mathrm{C}$.

Arora et al. [125] investigated various Bi containing metal-oxide catalysts for $\mathrm{MeOH}$ oxidation in 6 vol. $\% \mathrm{MeOH}$ and 11 vol. $\% \mathrm{O}_{2}$ at $280{ }^{\circ} \mathrm{C}$ and less than $10 \%$ conversion. For $\mathrm{V}_{2} \mathrm{O}_{5} / \mathrm{Bi}_{2} \mathrm{O}_{3}$, a FA selectivity of $83.5 \%$ was achieved after calcination at $500{ }^{\circ} \mathrm{C}$.

A mechanistic study of $\mathrm{MeOH}$ partial oxidation on $\mathrm{V}_{2} \mathrm{O}_{5}(001) / \mathrm{Au}(111)$ was conducted by Sturm et al. [206]. By STM, MeOH was found to form methoxy groups over the vanadyl oxygen vacancies and produce $\mathrm{FA}$ in the temperature range of $127-277^{\circ} \mathrm{C}$ under temperature-programmed desorption, whereas $\mathrm{MeOH}$ only adsorbed molecularly on non-reduced surfaces; thus, no FA was formed [206].

The reactivity of $\mathrm{V}$ oxide supported on Sn oxide was investigated by Reddy [207] at $175{ }^{\circ} \mathrm{C}$, with 4 vol. $\% \mathrm{MeOH}$ in the feed. With $4.3 \% \mathrm{~V}_{2} \mathrm{O}_{5}$ in the catalyst, selectivities of $97.6 \%$ and $2 \%$ towards FA and DME were achieved [207], which were quite good but also far from industrial reaction conditions.

The catalytic activity of V-Sn oxide catalysts was studied by Wang et al. [208] in $2.1 \mathrm{vol} . \% \mathrm{MeOH}$. The selectivity was found to be best at low temperatures and conversions and higher V loadings (Figure 33a). XPS showed that the $\mathrm{V}^{5+}$ fraction increased with increased loading; thus, a correlation between selectivity, conversion, and V oxidation state 
was found, which indicated $\mathrm{V}^{5+}$ to facilitate the chemisorption and partial oxidation of $\mathrm{MeOH}$ to FA Figure 33b).

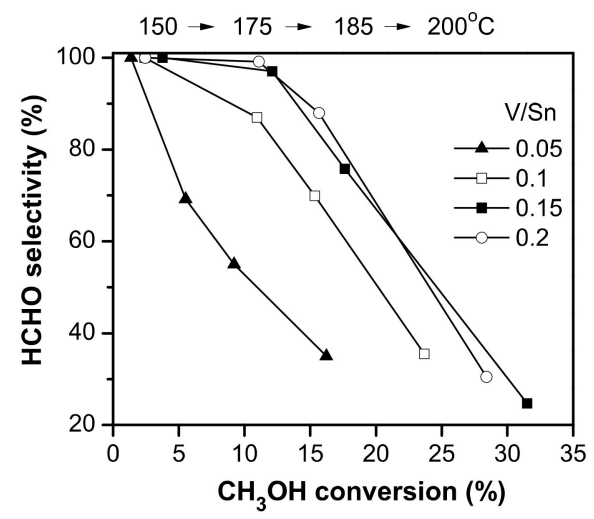

(a)

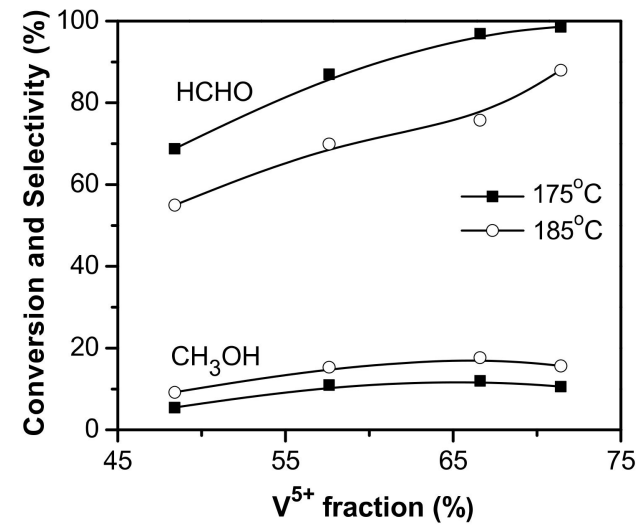

(b)

Figure 33. (a) V-Sn catalyst activity and selectivity for $\mathrm{MeOH}$ oxidation to FA at temperatures 150-200 ${ }^{\circ} \mathrm{C}$ [208]. (b) MeOH conversion and selectivity towards $\mathrm{CH}_{2} \mathrm{O}$ as function of $\mathrm{V}^{5+}$ fraction measured by XPS at the reaction temperatures $175{ }^{\circ} \mathrm{C}$ and $185^{\circ} \mathrm{C}$. Reprinted with permission from [208] (C) 2011 The American Ceramic Society.

Three $\mathrm{wt} \%$ and five $\mathrm{wt} \% \mathrm{~V}_{2} \mathrm{O}_{5} / \mathrm{HAP}$ were investigated by our group (see Supplementary Materials, Section 2.2.2, Tables S8 and S9, and Figures S8 and S9) and were found to be highly active with a selectivity of $94 \%$ at $77 \%$ conversion at $300{ }^{\circ} \mathrm{C}$ for the $5 \mathrm{wt} \%$ sample. The selectivity towards $\mathrm{CO}$ and $\mathrm{CO}_{2}$, however, increased drastically when proceeding close to full conversion. Similarly, it was found for $1 \mathrm{wt} \% \mathrm{~V}_{2} \mathrm{O}_{5} / \alpha-\mathrm{Al}_{2} \mathrm{O}_{3}$ (see Supplementary Materials, Section 2.2.2, Tables S8 and S9, and Figures S8 and S9).

The results reported in the literature for vanadium oxide catalysts are summarized in Figure 34 as formaldehyde selectivity vs. conversion (when possible). From Figure 34, the danger with selectivities at full conversion is also exemplified, as there was more than $15 \%$ variation in the reported selectivity of $\mathrm{V}_{2} \mathrm{O}_{5} / \mathrm{ZrO}_{2}$.

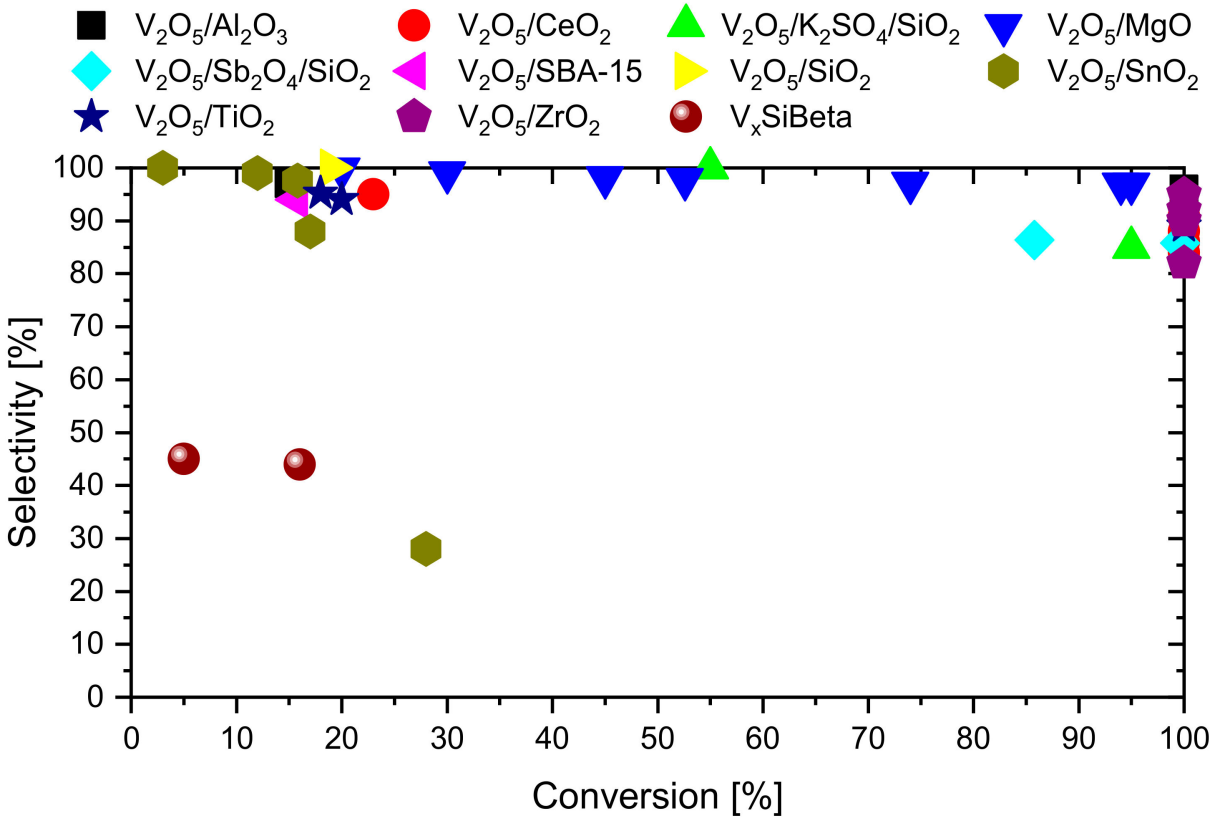

Figure 34. Summary of catalytic test results for V oxide catalysts in the literature shown as selectivity vs. conversion $[125,140,166,169,179,180,188,199,201,203,204,207,208]$. 
A general trend observed is the high activity of catalysts with a reducible support, e.g., $\mathrm{SnO}_{2}$ and $\mathrm{CeO}_{2}[184,208]$, which, however, also had a tendency to over oxidize the $\mathrm{MeOH}$ to $\mathrm{CO} / \mathrm{CO}_{2}$ at higher temperatures and result in conversions producing lower formaldehyde selectivities (Figure 34) [208]. Moreover, catalysts with basic supports such as $\mathrm{ZrO}_{2}, \mathrm{TiO}_{2}$, and $\mathrm{Bi}$ oxides had, in general, high activity and good selectivity if the temperatures were low (points in Figure 34) $[100,125,131]$; however, at industrially relevant temperatures, they catalyzed full oxidation to $\mathrm{CO}$ and $\mathrm{CO}_{2}[125,131]$. Vanadia supported on the more acidic $\mathrm{Al}_{2} \mathrm{O}_{3}$ and $\mathrm{SiO}_{2}$ supports had higher selectivity towards dehydration products $[100,199,203]$ and were generally less active than the basic and reducible supports $[100,179,184]$.

Many supported/mixed vanadium oxides have been investigated; however, most of them seem to have too low selectivity at the temperatures observed in the hot-spot under the industrial process $\left(350^{\circ} \mathrm{C}\right.$ to $\left.400^{\circ} \mathrm{C}\right)$ and are, thus, of limited interest. The most promising candidate reported was the $\mathrm{V}_{2} \mathrm{O}_{5} / \mathrm{MgO}$ catalyst, which has been reported to have $97 \%$ selectivity also at high temperatures and conversion ( 95\%), although Topsøe [131] reported it to catalyze the total oxidation to $\mathrm{CO}$ and $\mathrm{CO}_{2}$ in agreement with $\mathrm{MgO}$ being basic. In any case, a stability test sufficiently far from full conversion would be needed to assess applicability.

Bulk vanadates and spinel-type catalysts. $\mathrm{Ni}, \mathrm{Fe}$, and $\mathrm{Co}$ vanadates were investigated in the 1970s with $\mathrm{V} /(\mathrm{V}+\mathrm{Me})$ ratios from 0 to 1 by Malinski et al. [209] (Figure 35) with an optimum at $\mathrm{V} /(\mathrm{V}+\mathrm{Me})=0.5$ in conversion and $\mathrm{V} /(\mathrm{V}+\mathrm{Me})=0.5-0.95$ for selectivity.

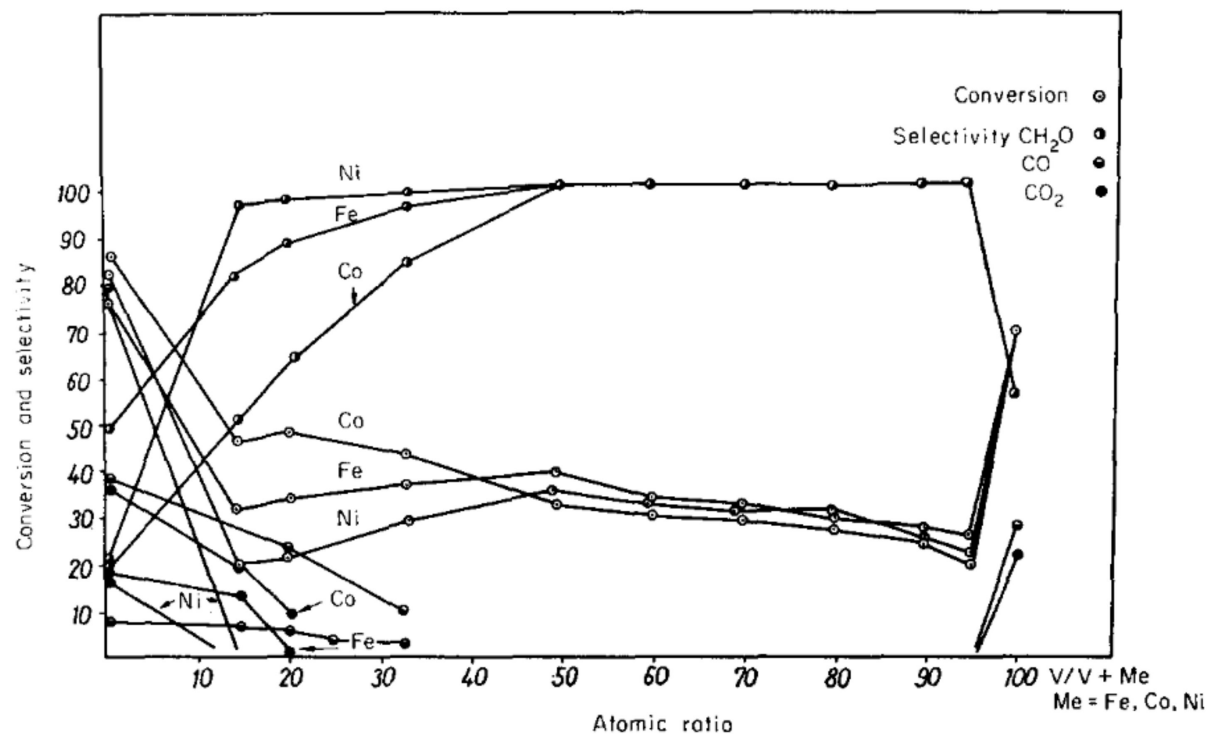

Figure 35. Effect of $\mathrm{V}$ to $\mathrm{Fe}, \mathrm{Co}$, and $\mathrm{Ni}$ ratio in vanadate catalysts after $1 \mathrm{~h}$ at a reaction temperature of $310^{\circ} \mathrm{C}, \mathrm{W} / \mathrm{F}=3.78 \mathrm{~g} \cdot \mathrm{h} / \mathrm{mol}, 44 \mathrm{vol} . \% \mathrm{MeOH}$, and mole ratio $\mathrm{MeOH} / \mathrm{O}_{2}=2.2$ [209]. Reproduced from [209] Copyright 1976, with permission from Elsevier.

Pure $\mathrm{V}_{2} \mathrm{O}_{5}, \mathrm{Fe}_{2} \mathrm{O}_{3}, \mathrm{NiO}$, and $\mathrm{Co}_{3} \mathrm{O}_{4}$ all had higher activity and lower selectivity than the mixed oxides. The nickel vanadate was the most selective of the three vanadates reaching close to $100 \%$ selectivity already with $\mathrm{V} / \mathrm{Ni}=0.3$. The three vanadates were also investigated by a $\mathrm{MeOH}$ pulsing experiment with no $\mathrm{O}_{2}$ (Figure 36). The selectivity relative to $\mathrm{FA}$ over the $\mathrm{Ni}$ and $\mathrm{Co}$ vanadate decreased monotonically with number of pulses (Co much faster than $\mathrm{Ni}$ ), whereas $\mathrm{FeVO}_{4}$ had constant selectivity but interestingly had a much higher formation of $\mathrm{H}_{2}$, which for the $\mathrm{NiVO}_{4}$ was very low and was increasing drastically for $\mathrm{CoVO}_{4}$ with the number of pulses. In addition, the $\mathrm{V}=\mathrm{O}$ bond disappeared in the cobalt vanadate but remained in the $\mathrm{Ni}$ and $\mathrm{Fe}$ vanadate [209]. The disappearance of the $\mathrm{V}=\mathrm{O}$ bond in $\mathrm{CoVO}_{4}$, thus, seems linked to increasing hydrogen formation. 


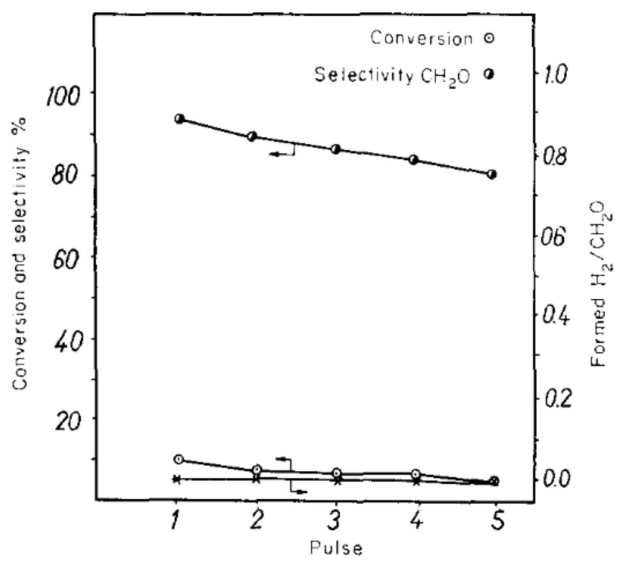

(a)

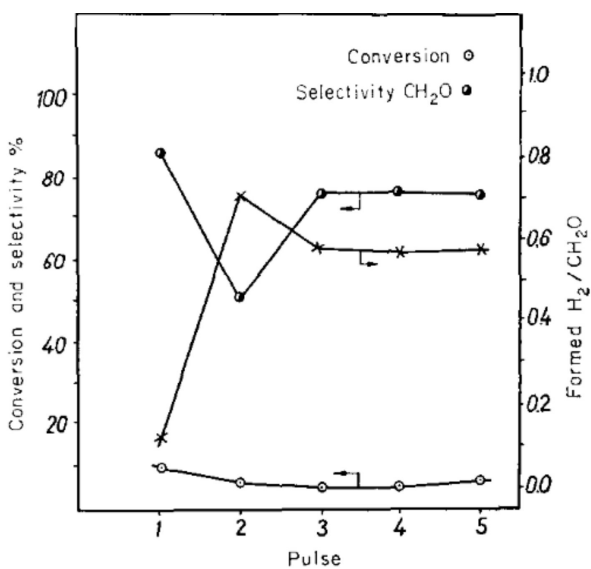

(b)

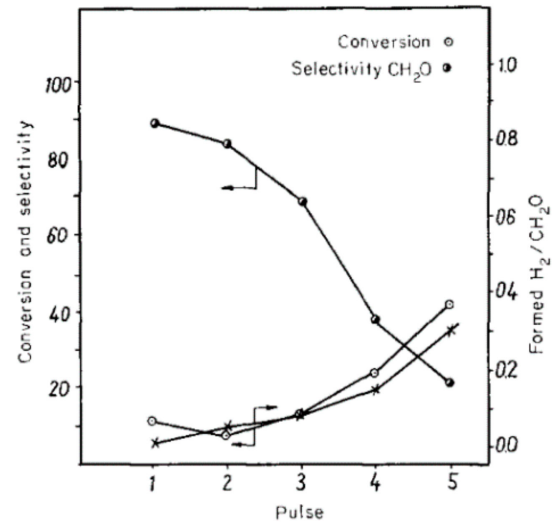

(c)

Figure 36. Overall conversion and selectivity in pulse reactions without $\mathrm{O}_{2}$ at $340{ }^{\circ} \mathrm{C}$ for $(\mathbf{a}) \mathrm{V} / \mathrm{Ni}=1,(\mathbf{b}) \mathrm{V} / \mathrm{Fe}=1$, and (c) V/Co = 1 [209]. Reproduced from [209] Copyright 1976, with permission from Elsevier.

The $\mathrm{NiVO}_{4}$ system was further investigated as supported catalysts [210], which gave higher activity per surface area but lower selectivity. Furthermore, the $\mathrm{V}=\mathrm{O}$ bond of the $\mathrm{NiVO}_{4}$ was reported to be weaker than for $\mathrm{V}_{2} \mathrm{O}_{5}$ and was given as an explanation for the increased selectivity of this phase [210].

The functionality of hexagonal orthovanadates $\left(\mathrm{Sr}_{3-x} \mathrm{La}_{2 x / 3}\left(\mathrm{VO}_{4}\right)_{2}, x=0.3-1.5\right)$ as catalysts for the oxidation of $\mathrm{MeOH}$ to FA was tested by Salagre and Sueiras [211] at $300{ }^{\circ} \mathrm{C}$ with 10 vol. $\% \mathrm{MeOH}$ and 15 vol. $\mathrm{O}_{2}$ in the feed. Seventy-eight percent selectivity was obtained for $x=1.1$ and a $\mathrm{MeOH}$ conversion of $12 \%$, which was significantly better than $\mathrm{Sr}_{3}\left(\mathrm{VO}_{4}\right)_{2}$ and $\mathrm{LaVO}_{4}$, which had 0 and 3\% selectivity, respectively [211].

Arora et al. [125] achieved 93.1\% selectivity relative to FA on Bi vanadates in a feed of 6 vol. $\% \mathrm{MeOH}$ and 11 vol. $\% \mathrm{O}_{2}$ at $280{ }^{\circ} \mathrm{C}$ at less than $10 \%$ conversion.

The Andersson group in Lund had performed investigations of $\mathrm{V}$ containing spineltype structures. Häggblad et al. [212] investigated a series of $\mathrm{Fe}_{1-x} \mathrm{Al}_{x} \mathrm{VO}_{4}$ with 6 vol.\% $\mathrm{MeOH}$ in the feed at $350{ }^{\circ} \mathrm{C}$. The selectivity increased for the first $16 \mathrm{~h}$ for all the samples, indicating structural rearrangements in the catalyst, snf they stabilized at approximately $90 \%$ selectivity towards FA after with less than $2 \%$ DME by-product formation when the conversion was between $95 \%$ and $98 \%$. The activity was lower than for the reference pure $\mathrm{V}_{2} \mathrm{O}_{5}$ catalyst; however, selectivity was better. The structure went from triclinic $\mathrm{Fe}_{1-x} \mathrm{Al}_{x} \mathrm{VO}_{4}$ phases to amorphous cation vacant spinel-type $\mathrm{Fe}_{1.5} \mathrm{~V}_{1.5} \mathrm{O}_{4}$ on top of the stable bulk $\mathrm{AlVO}_{4}$, which was supported by HRTEM [212].

Häggblad et al. [213] then investigated the activity of cation vacant $\mathrm{Fe}_{3-x-y} \mathrm{~V}_{x} \square_{y} \mathrm{O}_{4}$ spinel phase catalyst ( $\square$ denotes cation vacancies) at $300{ }^{\circ} \mathrm{C}$ and $10 \mathrm{vol} . \% \mathrm{MeOH}$ in the 
feed. The best selectivity was for a Fe/V ratio 2.8/0.2 (91\%), and the second best was from $1 / 1(90 \%)$. The specific activity was found to decrease with Fe content [213].

The $\mathrm{Fe}_{3-x-y} \mathrm{~V}_{x} \square_{y} \mathrm{O}_{4}$ catalyst was further investigated by Massa et al. [214] and compared to "theoretical" Fe-V-oxide layers (one theoretical layer was in this case defined as $12 \mu \mathrm{mol}$ cations $/ \mathrm{m}^{2}$ surface area of the support) on $\mathrm{TiO}_{2}, \alpha-\mathrm{Al}_{2} \mathrm{O}_{3}$, and $\mathrm{SiO}_{2}$ supports at the same conditions but with $80 \%$ conversion. None of the investigated supported samples had better selectivity than $\mathrm{FeVO}_{4}$ ranging from $80-88 \%$; however, the surface area specific activity was higher for the $\mathrm{TiO}_{2}$ supported $\mathrm{Fe}-\mathrm{V}$-oxide and much lower for the $\mathrm{SiO}_{2}$ supported catalysts (Figure 37). It was possible to stabilize $\mathrm{FeVO}_{4}$ by pre-oxidizing the samples into a spinel-like structure with the same selectivity [214].

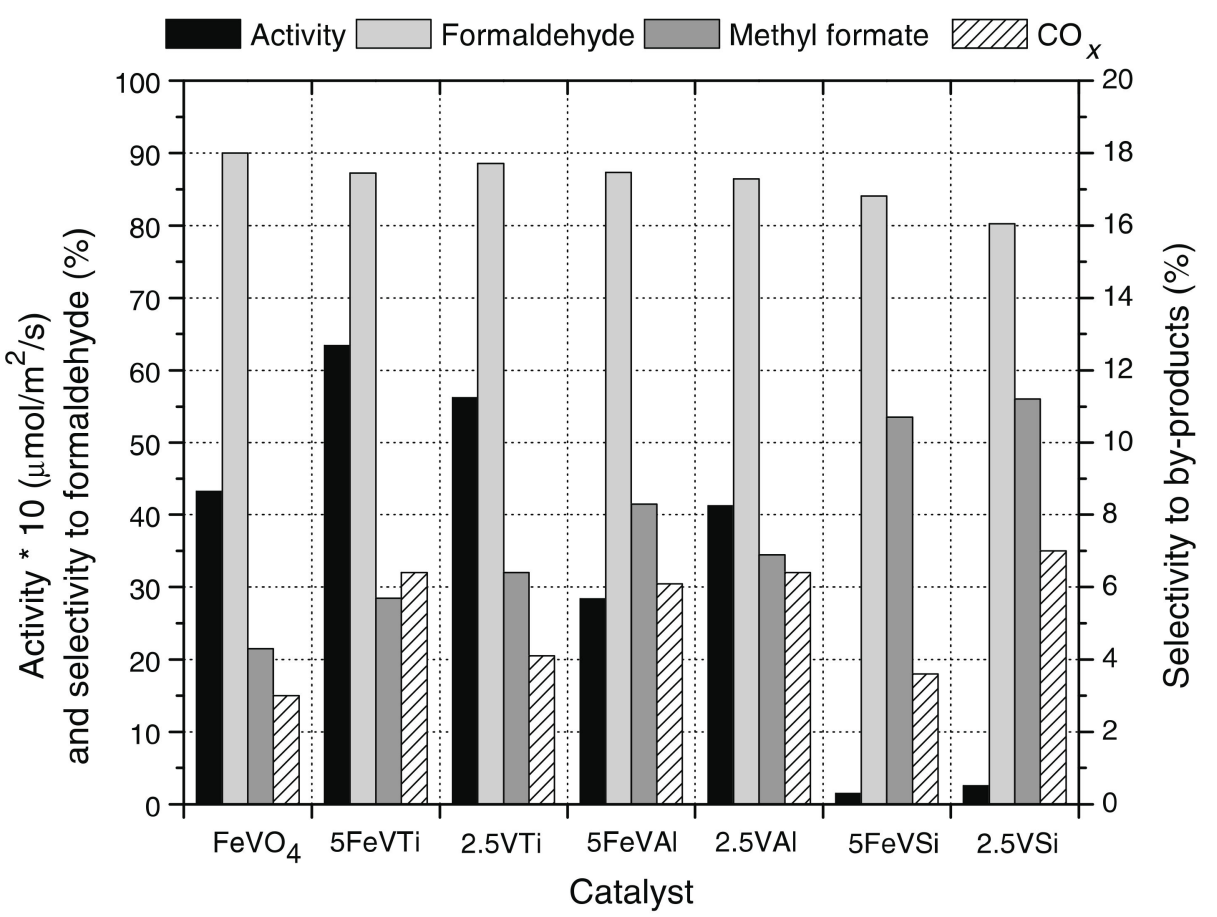

Figure 37. Activity and selectivity of $\mathrm{FeVO}_{4}$ and supported layers of $\mathrm{FeV}$ and $\mathrm{V}(5 \mathrm{FeV}=5$ theoretical layers of $\mathrm{FeV} ; 2.5 \mathrm{~V}=2.5$ theoretical layers) on $\mathrm{TiO}_{2}, \alpha-\mathrm{Al}_{2} \mathrm{O}_{3}$, and $\mathrm{SiO}_{2} . \mathrm{T}=300{ }^{\circ} \mathrm{C}$. Composition: 10 vol. $\% \mathrm{MeOH}$ and 10 vol. $\% \mathrm{O}_{2}$ in $\mathrm{N}_{2}$. Conversion of $80 \%$. Activities were measured at low conversions. Reprinted with permission from [214] Springer Science+Bussiness Media. Copyright @ (2011).

A spinel-type catalyst of $\mathrm{Fe}, \mathrm{V}$, and Mo was investigated by Massa et al. [215] at $300{ }^{\circ} \mathrm{C}$ by using a mixture of 10 vol. $\% \mathrm{MeOH}$ and 10 vol. $\% \mathrm{O}_{2}$ in $\mathrm{N}_{2}$. All the samples had selectivities of around $86 \%$ at $82-88 \%$ conversion, regardless of temperature-programmed pre-oxidation (Figure 38).

XANES and XPS showed that the surface metal ions were primarily in their highest oxidation state. The $\mathrm{Fe}_{2.5} \mathrm{~V}_{0.2} \mathrm{Mo}_{0.5} \mathrm{O}_{\mathrm{y}}$ catalyst was less selective than the commercial type FeMo catalyst, producing 93\% FA selectivity [215].

The selectivity of approximately $90 \%$ for $\mathrm{FeVO}_{4}$ towards $\mathrm{CH}_{2} \mathrm{O}$ was reproduced by our group (see Supplementary Materials, Section 2.2.2, Tables S8 and S9, and Figures S8 and S9), with the main byproduct being $\mathrm{CO}$. $\mathrm{FeVO}_{4}$ was by far the most active sample in our tests. By impregnation with $1 \mathrm{wt} \% \mathrm{NH}_{4} \mathrm{Cl}$, the selectivity towards $\mathrm{FA}$ was significantly improved by suppressing $\mathrm{CO}$ formation. Thus, the selectivity was $97.5 \%$ instead of $88.2 \%$ at $300{ }^{\circ} \mathrm{C}$. 


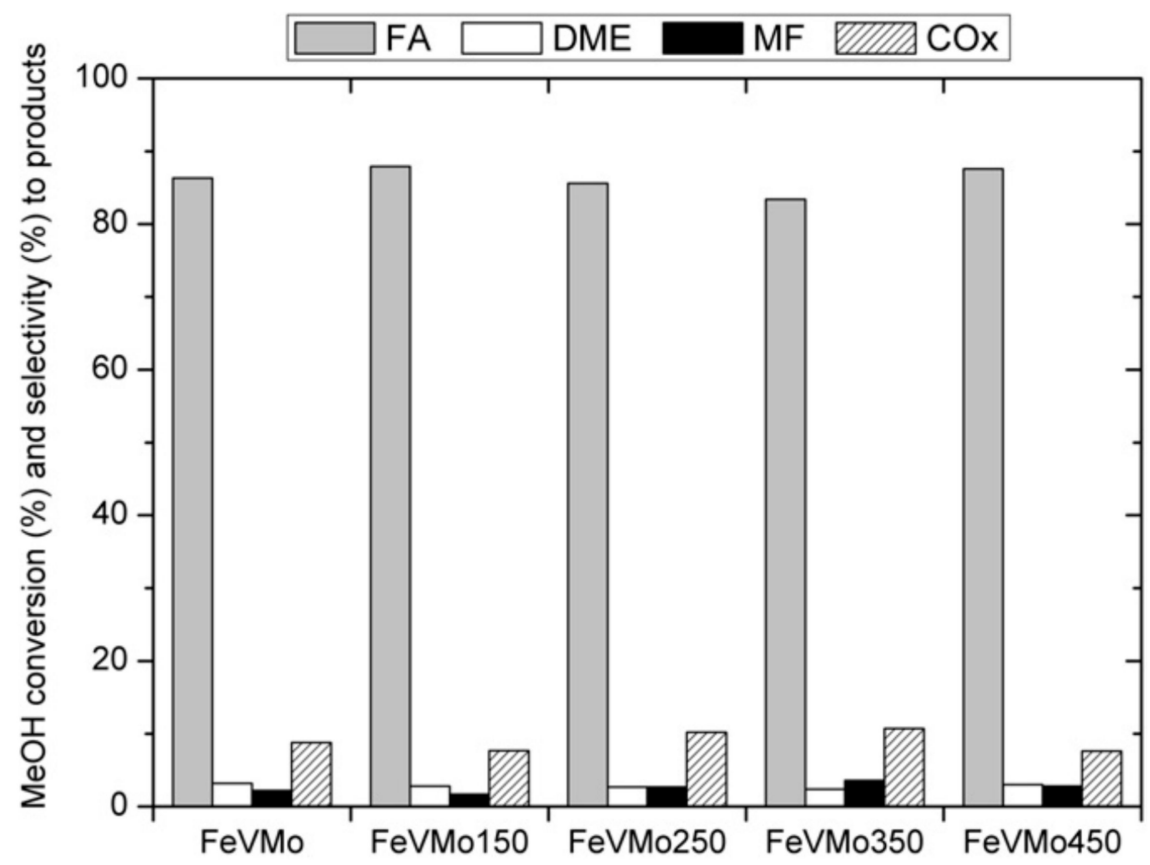

Figure 38. Selectivities to formaldehyde (FA), dimethyl ether (DME), methyl formate (MF), and carbon oxides over Fe-V-Mo-O spinel-type catalyst preoxidized up to different temperatures in the temperature programmed oxidation. The selectivities are taken after $16 \mathrm{~h}$ at a steady-state at $300{ }^{\circ} \mathrm{C}$ with a feed flow of $100 \mathrm{~mL} / \mathrm{min}$ of $10 \mathrm{vol} \% \mathrm{MeOH}$ and $10 \mathrm{vol} . \% \mathrm{O}_{2}$ in $\mathrm{N}_{2}$. The conversions were in the range of $82-88 \%$. Reprinted from [215] Copyright (c) (2011), with permission from Elsevier.

Different vanadates $\left(\mathrm{AlVO}_{4}, \mathrm{Co}_{3}\left(\mathrm{VO}_{4}\right)_{2}, \mathrm{FeVO}_{4}, \mathrm{Mg}_{3}\left(\mathrm{VO}_{4}\right)_{2}, \mathrm{Mn}_{3}\left(\mathrm{VO}_{4}\right)_{2}, \mathrm{Ni}_{3}\left(\mathrm{VO}_{4}\right)_{2}\right.$, and $\left.\mathrm{Zn}_{3}\left(\mathrm{VO}_{4}\right)_{2}\right)$ were investigated by Andersson et al. [6] and compared against the commercial Formox KH44L catalyst at $300{ }^{\circ} \mathrm{C}$ with 6 vol. $\% \mathrm{MeOH}$ and 11 vol. $\% \mathrm{O}_{2}$ in inert gas (Figure 39).

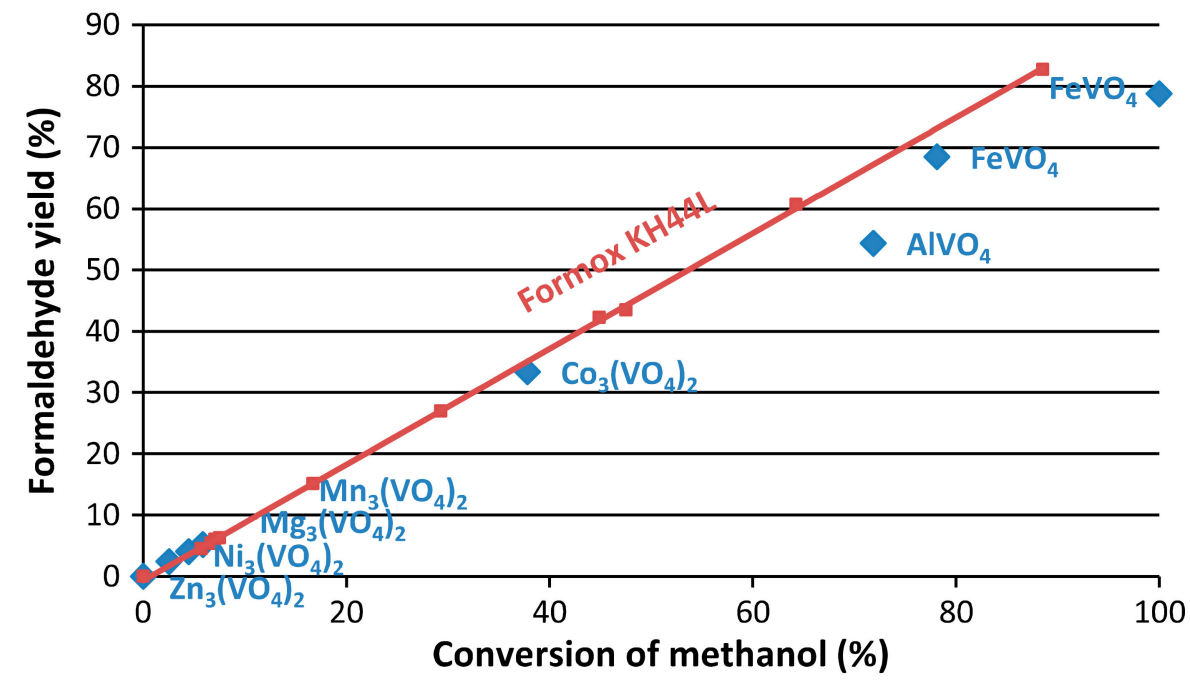

Figure 39. Comparison of catalytic performance of various vanadates to the Formox KH44L commercial catalyst shown as yield vs. conversion. $T=300{ }^{\circ} \mathrm{C}$. Feed: 6 vol. $\% \mathrm{MeOH}$ and $11 \mathrm{vol} . \% \mathrm{O}_{2}$ in inert gas. Flow: $227-277 \mathrm{~mL} / \mathrm{min}$. Catalyst loading: 25-1000 mg catalyst (surface area of catalyst 0.1-3 $\mathrm{m}^{2}$ ). Particle size: $0.215-0.425 \mathrm{~mm}$. Reprinted with permission from [6] Springer, Topics in catalysis, Copyright @ (2016).

The selectivities of $\mathrm{AlVO}_{4}$ and $\mathrm{FeVO}_{4}$ were between $76 \%$ and $87 \%$ when the conversion was above 50\% [6]. All the other vanadates must be assumed to have had low activity, but 
since no information on the amount or surface area of the samples in the reactor was given, this is unclear.

Selective oxidation of $\mathrm{MeOH}$ on $\mathrm{FeVO}_{4}$ catalysts was investigated by Klissurski et al. [216] The catalyst consisted of a single-phase Fe(III) vanadate. Mössbauer spectroscopy showed $\mathrm{Fe}(\mathrm{III})$ to be in a high spin state at various crystallographic sites. $\mathrm{V}^{5+}$ was partially reduced to $\mathrm{V}^{4+}$ on the surface during reaction, as measured by XPS. An increase in V content at the surface was also observed. The selectivity relative to FA was $100 \%$ at temperatures of $500{ }^{\circ} \mathrm{C}$ and below, while selectivity fell to $93 \%$ at $530{ }^{\circ} \mathrm{C}$ with 6.5 vol. $\% \mathrm{MeOH}$ in the feed (Figure 40) [216], thus reporting better selectivity results than the Andersson group [6,212].

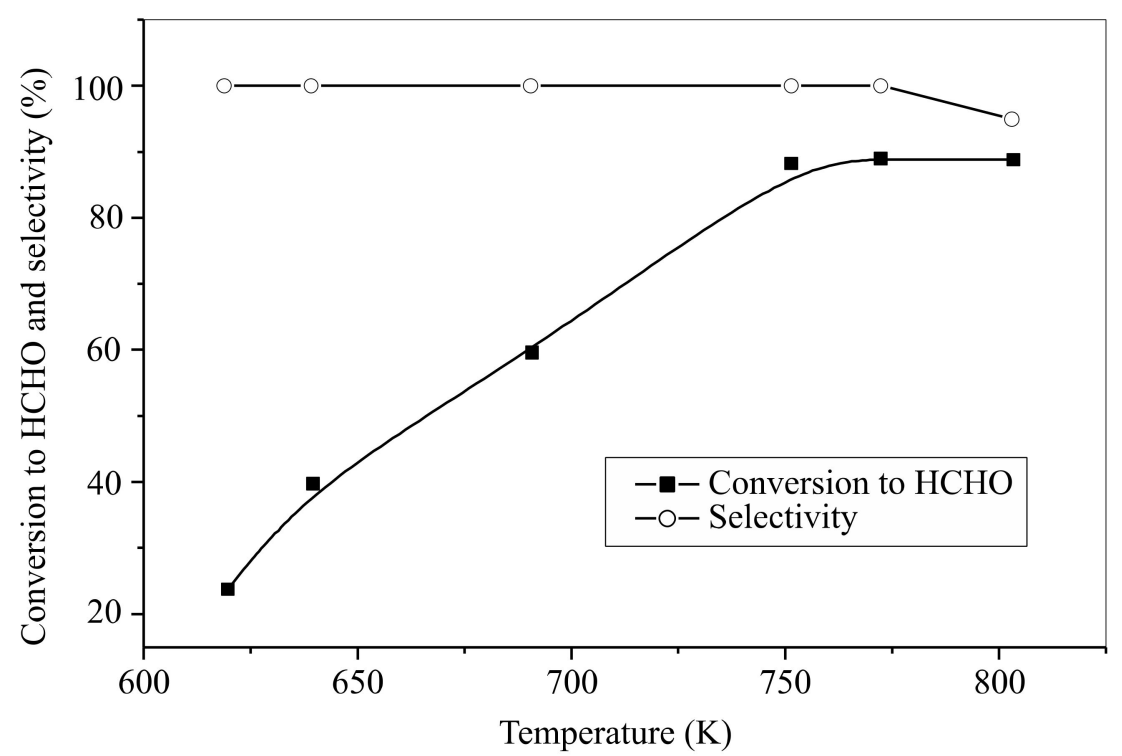

Figure 40. Temperature dependence of $\mathrm{MeOH}$ conversion and selectivity towards $\mathrm{FA}$ for $\mathrm{FeVO}_{4}$ catalyst at flow rate of $4 \mathrm{~mL} / \mathrm{min}, 6.5 \mathrm{vol} . \% \mathrm{MeOH}$ in the feed, and $0.6 \mathrm{~g}$ catalyst in the reactor. Reprinted from [216] with permission from copyright holder.

The structure of $\mathrm{FeVO}_{4}$ was investigated by Routray et al. [217] under MeOH oxidation reaction conditions. The surface of the bulk $\mathrm{FeVO}_{4}$ was enriched with $\mathrm{VO}_{x}$. This was similar to what was described for the commercial FeMo catalyst in Section 2.1.1 and to the measurements on $4 \% \mathrm{~V}_{2} \mathrm{O}_{5} / \mathrm{Fe}_{2} \mathrm{O}_{3}$. In both cases, there was a predominance of $\mathrm{V}-\mathrm{OCH}_{3}$ and $\mathrm{V}-\mathrm{CH}_{3} \mathrm{OH}$ intermediates on the surface and absence of distinct peaks for $\mathrm{Fe}-\mathrm{OCH}_{3}$ and $\mathrm{Fe}-\mathrm{CH}_{3} \mathrm{OH}$ peaks measured by IR. This taken together with minimal DME and DMM formation was stated by the authors to hint at the low concentration of acidic $\mathrm{FeO}_{x}$ sites at the surface, since they were covered by the $\mathrm{VO}_{x} \mathrm{ML}$ [217]. It was further concluded in another work by Wachs and Routray [218] that there likely will be an enrichment of one component at the surface in every bulk mixed oxide catalyst [218].

A study by Hellier et al. [219] showed the formation of $\mathrm{FeVO}_{4}, \mathrm{VO}_{x}$, and $\mathrm{Fe}_{2} \mathrm{O}_{3}$ upon the impregnation of $\mathrm{Fe}_{2} \mathrm{O}_{3}$ with $\mathrm{NH}_{4} \mathrm{VO}_{3}$, analogous to what was described for the FeMo catalyst (Section 2.1.1). Hellier et al. [220] prepared samples of $\mathrm{Fe}_{2} \mathrm{O}_{3}$ with $1 \mathrm{ML} \mathrm{VO}_{x}$ and $3 \mathrm{ML} \mathrm{VO}_{x}$ finding that $1 \mathrm{ML} \mathrm{VO}_{x} / \mathrm{Fe}_{2} \mathrm{O}_{3}$ was selective to FA albeit less than the corresponding $1 \mathrm{ML} \mathrm{MoO}_{x} / \mathrm{Fe}_{2} \mathrm{O}_{3}$ and that the selectivity dropped as $\mathrm{T}_{50}\left(230{ }^{\circ} \mathrm{C}\right)$ was reached for the pulses of $\mathrm{MeOH}$ into 10 vol. $\% \mathrm{O}_{2}$ in He. At higher temperatures, $\mathrm{CO}$ and $\mathrm{CO}_{2}$ were produced in high amounts. Neither $\mathrm{FeVO}_{4}$ nor $\mathrm{V}_{2} \mathrm{O}_{5}$ were detectable by Raman spectroscopy for the $1 \mathrm{ML} \mathrm{VO}_{x} / \mathrm{Fe}_{2} \mathrm{O}_{3}$ sample, but $\mathrm{FeVO}_{4}$ was observed for the $3 \mathrm{ML}$ $\mathrm{VO}_{x} / \mathrm{Fe}_{2} \mathrm{O}_{3}$ sample [220].

Malmusi et al. [221] investigated ethanol oxidation over $\mathrm{FeVO}_{4}$ and $\mathrm{V}_{2} \mathrm{O}_{5}$. This is a similar reaction as the $\mathrm{MeOH}$ oxidation. Both showed the primary product to be acetaldehyde. $\mathrm{FeVO}_{4}$ reduced to a spinel compound containing $\mathrm{V}^{3+}$ and $\mathrm{Fe}^{2+} / \mathrm{Fe}^{3+}$ ions, which had similar catalytic performance as $\mathrm{V}_{2} \mathrm{O}_{5}$, but it was more stable [221]. 
The results reported in the literature for bulk vanadates and spinel-type catalysts are summarized in Figure 41 as formaldehyde selectivity against conversion (when possible). Among those, $\mathrm{FeVO}_{4}$ showed high selectivities also at higher temperatures and high levels of conversion but also with some spreading in the results (our results for the iron vanadate were in the low end of the reported selectivities). The tendencies observed for the molybdenum based catalysts and the supported vanadium oxides were also observed for the bulk vanadates such that the Al vanadate performed poorly. The Co, $\mathrm{Zn}$, and Ni vanadates also had poor activity.

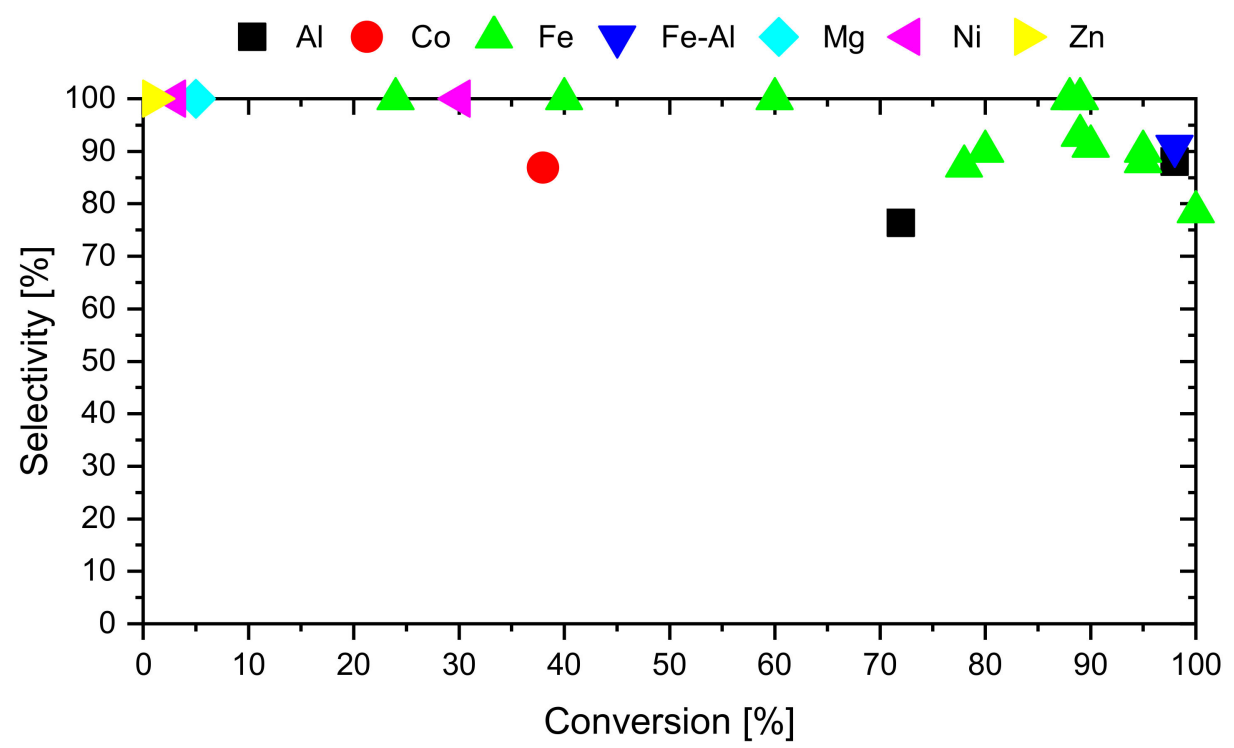

Figure 41. Summary of catalytic test results for vanadates and spinel-type catalysts in the literature [125,211-216].

\subsection{Other Types of Catalysts}

The surface and catalytic properties of $\mathrm{Au}$ and $\mathrm{CeO}_{2}$ containing catalysts supported on SBA-15 and the promotion with $\mathrm{Cu}$ and $\mathrm{Zr}$ species were investigated by Kaminski and Ziolek [222] with 4 vol. $\% \mathrm{MeOH}$ in the feed and an excess of $\mathrm{O}_{2} \cdot \mathrm{CeO}_{2}$ on SBA-15 had a selectivity of $50 \%$ towards FA at $13 \%$ conversion at $350{ }^{\circ} \mathrm{C}$, while the $\mathrm{Zr}$ containing supports had lower selectivity but higher conversion. None of the investigated catalysts had a selectivity higher than $39 \%$ towards FA at $250{ }^{\circ} \mathrm{C}$. Zr loading produced an increase in Brønsted acidity and selectivity towards DME, and $\mathrm{Cu}$ increased Lewis acidity and selectivity towards MF. Au and Ce catalyzed the total oxidation of $\mathrm{MeOH}$ [222]. Another investigation of Au supported on modified aluminosilicates found that $\mathrm{Ce}$ and $\mathrm{Zr}$ increased selectivity relative to FA. However, this was investigated under the conditions of the BASF (silver catalyst) process, with selectivities of 80-90\% [223]. Au, Ag, Zn, and Au-Ag alloys effect on $\mathrm{MeOH}$ oxidation was studied by Kaskow et al. [224] on MCM-36 supports at $100-250{ }^{\circ} \mathrm{C}$ in a $23.4 / 3.2 / 2.5 \mathrm{~mL} / \mathrm{min} \mathrm{Ar} / \mathrm{O}_{2} / \mathrm{MeOH}$ flow on $0.04 \mathrm{~g}$ of catalyst. The catalysts were found to reach high conversions already at $150{ }^{\circ} \mathrm{C}$, but all of the samples had a large over-oxidation selectivity to $\mathrm{CO}_{2}$ at $250{ }^{\circ} \mathrm{C}$ (Figure 42). Zn improved the FA selectivity of $\mathrm{Au}$, while $\mathrm{Ag}$ promoted combustion to $\mathrm{CO}_{2}$ [224].

FA had $95 \%$ selectivity relative to the main product from $\mathrm{MeOH}$ oxidation during a TPRS study at $307^{\circ} \mathrm{C}$ on a thin $\mathrm{ZnO}$ film over $\mathrm{Au}(111)$. This finding was supported by DFT studies [225]. 


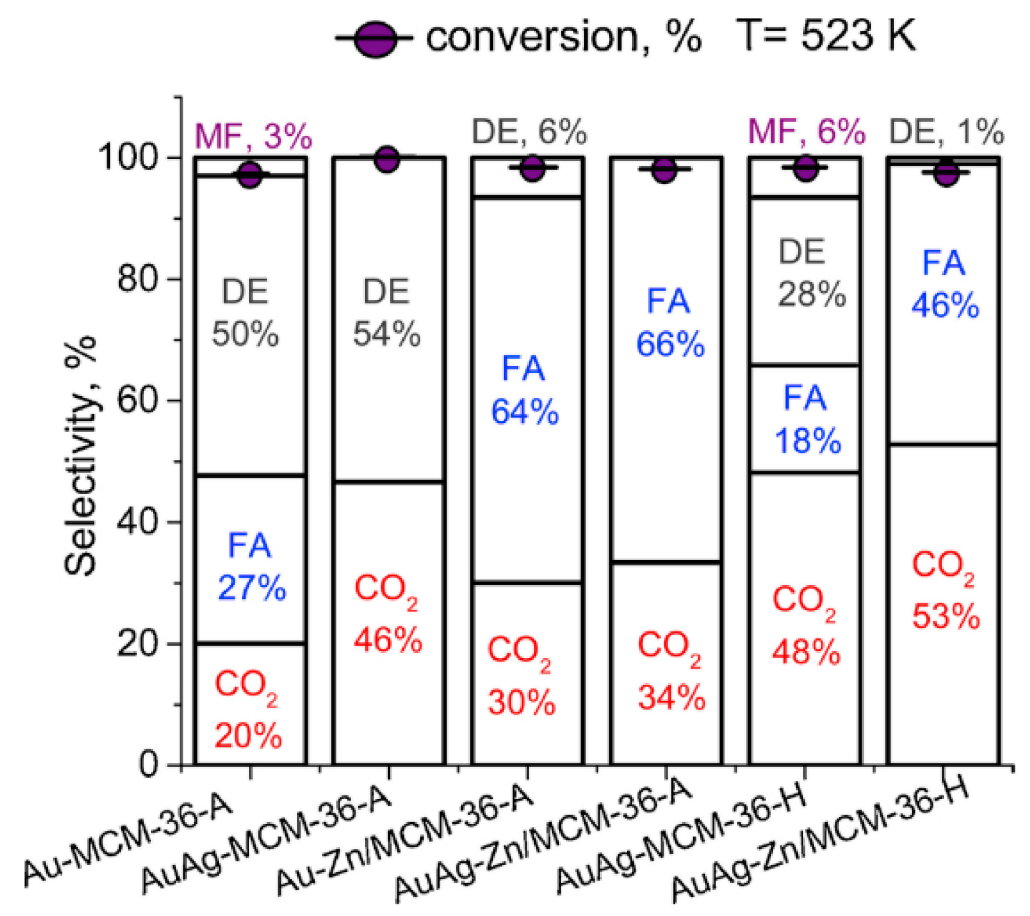

Figure 42. Selectivity of mono and bi-metallic catalysts investigated by Kaskow et al. [224] for the $\mathrm{MeOH}$ oxidation at close to $100 \%$ conversion and $250{ }^{\circ} \mathrm{C}$. FA $=$ Formaldehyde; $\mathrm{DE}=$ dimethyl ether; $\mathrm{MF}=$ methyl formate. Feed: 23.4/3.2/2.5 mL/min of $\mathrm{Ar} / \mathrm{O}_{2} / \mathrm{MeOH}$. Reprinted from [224] Copyright (C) (2020), with permision from Elsevier.

The catalytic properties of nanosized $\mathrm{Fe}_{2} \mathrm{O}_{3} / \mathrm{MgO}$ were investigated by El-Molla and Mahmoud [226]. The catalysts had $100 \%$ selectivity at $30{ }^{\circ} \mathrm{C}$. The $\mathrm{MeOH}$ concentration was not mentioned. Selectivities above $97.9 \%$ towards FA were reported at $400{ }^{\circ} \mathrm{C}$ [226]. This high selectivity was surprising as $\mathrm{Fe}_{2} \mathrm{O}_{3}$ is known to oxidize $\mathrm{MeOH}$ relative to $\mathrm{CO}_{2}$, and $\mathrm{MgO}$ is basic and would, thus, be expected to form $\mathrm{CO}_{2}$ as well (Figure 7). By following the synthesis method reported in [222], samples with 8.2 and $15.2 \mathrm{wt} \% \mathrm{Fe}_{2} \mathrm{O}_{3} / \mathrm{MgO}$ were synthesized (see Supplementary Materials, Section 2.2.3, Figures S10 and S11, and Tables S10 and S11). These catalysts showed very different catalytic properties than those reported by El-Molla and Mahmoud [226]. Full combustion of $\mathrm{MeOH}$ was achieved at $400{ }^{\circ} \mathrm{C}$, and selectivity was also significantly lower at $250-350{ }^{\circ} \mathrm{C}$. Selectivity close to $100 \%$ relative to FA seemed implausible from these results, which is in better agreement with the expectations for this catalyst.

An investigation of $\mathrm{Sb}$ - $\mathrm{Re}$-oxide catalysts for $\mathrm{DMM}$ production from $\mathrm{MeOH}$ was investigated by Yuan et al. [227]. The selectivity at $300{ }^{\circ} \mathrm{C}$ for $\mathrm{Re}_{2} \mathrm{O}_{7} / \mathrm{Sb}_{2} \mathrm{O}_{3}$ was $49.8 \%$ to FA, $42.7 \%$ to DME, and only $7.4 \%$ to DMM with $2.5 \%$ conversion of a 4 vol. $\% \mathrm{MeOH}$ feed. $\mathrm{Sb}_{2} \mathrm{O}_{5}$ was found to possess selectivity of $55.5 \%$ to $\mathrm{FA}, 26.4 \%$ to DME, and $18 \%$ to $\mathrm{CO}_{2}$ under the same conditions with $1.3 \%$ conversion [227].

The activity of Re oxide supported on $\mathrm{Al}_{2} \mathrm{O}_{3}$ and $\mathrm{TiO}_{2}$ was investigated by Burcham et al. [140] at $200{ }^{\circ} \mathrm{C}$ with $2000 \mathrm{ppm} \mathrm{MeOH}$ in the feed, where $\mathrm{Re}_{2} \mathrm{O}_{7} / \mathrm{Al}_{2} \mathrm{O}_{3}$ and $\mathrm{Re}_{2} \mathrm{O}_{7} / \mathrm{TiO}_{2}$ produced $72 \%$ and $90 \%$ selectivity towards $\mathrm{FA}$ and $\mathrm{CO}_{\mathrm{x}}$ combined and $28 \%$ and $2 \%$ selectivity towards DME, respectively [140].

Hutchings and Taylor [228] presented an approach to the design of oxidation catalysts, exemplified by the oxidation of methane to $\mathrm{MeOH}$. As a part of this, an investigation of the stability of $\mathrm{MeOH}$ on different oxides was conducted, where it was measured at what temperature $30 \%$ of the fed $\mathrm{MeOH}$, in a feed composition of $\mathrm{MeOH} / \mathrm{O}_{2} / \mathrm{He}=1 / 4 / 12$, was converted to carbon oxides (Figure 43). In particular, $\mathrm{Sb}_{2} \mathrm{O}_{3}, \mathrm{MoO}_{3}, \mathrm{WO}_{3}, \mathrm{Ta}_{2} \mathrm{O}_{5}$, and $\mathrm{Nb}_{2} \mathrm{O}_{5}$ performed well with respect to $\mathrm{MeOH}$ stability in their investigations. Moreover, all of them were observed to have high selectivities towards FA [228]. 


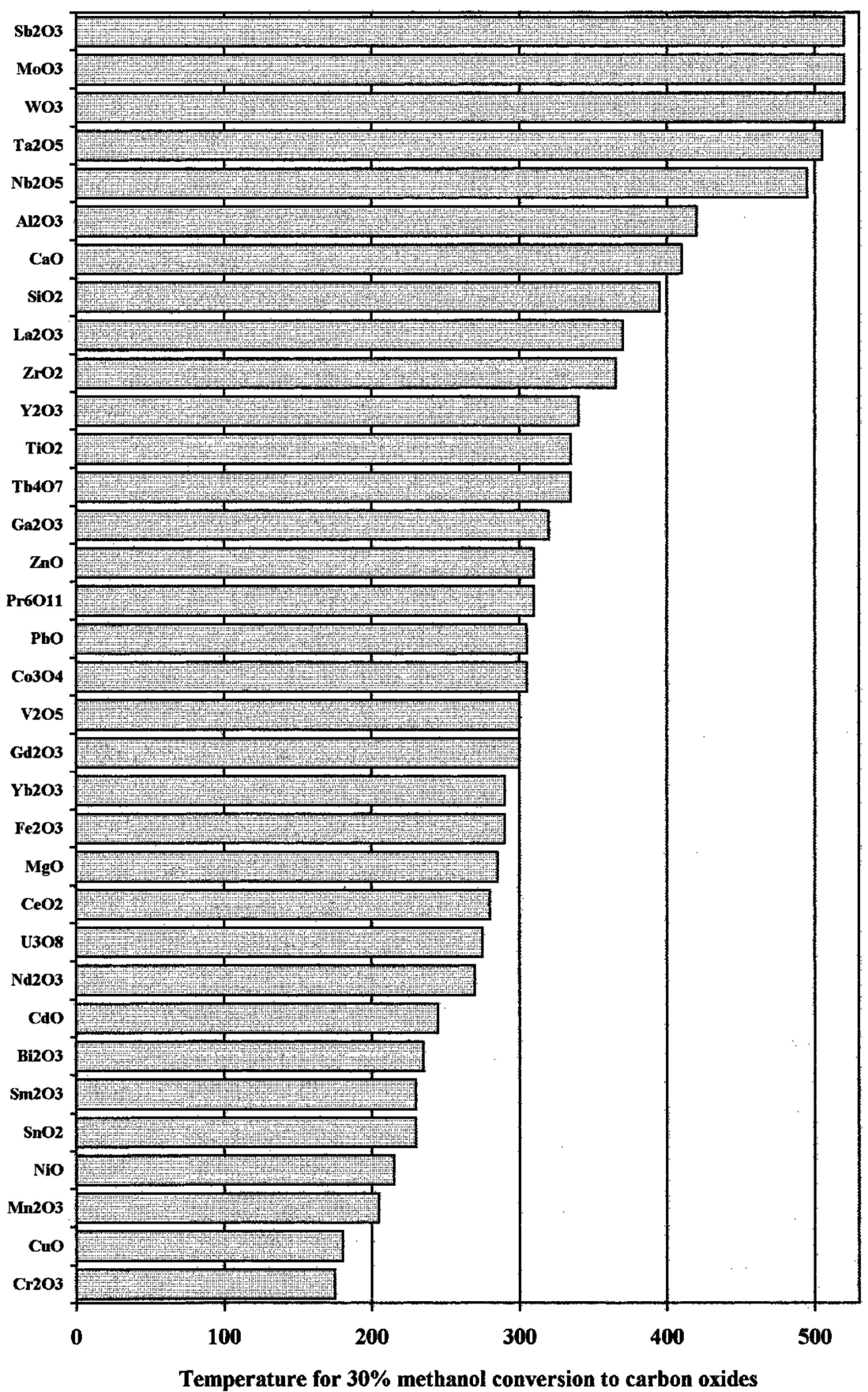

Figure 43. $\mathrm{MeOH}$ stability based on the temperature at which $30 \%$ conversion of the fed $\mathrm{MeOH}$ was converted to carbon oxides. $\mathrm{MeOH} / \mathrm{O}_{2} / \mathrm{He}=1 / 4 / 12,12000 \mathrm{~h}^{-1}$. Reprinted from [228] Copyright $($ ) (1999), with permision from Elsevier.

Harrison et al. [229] investigated the tungstate analogue to the FeMo $\left(\mathrm{Fe}_{2}\left(\mathrm{WO}_{3}\right)_{3}\right)$ at 200-350 ${ }^{\circ} \mathrm{C}$. The $\mathrm{O}_{2}$ to $\mathrm{MeOH}$ ratio varied from 0.2 to $35, \mathrm{H}_{2} \mathrm{O}$ to $\mathrm{MeOH}$ from 0.2 to 2 , and $\mathrm{MeOH}$ conversion from $10 \%$ to $60 \%$. The investigations were carried out on $3 \mathrm{~g}$ of catalyst with over 1 week on stream. No losses in activity, visible change, or difference in X-ray diffractograms were observed. The reaction kinetics were reported to be very similar to that of $\mathrm{Fe}_{2}\left(\mathrm{MoO}_{4}\right)_{3}, 0.5-1$ st-order in $\mathrm{MeOH}$, zero order in $\mathrm{O}_{2}$, and -0.5 thorder in $\mathrm{H}_{2} \mathrm{O}$. Product distribution was different as the main product was DME and the secondary product FA (Figure 44). The addition of $\mathrm{H}_{2} \mathrm{O}$ improved selectivity towards FA. The $\mathrm{Fe}_{2}\left(\mathrm{WO}_{3}\right)_{3}$ catalyst had only $14 \%$ of the activity per surface area of the FeMo [229]. According to Harrison et al. [229], Popov et al. had performed studies in the $1960 \mathrm{~s}$ on $\mathrm{WO}_{3}$ 
and tungstates with $\mathrm{Fe}(\mathrm{II}), \mathrm{Mn}, \mathrm{Co}, \mathrm{Ni}, \mathrm{Cu}$, and $\mathrm{Zn}$ claiming all to be selective catalysts, with $\mathrm{Fe}(\mathrm{II})$ being the most selective. It was not possible to procure the referenced material.

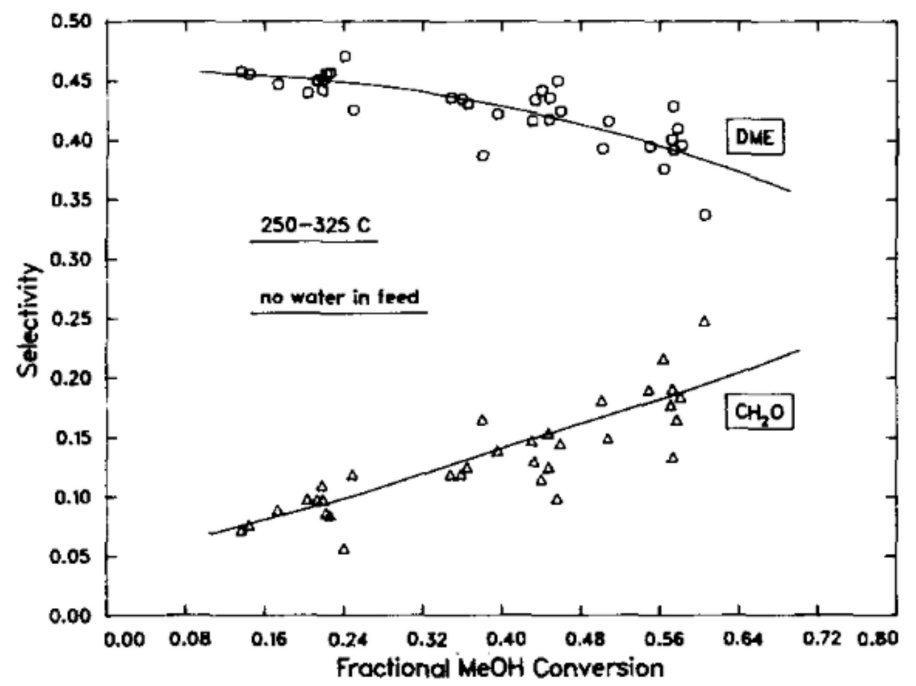

Figure 44. DME and FA selectivity as function of $\mathrm{MeOH}$ conversion over $\mathrm{Fe}_{2}\left(\mathrm{WO}_{3}\right)_{3}$. Reprinted from [229] Copyright (C (1985), with permision from Elsevier.

A study by Wachs et al. [230] on bulk mixed oxide catalysts $\left(\mathrm{Mo}_{0.6} \mathrm{~V}_{1.5} \mathrm{O}_{x}, \mathrm{Mo}_{1.0} \mathrm{~V}_{0.5} \mathrm{Te}_{0.16} \mathrm{O}_{x}\right.$, and $\mathrm{Mo}_{1.0} \mathrm{~V}_{0.5} \mathrm{Te}_{0.16} \mathrm{Nb}_{0.12} \mathrm{O}_{x}$ ) using $\mathrm{CH}_{3} \mathrm{OH}$-TPSR investigated the activities of the surface sites found in the catalysts. The most active sites were the fully oxidized cations. Selectivity decreased upon reduction. $\mathrm{V}^{5+}$ was more active than $\mathrm{Mo}^{6+}$, and they were both significantly more active than $\mathrm{Nb}^{5+}$ and $\mathrm{Te}^{4+} . \mathrm{V}^{5+}, \mathrm{Mo}^{6+}$, and $\mathrm{Te}^{4+}$ were stated to behave as redox sites, while $\mathrm{Nb}^{5+}$ was a Lewis site [230].

Badlani and Wachs [231] investigated the products from $\mathrm{MeOH}$ oxidation on pure metal oxide catalysts at low conversions in order to quantify the number of surface redox sites (FA, MF, and DMM as products), acidic sites (DME), and basic sites $\left(\mathrm{CO}_{2}\right)$ (Figure 45 ).

In the investigation of group $6 \mathrm{~b}$ oxides on $\mathrm{CeO}_{2}-\mathrm{ZrO}_{2}$ by Inokawa et al. [142], $\mathrm{WO}_{3}$ and $\mathrm{Cr}_{2} \mathrm{O}_{3}$ were investigated in the temperature range of $275-450{ }^{\circ} \mathrm{C}$. It was found over the entire range that selectivity and yield was poor, although the conversions were above $60 \%$ for both $\mathrm{Cr}_{2} \mathrm{O}_{3}$ and $\mathrm{WO}_{3}$ at $450{ }^{\circ} \mathrm{C}$ with the best selectivities being approximately $40 \%$ for both $\mathrm{Cr}_{2} \mathrm{O}_{3}$ and $\mathrm{WO}_{3}$ at 275 and $450{ }^{\circ} \mathrm{C}$, respectively [142].

Tungsten-titanium mixed oxide bronzes were investigated for $\mathrm{MeOH}$ transformation by Delgado et al. [232] at $200-400{ }^{\circ} \mathrm{C}$ with $100 \mathrm{~mL} / \mathrm{min}$ of $6 / 13 / 81 \mathrm{vol} . \% \mathrm{MeOH} / \mathrm{O}_{2} / \mathrm{N}_{2}$ on $0.10 \mathrm{~g}$ of catalyst $(0.25-0.4 \mathrm{~mm})$. For all the samples, the major product was DME, which is in good agreement with the measured acidity. For the Ti-free sample, the selectivity reached $20 \%$ for FA at $80 \%$ conversion with above $90 \%$ conversion to DME. For the Ti containing samples, the redox activity was much lower, with less than $5 \%$ selectivity relative to FA in all cases. The redox properties were believed to come from $\mathrm{W}^{5+}$, which was present in the Ti-free sample, whereas the Ti containing samples only had $\mathrm{W}^{6+}$ at the surface [232].

In the 1980s, the catalytic activity of pure $\mathrm{Sb}_{2} \mathrm{O}_{4}$ was investigated by Abadzhieva and Klissurski [233] at temperatures of 360-580 ${ }^{\circ} \mathrm{C}$. The formation of $\mathrm{CO}$ was observed only above $500{ }^{\circ} \mathrm{C}$, and selectivity relative to FA decreased strongly from $100 \%$ at $500{ }^{\circ} \mathrm{C}$ with increasing temperature (see Figure 46). Our tests of $\mathrm{Sb}$ oxide on $\mathrm{SiO}_{2}$ found it to have very low activity even though it had the largest surface area of the prepared samples (see Supplementary Materials, Sections 2.1.2 and 2.2.3). 

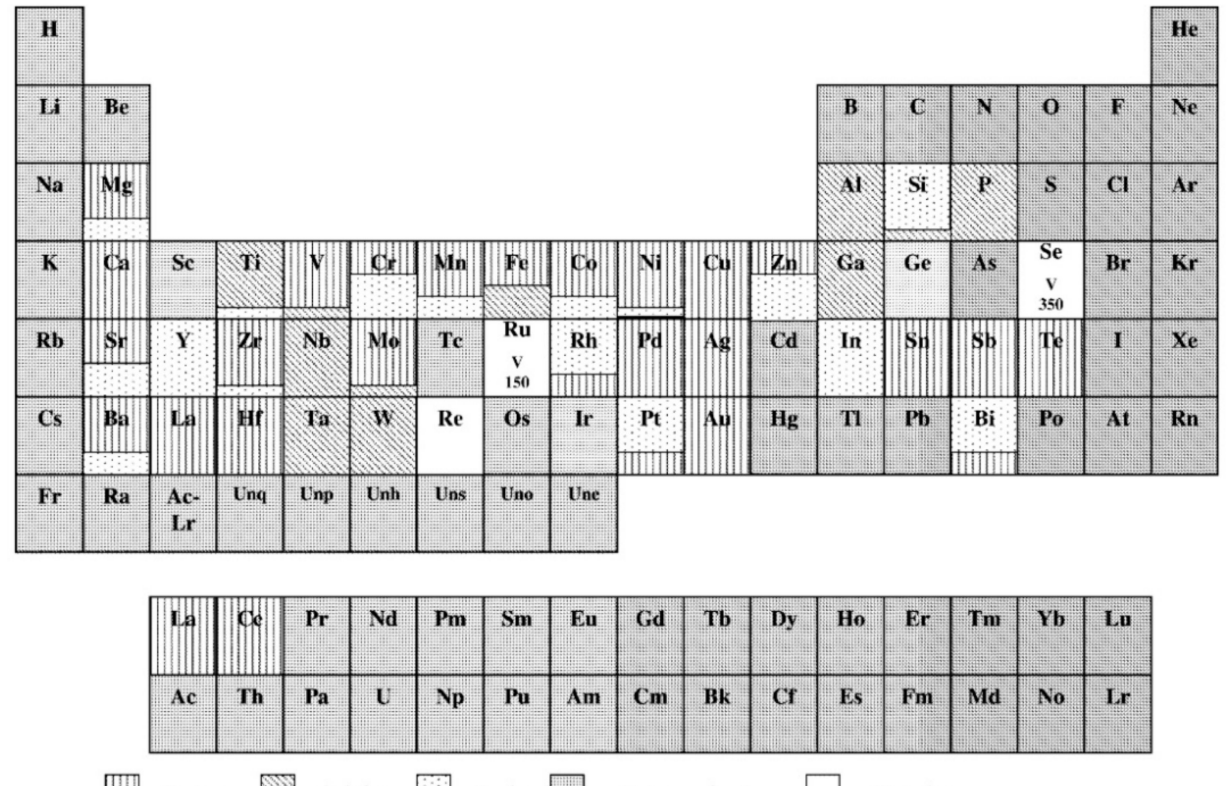

IIII Redox $\square$ Acidic $\square$ Basic $\square$ Not examined $\square$ Volatile

Figure 45. $\mathrm{MeOH}$ oxidation selectivity over the pure oxide catalysts. Redox = FA, MF, and DMM; Acidic $=\mathrm{DME}$; basic $=\mathrm{CO}_{2}$. Reprinted by permission from [231] Plenum Publishing Corporation, Catalysis Letters, Copyright (C) (2001).

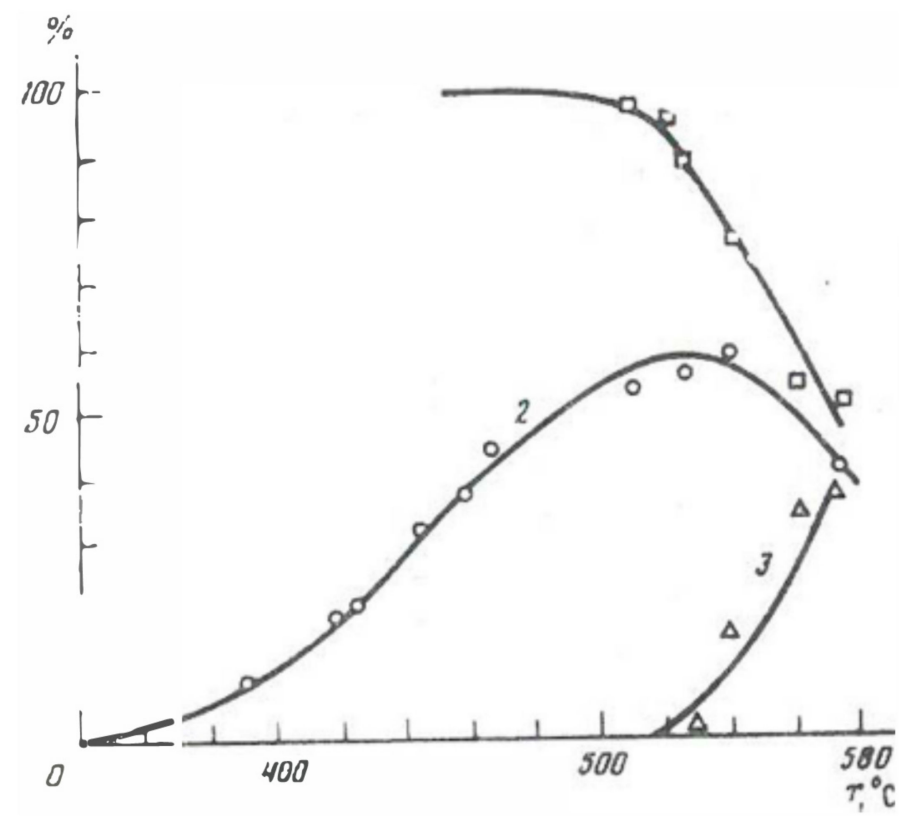

Figure 46. Catalytic performance of $\mathrm{Sb}_{2} \mathrm{O}_{4}$ for $\mathrm{MeOH}$ oxidation as function of temperature. 1: Selectivity towards FA; 2: Yield of FA; 3: Yield of CO. Feed: 4.1 vol.\% MeOH, $0.15 \mathrm{~mL}$ reaction mixture $/\left(\mathrm{m}^{2} \mathrm{~s}\right)$ [233].

The specific activity was reported to be an order of magnitude lower than for $\mathrm{MoO}_{3}$ and several orders of magnitude lower than for $\mathrm{V}_{2} \mathrm{O}_{5} . E_{a}$ of the reaction was determined to be $71 \mathrm{~kJ} / \mathrm{mol}$ [233]. In good agreement, Guerrero-Pérez et al. [200] found both bulk and $\mathrm{Al}_{2} \mathrm{O}_{3}$ supported antimonates had almost no acidic nor redox sites.

In the same decade, the group five transition metal oxide activities for FA production were investigated by Klissurski and Pesheva (Figure 47) [166]. The selectivity order of the oxides was $\mathrm{Ta}_{2} \mathrm{O}_{5}>\mathrm{Nb}_{2} \mathrm{O}_{5}>\mathrm{V}_{2} \mathrm{O}_{5}$. This was in contrast to the $\mathrm{Nb}$ containing catalysts 
in our investigation (see Supplementary Materials, Section 2.2.3, Tables S10 and S11, and Figures S10 and S11), which primarily made DME, whereas V containing catalysts mostly made FA. This may well arise from the difference in distribution between acidic and redox sites, as demonstrated by Wachs et al. [231] (Figure 45), but a better $\mathrm{NbO}_{x}$ surface layer may also have been achieved at higher calcination temperature according to Bowker et al. as the Tamman temperature for $\mathrm{Nb}_{2} \mathrm{O}_{5}$ is $620^{\circ} \mathrm{C}$.

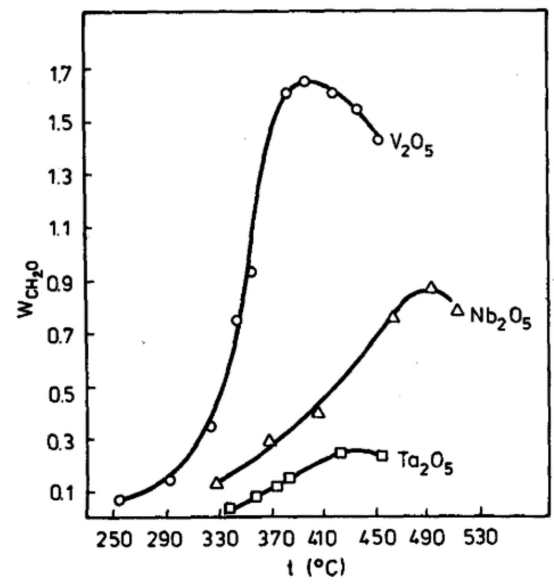

(a)

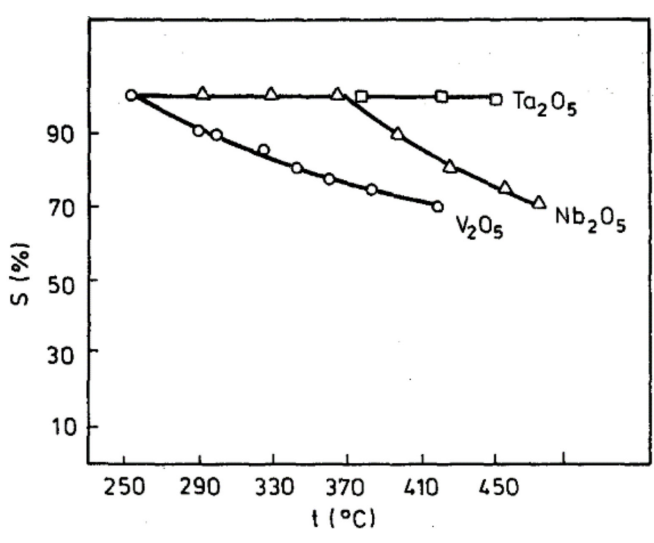

(b)

Figure 47. Dependence of activity (a) and selectivity (b) in MeOH oxidation of the group 5 metal oxides on temperature. Reprinted by permission from [166] Springer nature, Reaction Kinetics and Catalysis Letters, Copyright (1986).

The apparent activation energies of $\mathrm{V}_{2} \mathrm{O}_{5}, \mathrm{Nb}_{2} \mathrm{O}_{5}$, and $\mathrm{Ta}_{2} \mathrm{O}_{5}$ were 50,59 , and $92 \mathrm{~kJ} / \mathrm{mol}$, respectively [166]. Chen et al. [234] reported $\mathrm{ML}$ Ta oxide supported on $\mathrm{Al}_{2} \mathrm{O}_{3}, \mathrm{TiO}_{2}$, and $\mathrm{ZrO}_{2}$ to only have acidic surface sites and yielding only DME as the product of $\mathrm{MeOH}$ oxidation, whereas $\mathrm{TaO}_{x}$ on $\mathrm{SiO}_{2}$ had redox characteristics yielding $\mathrm{CH}_{2} \mathrm{O}$ and $\mathrm{CO}_{2}$ at low coverage and $\mathrm{MF}$ at $5 \% \mathrm{Ta}_{2} \mathrm{O}_{5} / \mathrm{SiO}_{2}$. Chen and Wachs [235] also investigated Ta oxide as a support for $1 \%$ $\mathrm{CrO}_{3}, \mathrm{MoO}_{3}, \mathrm{Nb}_{2} \mathrm{O}_{5}, \mathrm{Re}_{2} \mathrm{O}_{7}, \mathrm{~V}_{2} \mathrm{O}_{5}$, and $\mathrm{WO}_{3}$ at $230{ }^{\circ} \mathrm{C}$. $\mathrm{Cr}, \mathrm{Mo}$, Re, and $\mathrm{V}$ showed redox products with main selectivity towards $\mathrm{FA}$. $\mathrm{Nb}, \mathrm{W}$, and pure Ta oxide only yielded DME. Thus, the investigations by Chen et al. [234,235] did not find the same tendency with respect to selectivity as Klissurski and Pesheva [166], but they did agree on the order of the activity.

In the previously mentioned study by Arora et al. [125] with Bi containing catalysts, $\mathrm{Nb}_{2} \mathrm{O}_{5} / \mathrm{Bi}_{2} \mathrm{O}_{3}$ and $\mathrm{WO}_{3} / \mathrm{Bi}_{2} \mathrm{O}_{3}$ as well as pure $\mathrm{Bi}_{2} \mathrm{O}_{3}$ were investigated. Pure $\mathrm{Bi}$ oxide was reported not to possess selectivity above $18 \%$, while $\mathrm{Nb}_{2} \mathrm{O}_{5} / \mathrm{Bi}_{2} \mathrm{O}_{3}$ achieved $46.9 \%$ selectivity and $\mathrm{WO}_{3} / \mathrm{Bi}_{2} \mathrm{O}_{3}$ achieved $85.6 \%$ selectivity [125]. $\mathrm{Nb}_{2} \mathrm{O}_{5} / \mathrm{SiO}_{2}$ and $\mathrm{Nb}-\mathrm{MCM}-41$ were compared by Gao et al. [236] who found dispersed $\mathrm{NbO}_{4}$ species to be the active redox sites in both catalysts, which exhibited similar activity and selectivity, with up to $60 \%$ selectivity relative to FA, over $20 \%$ to MF, and the rest relative to DMM and DME [236].

Hellier et al. [220] tried, as for the $\mathrm{VO}_{x}$ and $\mathrm{MoO}_{x} / \mathrm{Fe}_{2} \mathrm{O}_{3}$, to prepare $1 \mathrm{ML}$ and $3 \mathrm{ML}$ $\mathrm{NbO}_{x} / \mathrm{Fe}_{2} \mathrm{O}_{3}$ catalysts. In contrast to the corresponding $\mathrm{VO}_{x}$ and $\mathrm{MoO}_{x} / \mathrm{Fe}_{2} \mathrm{O}_{3}$ samples, $1 \mathrm{ML} \mathrm{NbO}_{x} / \mathrm{Fe}_{2} \mathrm{O}_{3}$ primarily showed selectivity towards DME at lower temperatures, which were then superseded by selectivity towards $\mathrm{CO}_{2}$ at $\sim 300{ }^{\circ} \mathrm{C}$. It was proposed that the $\mathrm{NbO}_{x}$ layer was not properly formed as the calcination temperature $\left(500{ }^{\circ} \mathrm{C}\right)$ was below the Tamman temperature for $\mathrm{Nb}_{2} \mathrm{O}_{5}\left(620^{\circ} \mathrm{C}\right)$ and high enough mobility to properly disperse may not have been achieved. The incomplete coverage of the hematite core was supported by the low temperature onset of $\mathrm{MeOH}$ combustion and the absence of a distinctive $\mathrm{Nb}=\mathrm{O}$ peak in Raman spectroscopy after calcination [220].

Davies and Taylor [237] studied the use of niobium phosphates. The selectivity was maintained at above $80 \%$ with conversions over $90 \%$, and it was stated to be in contrast with many niobium oxide based catalysts [237], which mainly oxidize to $\mathrm{CO}_{x}$ at above $300{ }^{\circ} \mathrm{C}$ [238]. The temperature dependence of the selectivity of niobium oxide phosphates 
towards FA was investigated for the phosphates prepared either from pyro-phosphoric or ortho-phosphoric acid. The selectivity was $100 \%$ at temperatures below $400{ }^{\circ} \mathrm{C}$. The selectivity at $400{ }^{\circ} \mathrm{C}$ for the niobium oxide phosphate from pyro-phosphoric acid had slightly higher selectivity than from ortho-phosphoric acid. The niobium oxide phosphate from ortho-phosphoric acid had much higher conversion when calcined at $500^{\circ} \mathrm{C}$ but lower conversion when calcined at $400{ }^{\circ} \mathrm{C}$ or $600{ }^{\circ} \mathrm{C}$ compared to the niobium oxide phosphate from pyro-phosphoric acid [238].

The $\mathrm{Nb}_{2} \mathrm{O}_{5}$ and niobium phosphate samples prepared for this study were not very active (see Supplementary Materials, Section 2.2.3, Tables S10 and S11, and Figures S10 and S11), had primarily activity towards DME, and were, thus, not suitable as catalysts for the selective oxidation of $\mathrm{MeOH}$ to FA. When $\mathrm{Nb}_{2} \mathrm{O}_{5}$ was supported on $\mathrm{HAP}$ or $\alpha-\mathrm{Al}_{2} \mathrm{O}_{3}$, the selectivity towards DME was a little lower, but larger $\mathrm{CO}_{2}$ selectivity was observed.

The properties of $\mathrm{Al}_{2} \mathrm{O}_{3}$, intercalated into montmorillonite, were investigated by Hashimoto et al. [239] as a catalyst for conversion of $\mathrm{MeOH}$ to DME or FA in a feed with 11 vol. $\% \mathrm{MeOH}$ and $18 \mathrm{vol} . \% \mathrm{O}_{2}$. At $260-340{ }^{\circ} \mathrm{C}$, a maximum selectivity of $12 \%$ towards FA was achieved, with the rest almost exclusively being DME, thus being far from ideal as an alternative to the industrial FeMo catalyst [239].

The support materials $\mathrm{SiO}_{2}$ and $\mathrm{Al}_{2} \mathrm{O}_{3}$ were tested for their properties with respect to catalytic selective oxidation of $\mathrm{MeOH}$ in a fluid bed reactor for $60 \mathrm{~h}$ at $340^{\circ} \mathrm{C}$ with $5.5 \mathrm{vol} . \%$ $\mathrm{MeOH}$ in air by [240]. The main products were found to be $\mathrm{CO}$ and $\mathrm{CO}_{2}$ followed by MF. Small amounts of FA were also observed. The addition of $\mathrm{Na}$ and $\mathrm{Mg}$ to $\mathrm{SiO}_{2}$ decreased $\mathrm{CO}$ and $\mathrm{CO}_{2}$ yields [240].

The use of $\mathrm{Zr}$ phosphates, $\mathrm{CuX}$ zeolite, and their mixtures was investigated for $\mathrm{MeOH}$ transformations by Gryaznova et al. [241] at temperatures up to $240{ }^{\circ} \mathrm{C}$. None of the mixtures were selective towards FA [241]. An investigation of $\mathrm{FePO}_{4}$ by Klissurski et al. [242] in comparison reported high selectivity towards FA (Figure 48).

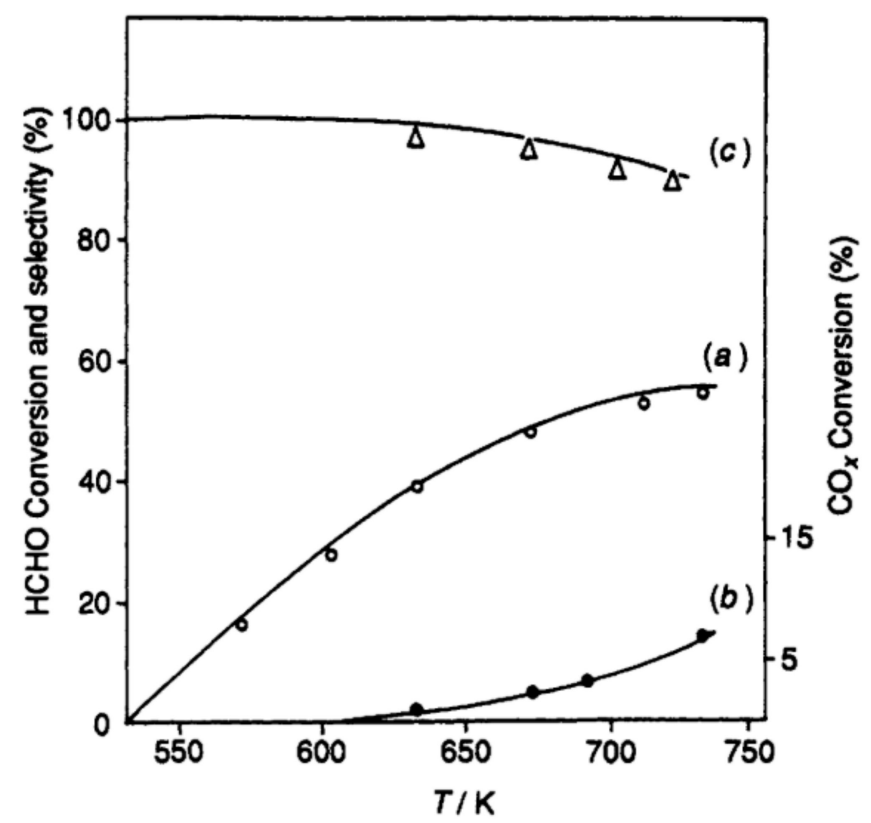

Figure 48. $\mathrm{MeOH}$ conversion (line a), FA selectivity (line b), and $\mathrm{CO}_{2}$ selectivity (line c) on $\mathrm{Fe}(\mathrm{III}$ ) phosphate as function of temperature in $240 \mathrm{~mL} / \mathrm{min} 4 \mathrm{vol}$ \% MeOH in air. Reproduced from [242] with permission from the Royal Society of Chemistry.

High selectivity was stated to be anticipated due to the similar relative electronegativity of $\mathrm{P}^{5+}(67.9)$ and $\mathrm{Mo}^{6+}(66.6)$ and ionicity (I) of the $\mathrm{P}^{5+}-\mathrm{O}(27.5 \%)$ and $\mathrm{Mo}^{6+}-\mathrm{O}(28.9 \%)$ bonds, resulting in the belief that they should have similar catalytic behavior [242]. This resulted in the investigation of $\mathrm{BiPO}_{4}$ by the same group [243] with $3.5 \mathrm{vol} . \% \mathrm{MeOH}$ in 
air, $480 \mathrm{~mL} / \mathrm{min}$ over $0.5 \mathrm{~g}$ of $0.3-0.5 \mathrm{~mm}$ particles with a BET surface area of $6 \mathrm{~m}^{2} / \mathrm{g}$, which achieved $\sim 42 \%$ conversion at $400{ }^{\circ} \mathrm{C}$ with no registered byproducts. At higher temperatures, $\mathrm{CO}_{2}$ was measured [243]. The $E_{a}$ on $\mathrm{BiPO}_{4}(67.2 \mathrm{~kJ} / \mathrm{mol})$ [243] and on $\mathrm{FePO}_{4}(56.6 \mathrm{~kJ} / \mathrm{mol})$ [242] were rather close to that reported on industrial FeMo catalysts $(64 \mathrm{~kJ} / \mathrm{mol})$ [244].

Sulfated- $\mathrm{TiO}_{2}$ binary metal oxide catalysts were investigated by Zhao et al. [245] for partial $\mathrm{MeOH}$ oxidation at $120-250^{\circ} \mathrm{C}$. The $\mathrm{Cr}, \mathrm{Mn}, \mathrm{Mo}$, and $\mathrm{V}$ oxide containing catalysts showed low selectivities $(<42 \%)$ towards FA, at $150{ }^{\circ} \mathrm{C}$ and $190^{\circ} \mathrm{C}$, whereas the Fe and Co containing catalysts showed no selectivity towards FA. The main products were DME and DMM [245].

The $\mathrm{CeO}_{2}$ surfaces (100) and (111) were investigated by using DFT calculations (using a dispersion-corrected $\mathrm{PBE}+\mathrm{U}$ model) for $\mathrm{MeOH}$ oxidation by Kropp and Paier [246]. The (100) facet was found to have an intrinsic barrier of $91 \mathrm{~kJ} / \mathrm{mol}$ while the (111) facet had $119 \mathrm{~kJ} / \mathrm{mol}$. The lower barrier inferred a lower FA desorption temperature, which was in agreement with TPD studies. The higher activity of the (100) facet was in agreement with lower oxygen defect formation energies for the (100) facet compared to the (111) facet, which was concluded to be a good reactivity descriptor for MvK mechanisms. FA was found to either desorb or form bridging dioxymethylene but adsorbed more exothermally on the (100) surface, implying a higher level of deep oxidation than on the (111) facet [246]. The C-H bond breaking on $\mathrm{CeO}_{2}(111)$ was probed by Sutton et al. [247] by a simulated temperature programmed reaction study by DFT and Kinetic Monte Carlo for $\mathrm{MeOH}$ oxidation compared with an experimental TPR study. The simulation showed formation and desorption of FA already below room temperature [247]. The effects of $\mathrm{Zr}, \mathrm{Hf}$, and Th as dopants on the $\mathrm{CeO}_{2}(111)$ surface were described as part of a descriptor analysis by Capdevila-Cortada and López [248] using DFT. Zr-doped and Hf-doped systems together with expanded lattice $\mathrm{CeO}_{2}$ had a decreased $E_{a}$ for the $\mathrm{C}-\mathrm{H}$ cleavage making the conversion of $\mathrm{CH}_{2} \mathrm{O}$ to $\mathrm{CO}$ more favorable. The desorption was stated to be controlled by geometric and acid-base factors, while the $\mathrm{C}-\mathrm{H}$ cleavage was governed by the acid-base and redox factors [248].

Pt supported on $\mathrm{SiO}_{2}, \mathrm{Co}_{3} \mathrm{O}_{4}, \mathrm{MnO}_{2}, \mathrm{Fe}_{2} \mathrm{O}_{3}, \mathrm{NiO}$, and $\mathrm{CeO}_{2}$ was investigated by Wang et al. [249] at $60^{\circ} \mathrm{C}$. No significant difference was observed in the selectivities towards $\mathrm{CO}_{2}, \mathrm{CH}_{2} \mathrm{O}$, and $\mathrm{MF}$ among the different supports, with the exception of the $\mathrm{MnO}_{2}$ supported sample, which showed larger $\mathrm{CH}_{2} \mathrm{O}$ selectivity (app. 60\%) compared to the others $(25-40 \%)$ but also orders of magnitude lower activity [249]. Pt-Bi bimetallic catalysts on activated carbon were investigated at $70-120{ }^{\circ} \mathrm{C}$ with 6 vol. $\% \mathrm{MeOH}$ and 1.5 vol. $\%$ $\mathrm{O}_{2}$ in $\mathrm{N}_{2}$ by Xiao et al. [250]. The best performing catalyst was the $1 \mathrm{wt} \% \mathrm{Pt}$ and $0.5 \mathrm{wt} \%$ Bi catalyst, which had $\mathrm{CH}_{2} \mathrm{O}$ selectivity above $70 \%$ for all temperatures at up to $17 \%$ conversion with $0.02 \mathrm{~g}$ catalyst in $100 \mathrm{~mL} / \mathrm{min}$ of feed. It demonstrated $98 \%$ selectivity and $8.1 \%$ conversion at $70{ }^{\circ} \mathrm{C}$ [250]. This was, however, unlikely to be usable in the Formox plants.

An $\mathrm{YBa}_{2} \mathrm{Cu}_{3} \mathrm{O}_{7-x}$ perovskite catalyst was investigated by Sun and Lee [251]. At low conversions, the selectivity relative to FA was $100 \%$. However, it decreased to $80 \%$ when the conversion increased to $40 \%$ at $300{ }^{\circ} \mathrm{C}$ with 8.8 vol. $\% \mathrm{MeOH}$ in the feed [251].

The catalytic performance of $\mathrm{Cu}$ and $\mathrm{Zn}$ incorporated in MCM-41 was investigated by Velu et al. [252] at $200-300{ }^{\circ} \mathrm{C}$ with $\mathrm{MeOH} / \mathrm{O}_{2}=2$ as the feed to the reactor. Selectivities of above $90 \%$ was achieved in the entire temperature interval with the exception of the high-loading $(4.2 \mathrm{wt} \% \mathrm{Cu}$ ) Cu-MCM-41, where the selectivity decreased drastically with increasing temperature [252].

The effect of $\mathrm{Pd}$ on the La-transitions metal perovskites for $\mathrm{MeOH}$ partial oxidation with 11 vol. $\% \mathrm{MeOH}$ and $5 \mathrm{vol} . \% \mathrm{O}_{2}$ in the feed was investigated by Li et al. [253,254] at $220-380{ }^{\circ} \mathrm{C}$. The addition of $5 \mathrm{~mol} \% \mathrm{Pd}$ (II) cations greatly improved the activity and the selectivity of $\mathrm{LaMnO}_{3}, \mathrm{LaFeO}_{3}$, and $\mathrm{LaCoO}_{3}$ so that the selectivity towards FA was approximately $90 \%$ for $\mathrm{LaMnO}_{3}$ and $\mathrm{LaCoO}_{3}$ and $85 \%$ for $\mathrm{LaFeO}_{3}$. No temperature dependence of selectivity was observed within the investigated temperature range [253]. 
The influence of Pd loading on $\mathrm{LaMnO}_{3}$ was investigated with $1 \%, 3 \%$, and $7 \%$ of the $\mathrm{Mn}$ ions exchanged with Pd. Selectivity increased with increasing Pd loading; however, the same temperature independence was not found [254].

The Topsøe group [131] has investigated the $\mathrm{W}$ based heteropolyanions $\left[\mathrm{PW}_{12} \mathrm{O}_{40}\right]^{3-}$ salts of $\mathrm{Cs}$ and $\mathrm{Fe}(\mathrm{III})$, both with very poor results. Moreover, $\mathrm{FePO}_{4}$ and $\mathrm{MnPO}_{4}$ were investigated by the Topsøe group, and both phosphates were found to have very low catalytic activity in contrast to the reports by [242,243]. Stoichiometric $\mathrm{MgFe}_{2} \mathrm{O}_{4}$ showed ignition behavior (large sudden change in activity) and increase in selectivity to $\mathrm{CO}$ and $\mathrm{CO}_{2}$ between 350 and $375^{\circ} \mathrm{C}$ and was, thus, deemed not to be interesting. $\mathrm{Fe}_{2}\left(\mathrm{WO}_{3}\right)_{3}$ has also been tested and rejected due to too low selectivity [131].

A study of the influence of supports has been conducted in the Topsøe group [131]. High $\left(56 \mathrm{~m}^{2} / \mathrm{g}\right)$ and low $\left(33 \mathrm{~m}^{2} / \mathrm{g}\right)$ surface area anatase $\mathrm{TiO}_{2}$ were tested in a pilot scale reactor. $\mathrm{TiO}_{2}$ showed high activity with low selectivity towards FA and high selectivity towards full oxidation at above $280^{\circ} \mathrm{C}$ for the high area anatase and above $290{ }^{\circ} \mathrm{C}$ for the low area anatase and was, thus, disqualified as a carrier since it may negatively influence selectivity towards FA. Anatase impregnated with $\mathrm{P}$ was also tested. It had lower activity and decreasing selectivity towards FA with time at $300{ }^{\circ} \mathrm{C} . \mathrm{ZrO}_{2}$ was tested as a carrier for $\mathrm{MeOH}$ oxidation activity, but it was found to be even more active towards the full oxidation of $\mathrm{MeOH}$ than anatase $\mathrm{TiO}_{2}$, and a runaway reaction occurred. $\gamma-\mathrm{Al}_{2} \mathrm{O}_{3}$ showed no runaway reaction, and the $\mathrm{CO}_{x}$ selectivity was acceptable, but there was high selectivity towards DME. However, when $\gamma-\mathrm{Al}_{2} \mathrm{O}_{3}$ was tested for FA oxidation by first having a layer of the commercial catalyst to convert $\mathrm{MeOH}$ to $\mathrm{FA}$, it converted the major part of the FA to $\mathrm{CO}$ and was, thus, discarded as carrier since it may convert the FA at high conversions. $\alpha$ $\mathrm{Al}_{2} \mathrm{O}_{3}$ was tested for $\mathrm{MeOH}$ oxidation and was found to have negligible activity for $\mathrm{MeOH}$ oxidation and converted a significantly smaller fraction of FA to $\mathrm{CO}$ and $\mathrm{CO}_{2}$. The $\alpha-\mathrm{Al}_{2} \mathrm{O}_{3}$ was, thus, a possible support, which we have used with Mo and V, with good selectivities but quick loss of Mo and V (see Supplementary Materials, Sections 2.2.2 and 2.2.3). Lastly, a $\mathrm{MgAl}_{2} \mathrm{O}_{4}$ carrier, prepared by hot impregnation of $8 \mathrm{wt} \% \mathrm{Mg}$ on $\gamma-\mathrm{Al}_{2} \mathrm{O}_{3}$, was tested. It was found to behave similarly to $\gamma-\mathrm{Al}_{2} \mathrm{O}_{3}$ with high activity towards DME [131].

The results reported in the literature for the catalysts not containing Mo or $\mathrm{V}$ are summarized in Figure 49 as formaldehyde selectivity against conversion. Some of the same trends observed for the $\mathrm{V}$ and Mo based catalysts are again visible. Thus, catalysts with $\mathrm{CeO}_{2}$ and $\mathrm{ZrO}_{2}$ account for the six points with the lowest selectivity. $\mathrm{Re}_{2} \mathrm{O}_{7}$ based catalysts reached a maximum selectivity of $90 \%$ at $14 \%$ conversion and are, thus, without promise as it, in addition, is a very expensive metal. The perovskites $\left(\mathrm{YBa}_{2} \mathrm{Cu}_{3} \mathrm{O}_{7-x}\right.$ and $\left.\mathrm{Pd} / \mathrm{La}(\mathrm{Co} / \mathrm{Fe} / \mathrm{Mn}) \mathrm{O}_{3}\right)$ and $\mathrm{Cu}(\mathrm{Zn}) / \mathrm{MCM}-41$ had too low selectivity at high conversion and is likely to oxidize to $\mathrm{CO} / \mathrm{CO}_{2}$ as $\mathrm{Cu}$ is the main component in methanol synthesis and, thus, likely to catalyze the decomposition to $\mathrm{CO} / \mathrm{CO}_{2}$ and $\mathrm{H}_{2}$ from the principle of micro kinetic reversibility. The $\mathrm{Fe}_{2} \mathrm{O}_{3} / \mathrm{MgO}$ catalyst had reported high selectivities and would, thus, have been very interesting, as there were no components that could be believed to become volatile during reaction exposure; however, our results for the Fe-Mg-O system could not reproduce promising results and showed poor selectivities to FA. The $\mathrm{NbPO}$ catalyst and the $\mathrm{CrO}_{3} / \mathrm{Cr}_{2} \mathrm{O}_{5}$ catalysts both had significantly lower reported selectivities than the $\mathrm{VPO}$ and $\mathrm{MoO}_{3}$ counterparts (Figures 25 and 26). Generally, these catalyst systems show too low selectivity and/or activity to be of interest as replacement catalysts for the Formox process. 


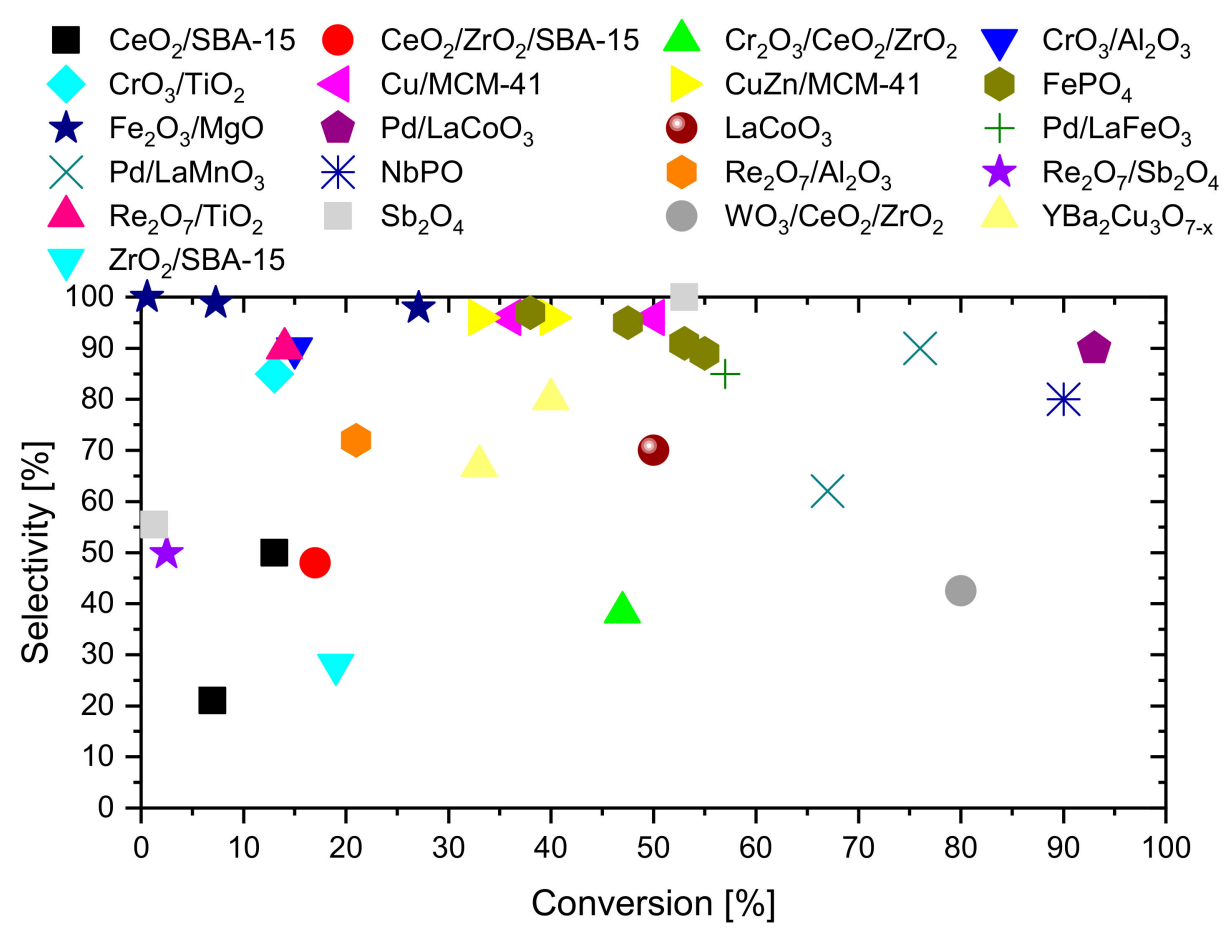

Figure 49. Summary of catalytic test results in the literature shown as selectivity vs. conversion for catalysts not containing V or Mo shown [125,140,166,222,223,226,227,233,237,241,251-254].

Volatility of the Active Phase

Reaction induced spreading of $\mathrm{MoO}_{3}$ and $\mathrm{V}_{2} \mathrm{O}_{5}$ was investigated with in situ Raman spectroscopy under $\mathrm{MeOH}$ oxidation reaction conditions by Cai et al. [255]. For a $4 \mathrm{wt} \%$ $\mathrm{MoO}_{3} / \mathrm{TiO}_{2}$ physical mixture, it was suggested that $\mathrm{MoO}_{3}$ was dispersed at $230{ }^{\circ} \mathrm{C}$ as only a small amount of crystalline $\mathrm{MoO}_{3}$ could be observed. If the reaction temperature was increased to $300{ }^{\circ} \mathrm{C}$, all crystalline $\mathrm{MoO}_{3}$ had disappeared. The same behavior was observable on $0.5-1 \% \mathrm{MoO}_{3} / \mathrm{SnO}_{2}$ physical mixtures. Comparably, if the spreading was performed by thermal treatment (whether in inert or oxidative atmosphere was not reported), $400{ }^{\circ} \mathrm{C}$ produced significant spreading, while $500{ }^{\circ} \mathrm{C}$ produced almost complete dispersion. For $4 \mathrm{wt} \% \mathrm{~V}_{2} \mathrm{O}_{5} / \mathrm{TiO}_{2}$, the $\mathrm{V}_{2} \mathrm{O}_{5}$ crystalline phase disappeared completely at $230{ }^{\circ} \mathrm{C}$ under reaction conditions and showed only surface vanadia species. In contrast to $\mathrm{MoO}_{3} / \mathrm{TiO}_{2}$, there was no spreading observed for the vanadia on $\mathrm{TiO}_{2}$ at $400-500{ }^{\circ} \mathrm{C}$ without methanol in the feed. $\mathrm{O}_{2}$-free experiments were later performed and showed that spreading was not related to $\mathrm{O}_{2}$. It was suggested that the spreading came from $\mathrm{MeOH}$ strongly binding with $\mathrm{Mo}$ and $\mathrm{V}$ in the crystalline $\mathrm{MoO}_{3}$ and $\mathrm{V}_{2} \mathrm{O}_{5}$ to form volatile $\mathrm{Mo}\left(\mathrm{OCH}_{3}\right)_{n}$ and $\mathrm{V}\left(\mathrm{OCH}_{3}\right)_{n}$. The alkoxy complexes of vanadia and molybdena are stated by Cai et al. [255] to be well known and to be liquids at room temperatures with high vapor pressures. However, no chemical formulas were given, and properties of Mo and $\mathrm{V}$ alkoxides were not reported.

In the $\mathrm{Fe}_{1-x} \mathrm{Al}_{x} \mathrm{VO}_{4}$ spinel-type catalyst, the $\mathrm{V} /(\mathrm{Fe}+\mathrm{Al})$ atomic ratio was stable as measured by XPS except for a small depletion of Fe, when comparing fresh and spent samples after $16 \mathrm{~h}$ [212]. The stability of the cation vacant $\mathrm{Fe}_{3-x-y} \mathrm{~V}_{x} \square_{y} \mathrm{O}_{4}$ spinel-type catalyst was evaluated by ICP after 5 days on stream and compared to the fresh catalyst. A small increase in $\mathrm{Fe} / \mathrm{V}$ ratio was observed for the 1:1 catalyst, while a small decrease was observed for the 2:1 ratio catalyst. For the remaining three investigated samples, no difference was measured with ICP within the time frame of 5 days [213]. The same was observed by Massa et al. [214]. The volatility of $\mathrm{FeVO}_{4}$, commercial type $\mathrm{Fe}_{2}\left(\mathrm{MoO}_{4}\right)_{3} / \mathrm{MoO}_{3}$ catalysts, and $\mathrm{Fe}-\mathrm{V}$-oxide layers supported on $\mathrm{TiO}_{2}, \alpha-\mathrm{Al}_{2} \mathrm{O}_{3}$, and $\mathrm{SiO}_{2}$ was investigated by Massa et al. [214]. There was a stabilizing effect of Fe on $\mathrm{V}$ on all the supports (Figure 50). 


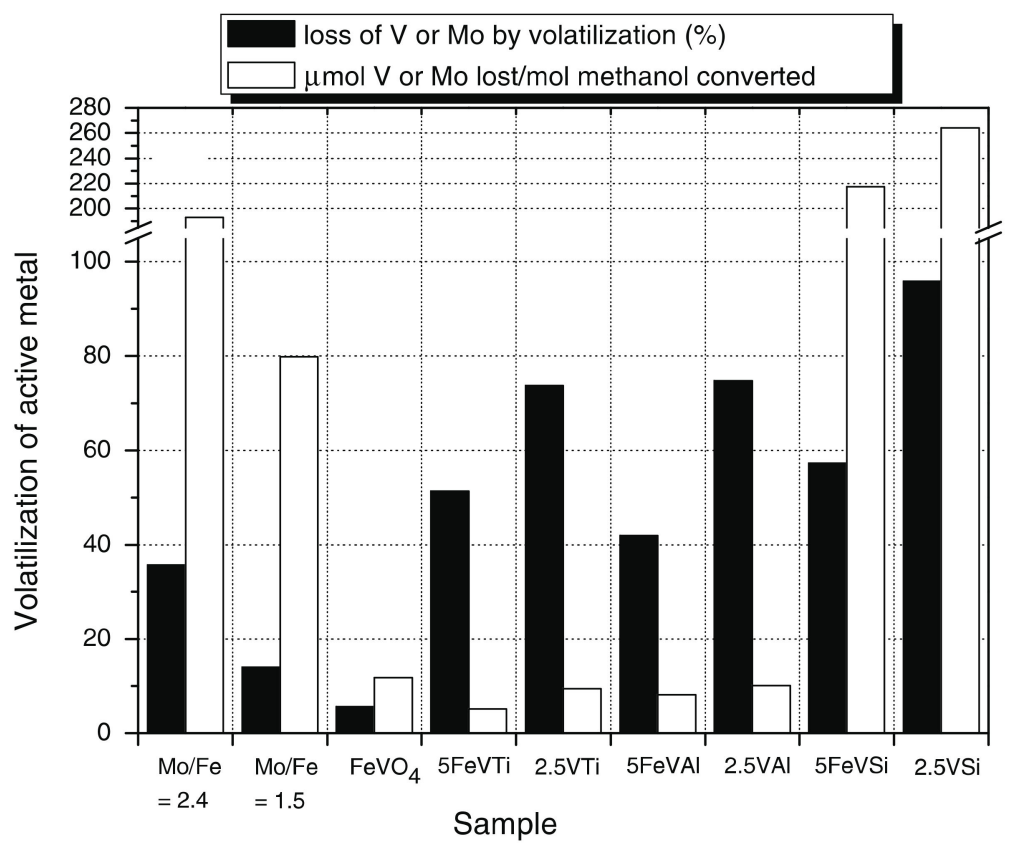

Figure 50. A comparison of the loss of $\mathrm{V}$ or Mo from the catalysts by volatilization during $\mathrm{MeOH}$ oxidation for 5 days, at $300{ }^{\circ} \mathrm{C}$ feeding $10 \mathrm{vol} . \% \mathrm{MeOH}$ and $10 \mathrm{vol} . \% \mathrm{O}_{2}$ in $\mathrm{N}_{2} .5 \mathrm{FeV}=$ five theoretical layers with $\mathrm{V}$ :Fe of $1: 1$ on support; $2.5 \mathrm{~V}=2.5$ theoretical layer of vanadia on support. $\mathrm{Al}=\alpha-\mathrm{Al}_{2} \mathrm{O}_{3}$; $\mathrm{Ti}=\mathrm{TiO}_{2} ; \mathrm{Si}=\mathrm{SiO}_{2}$. Reprinted with permission from [214] Springer Science+Bussiness Media. Copyright () (2011).

$\mathrm{TiO}_{2}$ and $\alpha-\mathrm{Al}_{2} \mathrm{O}_{3}$ have a stabilizing effect on the volatility of $\mathrm{V}$, since the absolute amount of $\mathrm{V}$ or Mo lost/mol MeOH converted decreased (Figure 50). However, the content of vanadia was so low in the supported catalysts that the relative decrease in vanadia content became very large. Supported Fe-V-oxides were concluded not suitable for industrial purposes since low $\mathrm{V}$ content made it very sensitive to volatilization and shortens the catalyst lifespan even though the volatilization rate may be lower with a support [214]. The $\mathrm{Fe}_{2.5} \mathrm{~V}_{0.2} \mathrm{Mo}_{0.5} \mathrm{O}_{\mathrm{y}}$ catalyst was tested with the same method, and there were no signs of volatility from ICP [215].

The volatility of various molybdates and vanadates was investigated by Andersson et al. [6] during $96 \mathrm{~h}$ of $\mathrm{MeOH}$ oxidation experiments at the conditions used for the comparisons of the molybdates and vanadates with the Formox KH44L (Table 2).

Table 2. Volatilization of Mo and V measured in the decrease in their surface areas from different molybdates and vanadates, respectively, under $96 \mathrm{~h}$ of $\mathrm{MeOH}$ oxidation. $T=300{ }^{\circ} \mathrm{C}$. Feed: 6 vol. $\%$ $\mathrm{CH}_{3} \mathrm{OH}$ and 11 vol.\% $\mathrm{O}_{2}$ in inert gas. Flow: $277 \mathrm{~mL} / \mathrm{min}$; loading: $30 \mathrm{mg}$ catalyst; particle size: 0.250-0.425 mm. Reprinted with permission from [6] Springer, Topics in catalysis, Copyright @ (2016).

\begin{tabular}{cc}
\hline Catalyst & $\begin{array}{c}\text { Mo- and V-Loss } \\
\left(\mathbf{\%} / \mathbf{m}^{2} \text { Surface Area) }\right.\end{array}$ \\
\hline $\mathrm{MoO}_{3} / \mathrm{Fe}_{2}\left(\mathrm{MoO}_{4}\right)_{3}$ & 9.3 \\
$\mathrm{Fe}_{2}\left(\mathrm{MoO}_{4}\right)_{3}$ & 2.3 \\
$\mathrm{Cr}_{2}\left(\mathrm{MoO}_{4}\right)_{3}$ & 6.2 \\
$\mathrm{Zr}\left(\mathrm{MoO}_{4}\right)_{3}$ & 9.7 \\
$\mathrm{FeVO}_{4}$ & 1.9 \\
$\mathrm{AlVO}_{4}$ & 4.8 \\
$\mathrm{Mn}_{3}\left(\mathrm{VO}_{4}\right)_{2}$ & 2.9 \\
\hline
\end{tabular}

Exactly how the surface area was correlated with component loss was not clear, but the paper states it was found by XPS. It was believed that the surface area should be 
understood as the part of the total surface area of the sample, which was covered with Mo or V. The FeMo catalyst with excess $\mathrm{MoO}_{3}$ lost Mo fast and faster than the FeMo with no surplus of Mo oxide. However, the consequence was lower selectivity when there was no surplus of Mo. It can also be observed that with respect to keeping the active component, $\mathrm{FeVO}_{4}$ was the most stable of the investigated samples, but it had still lost $1.9 \%$ of its vanadate surface area within 96 h of operation [6].

Excess crystalline $\mathrm{MoO}_{3}$ was found by Thrane et al. [107] to quickly volatilize from alkali earth metal molybdates at $400{ }^{\circ} \mathrm{C}$ as also observed on the FeMo catalyst. However, no Mo volatilization past the point of stoichiometry for the bulk alkali earth metal molybdates was observed by Raman spectroscopy [107]. However, in the later study of $\mathrm{MoO}_{3}$ supported on HAP and the Sr analogue, Thrane et al. [110] found that the amount of $\mathrm{CaMoO}_{4}$ and $\mathrm{SrMoO}_{4}$ quantified by XRD decreased with TOS for samples with nominal loadings of 10 and $15 \mathrm{wt} \% \mathrm{MoO}_{3}$. Thus, $\mathrm{CaMoO}_{4}$ loading went from 8.1 to $3.1 \mathrm{wt} \%$ after $408 \mathrm{~h}$ on stream for the $10 \mathrm{wt} \% \mathrm{MoO}_{3} / \mathrm{HAP}$. From exposure to reaction conditions, weight loss from $10 \mathrm{wt} \% \mathrm{MoO}_{3} / \mathrm{HAP}$ pellets and FeMo pellets were measured after $118.5 \mathrm{~h}$ on stream at $350{ }^{\circ} \mathrm{C}, 3 \mathrm{NL} / \mathrm{min}$ with 4 pellets (60 to $90 \mathrm{mg}$ each pellet) in the reactor, 5 vol.\% MeOH, and 10 vol. $\% \mathrm{O}_{2}$ in $\mathrm{N}_{2}$. Weight loss was found to increase with decreasing pellet density (increasing porosity) (Figure 51) and correlated well with the Mo loss found by ICP. The Mo loss from the Mo/HAP pellets was 70\% lower than from the FeMo pellet based on the mass loss. As the catalyst showed similar activities but $\mathrm{MoO}_{3} / \mathrm{HAP}$ slightly lower selectivity, it was reported to be of potential interest for utilization in the front-end of the bed in the Formox process [112].

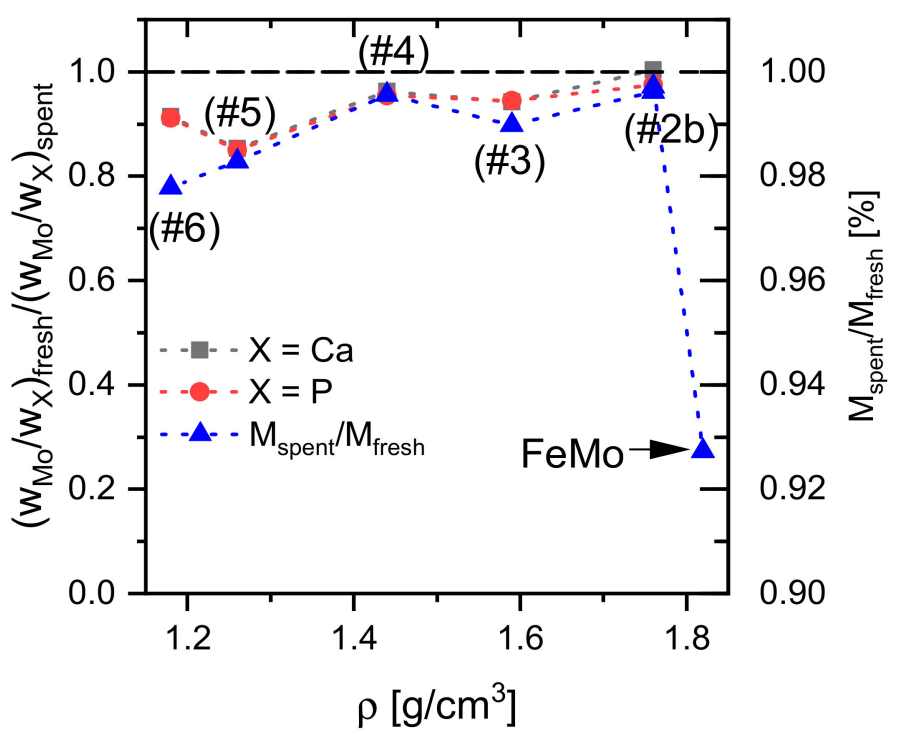

Figure 51. Ratio of Mo to Ca and P (three pellets combined and measured for each sample) and measured mass loss (four pellets combined and measured for each sample) after $118.5 \mathrm{~h}$ at $350{ }^{\circ} \mathrm{C}$, $3000 \mathrm{NmL} / \mathrm{min}, 5 \mathrm{vol} . \% \mathrm{MeOH}$, and 10 vol. $\% \mathrm{O}_{2}$ in $\mathrm{N}_{2}$ (<15\% conversion estimated) compared to the fresh samples. Reproduced from [112] with permission from the Royal Society of Chemistry.

During a mechanistic investigation of isolated vanadate species on MCM-48 by Bronkema and Bell [172], it was found from an in situ XANES experiment, under 4 vol.\% $\mathrm{MeOH}$ in $\mathrm{He}$ at $100{ }^{\circ} \mathrm{C}$, that the main edge and pre-edge features decreased with time. Calculations from the lost intensity showed $68 \%$ of the $\mathrm{V}$ was lost during 28 min exposure to $\mathrm{MeOH}$. In a separate experiment, the sample was exposed to 9 vol. $\% \mathrm{MeOH}$ in $\mathrm{He}$ at $100{ }^{\circ} \mathrm{C}$, where the $\mathrm{V}$ content fell from $5.2 \%$ to $0.9 \%$ during $12 \mathrm{~h}$ with a green deposit forming at the reactor outlet. The loss of $\mathrm{V}$ was believed to stem from volatile $\mathrm{V}$ methoxide species [172]. 
From in situ spectroscopic investigations of the molecular structures of vanadia on $\mathrm{SiO}_{2}$ by Gao et al. [256], it was found that alcoholysis of the V-O-Si bonds in the catalyst destabilizes the $\mathrm{V}$ oxide species, which results in the aggregation of surface $\mathrm{V}$ oxide species. Furthermore, it also resulted in the production of some volatile V-methoxy species under $\mathrm{MeOH}$ oxidation at higher temperatures [256].

In an investigation of the reactivity of vanadia on different supports, there were deposits at the outlet of the reactor due to volatilization of the $\mathrm{V}$ oxide in the $\mathrm{MeOH}$ oxidation environment for all investigated $\mathrm{V}_{2} \mathrm{O}_{5} / \mathrm{SiO}_{2}$ samples [180].

In an investigation of the structure of the V-MCM-41 catalyst by Yang et al. [170] using Raman spectroscopy, it was observed that $\mathrm{V}$ was incorporated atomically into the MCM-41 framework. It was stated that they would not migrate to the surface under reaction conditions of $\mathrm{MeOH}$ oxidation even though the $\mathrm{V}-\mathrm{OCH}_{3}$ intermediate was quite volatile [170].

These results indicate that $\mathrm{V}$ oxide containing catalysts cannot solve the volatility problem encountered from Mo based catalysts, since it might be even more volatile than the Mo oxide. However, $\mathrm{V}$ incorporated into the crystal structure of the support may be another matter.

The dynamic state of $\mathrm{SiO}_{2}$ supported metal oxide $(\mathrm{V}, \mathrm{Nb}, \mathrm{Cr}, \mathrm{Mo}, \mathrm{W}$, and $\mathrm{Re}$ ) catalysts during $\mathrm{MeOH}$ oxidation was investigated by Jehng et al. [257] by using in situ Raman spectroscopy. The reaction conditions were $230{ }^{\circ} \mathrm{C}$, with 4 vol. \% $\mathrm{MeOH}$ in $\mathrm{He} / \mathrm{O}_{2}$ ratio of $11 / 6$. Among those, only the $\mathrm{V}_{2} \mathrm{O}_{5} / \mathrm{SiO}_{2}$ had stable surface $\mathrm{M}-\mathrm{OCH}_{3}$ species. For $\mathrm{V}_{2} \mathrm{O}_{5} / \mathrm{SiO}_{2}$, the initial Raman spectra was obtained after reoxidation at $350{ }^{\circ} \mathrm{C}$ with a flow of $\mathrm{O}_{2}$. The Raman intensity of dehydrated $\mathrm{Nb}_{2} \mathrm{O}_{5} / \mathrm{SiO}_{2}$ decreased in the $\mathrm{MeOH}$ oxidation environment, and was not fully recovered after reoxidation. $\mathrm{MoO}_{3} / \mathrm{SiO}_{2}$ was found to form an amorphous $\mathrm{MoO}_{3}$ overlayer on the $\mathrm{SiO}_{2}$ support since the Raman features of crystalline $\alpha-\mathrm{MoO}_{3}$ disappeared under the $\mathrm{MeOH}$ oxidation conditions. After reoxidation, it was transformed into microcrystalline $\beta-\mathrm{MoO}_{3}$ particles [257]. Similar results were found by Bañares et al. [141] during $\mathrm{MeOH}$ oxidation over $\mathrm{MoO}_{3} / \mathrm{SiO}_{2}$, where $\mathrm{MoO}_{3}$ was reported to be volatile at higher loadings [141]. Jehng et al. [257] observed that the $\mathrm{WO}_{3}$ surface species could not be totally restored after reoxidation. For $\mathrm{Re}_{2} \mathrm{O}_{7} / \mathrm{SiO}_{2}$, there were no Raman features of Re at all after reoxidation even at higher temperatures, showing that the surface Re oxide species had become volatile at reaction conditions. The $\mathrm{CrO}_{3}$ species were partly reduced, which produced fluorescence in the Raman spectra [257].

In our investigation of $\mathrm{Sb}$ oxide on $\mathrm{SiO}_{2}$ (see Supplementary Materials, Section 2.2.3), a visible deposit was observed at the reactor outlet after an $8 \mathrm{~h}$ test with no Mo loaded into the reactor. Thus, $\mathrm{Sb}$ oxide seemed to also be volatile under $\mathrm{MeOH}$ oxidation conditions and requires further studies before a conclusion can be drawn on whether it could be applicable as a stabilizer.

Wachs et al. [230] found $\mathrm{TeO}_{x}$ to be volatile under $\mathrm{MeOH}$ oxidation conditions of $230{ }^{\circ} \mathrm{C}$, with 6 vol. $\% \mathrm{MeOH}$ and 13 vol. $\% \mathrm{O}_{2}$ [230].

Studies of methoxides of $\mathrm{Li}, \mathrm{Mg}$, and La showed them to remain unchanged when kept

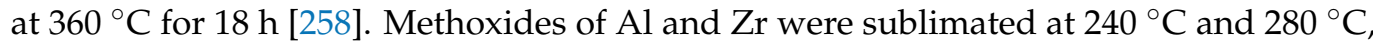
respectively, in a vacuum. For the physical properties of alkoxides, it was stated that they depend largely on the size and shape on the alkyl group (methoxy in this case), valence, atomic radius, stereochemistry, and coordination number of the metal. The alkoxide shift gradually from nonvolatile ionic alkoxides formed by some of the alkali metals to volatile covalent alkoxides of metals with valences of three, four, five, or six. It was stated that it was probable that most alkoxides of metals with valences of four and higher would be covalent, where the properties of the alkoxide would then be dependent on the tendency of the metal to increase its valence by intermolecular bonding with oxygen, providing relatively nonvolatile compounds. The other tendency was the steric effect of the alkyl group and its effect to block intermolecular bonding and keeping the alkoxide monomeric [258]. However, this should be the same in all cases since the alkyl group is a methoxy group in all cases. 
Interestingly the volatility of monomeric alkoxides with the same alkyl group increases with increasing molecular weight $\left(P_{\mathrm{Hf}}>P_{\mathrm{Zr}}>P_{\mathrm{Ti}}\right)$ [258]. Thus, a heavier metal as the active center in the same group, e.g., $\mathrm{Nb}$ instead of $\mathrm{V}$, and $\mathrm{W}$ instead of Mo may not increase the stability of the catalyst.

Summing up on the volatility, Mo in many (if not all) Mo oxide-based catalysts are volatile in the presence of $\mathrm{MeOH}$. This has also been found for $\mathrm{V}$ in various vanadia systems, as well as for Te and Re. Thus, exchanging Mo with $\mathrm{V}$ may only exchange one volatility problem with another and decrease selectivity at the same time. $\mathrm{FeVO}_{4}$ has been reported to be more stable towards volatilization than the FeMo catalysts. In addition, the spinel-type catalysts (reduced vanadates) have been reported to be stable under reaction conditions. Most of the catalytic systems reported in the literature were not investigated for the stability of the catalyst, and some of those that were investigated were performed under conditions unsuitable for stability measurements (i.e., overloaded reactor with full conversion). Thus, some of the most promising catalytic systems may be highly unstable at industrial reaction conditions. From the volatility of methoxides, $\mathrm{Al}$ and $\mathrm{Zr}$ based supports may not be suitable due to a risk of volatility issues; however, from $\mathrm{Al}_{2} \mathrm{O}_{3}$ being part of the commercial type methanol synthesis catalyst, it seems unlikely to be a problem. A general thought would also be that $\mathrm{Cr}$ should be less volatile than $\mathrm{Mo}$, and $\mathrm{Nb}$ should be less volatile than $\mathrm{V}$ due to the higher molecular weight, but mentioning the use of $\mathrm{Cr}$ in modern catalysis is undesired. However, it should be kept in mind that the volatility may actually very well increase with increasing molecular weight instead of decreasing. Thus, there is a number of considerations to keep in mind under the search for alternative catalysts for the selective oxidation of methanol.

\section{Summary of the Experimental Reproductions of the Most Interesting Alternative Catalysts}

There have been attempts to reproduce a number of the most interesting catalysts from the literature as well as some analogues. Thus, in the Supplementary Materials, results for the following types of catalysts can be found: $\mathrm{Fe}_{2} \mathrm{O}_{3} / \mathrm{MgO}, \mathrm{VPO}, \mathrm{MoO}_{3} / \alpha-\mathrm{Al}_{2} \mathrm{O}_{3}$, $\mathrm{V}_{2} \mathrm{O}_{5} / \alpha-\mathrm{Al}_{2} \mathrm{O}_{3}, \mathrm{Nb}_{2} \mathrm{O}_{5} / \alpha-\mathrm{Al}_{2} \mathrm{O}_{3}, \mathrm{~V}_{2} \mathrm{O}_{5} / \mathrm{HAP}, \mathrm{Nb}_{2} \mathrm{O}_{5} / \mathrm{HAP}, \mathrm{NbPO}, \mathrm{Nb}_{2} \mathrm{O}_{5}, \mathrm{FeVO}_{4}, \mathrm{Sb}$ oxide on silica, Mo-Sb mixed oxide, and $\mathrm{V}-\mathrm{Sb}$ mixed oxide.

The main conclusions from the experimental screening of alternative catalyst were that the molybdenum containing catalysts were in general selective with FA selectivities that were not that far from the FeMo catalyst (>92\% selectivity) with DME as a significant byproduct. However, significant deactivations were visible even within $8 \mathrm{~h}$ on stream at $400{ }^{\circ} \mathrm{C}$ for these catalysts. The vanadium containing catalysts were generally more active than the molybdenum containing catalysts, and several of them were more active than the FeMo catalyst, but the selectivity was lower than for the molybdenum containing catalysts, especially at higher temperatures and conversion. DME was only a minor byproduct with $\mathrm{CO}$ and $\mathrm{CO}_{2}$ being the most significant byproducts. The VPO catalysts were more selective towards formaldehyde and DME but also had significantly lower activity than the other $\mathrm{V}$ based catalysts. For catalysts with neither molybdenum nor vanadium, the DME corrected selectivity to FA was low in general, and they were also less active than the molybdenum or vanadium containing catalysts, with the exception of the $\mathrm{Fe}_{2} \mathrm{O}_{3} / \mathrm{MgO}$ catalysts, which over oxidized to $\mathrm{CO}$ and $\mathrm{CO}_{2}$. $\mathrm{Nb}$ based catalysts made significant amounts of DME, and over oxidation resulted primarily in $\mathrm{CO}_{2}$.

\section{Concluding Remarks}

Despite the fact that the industrial FeMo catalyst is active and very selective for the oxidation of methanol to formaldehyde, mainly due to the low adsorption energy of FA, it is not a perfect catalyst. This review has summarized the FeMo catalysts' main problem of forming volatile Mo species with $\mathrm{MeOH}$. This results in the depletion of Mo at the top of the reactor/hot spot and the formation of deposits of Mo oxides further down in the reactor, resulting in an increase in pressure drop, decrease in selectivity, and finally shut down of the plant in order to exchange the catalyst. 
This has motivated the search for alternative and more stable catalysts with similar activity and equally high selectivity. These efforts were also reviewed and several classes of alternative catalysts were identified from the open literature and some patents. Most of the investigated catalysts contain either Mo or V in some form, especially for the catalysts showing promising selectivity and conversion. A number of the studies reporting good performances of alternative materials are many decades old; thus, the lack of implementation in industry could indicate that they did not pass the test if they were tested industrially.

Mo based catalysts were the most selective catalysts for the oxidation of $\mathrm{MeOH}$ to FA. $\mathrm{V}$ based catalysts were rather selective, but mostly they were not as selective as the Mo based catalysts but more active. The catalysts without Mo and V were mostly lacking in either activity, selectivity, or both. $\mathrm{V}$ based catalysts have mostly been investigated as an alternative to Mo based catalysts; however, $\mathrm{V}$ also becomes volatile with $\mathrm{MeOH}$ in the feed and may, thus, only exchange one volatile component with another.

The operating temperature and pressure in the industrial Formox plants of $250-380{ }^{\circ} \mathrm{C}$ and $\sim 0.5$ barg [6] have in general led the conditions of the investigations of alternative catalysts $\left(\sim 150-500^{\circ} \mathrm{C}\right.$ and $\left.\sim 1 \mathrm{~atm}\right)$ as an alternative catalyst optimally should be applicable at a similar temperature and pressure in order to be of relevance in the existing Formox plants.

At this point, no catalyst that has the potential to fully exchange the FeMo catalyst in the industrial (Formox) process has been reported. However, some catalysts showed higher stability/lower molybdenum loss and similar activity and reasonable, but slightly lower, selectivity compared to the FeMo catalyst, including a recently developed $\mathrm{MoO}_{3} / \mathrm{HAP}$ catalyst [110,112]. Such catalysts could possibly be used in the inlet section of the reactor, providing moderate conversion over this alternative catalyst, where selectivity is rather high. Moreover, FeMo catalyst is exposed to decreasing $\mathrm{MeOH}$ concentration at the downstream, thus prolonging its lifetime without significantly losing FA to over oxidation products.

Supplementary Materials: The following are available at https:/ / www.mdpi.com/article/10.3390/ catal11111329/s1, experimental procedures and results for the revisitation on the literature. Figure S1: XRD diffractograms measured for the catalyst samples supported on the commercial hydroxy-apatite (HAP), Figure S2: XRD diffractograms measured for the catalyst samples supported on $\alpha-\mathrm{Al} 2 \mathrm{O} 3$, Figure S3: XRD diffractograms measured for the antimony containing samples, Figure S4: XRD diffractogram measured for the vanadyl phosphate samples. VPO (a) was when the VOPO4.2H2O sample, obtained after the first reflux, was calcined. VPO (b) was when the VOHPO4.0.5H2O sample, obtained after additional refluxes in isobutanol and water, was calcined, Figure S5: XRD diffractograms for $\mathrm{NbPO}, \mathrm{FeVO} 4$ and Fe2O3/MgO samples, Figure S6: Screening results for molybdenum containing catalysts. FeMo included for comparison. $50 \mathrm{mg}$ of catalyst in a feed of $3-5 \% \mathrm{MeOH}$ in 127.5 NmL/min N2 and $15 \mathrm{NmL} / \mathrm{min} \mathrm{O}$. (a) Scor vs. temperature, (b) Xcor vs. temperature and (c) Scor vs. Xcor, Figure S7: Arrhenius plot for molybdenum containing catalysts, Figure S8: Screening results for vanadium containing catalysts. FeMo included for comparison. $50 \mathrm{mg}$ of catalyst (except for the FeVO4 samples, here it was $7.5 \mathrm{mg}$ ) in a feed of 3-5\% MeOH in $127.5 \mathrm{NmL} / \mathrm{min} \mathrm{N2}$ and 15 $\mathrm{NmL} / \mathrm{min}$ O2. (a) Scor vs. temperature, (b) Xcor vs. temperature and (c) Scor vs. Xcor, Figure S9: Arrhenius plot for vanadium containing catalysts, Figure S10: Screening results for alternative catalysts not containing molybdenum or vanadium. FeMo included for comparison. $50 \mathrm{mg}$ of catalyst in a feed of 3-5\% MeOH in $127.5 \mathrm{NmL} / \mathrm{min} \mathrm{N2}$ and $15 \mathrm{NmL} / \mathrm{min} \mathrm{O} 2$. (a) Scor vs. temperature, (b) Xcor vs. temperature and (c) Scor vs. Xcor, Figure S11: Arrhenius plot for catalysts not containing molybdenum or vanadium, Table S1: Overview of catalyst systems which were revisited, Table S2: Amounts of chemicals used for the preparation of HAP supported samples, Table S3: Amounts of chemicals used for the preparation of $\alpha$-Al2O3 supported samples, Table S4: Overview of BET surface areas measured on the catalysts tested, Table S5: Results of elemental analysis for catalysts samples, which were filtered during the preparation, Table S6: Selectivities at $250-400{ }^{\circ} \mathrm{C}$, conversion and reaction rate constants for the fresh molybdenum con-taining catalysts with $50 \mathrm{mg}$ of catalyst, in a feed flow of $15 \mathrm{NmL} / \mathrm{min} \mathrm{O}, 127.5 \mathrm{NmL} / \mathrm{min} \mathrm{N} 2$ and 3-5\% CH3OH, Table S7: Pre-exponential factor $(\mathrm{k} 0)$ and activation energy (Ea) of molybdenum containing catalysts, Table S8: Selectivities at $250-400{ }^{\circ} \mathrm{C}$, conversion and reaction rate constants for the vanadium containing catalysts with $50 \mathrm{mg}$ of catalyst (except $\mathrm{FeVO} 4$ and $\mathrm{FeVO} 4-\mathrm{Cl}$ which were tested with $7.5 \mathrm{mg}$ ), in a feed flow 
of $15 \mathrm{NmL} / \mathrm{min} \mathrm{O} 2,127.5 \mathrm{NmL} / \mathrm{min} \mathrm{N} 2$ and 3-5\% CH3OH, Table S9: Pre-exponential factor (k0) and activation energy (Ea) of vanadium containing catalysts, Table S10: Specific selectivities at 250-400 ${ }^{\circ} \mathrm{C}$, conversion and reaction rate constants for the catalysts not containing molybdenum or vanadium with $50 \mathrm{mg}$ of catalyst, in a feed flow of $15 \mathrm{NmL} / \mathrm{min} \mathrm{O} 2,127.5 \mathrm{NmL} / \mathrm{min} \mathrm{N2}$ and 3-5\% $\mathrm{CH} 3 \mathrm{OH}$, Table S11: Pre-exponential factor (k0) and activation energy (Ea) of catalysts not containing molybdenum or vanadium.

Author Contributions: Conceptualization, U.V.M., M.T., M.H. and A.D.J.; methodology, J.T., U.V.M., M.T., M.H. and A.D.J.; formal analysis, J.T.; investigation, J.T.; funding aquisition, M.H. and A.D.J.; writing —original draft preparation, J.T.; writing—review and editing, U.V.M., M.T., M.H. and A.D.J.; visualization, J.T. All authors have read and agreed to the published version of the manuscript.

Funding: This research was funded by the Independent Research Fund Denmark, grant number DFF-4184-00336.

Data Availability Statement: In this section, please provide details regarding where data supporting reported results can be found, including links to publicly archived datasets analyzed or generated during the study. Please refer to suggested Data Availability Statements in section "MDPI Research Data Policies" at https:/ /www.mdpi.com/ethics. You might choose to exclude this statement if the study did not report any data.

Conflicts of Interest: The authors declare no conflict of interest.

\section{References}

1. Franz, A.W.; Kronemayer, H.; Pfeiffer, D.; Pilz, R.D.; Reuss, G.; Disteldorf, W.; Gamer, A.O.; Hilt, A. Formaldehyde. In Ullmann's Encyclopedia of Industrial Chemistry; John Wiley \& Sons Inc.: Hoboken, NJ, USA, 2016; pp. 1-34.

2. Soares, A.P.V.; Portela, M.F.; Kiennemann, A. Methanol Selective Oxidation to Formaldehyde over Iron-Molybdate Catalysts. Catal. Rev. Sci. Eng. 2005, 47, 125-174. [CrossRef]

3. IHS Markit Formaldehyde. Available online: https://www.ihs.com/products/formaldehyde-chemical-economics-handbook. html (accessed on 28 September 2017).

4. American Chemistry Council Formaldehyde. Available online: https:/ / formaldehyde.americanchemistry.com/Applications / (accessed on 28 September 2017).

5. ICIS Formaldehyde Production and Manufacturing Process. Available online: https://www.icis.com/resources/news/2007/11/ 05/9076014/formaldehyde-production-and-manufacturing-process / (accessed on 28 September 2017).

6. Andersson, A.; Holmberg, J.; Häggblad, R. Process Improvements in Methanol Oxidation to Formaldehyde: Application and Catalyst Development. Top. Catal. 2016, 59, 1589-1599. [CrossRef]

7. Cision Global Formaldehyde Market 2018-2022. Available online: https://www.prnewswire.com/news-releases/globalformaldehyde-market-2018-2022-300633054.html (accessed on 25 April 2019).

8. Kortewille, B.; Wachs, I.E.; Cibura, N.; Pfingsten, O.; Bacher, G.; Muhler, M.; Strunk, J. Proof of Equivalent Catalytic Functionality upon Photon-Induced and Thermal Activation of Supported Isolated Vanadia Species in Methanol Oxidation. ChemCatChem 2018, 10, 2360-2364. [CrossRef]

9. Wang, C.T.; Willey, R.J. Mechanistic aspects of methanol partial oxidation over supported iron oxide aerogels. J. Catal. 2001, 202, 211-219. [CrossRef]

10. Sukumar, M.; Kennedy, L.J. Catalytic Conversion of Methanol to Formaldehyde Over La2CuO4 Nanoparticles. J. Nanosci. Nanotechnol. 2019, 19, 826-832. [CrossRef]

11. Espinosa, M.R.; Charboneau, D.J.; Garcia de Oliveira, A.; Hazari, N. Controlling Selectivity in the Hydroboration of Carbon Dioxide to the Formic Acid, Formaldehyde, and Methanol Oxidation Levels. ACS Catal. 2019, 9, 301-314. [CrossRef]

12. Siebert, M.; Seibicke, M.; Siegle, A.; Kräh, S.; Trapp, O. Selective Ruthenium-Catalyzed Transformation of Carbon Dioxide: An Alternative Approach towards Formaldehyde. J. Am. Chem. Soc. 2019, 141, 334-341. [CrossRef] [PubMed]

13. Han, Z.S.; Pan, W.X.; Pan, W.X.; Li, J.L.; Zhu, Q.M.; Tin, K.C.; Wong, N.B. Preparation and effect of Mo-V-Cr-Bi-Si oxide catalysts on controlled oxidation of methane to methanol and formaldehyde. Korean J. Chem. Eng. 1998, 15, 496-499. [CrossRef]

14. Santos, O.S.; Mascarenhas, A.J.S.; Andrade, H.M.C. N2O-assisted methanol selective oxidation to formaldehyde on cobalt oxide catalysts derived from layered double hydroxides. Catal. Commun. 2018, 113, 32-35. [CrossRef]

15. Koivikko, N.; Laitinen, T.; Mouammine, A.; Ojala, S.; Keiski, R.L. Catalytic activity studies of Vanadia/Silica-Titania catalysts in SVOC partial oxidation to formaldehyde: Focus on the catalyst composition. Catalysts 2018, 8, 56. [CrossRef]

16. Gerberich, H.R.; Seaman, G.C. Hoechst-Celanese Corporation Formaldehyde. In Kirk-Othmer Encyclopedia of Chemical Technology; John Wiley \& Sons, Inc.: Hoboken, NJ, USA, 2013; pp. 24-26. ISBN 9780471238966.

17. Söderhjelm, E.; House, M.P.; Cruise, N.; Holmberg, J.; Bowker, M.; Bovin, J.-O.; Andersson, A. On the Synergy Effect in MoO3-Fe2(MoO4)3 Catalysts for Methanol Oxidation to Formaldehyde. Top. Catal. 2008, 50, 145-155. [CrossRef]

18. Methanex Methanex Monthly Average Regional Posted Contract Price History. Available online: https:/ /www.methanex.com/ sites/default/files/methanol-price/MxAvgPrice_Sept29\%2C2017.pdf (accessed on 29 September 2017). 
19. Andersson, L.-O. New Green Policies in China. In Informally Speaking A Formaldehyde Magazine from Johnson Matthey; Johnson Matthey: London, UK, 2019; pp. 12-13.

20. Andersson, A.; Hernelind, M.; Augustsson, O. A study of the ageing and deactivation phenomena occurring during operation of an iron molybdate catalyst in formaldehyde production. Catal. Today 2006, 112, 40-44. [CrossRef]

21. Abaulina, L.I.; Kustova, G.N.; Klevtsova, R.F.; Popov, B.I.; Bibin, V.N.; Melekhina, V.A.; Kolomiichuk, V.N.; Boreskov, G.K. Stydy of an iron-molybdenum oxide catalyst for oxidation of methanol to formaldehyde V. Formation of a solid-solution of molybdenum trioxide in iron molybdate and nature of catalytically active component. Kinet. Catal. 1976, 17, $1126-1132$.

22. Chapman, S.; Brookes, C.; Bowker, M.; Gibson, E.K.; Wells, P.P. Design and stabilisation of a high area iron molybdate surface for the selective oxidation of methanol to formaldehyde. Faraday Discuss 2016, 188, 115-129. [CrossRef]

23. Brookes, C.; Wells, P.P.; Dimitratos, N.; Jones, W.; Gibson, E.K.; Morgan, D.J.; Cibin, G.; Nicklin, C.; Mora-Fonz, D.; Scanlon, D.O.; et al. The Nature of the Molybdenum Surface in Iron Molybdate. The Active Phase in Selective Methanol Oxidation. J. Phys. Chem. C 2014, 118, 26155-26161. [CrossRef]

24. Brookes, C.; Bowker, M.; Gibson, E.K.; Gianolio, D.; Mohammed, K.M.H.; Parry, S.; Rogers, S.M.; Silverwood, I.P.; Wells, P.P. In situ spectroscopic investigations of $\mathrm{MoOx} / \mathrm{Fe} 2 \mathrm{O} 3$ catalysts for the selective oxidation of methanol. Catal. Sci. Technol. 2016, 6, 722-730. [CrossRef]

25. Brookes, C.; Wells, P.P.; Cibin, G.; Dimitratos, N.; Jones, W.; Morgan, D.J.; Bowker, M. Molybdenum Oxide on Fe2O3 Core-Shell Catalysts: Probing the Nature of the Structural Motifs Responsible for Methanol Oxidation Catalysis. ACS Catal. 2014, 4, 243-250. [CrossRef]

26. Uhlrich, J.J.; Sainio, J.; Lei, Y.; Edwards, D.; Davies, R.; Bowker, M.; Shaikhutdinov, S.; Freund, H.J. Preparation and characterization of iron-molybdate thin films. Surf. Sci. 2011, 605, 1550-1555. [CrossRef]

27. House, M.P.; Shannon, M.D.; Bowker, M. Surface segregation in iron molybdate catalysts. Catal. Lett. 2008, 122, $210-213$. [CrossRef]

28. Brookes, C.; Bowker, M.; Wells, P. Catalysts for the Selective Oxidation of Methanol. Catalysts 2016, 6, 92. [CrossRef]

29. Routray, K.; Zhou, W.; Kiely, C.J.; Grünert, W.; Wachs, I.E. Origin of the synergistic interaction between MoO3 and iron molybdate for the selective oxidation of methanol to formaldehyde. J. Catal. 2010, 275, 84-98. [CrossRef]

30. Bowker, M.; Brookes, C.; Carley, A.F.; House, M.P.; Kosif, M.; Sankar, G.; Wawata, I.; Wells, P.P.; Yaseneva, P. Evolution of active catalysts for the selective oxidative dehydrogenation of methanol on Fe2O3 surface doped with Mo oxide. Phys. Chem. Chem. Phys. 2013, 15, 12056-12067. [CrossRef]

31. Bowker, M.; House, M.; Alshehri, A.; Brookes, C.; Gibson, E.K.; Wells, P.P. Selectivity determinants for dual function catalysts: Applied to methanol selective oxidation on iron molybdate. Catal. Struct. React. 2015, 1, 95-100. [CrossRef]

32. Bowker, M.; Gibson, E.K.; Silverwood, I.P.; Brookes, C. Methanol oxidation on Fe2O3 catalysts and the effects of surface Mo. Faraday Discuss. 2016, 188, 387-398. [CrossRef] [PubMed]

33. Bowker, M.; Holroyd, R.; Elliott, A.; Morrall, P.; Alouche, A.; Entwistle, C.; Toerncrona, A. The selective oxidation of methanol to formaldehyde on iron molybdate catalysts and on component oxides. Catal. Lett. 2002, 83, 165-176. [CrossRef]

34. Yamada, H.; Niwa, M.; Murakami, Y. Methanol oxidation on a molybdena monolayer supported on iron oxide. Appl. Catal. A Gen. 1993, 96, 113-123. [CrossRef]

35. Busca, G. On the mechanism of methanol oxidation over vanadia-based catalysts: A FT-IR study of the adsorption of methanol, formaldehyde and formic acid on vanadia-silica. J. Mol. Catal. 1989, 50, 241-249. [CrossRef]

36. Chung, J.S.; Miranda, R.; Bennett, C.O. Mechanism of Partial Oxidation of Methanol over MoO3. J. Catal. 1988, 114, 398-410. [CrossRef]

37. Louis, C.; Tatibouët, J.M.; Che, M. Catalytic properties of silica-supported molybdenum catalysts in methanol oxidation: The influence of molybdenum dispersion. J. Catal. 1988, 109, 354-366. [CrossRef]

38. Bowker, M.; Carley, A.F.; House, M. Contrasting the behaviour of MoO3 and $\mathrm{MoO} 2$ for the oxidation of methanol. Catal. Lett. 2008, 120, 34-39. [CrossRef]

39. Bowker, M.; Holroyd, R.; House, M.; Bracey, R.; Bamroongwongdee, C.; Shannon, M.; Carley, A. The selective oxidation of methanol on iron molybdate catalysts. Top. Catal. 2008, 48, 158-165. [CrossRef]

40. Trifirò, F.; Notarbartolo, S.; Pasquon, I. The nature of the active component in a Fe2O3-MoO3 catalyst. II. Study of the variations occurring during high temperature treatment. J. Catal. 1971, 22, 324-332. [CrossRef]

41. Dias, A.P.S.; Montemor, F.; Portela, M.F.; Kiennemann, A. The role of the suprastoichiometric molybdenum during methanol to formaldehyde oxidation over Mo-Fe mixed oxides. J. Mol. Catal. A Chem. 2015, 397, 93-98. [CrossRef]

42. Hummadi, K.K.; Hassan, K.H.; Mitchell, P.C.H. Selectivity and activity of iron molybdate catalysts in oxidation of methanol. J. Eng. Res. 2009, 6, 1-7.

43. Raun, K.V.; Lundegaard, L.F.; Chevallier, J.; Beato, P.; Appel, C.C.; Nielsen, K.; Thorhauge, M.; Jensen, A.D.; Høj, M. Deactivation behavior of an iron-molybdate catalyst during selective oxidation of methanol to formaldehyde. Catal. Sci. Technol. 2018, 8 , 4626-4637. [CrossRef]

44. Pernicone, N.; Liberti, G.; Ersini, L. Catalytic Activity of Pure MoO3 and of Mixtures of MoO3 with Trivalent Metal Molybdates in the Oxidation of $\mathrm{CH} 3 \mathrm{OH}$ to $\mathrm{CH} 2 \mathrm{O}$. In Proceedings of the Fourth International Congress on Catalysis, Moscow, Russia, 23-29 June 1968; pp. 287-296.

45. Tatibouët, J.M. Methanol oxidation as a catalytic surface probe. Appl. Catal. A Gen. 1997, 148, 213-252. [CrossRef] 
46. Ivanov, K.; Dimitrov, D. On the mechanism of the selective oxidation of methanol over iron-molybdate catalysts. Oxid. Commun. 2008, 31, 444-455.

47. AI, M. Catalytic Activity for the Oxidation of Methanol and the Acid-Base Properties of Metal Oxides. J. Catal. 1978, 54, 426-435. [CrossRef]

48. Nikolenko, N.V.; Kalashnikov, Y.V.; Kostyniuk, A.O.; Poloz, A.Y.; Aksenenko, E.V. Difference in adsorption properties of Fe(III), $\mathrm{Mo}(\mathrm{VI})$ oxides and Fe(III) molybdate as a cause of high selectivity of methanol oxidation on iron molybdate catalyst. Vopr. Khimii Khimicheskoi Tekhnologii 2019, 3, 35-45.

49. Wachs, I.E. Raman and IR studies of surface metal oxide species on oxide supports: Supported metal oxide catalysts. Catal. Today 1996, 27, 437-455. [CrossRef]

50. Pernicone, N.; Lazzerin, F.; Lanzavecchia, G. The effect of water on the catalytic oxidation of methanol to formaldehyde. J. Catal. 1968, 10, 83-84. [CrossRef]

51. Pernicone, N.; Lazzerin, F.; Liberti, G.; Lanzavecchia, G. On the mechanism of CH3OH oxidation to $\mathrm{CH} 2 \mathrm{O}$ over MoO3-Fe2(MoO4)3 catalyst. J. Catal. 1969, 14, 293-302. [CrossRef]

52. Rellán-Piñeiro, M.; López, N. The active molybdenum oxide phase in the methanol oxidation to formaldehyde (Formox process): A DFT study. ChemSusChem 2015, 8, 2231-2239. [CrossRef] [PubMed]

53. Liberti, G.; Pernicone, N.; Soattini, S. Pulse microreactor study of methanol oxidation over MoO3-Fe2(MoO4)3 catalyst. J. Catal. 1972, 27, 52-55. [CrossRef]

54. Holstein, W.L.; Machiels, C.J. Inhibition of Methanol Oxidation by Water Vapor-Effect on Measured Kinetics and Relevance to the Mechanism. J. Catal. 1996, 162, 118-124. [CrossRef]

55. Drăgan, S.; Kulic, I. A macrokinetic study of the oxidation of methanol to formaldehyde on Fe2O3-MoO3 oxide catalyst. Stud. Univ. Babes-Bolyai Chem. 2016, LXI, 155-166.

56. Bhattacharyya, S.K.; Janakiram, K.; Ganguly, N.D. Kinetics of the Vapor-Phase Oxidation of Methyl Alcohol on Vanadium Pentoxide Catalyst. J. Catal. 1967, 18, 128-136. [CrossRef]

57. Bibin, V.N.; Popov, B.I. Kinetics of methanol oxidation by air on iron-molybdenum oxide catalysts. Kinet. Catal. 1969, 10, 1091-1098.

58. Evmenenko, N.P.; Gorokhovatskii, Y.B. Kinetics of methanol oxidation at a ferromolybdenum catalyst. Kinet. Katal. 1968, 10, 1299-1304.

59. Santacesaria, E.; Morbidelli, M.; Carrà, S. Kinetics of the catalytic oxidation of methanol to formaldehyde. Chem. Eng. Sci. 1981, 36, 909-918. [CrossRef]

60. Deshmukh, S.A.R.K.; van Sint Annaland, M.; Kuipers, J.A.M. Kinetics of the partial oxidation of methanol over a Fe-Mo catalyst. Appl. Catal. A Gen. 2005, 289, 240-255. [CrossRef]

61. Ulukardesler, A.H.; Atalay, S.; Atalay, F.S. Determination of Optimum Conditions and the Kinetics of Methanol Oxidation. Chem. Eng. Technol. 2010, 33, 167-176. [CrossRef]

62. Tesser, R.; Di Serio, M.; Santacesaria, E. Catalytic oxidation of methanol to formaldehyde: An example of kinetics with transport phenomena in a packed-bed reactor. Catal. Today 2003, 77, 325-333. [CrossRef]

63. Machiels, C.; Sleight, A.W. Kinetic isotope effect in the selective oxidation of methanol to formaldehyde over some molybdate catalysts. J. Catal. 1982, 76, 238-239. [CrossRef]

64. Machiels, C. Development of a pulse reactor with online MS analysis to study the oxidation of methanol. Acs Symp. Ser. 1982, 178, 240-251.

65. Yang, T.-J.; Lunsford, J.H. Partial oxidation of Methanol to Formaldehyde over Molybdenum Oxide on Silica. Catal. Lett. 1987, 103, 55-64. [CrossRef]

66. Routray, K.; Briand, L.E.; Wachs, I.E. Is there a relationship between the $\mathrm{M}=\mathrm{O}$ bond length (strength) of bulk mixed metal oxides and their catalytic activity? J. Catal. 2008, 256, 145-153. [CrossRef]

67. Lafyatis, D.S.; Creten, G.; Froment, G.F. TAP reactor study of the partial oxidation of methanol to formaldehyde using an industrial Fe-Cr-Mo oxide catalyst. Appl. Catal. A Gen. 1994, 120, 85-103. [CrossRef]

68. Szabo, A.; Urda, A.; Alifanti, M. Aspects concerning the mechanism of the partial oxidation reactions. Analele Univ. Bucureşti Chim. Anul. 2006, II, 85-91.

69. O'Brien, M.G.; Beale, A.M.; Jacques, S.D.M.; Buslaps, T.; Honkimaki, V.; Weckhuysen, B.M. On the Active Oxygen in Bulk MoO3 during the Anaerobic Dehydrogenation of Methanol. J. Phys. Chem. C 2009, 113, 4890-4897. [CrossRef]

70. House, M.P.; Carley, A.F.; Bowker, M. Selective oxidation of methanol on iron molybdate catalysts and the effects of surface reduction. J. Catal. 2007, 252, 88-96. [CrossRef]

71. Choksi, T.; Greeley, J. Partial Oxidation of Methanol on MoO3(010): A DFT and Microkinetic Study. ACS Catal. 2016, 6, 7260-7277. [CrossRef]

72. Peyrovi, M.H.; Parsafard, N.; Hasanpour, H. Catalytic Study of the Partial Oxidation Reaction of Methanol to Formaldehyde in the Vapor Phase. Bull. Chem. React. Eng. Catal. 2018, 13, 520. [CrossRef]

73. Ivanov, K.; Dimitrov, D.; Boyanov, B. Optimization of the methanol oxidation over iron-molybdate catalysts. Chem. Eng. J. 2009, 154, 189-195. [CrossRef]

74. Partopour, B.; Dixon, A.G. Effect of particle shape on methanol partial oxidation in a fixed bed using CFD reactor modeling. AIChE J. 2019, 1-13. [CrossRef] 
75. Popov, B.I.; Bibin, V.N.; Boreskov, G.K. Study of an Iron-Molybdenum oxide catalyst for the oxidation of methanol to formaldehyde. IV. Entrainment of Molybdenum from the catalyst, the main reason for the decrease in its activity during use. Kinet. Katal. 1976, 17, 371-377.

76. Carbucicchio, M.; Forzatti, P.; Trifiro', F.; Tronconi, E.; Villa, P.L.L. Deactivation of silica supported Fe2O3-MoO3 catalyst for the oxidation of methanol. Stud. Surf. Sci. Catal. 1980, 6, 103-113.

77. Popov, B.I.; Skomorokhova, N.G. Changes in activity, selectivity and surface area along an iron-molybdenum catalyst bed after its industrial application. React. Kinet. Catal. Lett. 1982, 18, 101-105. [CrossRef]

78. Burriesci, N.; Garbassi, F.; Petrera, M.; Petrini, G.; Pernicone, N. Solid state reactions in Fe-Mo oxide catalysts for methanol oxidation during aging in industrial plants. Stud. Surf. Sci. Catal. 1980, 6, 115-126.

79. Ma, Y.H.; Kmiotek, S.J. Deactivation kinetics of ferric molybdate catalysts. J. Catal. 1988, 109, 132-142. [CrossRef]

80. Smith, R.L.; Rohrer, G.S. The morphological evolution of the MoO3(010) surface during reactions in methanol-air mixtures. J. Catal. 1998, 180, 270-278. [CrossRef]

81. Mccarron, E.M.; Staley, R.H.; Sleight, A.W. Oxy-Methoxy Compounds of Hexavalent Molybdenum. Inorg. Chem. 1984, 23, 1043-1045. [CrossRef]

82. Ivanov, K.I.; Dimitrov, D.Y. Deactivation of an industrial iron-molybdate catalyst for methanol oxidation. Catal. Today 2010, 154, 250-255. [CrossRef]

83. O'Brien, M.G.; Beale, A.M.; Jacques, S.D.M.; Di Michiel, M.; Weckhuysen, B.M. Spatiotemporal multitechnique imaging of a catalytic solid in action: Phase variation and volatilization during molybdenum oxide reduction. ChemCatChem 2009, 1, 99-102. [CrossRef]

84. Soares, A.P.V.; Portela, M.F.; Kiennemann, A.; Millet, J.M.M. Iron-molybdate deactivation during methanol to formaldehyde oxidation: Effect of water. React. Kinet. Catal. Lett. 2002, 75, 13-20. [CrossRef]

85. Soares, A.P.V.; Portela, M.F.; Kiennemann, A.; Hilaire, L. Mechanism of deactivation of iron-molybdate catalysts prepared by coprecipitation and sol-gel techniques in methanol to formaldehyde oxidation. Chem. Eng. Sci. 2003, 58, 1315-1322. [CrossRef]

86. Soares, A.P.V.; Farinha Portela, M.; Kiennemann, A.; Hilaire, L.; Millet, J.M.M. Iron molybdate catalysts for methanol to formaldehyde oxidation: Effects of Mo excess on catalytic behaviour. Appl. Catal. A Gen. 2001, 206, 221-229. [CrossRef]

87. Raun, K.V.; Schumann, M.; Høj, M.; Thorhauge, M.; Beato, P.; Damsgaard, C.D.; Chevallier, J.; Nielsen, K.; Grundwaldt, J.-D.; Jensen, A.D. Studies of Deactivation of Methanol to Formaldehyde Selective Oxidation Catalyst. In Proceedings of the 13th European Congress on Catalysis, Florence, Italy, 27-31 August 2017.

88. Raun, K.V.; Lundegaard, L.F.; Beato, P.; Appel, C.C.; Nielsen, K.; Thorhauge, M.; Schumann, M.; Jensen, A.D.; Grunwaldt, J.D.; Høj, M. Stability of Iron-Molybdate Catalysts for Selective Oxidation of Methanol to Formaldehyde: Influence of Preparation Method. Catal. Lett. 2020, 150, 1434-1444. [CrossRef]

89. Gaur, A.; Schumann, M.; Raun, K.V.; Stehle, M.; Beato, P.; Jensen, A.D.; Grunwaldt, J.-D.; Høj, M. Operando XAS/XRD and Raman spectroscopy study of structural changes of the iron molybdate catalyst during selective oxidation of methanol. ChemCatChem 2019, 11, 4871-4883. [CrossRef]

90. Gaur, A.; Stehle, M.; Raun, K.V.; Thrane, J.; Jensen, A.D.; Grunwaldt, J.-D.; Høj, M. Structural dynamics of an iron molybdate catalyst under redox cycling conditions studied with in situ multi edge XAS and XRD. Phys. Chem. Chem. Phys. 2020, 22, 11713-11723. [CrossRef] [PubMed]

91. Carbucicchio, M.; Trifirò, F. Redox processes at the surfaces of Fe2O3-MoO3/SiO2 catalysts. J. Catal. 1980, 62, 13-18. [CrossRef]

92. Carbucicchio, M.; Trifirò, F. Surface and bulk redox processes in iron-molybdate-based catalysts. J. Catal. 1976, 45, 77-85. [CrossRef]

93. Pernicone, N. Deactivation of Fe-Mo oxide catalyst in industrial plant and simulation tests on laboratory scale. Catal. Today 1991, 11, 85-91. [CrossRef]

94. Mitov, I.; Asenov, S.; Tomov, T.; Klissurski, D. In situ mössbauer study of the interaction of methanol with an iron-molybdenum oxide catalyst. J. Phys. Chem. C 2007, 111, 5389-5393. [CrossRef]

95. O'Brien, M.G.; Beale, A.M.; Jacques, S.D.M.; Di Michiel, M.; Weckhuysen, B.M. Closing the operando gap: The application of high energy photons for studying catalytic solids at work. Appl. Catal. A Gen. 2011, 391, 468-476. [CrossRef]

96. Raun, K.V.; Johannessen, J.; McCormack, K.; Appel, C.C.; Baier, S.; Thorhauge, M.; Høj, M.; Jensen, A.D. Modeling of the molybdenum loss in iron molybdate catalyst pellets for selective oxidation of methanol to formaldehyde. Chem. Eng. J. 2019, 361, 1285-1295. [CrossRef]

97. Raun, K.V.; Thorhauge, M.; Høj, M.; Jensen, A.D. Modeling of molybdenum transport and pressure drop increase in fixed bed reactors used for selective oxidation of methanol to formaldehyde using iron molybdate catalysts. Chem. Eng. Sci. 2019, 202, 347-356. [CrossRef]

98. Wachs, I.E.; Briand, L.E. In Situ Regeneration of Metal-Molybdate Catalysts for Methanol Oxidation to Formaldehyde. U.S. Patent No. 6,037,290, 14 March 2000.

99. Burcham, L.J.; Briand, L.E.; Wachs, I.E. Quantification of Active Sites for the Determination of Methanol Oxidation Turn-over Frequencies Using Methanol Chemisorption and in Situ Infrared Techniques. 2. Bulk Metal Oxide Catalysts. Langmuir 2001, 17, 6175-6184. [CrossRef] 
100. Burcham, L.J.; Briand, L.E.; Wachs, I.E. Quantification of Active Sites for the Determination of Methanol Oxidation Turn-over Frequencies Using Methanol Chemisorption and in Situ Infrared Techniques. 1. Supported Metal Oxide Catalysts. Langmuir 2001, 17, 6164-6174. [CrossRef]

101. Popov, B.I.; Shkuratova, L.N.; Orlova, L.B. Effect of excess molybdenum trioxide on the activity and selectivity of some molybdates in methanol oxidation. React. Kinet. Catal. Lett. 1976, 4, 323-328. [CrossRef]

102. Shkuratova, L.N.; Pankratiev, Y.D.; Popov, B.I.; Turkov, V.M. Steady state catalytic properties and oxygen biding energy of cadmium-molybdenum catalysts in methanol oxidation. React. Kinet. Catal. Lett. 1977, 7, 229-233. [CrossRef]

103. Sutula, V.D.; Zeif, A.P.; Popov, B.I.; Vadash, P.I. Indo study of the interaction of methanol with molybdates. React. Kinet. Catal. Lett. 1978, 9, 79-83. [CrossRef]

104. Sutula, V.D.; Zeif, A.P.; Popov, B.I.; Chernyavskii, L.I. Interaction of methanol and propene with iron and gallium molybdates by the extended Hüchel method. J. Struct. Chem. 1979, 20, 204-212. [CrossRef]

105. Popov, B.I.; Shkuratova, L.N.; Maksimov, Y.V.; Gustov, V.V. Catalytic properties and radiothermoluminescence of calcium molybdate with MoO3 additives. React. Kinet. Catal. Lett. 1982, 20, 293-297. [CrossRef]

106. Malka, K.; Tatibouet, J. A Two-Step Preparation of Silica-Supported Calcium-Molybdenum Catalysts. J. Catal. 1998, 175, $204-212$. [CrossRef]

107. Thrane, J.; Lundegaard, L.F.; Beato, P.; Mentzel, U.V.; Thorhauge, M.; Jensen, A.D.; Høj, M. Alkali Earth Metal Molybdates as Catalysts for the Selective Oxidation of Methanol to Formaldehyde-Selectivity, Activity, and Stability. Catalysts 2020, 10, 82. [CrossRef]

108. Said, A.E.A.A.; El-Wahab, M.M.M.A.; Alian, A.M. Selective Oxidation of Methanol to Formaldehyde over Active Molybdenum Oxide Supported on Hydroxyapatite Catalysts. Catal. Lett. 2016, 146, 82-90. [CrossRef]

109. Said, A.A.; El-Wahab, M.M.A.; Alian, A.M. New approach on the catalytic oxidation of methanol to formaldehyde over MoO3 supported on nano hydroxyapatite catalysts. IOP Conf. Ser. Mater. Sci. Eng. 2014, 64, 012058. [CrossRef]

110. Thrane, J.; Elvebakken, C.F.; Juelsholt, M.; Christiansen, T.L.; Jensen, K.M.Ø.; Hansen, L.P.; Lundegaard, L.F.; Mentzel, U.V.; Thorhauge, M.; Jensen, A.D.; et al. Highly Stable Apatite Supported Molybdenum Oxide Catalysts for Selective Oxidation of Methanol to Formaldehyde: Structure, Activity and Stability. ChemCatChem Accepted Author Manuscript. 2021. [CrossRef]

111. Thrane, J. Investigation of Copper Based Catalysts by Chemisorption Methods; Technical University of Denmark: Lyngby, Denmark, 2015.

112. Thrane, J.; Mentzel, U.V.; Thorhauge, M.; Høj, M.; Jensen, A.D. Hydroxyapatite Supported Molybdenum Oxide Catalyst for Selective Oxidation of Methanol to Formaldehyde: Studies of Industrial Sized Catalyst Pellets. Catal. Sci. Technol. 2021, 11, 970-983. [CrossRef]

113. Kostynyuk, A.; Nikolenko, M. Iron molybdate catalyst stabilized by calcium oxide for methanol to formaldehyde conversion. Chem. Chem. Technol. 2011, 5, 89-93. [CrossRef]

114. Popov, B.I.; Shkuratova, L.N.; Skorokhova, N.G. Influence of sodium salts on the catalytic properties of iron-molybdenum oxide catalysts in the oxidation of methanol to formaldehyde. React. Kinet. Catal. Lett. 1975, 3, 463-469. [CrossRef]

115. Popov, T.S.; Popov, B.I.; Bibin, V.N.; Bliznakov, G.M.; Boreskov, G.K. Catalytic properties of chromium-molybdenum oxide catalysts in methanol oxidation. React. Kinet. Catal. Lett. 1975, 3, 169-175. [CrossRef]

116. Popov, T.S.; Klissurski, D.G.; Ivanov, K.I.; Pesheva, J. Effect of ultrasonic treatment on the physicochemical properties of Cr-Mo-O catalysts for methanol oxidation. Stud. Surf. Sci. Catal. 1987, 31, 191-197.

117. Cheshkova, K.T.; Bibin, V.N.; Popov, B.I. Kinetics of oxidation of methanol with air on a chromium-molybdenum oxide catalyst supported on porous a-Al2O3. React. Kinet. Catal. Lett. 1976, 4, 307-313. [CrossRef]

118. Ivanov, K.; Krustev, S.; Litcheva, P. Oxidation of methanol on sodium modified chromium-molybdenum catalysts. J. Alloys Compd. 1998, 279, 132-135. [CrossRef]

119. Ivanov, K.I.; Mitov, I.G.; Krustev, S.V.; Boyanov, B.S. Mössbauer study of modified iron-molybdenum catalysts for methanol oxidation. J. Phys. Conf. Ser. 2010, 217, 012046. [CrossRef]

120. Meyer, A.; Renken, A. Sodium Compounds as Catalysts for Methanol Dehydrogenation to Water-Free Formaldehyde. Chem. Eng. Technol. 1990, 13, 145-149. [CrossRef]

121. Del Arco, M.; Martin, C.; Rives, V.; Estevez, A.M.; Marquez, M.C.; Tena, A.F. Effect of doping with chromium on the physicochemical properties of iron-molybdenum oxide systems. J. Mater. Sci. 1989, 24, 3750-3755. [CrossRef]

122. Klissurski, D.; Rives, V.; Pesheva, Y.; Mitov, I.; Abadzhjieva, N. Iron-chromium-molybdenum oxide catalysts for methanol oxidation. Catal. Lett. 1993, 18, 265-271. [CrossRef]

123. Pesheva, Y.; Nemska, S.; Stefanov, P.; Klissurski, D.; Rives, V. Surface reduction of iron-chromium-molybdenum oxide catalysts for methanol oxidation. J. Mater. Sci. Lett. 1994, 13, 1567-1569. [CrossRef]

124. Popov, B.I.; Bibin, V.N. Catalytic properties of bismuth molybdate and its constituent oxides in methanol oxidation. React. Kinet. Catal. Lett. 1975, 3, 337-341. [CrossRef]

125. Arora, N.; Deo, G.; Wachs, I.E.; Hirt, A.M. Surface aspects of bismuth-metal oxide catalysts. J. Catal. 1996, 159, 1-13. [CrossRef]

126. Mann, R.S.; Hahn, K.W. Kinetics of vapor-phase oxidation of methyl alcohol on Manganese Dioxide-Molybdenum Trioxide Catalyst. J. Catal. 1969, 15, 329-341. [CrossRef]

127. Mann, R.S.; Hahn, K.W. Oxidation of Methanol Over Manganese Dioxide-Molybdenum Trioxide Catalyst. Ind. Eng. Chem. Process Des. Dev. 1970, 9, 43-46. [CrossRef] 
128. Ivanov, K.; Litcheva, P.; Popov, T. Thermal Stability of MnMoO4-MoO3 Catalysts for Methanol Oxidation. J. Therm. Anal. 1990, 36, 1361-1368. [CrossRef]

129. Ivanov, K.; Litcheva, P.; Klissurski, D. Mn-Mo-O Catalysts for Methanol Oxidation. II. Oxidation of Methanol. Collect. Czechoslov. Chem. Commun. 1992, 57, 2539-2547. [CrossRef]

130. Ivanov, K.; Litcheva, P. Mn-Mo-O Catalysts for methanol oxidation. I. Preparation and Characterization of catalysts. Collect. Czechoslov. Chem. Commun. 1992, 57, 2529-2538. [CrossRef]

131. Thorhauge, M. Internal Reports—Haldor Topsoe A/S 2017; Haldor Topsøe: Lyngby, Denmark, 2017.

132. Mann, R.S.; Jain, S.K.; Dosi, M.K.; Mann, S.; Jain, S.K.; Dosi, M.K. Catalytic Oxidation of Methanol over Molybdenum OxideTungsten Oxide. J. Appl. Chem. Biotechnol. 1977, 27, 198-204. [CrossRef]

133. Machiels, C.J.; Cheng, W.H.; Chowdhry, U.; Farneth, W.E.; Hong, F.; Mc Carron, E.M.; Sleight, A.W. The effect of the structure of molybdenum oxides on the selective oxidation of methanol. Appl. Catal. 1986, 25, 249-256. [CrossRef]

134. Ivanov, K.; Mitov, I.; Krustev, S. Selective oxidation of methanol on Fe-Mo-W catalysts. J. Alloys Compd. 2000, 309, 57-60. [CrossRef]

135. Ramachandra, B.; Choi, J.S.; Choo, K.Y.; Sung, J.S.; Song, S.D.; Kim, T.H. Partial oxidation of methanol to formaldehyde on molybdenum based mixed oxide catalyst. Catal. Lett. 2005, 105, 23-27. [CrossRef]

136. Klissurski, D.; Pesheva, Y.; Abadjieva, N.; Mitov, I.; Filkova, D.; Petrov, L. Multicomponent oxide catalysts for the oxidation of methanol to formaldehyde. Appl. Catal. 1991, 77, 55-66. [CrossRef]

137. Klissurski, D.; Petridis, D.; Abadzhieva, N.; Hadjiivanov, K. MoO3 supported on montmorillonite type pillared clays: Characterization, surface acidity and catalytic properties towards the oxidation of methanol. Appl. Clay Sci. 1996, 10, 451-459. [CrossRef]

138. Mann, R.S.; Dosi, M.K. Kinetics of the Vapor-Phase Oxidation of Methyl Alcohol on Vanadium Pentoxide-Molybdenum Trioxide Catalyst. J. Catal. 1973, 28, 282-288. [CrossRef]

139. Matsuoka, Y.; Niwa, M.; Murakami, Y. Morphology of molybdena supported on various oxides and its activity for methanol oxidation. J. Phys. Chem. 1990, 94, 1477-1482. [CrossRef]

140. Burcham, L.J.; Badlani, M.; Wachs, I.E. The Origin of the Ligand Effect in Metal Oxide Catalysts: Novel Fixed-Bed in Situ Infrared and Kinetic Studies during Methanol Oxidation. J. Catal. 2001, 203, 104-121. [CrossRef]

141. Banares, M.A.; Hu, H.; Wachs, I.E. Molybdena on Silica Catalysts: Role of Preparation Methos on the Structure-Selectivity Properties for the Oxidation of Methanol. J. Catal. 1994, 150, 407-420. [CrossRef]

142. Inokawa, H.; Zaman, S.; Driss, H.; Daous, M.; Al-zahrani, A. Partial Oxidation of Methanol over Oxides of Cr, Mo and W Supported on Mixed CeO2-ZrO2 Carrier. In Proceedings of the EUROPA CAT, Basel, Switzerland, 7-11 August 2017.

143. Niwa, M.; Mizutani, M.; Murakami, Y. Measurement of M+5 spectra during methanol oxidation. Chem. Lett. 1975, 4, 1295-1298. [CrossRef]

144. Niwa, M.; Mizutani, M.; Murakami, Y. Oxidation of Methanol over SnO2-MoO3-Catalysts. Nippun Kagaku Kaishi 1977, 6, 757-760. [CrossRef]

145. Niwa, M.; Mizutani, M.; Takahashi, M.; Murakami, Y. Mechanism of methanol oxidation over oxide catalysts containing MoO3. J. Catal. 1981, 70, 14-23. [CrossRef]

146. Niwa, M.; Igarashi, J.Y. Role of the solid acidity on the MoO3 loaded on SnO2 in the methanol oxidation into formaldehyde. Catal. Today 1999, 52, 71-81. [CrossRef]

147. Niwa, M.; Habuta, Y.; Okumura, K.; Katada, N. Solid acidity of metal oxide monolayer and its role in catalytic reactions. Catal. Today 2003, 87, 213-218. [CrossRef]

148. Niwa, M.; Yamada, H.; Murakami, Y. Activity for the oxidation of methanol of a molybdena monolayer supported on tin oxide. J. Catal. 1992, 134, 331-339. [CrossRef]

149. Narishige, N.; Niwa, M. Adsorbed species of methanol on zirconia support and molybdenum oxide monolayer. Its role in the methanol oxidation. Catal. Lett. 2001, 71, 63-67. [CrossRef]

150. Valente, N.G.; Arrúa, L.A.; Cadús, L.E. Structure and activity of Sn-Mo-O catalysts: Partial oxidation of methanol. Appl. Catal. A Gen. 2001, 205, 201-214. [CrossRef]

151. Mann, R.S.; Diaz-Real, R.A. Oxidation of Methanol to Formaldehyde over Antimony-Molybdenum Oxide. In Proceedings of the 10th International Congress on Catalysis, Budapest, Hungary, 19-24 July 1993; pp. 1991-1994.

152. Castillo, R.; Dewaele, K.; Ruiz, P.; Delmon, B. Mechanical mixtures of alfa-Sb2O4 and MoO3 as highly selective catalysts for the oxidation of methanol to formaldehyde. Appl. Catal. A Gen. 1997, 153, L1-L8. [CrossRef]

153. Xiong, Y.L.; Cadus, L.E.; Daza, L.; Bertrand, P.; Ladri, J. Solid-state reactivity of iron molybdate artificially contaminated by antimony ions and its relation with catalytic activity in the selective oxidation of isobutene to methacrolein. Top. Catal. 2000, 12, 167-180. [CrossRef]

154. Xiong, Y.L.; Weng, L.T.; Bertrand, P.; Ladrière, J.; Daza, L.; Ruiz, P.; Delmon, B. Synergy between $\alpha$-SB2O4 and Fe2(MoO4)3 during the first hours of the catalytic oxidation of isobutene to methacrolein. J. Mol. Catal. A Chem. 2000, 155, 59-71. [CrossRef]

155. Xiong, Y.L.; Castillo, R.; Papadopoulou, C.; Daza, L.; Ladrière, J.; Ruiz, P.; Delmon, B. The Protecting Role of Antimony Oxide Against Deactivation of Iron Molybdate in Oxidation Catalysts. Stud. Surf. Sci. Catal. 1991, 68, 425-432.

156. Chernyshkova, F.A. Heteropolyacids and their salts as new promising catalysts for petrochemical and organic synthesis. Pet. Chem. 1991, 31, 571-584. 
157. Whiting, G.T.; Bartley, J.K.; Dummer, N.F.; Hutchings, G.J.; Taylor, S.H. Vanadium promoted molybdenum phosphate catalysts for the vapour phase partial oxidation of methanol to formaldehyde. Appl. Catal. A Gen. 2014, 485, 51-57. [CrossRef]

158. Harrison, W.T.A.; Cheetham, A.K.; Faber, J. The Crystal Determined Structure of Aluminum by Time-of-Flight Powder Neutron. J. Solid State Chem. 1988, 76, 328-333. [CrossRef]

159. Bowker, M.; Hellier, P.; Decarolis, D.; Gianolio, D.; Mohammed, K.M.H.; Stenner, A.; Hulthwelker, T.; Wells, P.P. Al-doped Fe ${ }_{2} \mathrm{O}_{3}$ as a support for molybdenum oxide methanol oxidation catalysts. Phys. Chem. Chem. Phys. 2020, 22, 18911-18918. [CrossRef] [PubMed]

160. Al-Ghanem, H. Evaluation of Nanoparticles Iron-Molybdate Catalyst Using Physical Properties Measurements; Wichita State University: Wichita, KS, USA, 2006.

161. Pham, T.T.P.; Nguyen, P.H.D.; Vo, T.T.; Luu, C.L.; Nguyen, H.H.P. Preparation of NO-doped $\beta-M o O 3$ and its methanol oxidation property. Mater. Chem. Phys. 2016, 184, 5-11. [CrossRef]

162. Weckhuysen, B.M.; Keller, D.E. Chemistry, spectroscopy and the role of supported vanadium oxides in heterogeneous catalysis. Catal. Today 2003, 78, 25-46. [CrossRef]

163. Kapoor, M.P.; Raj, A. Novel synthesis of a vanadium—Titanium aluminophosphate molecular sieve of MFI structure (VTAPO-5) and catalytic activity for the partial oxidation of methanol. Chem. Commun. 1999, 15, 1409-1410. [CrossRef]

164. Behera, G.C.; Parida, K. Selective gas phase oxidation of methanol to formaldehyde over aluminum promoted vanadium phosphate. Chem. Eng. J. 2012, 180, 270-276. [CrossRef]

165. Behera, G.C.; Parida, K.; Dummer, N.F.; Whiting, G.; Sahu, N.; Carley, A.F.; Conte, M.; Hutchings, G.J.; Bartley, J.K. Tungstate promoted vanadium phosphate catalysts for the gas phase oxidation of methanol to formaldehyde. Catal. Sci. Technol. 2013, 3, 1558-1564. [CrossRef]

166. Klissurski, D.; Pesheva, Y. Comparative Study of the Catalytic Properties of V2O5, Nb2O5 and Ta2O5 in the Oxidation of Methanol to Formaldehyde. React. Kinet. Catal. Lett. 1986, 32, 77-82. [CrossRef]

167. Smith, M.A.; Zoelle, A.; Yang, Y.; Rioux, R.M.; Hamilton, N.G.; Amakawa, K.; Nielsen, P.K.; Trunschke, A. Surface roughness effects in the catalytic behavior of vanadia supported on SBA-15. J. Catal. 2014, 312, 170-178. [CrossRef]

168. Smith, M.A.; Lobo, R.F. A fractal description of pore structure in block-copolymer templated mesoporous silicates. Microporous Mesoporous Mater. 2010, 131, 204-209. [CrossRef]

169. Hess, C. Characterization of the synthesis and reactivity behavior of nanostructured vanadia model catalysts using XPS and vibrational spectroscopy. Surf. Sci. 2006, 600, 3695-3701. [CrossRef]

170. Yang, Y.; Du, G.; Lim, S.; Haller, G.L. Radius of curvature effect of V-MCM-41 probed by methanol oxidation. J. Catal. 2005, 234, 318-327. [CrossRef]

171. Yang, Y.; Lim, S.; Wang, C.; Harding, D.; Haller, G. Multivariate correlation and prediction of the synthesis of vanadium substituted mesoporous molecular sieves. Microporous Mesoporous Mater. 2004, 67, 245-257. [CrossRef]

172. Bronkema, J.L.; Bell, A.T. Mechanistic Studies of Methanol Oxidation to Formaldehyde on Isolated Vanadate Sites Supported on MCM-48. J. Phys. Chem. C 2007, 111, 420-430. [CrossRef]

173. Bronkema, J.L.; Bell, A.T.; Leo, D.C.; Bell, A.T. Mechanistic Studies of Methanol Oxidation to Formaldehyde on Isolated Vanadate Sites Supported on High Surface Area Anatase. J. Phys. Chem. C 2007, 111, 14530-14540. [CrossRef]

174. Döbler, J.; Pritzsche, M.; Sauer, J. Oxidation of methanol to formaldehyde on supported vanadium oxide catalysts compared to gas phase molecules. J. Am. Chem. Soc. 2005, 127, 10861-10868. [CrossRef]

175. Trejda, M.; Millot, Y.; Chalupka, K.; Dzwigaj, S. Preparation of two series of VxSiBeta zeolite catalysts with V centres in framework and extra-framework positions and their application in selective oxidation of methanol. Appl. Catal. A Gen. 2019, 579, 1-8. [CrossRef]

176. Vieira, L.; Possato, L.; Chaves, T.; Lee, J.; Sulmonetti, T.; Jones, C.; Martins, L. This Insights into redox dynamics of vanadium species impregnated in layered siliceous zeolitic structures during methanol oxidation reactions. ChemCatChem Catal. 2020, 12, 141-151. [CrossRef]

177. Zhang, C.; Wu, P.; Liu, G.; Zhu, Z.; Zeng, G. Co-Electrospun VTiOx Hollow Nanofibers for Selective Oxidation of Methanol to High Value Chemicals. ACS Appl. Nano Mater. 2019, 2, 5224-5232. [CrossRef]

178. Agarwal, D.C.; Nigam, P.C.; Srivastava, R.D. Kinetics of Vapor Phase Oxidation of Methyl Alcohol over Supported V2O5-K2SO4 Catalyst. J. Catal. 1978, 55, 1-9. [CrossRef]

179. Roozeboom, F.; Cordingley, P.D.; Gellings, P.J. Vanadium Oxide Monolayer Catalysts The Vapor-Phase Oxidation of Methanol. J. Catal. 1981, 68, 464-472. [CrossRef]

180. Deo, G.; Wachs, I.E.; Goutam, D. Reactivity of Supported Vanadium Oxide Catalysts: The Partial Oxidation of Methanol. J. Catal. 1994, 146, 323-334. [CrossRef]

181. Fievez, T.; Weckhuysen, B.M. Chemical reactivity indices as a tool for understanding the support-effect in supported metal oxide catalysts. J. Phys. Chem. C 2009, 11, 19905-19912. [CrossRef]

182. Kaichev, V.V.; Popova, G.Y.; Chesalov, Y.A.; Saraev, A.A.; Andrushkevich, T.V.; Bukhtiyarov, V.I. Active component of supported vanadium catalysts in the selective oxidation of methanol. Kinet. Catal. 2016, 57, 82-94. [CrossRef]

183. Andrushkevich, T.V.; Kaichev, V.V.; Chesalov, Y.A.; Saraev, A.A.; Buktiyarov, V.I. Selective oxidation of ethanol over vanadia-based catalysts: The influence of support material and reaction mechanism. Catal. Today 2017, 279, 95-106. [CrossRef] 
184. Burcham, L.J.; Wachs, I.E. The origin of the support effect in supported metal oxide catalysts: In situ infrared and kinetic studies during methanol oxidation. Catal. Today 1999, 49, 467-484. [CrossRef]

185. Kim, T.; Wachs, I.E. CH3OH oxidation over well-defined supported V2O5/A12O3 catalysts: Influence of vanadium oxide loading and surface vanadium-oxygen functionalities. J. Catal. 2008, 255, 197-205. [CrossRef]

186. Khaliullin, R.Z.; Bell, A.T. A density functional theory study of the oxidation of methanol to formaldehyde over vanadia supported on silica, titania, and zirconia. J. Phys. Chem. B 2002, 106, 7832-7838. [CrossRef]

187. Zhanpeisov, N.U. A density functional theory study of the oxidation of methanol to formaldehyde over vanadia supported on silica, titania and zirconia. Res. Chem. Intermed. 2004, 30, 133-141. [CrossRef]

188. Makedonski, L.; Nikolov, V.; Anastasov, A.; Stancheva, M. Effect of calcination temperature on the properties of industrial V2O5-TiO2 (anatase) catalysts in methanol oxidation. React. Kinet. Catal. Lett. 2004, 81, 21-25. [CrossRef]

189. Bronkema, J.L.; Bell, A.T. Mechanistic studies of methanol oxidation to formaldehyde on isolated vanadate sites supported on high surface area zirconia. J. Phys. Chem. C 2008, 112, 6404-6412. [CrossRef]

190. Goodrow, A.; Bell, A.T. A Theoretical Investigation of the Selective Oxidation of Methanol to Formaldehyde on Isolated Vanadate Species Supported on Titania. J. Phys. Chem. C 2008, 112, 13204-13214. [CrossRef]

191. González-Navarrete, P.; Gracia, L.; Calatayud, M.; Andrés, J. Unraveling the mechanisms of the selective oxidation of methanol to formaldehyde in vanadia supported on titania catalyst. J. Phys. Chem. C 2010, 114, 6039-6046. [CrossRef]

192. Busca, G.; Elmi, A.S.; Forzatti, P. Mechanism of selective methanol oxidation over vanadium oxide-titanium oxide catalysts: A FT-IR and flow reactor study. J. Phys. Chem. 1987, 91, 5263-5269. [CrossRef]

193. Kim, H.Y.; Lee, H.M.; Pala, R.G.S.; Metiu, H. Oxidative dehydrogenation of methanol to formaldehyde by isolated vanadium, molybdenum, and chromium oxide clusters supported on rutile TiO2(110). J. Phys. Chem. C 2009, 113, 16083-16093. [CrossRef]

194. Ganduglia-Pirovano, M.V.; Popa, C.; Sauer, J.; Abbott, H.; Uhl, A.; Baron, M.; Stacchiola, D.; Bondarchuk, O.; Shaikhutdinov, S.; Freund, H.J. Role of ceria in oxidative dehydrogenation on supported vanadia catalysts. J. Am. Chem. Soc. 2010, 132, 2345-2349. [CrossRef]

195. Kropp, T.; Paier, J.; Sauer, J. Oxidative dehydrogenation of methanol at ceria-supported vanadia oligomers. J. Catal. 2017, 352, 382-387. [CrossRef]

196. Kropp, T.; Paier, J.; Sauer, J. Support effect in oxide catalysis: Methanol oxidation on vanadia/ceria. J. Am. Chem. Soc. 2014, 136, 14616-14625. [CrossRef]

197. Feng, T.; Vohs, J.M. A TPD study of the partial oxidation of methanol to formaldehyde on CeO2-supported vanadium oxide. J. Catal. 2004, 221, 619-629. [CrossRef]

198. Vining, W.C.; Strunk, J.; Bell, A.T. Investigation of the structure and activity of VOx/CeO2/SiO2 catalysts for methanol oxidation to formaldehyde. J. Catal. 2012, 285, 160-167. [CrossRef]

199. Zhang, H.; Liu, Z.; Feng, Z.; Li, C. Effective silica supported Sb-V mixed oxide catalyst for selective oxidation of methanol to formaldehyde. J. Catal. 2008, 260, 295-304. [CrossRef]

200. Guerrero-Pérez, M.O.; Kim, T.; Ban, M.A.; Wachs, I.E. Nature of Catalytic Active Sites for Sb-V-O Mixed Metal Oxides. J. Phys. Chem. C 2008, 112, 16858-16863. [CrossRef]

201. Isaguliants, G.V.; Belomestnykh, I.P. Selective oxidation of methanol to formaldehyde over V-Mg-O catalysts. Catal. Today 2005, 100, 441-445. [CrossRef]

202. Nielsen, N.D.; Thrane, J.; Jensen, A.D.; Christensen, J.M. Bifunctional Synergy in CO Hydrogenation to Methanol with Supported Cu. Catal. Lett. 2020, 150, 1427-1433. [CrossRef]

203. Lakshmi, L.J.; Narsimha, K.; Rao, P.K. Chemisorptive and Catalytic Properties of V2O5 Supported on Phosphate Modified Gamma-alumina. Appl. Catal. A Gen. 1993, 94, 61-70. [CrossRef]

204. Bliznakov, G.; Pesheva, Y.; Klissurski, D.; Marinov, M.; Kozhukharov, V. Methanol Oxidation on V2O5-MoO3-TeO3. Appl. Catal. 1987, 29, 211-218. [CrossRef]

205. Pesheva, Y.; Abadzhjieva, N.; Vrachnou, E.; Kovanis, Y.; Rives, V.; del Hoyo, C.; Klissurski, D. Selective oxidation of methanol on V2O5 and V2O5 MoO 3 supported on montrmorillonite. React. Kinet. Catal. Lett. 1994, 53, 283-288. [CrossRef]

206. Sturm, J.M.; Göbke, D.; Kuhlenbeck, H.; Döbler, J.; Reinhardt, U.; Ganduglia-Pirovano, M.V.; Sauer, J.; Freund, H.-J. Partial oxidation of methanol on well-ordered V2O5(001)/Au(111) thin films. Phys. Chem. Chem. Phys. 2009, 11, 3010. [CrossRef]

207. Reddy, B.M. Structure and Reactivity of Tin Oxide Supported Vanadium Oxide Catalysts. ACS Symp. Ser. 1993, 523, 204-216.

208. Wang, C.-T.; Chen, M.-T.; Lai, D.-L. Vanadium-tin oxide nanoparticles with Gas-sensing and Catalytic Activity. J. Am. Ceram. Soc. 2011, 94, 4471-4477. [CrossRef]

209. Malinski, R.; Akimoto, M.; Echigoya, E. Catalytic activity of Vanadates in oxidation of Methanol. J. Catal. 1976, 44, 101-106. [CrossRef]

210. Maliński, R. The catalytic activity of Ni-V oxide catalysts. React. Kinet. Catal. Lett. 1976, 5, 265-271. [CrossRef]

211. Salagre, P.; Sueiras, J.E. Hexagonal Orthovanadates as Catalysts in the Oxidation of Methanol to Formaldehyde. J. Chem. Soc. Chem. Commun. 1988, 16, 1084-1085. [CrossRef]

212. Häggblad, R.; Wagner, J.B.; Hansen, S.; Andersson, A. Oxidation of methanol to formaldehyde over a series of Fe1-xAlx-V-oxide catalysts. J. Catal. 2008, 258, 345-355. [CrossRef]

213. Häggblad, R.; Hansen, S.; Wallenberg, L.R.; Andersson, A. Stability and performance of vacant Fe3-x-yVx $\square$ yO4 spinel phase catalysts in methanol oxidation. J. Catal. 2010, 276, 24-37. [CrossRef] 
214. Massa, M.; Häggblad, R.; Andersson, A. Cation Vacant Fe3-x-yVx $\square$ yO4 Spinel-Type Catalysts for the Oxidation of Methanol to Formaldehyde. Top. Catal. 2011, 54, 685-697. [CrossRef]

215. Massa, M.; Häggblad, R.; Hansen, S.; Andersson, A. Oxidation of methanol to formaldehyde on cation vacant Fe-V-Mo-oxide. Appl. Catal. A Gen. 2011, 408, 63-72. [CrossRef]

216. Klissurski, D.; Abadzhieva, N.; Kassabov, S.; Stefanov, P.; Kovacheva, D.; Uzunov, I. Selective oxidation of methanol to formaldehyde on iron vanadate catalyst. Comptes Rendus L'Academie Bulg. Sci. 2009, 62, 1073-1078.

217. Routray, K.; Zhou, W.; Kiely, C.J.; Wachs, I.E. Catalysis science of methanol oxidation over iron vanadate catalysts: Nature of the Catalytic Active sites. ACS Catal. 2011, 1, 54-66. [CrossRef]

218. Wachs, I.E.; Routray, K. Catalysis science of bulk mixed oxides. ACS Catal. 2012, 2, 1235-1246. [CrossRef]

219. Hellier, P.; Wells, P.P.; Gianolio, D.; Bowker, M. VOx/Fe2O3 Shell-Core Catalysts for the Selective Oxidation of Methanol to Formaldehyde. Top. Catal. 2018, 61, 357-364. [CrossRef]

220. Hellier, P.; Wells, P.P.; Bowker, M. Methanol oxidation over shell-core MOx/Fe2O3 (M=Mo, V, Nb) catalysts. Chin. J. Catal. 2019, 40, 1686-1692. [CrossRef]

221. Malmusi, A.; Velasquez Ochoa, J.; Tabanelli, T.; Basile, F.; Lucarelli, C.; Agnoli, S.; Carraro, F.; Granozzi, G.; Cavani, F. Ethanol aerobic and anaerobic oxidation with FeVO4 and V2O5 catalysts. Appl. Catal. A Gen. 2018, 570, 139-147. [CrossRef]

222. Kaminski, P.; Ziolek, M. Surface and catalytic properties of Ce-, Zr-, Au-, Cu-modified SBA-15. J. Catal. 2014, 312, $249-262$. [CrossRef]

223. Pestryakov, A.N.; Lunin, V.V.; Bogdanchikova, N.; Temkin, O.N.; Smolentseva, E. Active states of gold in small and big metal particles in CO and methanol selective oxidation. Fuel 2013, 110, 48-53. [CrossRef]

224. Kaskow, I.; Wojtaszek-Gurdak, A.; Sobczak, I. Methanol oxidation on AuAg-Zn/MCM-36-The effect of catalyst components and pretreatment. Catal. Today 2019, 354, 1-10. [CrossRef]

225. Deng, X.; Sorescu, D.C.; Lee, J. Methanol Oxidation to Formaldehyde Promoted at the Step Sites of Ultrathin ZnO. Top. Catal. 2018, 61, 499-508. [CrossRef]

226. El-Molla, S.A.; Mahmoud, H.R. Synthesis, textural and catalytic properties of nanosized Fe2O3/MgO system. Mater. Res. Bull. 2013, 48, 4105-4111. [CrossRef]

227. Yuan, Y.; Liu, H.; Imoto, H.; Shido, T.; Iwasawa, Y. Performance and Characterization of a New Crystalline SbRe2O6 Catalyst for Selective Oxidation of Methanol to Methylal. J. Catal. 2000, 195, 51-61. [CrossRef]

228. Hutchings, G.J.; Taylor, S.H. Designing oxidation catalysts. Catal. Today 1999, 49, 105-113. [CrossRef]

229. Harrison, W.T.A.; Chowdhry, U.; Machiels, C.J.; Sleight, A.W.; Cheetham, A.K. Preparation of ferric tungstate and its catalytic behavior toward methanol. J. Solid State Chem. 1985, 60, 101-106. [CrossRef]

230. Wachs, I.E.; Jehng, J.-M.; Ueda, W. Determination of the Chemical Nature of Active Surface Sites Present on Bulk Mixed Metal Oxide Catalysts. J. Phys. Chem. B 2005, 109, 2275-2284. [CrossRef]

231. Badlani, M.; Wachs, I.E. Methanol: A "smart" chemical probe molecule. Catal. Lett. 2001, 75, 137-149. [CrossRef]

232. Delgado, D.; Soriano, M.D.; Solsona, B.; Zamora, S.; Agouram, S.; Concepción, P.; López Nieto, J.M. Tungsten-titanium mixed oxide bronzes: Synthesis, characterization and catalytic behavior in methanol transformation. Appl. Catal. A Gen. 2019, 582, 117092. [CrossRef]

233. Abadzhieva, N.; Klisurski, D.G. Oxidation of Methanol to Formaldehyde on Sb2O4. Kinet. Katal. 1987, $28,735-736$.

234. Chen, Y.; Fierro, J.L.G.; Tanaka, T.; Wachs, I.E. Supported Tantalum Oxide Catalysts: Synthesis, Physical Characterization, and Methanol Oxidation Chemical Probe Reaction. J. Phys. Chem. B 2003, 107, 5243-5250. [CrossRef]

235. Chen, Y.; Wachs, I.E. Tantalum oxide-supported metal oxide (Re2O7, CrO3, MoO3, WO3, V2O5, and Nb2O5) catalysts: Synthesis, Raman characterization and chemically probed by methanol oxidation. J. Catal. 2003, 217, 468-477. [CrossRef]

236. Gao, X.; Wachs, I.E.; Wong, M.S.; Ying, J.Y. Structural and Reactivity Properties of Nb-MCM-41: Comparison with That of Highly Dispersed Nb2O5/SiO2 Catalysts. J. Catal. 2001, 203, 18-24. [CrossRef]

237. Davies, A.M.; Taylor, S.H. CATL 15 Nb-Phosphates as Catalysts for the Partial Oxidation og Methanol to Formaldehyde. In Proceedings of the 236th National Meeting and Exposition, Philadelphia, PA, USA, 17-21 August 2008; American Chemical Society: Philadelphia, PA, USA, 2008.

238. Davies, A.M. Selective Oxidation and Oxidative Dehydrogenation Reactions Using Niobium Based Catalysts; Cardiff University: Cardiff, UK, 2009.

239. Hashimoto, K.; Hanada, Y.; Minami, Y.; Kera, Y. Conversion of methanol to dimethyl ether and formaldehyde over alumina intercalated in a montmorillonite. Appl. Catal. A Gen. 1996, 141, 57-69. [CrossRef]

240. Cairati, L.; Trifirò, F. SiO2 and Al2O3 as oxidation catalysts of methanol. J. Catal. 1983, 80, 25-30. [CrossRef]

241. Gryaznova, Z.V.; Ponomareva, N.N.; Nefedova, A.R.; Yeschenko, L.S.; Dvoskina, R.N.; Yakovenko, Z.I. Methanol transformations on zirconium phosphate, CuX zeolite and their mixtures. React. Kinet. Catal. Lett. 1982, 19, 393-396. [CrossRef]

242. Klissurski, D.; Rives, V.; Abadzhjieva, N.; Pesheva, Y.; Pomonis, P.; Sdoukos, T.; Petrakis, D. High performance of iron(III) phosphate for selective oxidation of methanol. J. Chem. Soc. Chem. Commun. 1993, 21, 1606-1607. [CrossRef]

243. Abadzhjieva, N.; Tzokov, P.; Uzunov, I.; Minkov, V.; Klissurski, D.I.; Rives, V. Methanol Oxidation to Formaldehyde on Bismuth Phosphate-Based Catalysts. React. Kinet. Catal. Lett. 1994, 53, 413-418. [CrossRef] 
244. Nikolenko, N.V.; Kozhevnikov, I.V.; Kostyniuk, A.O.; Bayahia, H.; Kalashnykov, Y.V. Preparation of iron molybdate catalysts for methanol to formaldehyde oxidation based on ammonium molybdoferrate(II) precursor. J. Saudi Chem. Soc. 2018, 22, 372-379. [CrossRef]

245. Zhao, H.; Bennici, S.; Shen, J.; Auroux, A. Influence of the host oxide of sulfated-titania catalysts on partial oxidation methanol reaction. Appl. Catal. A Gen. 2010, 385, 224-231. [CrossRef]

246. Kropp, T.; Paier, J. Activity versus Selectivity of the Methanol Oxidation at Ceria Surfaces: A Comparative First-Principles Study. J. Phys. Chem. C 2015, 119, 23021-23031. [CrossRef]

247. Sutton, J.E.; Danielson, T.; Beste, A.; Savara, A. Below-Room-Temperature C-H Bond Breaking on an Inexpensive Metal Oxide: Methanol to Formaldehyde on CeO2(111). J. Phys. Chem. Lett. 2017, 8, 5810-5814. [CrossRef] [PubMed]

248. Capdevila-Cortada, M.; López, N. Descriptor Analysis in Methanol Conversion on Doped CeO2(111): Guidelines for Selectivity Tuning. ACS Catal. 2015, 5, 6473-6480. [CrossRef]

249. Wang, H.; An, K.; Sapi, A.; Liu, F.; Somorjai, G.A. Effects of nanoparticle size and metal/support interactions in pt-catalyzed methanol oxidation reactions in gas and liquid phases. Catal. Lett. 2014, 144, 1930-1938. [CrossRef]

250. Xiao, Y.; Wang, Y.; Varma, A. Low-temperature selective oxidation over Pt-Bi bimetallic catalysts. J. Catal. 2018, 363, 144-153. [CrossRef]

251. Sun, Y.K.; Lee, W.Y. Catalytic behavior of YBa2Cu3O7-x in the partial oxidation of methanol to formaldehyde. Korean J. Chem. Eng. 1995, 12, 36-38. [CrossRef]

252. Velu, S.; Wang, L.; Okazaki, M.; Suzuki, K.; Tomura, S. Characterization of MCM-41 mesoporous molecular sieves containing copper and zinc and their catalytic performance in the selective oxidation of alcohols to aldehydes. Microporous Mesoporous Mater. 2002, 54, 113-126. [CrossRef]

253. Li, C.-L.; Wang, C.-L.; Lin, Y.-C. Pd-integrated lanthanum-transition metal perovskites for methanol partial oxidation. Catal. Today 2011, 174, 135-140. [CrossRef]

254. Li, C.L.; Jiang, B.S.; Fanchiang, W.L.; Lin, Y.C. The effect of Pd content in LaMnO3 for methanol partial oxidation. Catal. Commun. 2011, 16, 165-169. [CrossRef]

255. Cai, Y.; Wang, C.-B.; Wachs, I.E. Reaction induced spreading of metal oxides: In situ Raman spectroscopic studies during oxidation reactions. Stud. Surf. Sci. Catal. 1997, 110, 255-264.

256. Gao, X.; Bare, S.R.; Weckhuysen, B.M.; Wachs, I.E. In Situ Spectroscopic Investigation of Molecular Structures of Highly Dispersed Vanadium Oxide on Silica under Various Conditions. J. Phys. Chem. B 1998, 102, 10842-10852. [CrossRef]

257. Jehng, J.-M.; Hu, H.; Gao, X.; Wachs, I.E. The dynamic states of silica-supported metal oxide catalysts during methanol oxidation. Catal. Today 1996, 28, 335-350. [CrossRef]

258. Bradley, D.C. Metal Alkoxides. In Progress in Inorganic Chemistry; Cotton, F.A., Ed.; John Wiley \& Sons Inc.: New York, NY, USA; London, UK, 1960; Volume II, pp. 303-362. 